Document downloaded from:

http://hdl.handle.net/10251/37347

This paper must be cited as:

Moragues Pons, ME.; Martínez Mañez, R.; Sancenón Galarza, F. (2011). Chromogenic and fluorogenic chemosensors and reagents for anions. A comprehensive review of the year 2009. Chemical Society Reviews. 40(5):2593-2643. doi:10.1039/c0cs00015a.

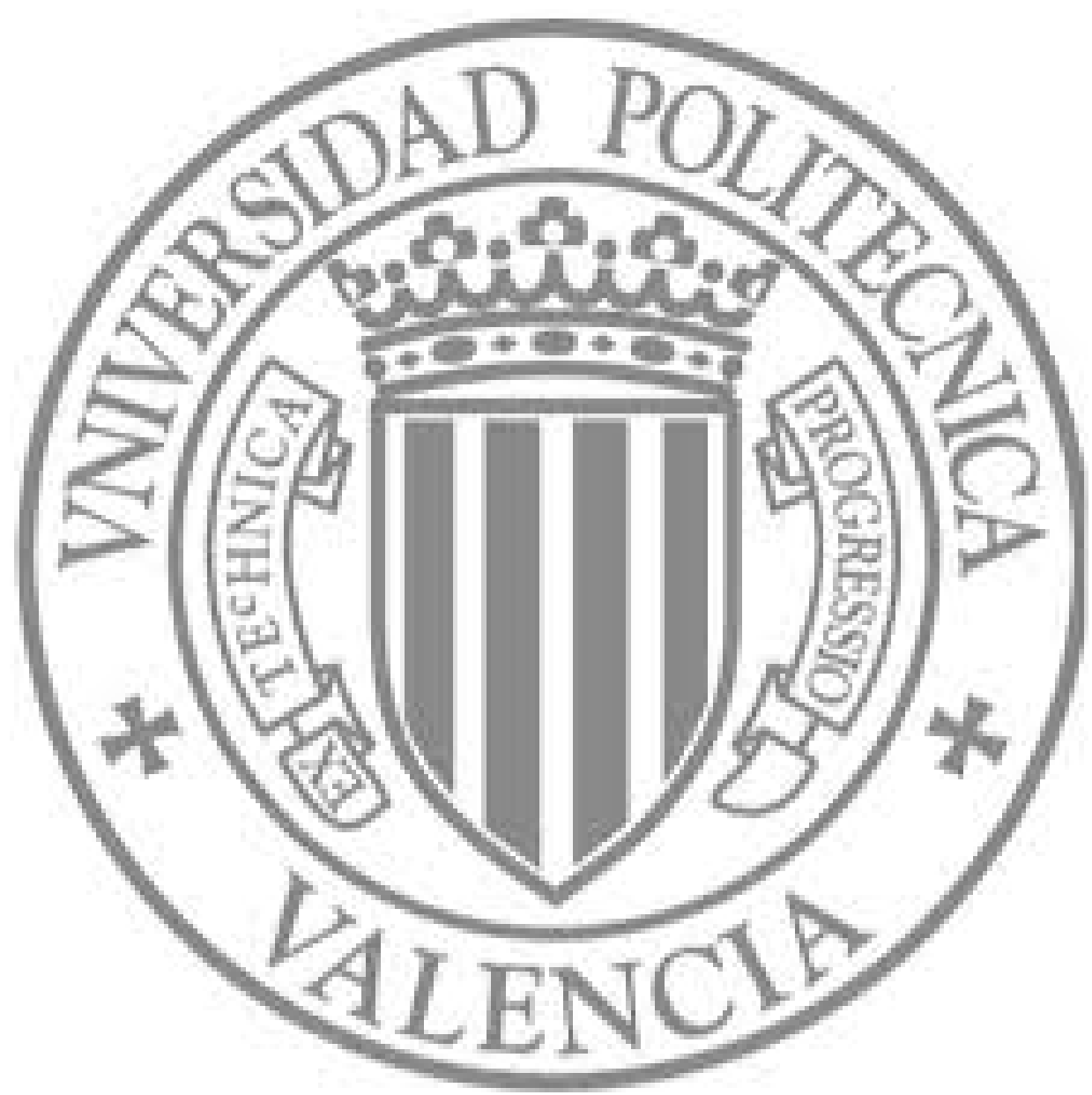

The final publication is available at

http://dx.doi.org/10.1039/c0cs00015a

Copyright Royal Society of Chemistry 


\title{
Chromogenic and fluorogenic chemosensors and reagents for anions. A comprehensive review of year 2009.
}

\author{
María E. Moragues, ${ }^{\text {a,b,c }}$ Ramón Martínez-Máñez ${ }^{\text {a,b,c }}$ and Félix Sancenón ${ }^{\text {a,b,c }}$ \\ ${ }^{\text {a }}$ Centro Interuniversitario de Reconocimiento Molecular y Desarrollo Tecnológico, \\ (IDM), Unidad Mixta Universidad Politécnica de Valencia - Universitat de València, \\ Spain. \\ ${ }^{\mathrm{b}}$ Departamento de Química. Universidad Politécnica de Valencia. Camino de Vera s/n. \\ E-46022, Valencia, Spain. \\ ${ }^{\mathrm{c}}$ CIBER de Bioingeniería, Biomateriales y Nanomedicina (CIBER-BBN).
}

This review is focused on examples reported in the year 2009 dealing with the design of chromogenic and fluorogenic chemosensors or reagents for anions.

\section{1.- Introduction.}

The supramolecular chemistry of anions is one of the most promising sub-areas within the supramolecular chemistry field. Anion supramolecular chemistry involves the development and use of selective anion receptors. ${ }^{1-14}$ In fact, today a large number of coordination studies can be found in the literature describing a wide range of different ligands for anion coordination mainly involving hydrogen bonding, ${ }^{15-19}$ electrostatic interactions ${ }^{20-27}$ or coordination with suitable metal cations. ${ }^{28-33}$ The nature of the binding sites and their specific spatial arrangement determine the binding constant with a certain anion and usually selective coordination can be found when a large host-guest complementarity is reached. An issue related with anion binding is the development of anion chemosensors or reagents. These are molecular entities or ensembles that are capable of signalling the presence of a certain anion. ${ }^{34-37}$ Whereas chemical sensors or chemosensors usually refers to systems that typically employ coordinative forces for anion binding, the term reagents or chemodosimeter is related with the use of specific 
irreversible reactions involving anions. Additionally a chemosensor or reagent usually contains a "signalling subunit" capable of give information about the binding event; i.e. electrochemical shifts of the redox potentials in redox-active molecules, colour changes or modification of the fluorescence emission behaviour, have been popular output signals in the development of chemical sensors and reagents. ${ }^{38-40}$ Among them there are a larger number of studies using optical signals than electrochemical redox shifts. In particular, the large known variety of fluorescence and dye moieties, the simple instrumentation required (especially when using colorimetric signalling) and the usually low detection limit reached (especially when using fluorescence signalling), make the optical approach largely appealing in the research community.

By now, most of the reported examples of chemosensors or reagents for anions belong to one of the tree main approaches used in the development of optical signalling systems; namely (i) the "binding site-signalling subunit" approach, (ii) the "displacement" protocol and (iii) the "chemodosimeter" paradigm. The first two use anion "binding sites" and "signalling subunits". In the "binding site-signalling subunit" approach these two parts are linked through a covalent bond and the interaction of the anion with the binding site changes the electronic properties of the signalling subunit resulting in a sensing of the target anion via colour or emission modulation. ${ }^{41-43}$ The displacement protocol also uses binding sites and signalling subunits but in this case these are not covalently bonded but the units from a molecular ensemble. ${ }^{44,45}$ The sensing paradigm relies in a displacement; i.e. the coordination of a target anion in the binding site results in the release of the signalling subunit with a concomitant change in its optical characteristics. A third method to the optical signalling of anions is the "chemodosimeter" approach that takes advantage of anion-induced reactions that results in a changes in fluorescence or in colour. ${ }^{46}$ A large number of optical sensors and reagents for anions has been synthesised by using one of the three approaches described above. Additionally, as we will see below, there are certain interesting systems that are based in the use of nanomaterials. However these are still rare.

This review aims to be a comprehensive recompilation of the examples reported in the year 2009 related with the design of chromogenic and fluorogenic chemosensors or reagents for small anions (systems dealing with the recognition of large anionic macromolecules such as DNA are not included). Additionally, although they are not strictly anions, we have also included examples designed for the detection of amino acids. We published a review on chromo-fluorogenic signalling of anions in 2003 and 
also reported a survey dealing with fluorescent detection of anions in $2005 .^{33,47}$ Since then the number of examples on anion signaling has been growing year by year. The review has been divided into two main sections: (a) chromogenic and (b) fluorogenic chemosensors and reagents. Each section has been divided attending to the approach used in the signaling process; i.e. (i) the binding site - signaling unit protocol, (ii) the displacement approach, (iii) the chemodosimeter paradigm and (iv) the use of hybrid materials.

\section{2.- Chromogenic anion chemosensors and reagents.}

\section{1.- Binding site-signalling subunit approach.}

This is still the most widely used approach in the development of chromogenic and fluorogenic anion chemosensors and basically consists of the attachment, through covalent bonds, of a binding site and a signalling subunit. In the chromogenic examples these two units are electronically connected in such as way that anion coordination changes the electronic properties of the molecule resulting in a colour modulation. The following examples are organized using a classification based on the signalling unit. In most cases, colorimetric signalling using this approach only show sensing features in organic solvents, the changes in colour being related with the basicity of anions that either, form hydrogen bonding interactions or/and induce deprotonation of the receptor.

2.1.1.- Containing nitroaromatic derivatives.<smiles>O=[N+]([O-])c1ccc(O)c(/N=C/c2ccccc2O)c1</smiles>

1<smiles>[X]c1ccc(N/N=C/c2cc(Cl)cc(/C=N/Nc3ccc([X])cc3[X])c2O)c([X])c1</smiles>

$2 \mathrm{X}=\mathrm{NO}_{2}, \mathrm{Y}=\mathrm{H}$ $3 X=\mathrm{NO}_{2}, \mathrm{Y}=\mathrm{NO}_{2}$<smiles>O=[N+]([O-])c1ccc(N/N=C/c2ccccc2O)c([N+](=O)[O-])c1</smiles>

4

Fig. 1 Structures of receptors 1, 2, 3 and 4.

Compound N-(2-hydroxy-5-nitrophenyl)salicylidene, 1 (Figure 1), is one of the few examples of salicylidenes derivatives used as chemical sensors for anions. Acetonitrile solutions of $\mathbf{1}$ are yellow due to the presence of a broad absorption band at 
$342 \mathrm{~nm}^{48}$ Addition of increasing quantities of $\mathrm{F}^{-}, \mathrm{AcO}^{-}$and $\mathrm{H}_{2} \mathrm{PO}_{4}^{-}$induced a progressive decrease of the $342 \mathrm{~nm}$ band and the apparition of a new visible absorption at $450 \mathrm{~nm}$. Colour changes were attributed to the formation of hydrogen bonding interactions between the hydroxyl groups of the receptor and the anions. 1:1 complexes were formed. Under the same conditions, addition of increasing quantities of $\mathrm{Br}^{-}, \mathrm{Cl}^{-}$, $\mathrm{ClO}_{4}{ }^{-}$and $\mathrm{HSO}_{4}{ }^{-}$induced negligible colour changes. The selectivity trend observed was clearly related with the basicity of the anions. The selectivity of the receptor can additionally be modulated by using $10 \%$ water-acetonitrile mixtures because in this highly competitive medium only the presence of $\mathrm{AcO}^{-}$induced colour modulations.

Receptors 2-4 contain p-nitrophenyl signalling (Figure 1) subunits linked with phenol and hydrazone groups that are able to coordinate with certain anions through hydrogen bonding interactions. ${ }^{49}$ In DMSO solutions, the three receptors showed colour changes from orange (band centred at $440 \mathrm{~nm}$ ) to magenta (a new band is formed in the $500-550 \mathrm{~nm}$ interval) upon addition of $\mathrm{F}^{-}, \mathrm{AcO}^{-}$and $\mathrm{H}_{2} \mathrm{PO}_{4}{ }^{-}$anions, whereas addition of $\mathrm{Cl}^{-}, \mathrm{Br}^{-}, \mathrm{I}^{-}$and $\mathrm{HSO}_{4}^{-}$induced negligible changes. These changes in the presence of basic anions were assigned to a deprotonation of the phenol O-H and hydrazone $\mathrm{N}-\mathrm{H}$ protons. On changing from DMSO to DMSO-water 9:1 v/v mixtures the selectivity was increased; only receptors 2 and 3 were able to give colour changes in the presence of $\mathrm{F}^{-}$ and $\mathrm{AcO}^{-}$whereas $\mathrm{H}_{2} \mathrm{PO}_{4}^{-}$was able to induce colour changes only in the presence of receptor 3. Finally the use of DMSO-water 7.5:2.5 v/v mixtures lead to a selective response in the presence of $\mathrm{AcO}^{-}$for receptors $\mathbf{2}$ and $\mathbf{3}$.

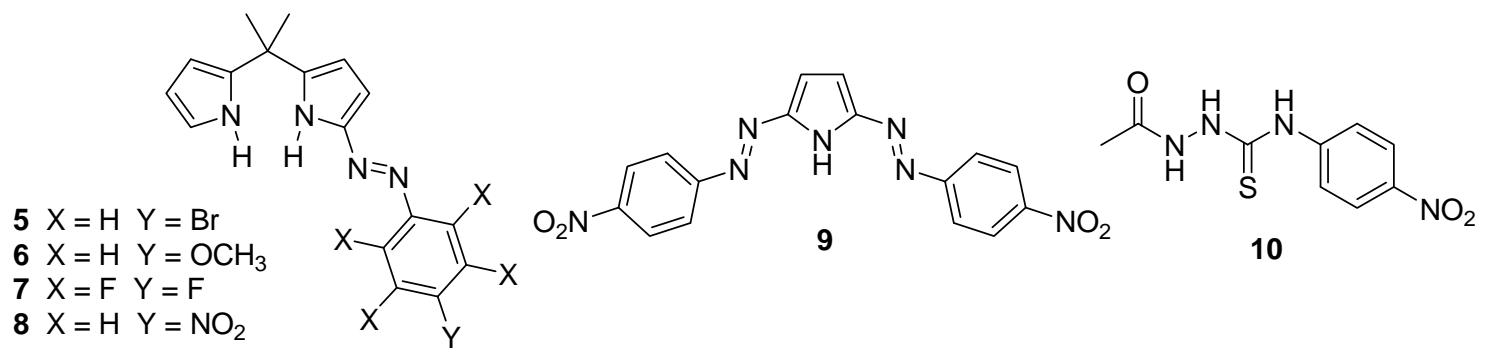

Fig.2 Chemical structures of receptors 5-8, 9 and 10.

Dipyrromethanes have already been used for the development of chromogenic chemosensors for anions. ${ }^{50-57}$ Receptors 5-9 (Figure 2) were synthesized and their coordination behaviour with $\mathrm{F}^{-}, \mathrm{Cl}^{-}, \mathrm{Br}^{-}, \mathrm{I}^{-}, \mathrm{AcO}^{-}, \mathrm{H}_{2} \mathrm{PO}_{4}{ }^{-}$and $\mathrm{HSO}_{4}{ }^{-}$in acetonitrile studied. ${ }^{58}$ All the receptors, with the exception of $\mathbf{5}$, show dramatic changes in colour 
upon addition of anions. For instance, acetonitrile solutions of $\mathbf{6}$ and $\mathbf{7}$ are yellow (band at $388 \mathrm{~nm}$ for receptor 6) and changed to orange (decrease of the absorbance at $388 \mathrm{~nm}$ with the apparition of a shoulder centred at $430 \mathrm{~nm}$ for receptor 6) upon addition of $\mathrm{F}^{-}$ whereas the other anions tested induced negligible changes in the visible bands. A more rich response was obtained with acetonitrile solutions of 8 . In this case anions $\mathrm{F}^{-}$, $\mathrm{H}_{2} \mathrm{PO}_{4}^{-}$and $\mathrm{AcO}^{-}$induced colour changes from yellow to blue, green and violet, respectively. The authors suggested that these colour modulations are due to the formation of hydrogen bonds, between the nitrogen atoms of the pyrrole moieties and the anions. The different response obtained was assigned to the increasing acidity of $\mathrm{N}$ $\mathrm{H}$ groups in $\mathbf{8}$, when compared to $\mathbf{6}$ and $\mathbf{7}$, due to the presence of strong electron withdrawing nitro groups in the structure of the former. Acetonitrile solutions of 9 show an absorption band at $505 \mathrm{~nm}$ that gradually decreases with the appearance of new absorption at $591 \mathrm{~nm}$ upon addition of $\mathrm{F}^{-}, \mathrm{H}_{2} \mathrm{PO}_{4}^{-}$and $\mathrm{AcO}^{-}$anions. The authors assigned this new absorption band to a deprotonation process.

Acetonitrile solutions of the $N$-(acetamido)thiourea receptor 10 (Figure 2) show an UV band centred at $331 \mathrm{~nm}$ of charge transfer nature. ${ }^{59}$ Addition of $\mathrm{F}^{-}, \mathrm{AcO}^{-}$and $\mathrm{H}_{2} \mathrm{PO}_{4}{ }^{-}$induced the disappearance of the $331 \mathrm{~nm}$ band together with the apparition of a new absorption centred at $396 \mathrm{~nm}$ (colour change from colourless to yellow). ${ }^{1} \mathrm{H}-\mathrm{NMR}$ experiments showed that the observed colour change was related with a deprotonation of the thioureido N-H group located near the p-nitrobenzyl moiety. Less basic anions such as $\mathrm{Cl}^{-}, \mathrm{Br}^{-}, \mathrm{I}^{-}, \mathrm{NO}_{3}{ }^{-}, \mathrm{ClO}_{4}{ }^{-}$and $\mathrm{HSO}_{4}{ }^{-}$remained silent.
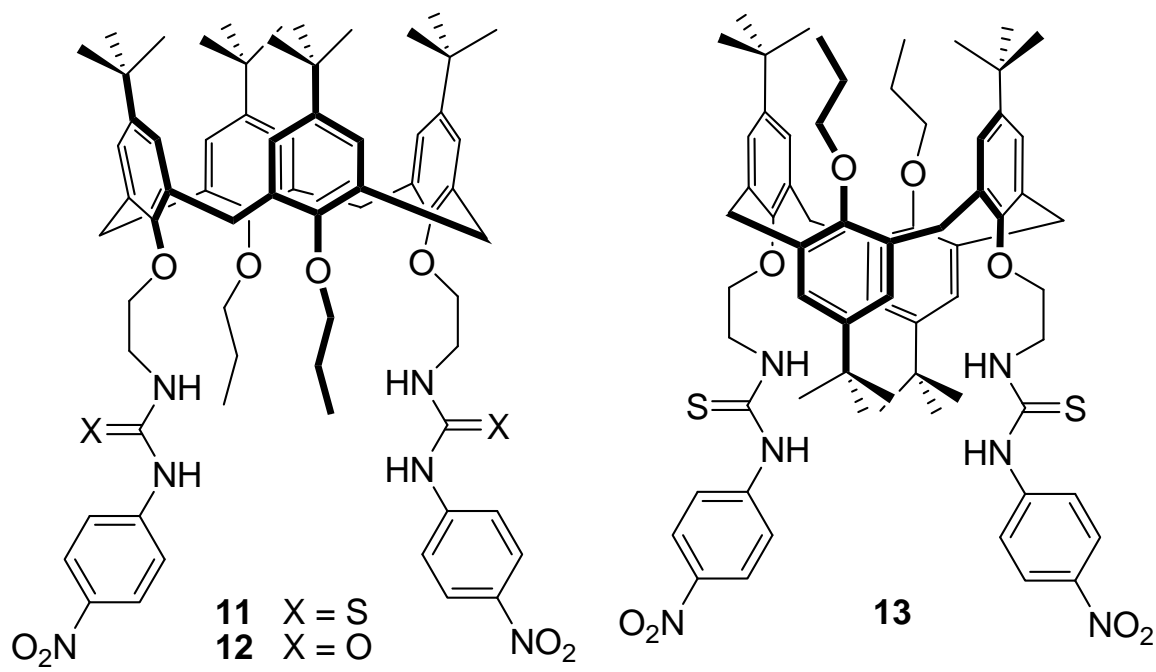

Fig. 3 Structure of calix[4]arene based receptors 11, 12 and 13. 
Calix[4]arene receptors 11-13 in cone and 1,3-alternate conformations (Figure 3) were prepared and their coordination ability towards selected anions $\left(\mathrm{F}^{-}, \mathrm{AcO}^{-}, \mathrm{Cl}^{-}, \mathrm{Br}^{-}\right.$, $\mathrm{I}^{-}$and $\mathrm{NO}_{3}{ }^{-}$) tested in THF solutions. ${ }^{60}$ Addition of $\mathrm{F}^{-}$and $\mathrm{AcO}^{-}$anions to $\mathbf{1 1}$ induced a colour change from colourless to orange-red (the band at $339 \mathrm{~nm}$ is red shifted by 131 and $112 \mathrm{~nm}$ for $\mathrm{F}^{-}$and $\mathrm{AcO}^{-}$respectively). The spectral changes are attributed to a proton transfer process from 11 to $\mathrm{F}^{-}$and $\mathrm{AcO}^{-}$anions. As a consequence of the removal of the thiourea protons located near the nitrophenyl group a negatively charged $p$ nitroanilide ion was formed which causes a significant increase in the charge density on the thioureido nitrogen atom. The other anions tested induced moderate red shifts upon coordination with receptor $\mathbf{1 1}$ indicative of the formation of 1:1 complexes through hydrogen bonding interactions with the thiourea moieties. For 13, only addition of $\mathrm{F}^{-}$ induced deprotonation whereas the other anions tested gave the corresponding hydrogen-bonding 1:1 host-guest complexes. On the other hand, receptor 12, functionalized with less acidic urea binding sites, only only hydrogen-bonded complexes with all the anions tested.
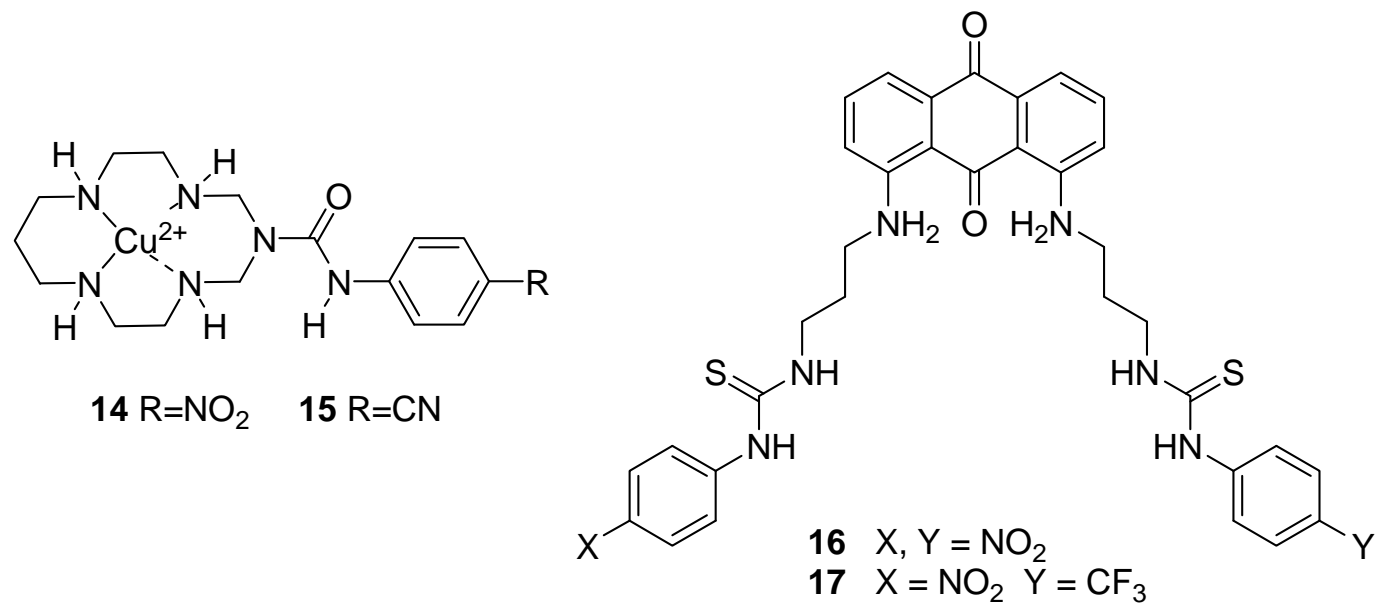

Fig. 4 Chemical structures of receptors 14, 15, 16 and 17.

Binding tendencies towards anions were studied for copper(II) azacyclam, containing phenylurea moieties, complexes 14 and 15 (see Figure 4). ${ }^{61}$ Equilibrium studies in DMSO proved that, while the NH group of an amide model compound and the metal centre of the plain $\mathrm{Cu}^{\mathrm{II}}(\text { azacyclam })^{2+}$ complex did not interact with anions, $\mathbf{1 4}$ and 15 established strong interactions with oxo anions, profiting from a pronounced 
cooperative effect. DMSO solutions of 14 showed an absorption band centred at $330 \mathrm{~nm}$ that progressively decreased in intensity with the concomitant appearance of a new band centred at $450 \mathrm{~nm}$ upon addition of $\mathrm{AcO}^{-}$anion. Nearly the same results were obtained upon addition of $\mathrm{AcO}^{-}$to DMSO solutions of 15. This blue shift in the presence of $\mathrm{AcO}^{-}$ was ascribed to the fact that $\mathbf{1 4}$ and $\mathbf{1 5}$ underwent deprotonation of the amido NH group and thus profit from axial coordination of the negatively charged carbonyl oxygen atom in a scorpionate binding mode. Both receptors formed stable 1:1 and 1:2 host-guest complexes with $\mathrm{H}_{2} \mathrm{PO}_{4}^{-}$in a stepwise mode via both hydrogen-bonding and metalligand interactions. Interestingly, less basic oxoanions such as $\mathrm{HSO}_{4}{ }^{-}$and $\mathrm{NO}_{3}{ }^{-}$did not modify the UV-vis absorption spectra of both amide funcionalized azacyclam complexes. Other anions such as $\mathrm{Cl}^{-}, \mathrm{Br}^{-}$and $\mathrm{I}^{-}$induced negligible changes.

Chromogenic receptors 16 and 17, containing an anthraquinone signalling unit and thiourea binding sites (Figure 4), were designed for the recognition of isomeric dicarboxylates (maleate, fumarate, malate and tartrate) and tricarboxylates (cis-aconitate and trans-aconitate). ${ }^{62}$ Receptor 16 was able to chromogenically distinguish between the isomeric dicarboxylates maleate and fumarate. DMSO solutions of $\mathbf{1 6}$ are violet (absorption bands at 353 and $554 \mathrm{~nm}$ ). Addition of maleate induced a progressive decrease in the intensity of the band at $353 \mathrm{~nm}$, while a new band centred at $493 \mathrm{~nm}$ grow (consequently the colour of the solution turned red). Surprisingly the presence of fumarate was unable to induce changes in the UV-visible spectra. Both dicarboxylates form 1:1 hydrogen-bonded complexes with chromoreactand $\mathbf{1 6}$ at low anion:receptor ratios but only maleate (due to its high basicity) was able to induce deprotonation of $\mathbf{1 6}$ at higher anion:receptor ratios. Nearly the same response was found for cis-aconitate and trans-aconitate tricarboxylates in the presence of receptor 16, namely hydrogenbonded complexation and deprotonation with the cis isomer and only hydrogen-bonded complexation for the trans isomer. Finally chromoreactand $\mathbf{1 6}$ was also able to discriminate malate from tartrate because only malate was able to induce the apparition of the band centred at $492 \mathrm{~nm}$. A similar response was obtained in the presence of chromoreactand $\mathbf{1 7}$ that was functionalized with one 4-trifluoromethylphenyl group instead of a 4-nitrophenyl moiety. This chromoreactand was able to discriminate colorimetrically maleate or malate versus fumarate or tartrate but was unable to distinguish between cis- and trans-aconitate. 
<smiles>C[C@H](NC(=O)c1ccccc1)C(=O)NNC(=S)NNC(=S)Nc1ccc([N+](=O)[O-])cc1</smiles>

18<smiles>C[C@H](NC(=O)c1ccccc1)C(=O)NCCNC(=S)Nc1ccc([N+](=O)[O-])cc1</smiles>

19

Fig. 5 Structures of receptor 18 and 19.

Chromogenic receptors 18 and 19 used ferrocene as preorganized platform in which hydrogen donor moieties, such as thiourea and amide, were attached in order to prepare chiral chromogenic ligands that were capable of distinguish between $\mathrm{N}$-acetylL-aspartate and $N$-acetyl-D-aspartate (see Figure 5). ${ }^{63}$ The UV-vis spectrum of 18 in DMSO shows a charge transfer band at $370 \mathrm{~nm}$. With the addition of $N$-acetyl-Laspartate the band at $370 \mathrm{~nm}$ decreased gradually (with a red shift of $20 \mathrm{~nm}$ ) and a new band at $484 \mathrm{~nm}$ increased progressively (colour change from light yellow to red). A very similar response was obtained upon addition of $N$-acetyl-D-aspartate with the apparition of the band centred at $484 \mathrm{~nm}$ but with less intensity than that obtained with the $\mathrm{L}$ isomer (colour change from light yellow to nacarat). The authors attributed the colour changes to an increase of ICT (internal charge transfer) upon coordination, through hydrogen bonding interactions, of anions with the amide and thiourea moieties in 18. Receptor 19 showed an inverse selectivity because was able to form stronger complexes with $\mathrm{N}$-acetyl-D-aspartate than with $\mathrm{N}$-acetyl-L-aspartate. The authors suggested that the different chiral recognition abilities of these receptors were closely related with their chemical conformation; i.e. in $\mathbf{1 8}$ the two functional arms occupy different sides of the ferrocene whereas in $\mathbf{1 9}$ both functional arms are located in the same side of the ferrocene moiety. This diverse conformation could account for the colorimetric chiral recognition observed upon coordination with both isomers of $\mathrm{N}$ acetylaspartate.

\subsection{2.- Containing aromatic alcohols.}




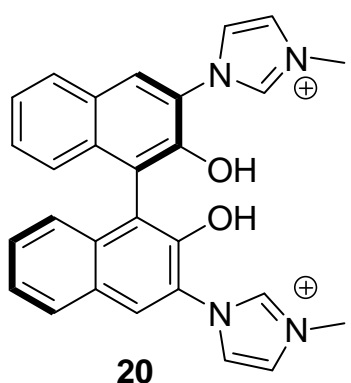

20<smiles>O=C(Nc1ccccc1/N=C\c1ccccc1O)c1cccc(C(=O)Nc2ccccc2/N=C\c2ccccc2O)c1</smiles>

21<smiles>Cc1c(CSc2ccccc2/N=C/c2cccc(O)c2O)c(C)c(CSc2ccccc2/N=C/c2cccc(O)c2O)c(C)c1CSc1ccccc1/N=C/c1cccc(O)c1O</smiles>

22

Fig. 6 Structure of receptors 20, 21 and 22.

The imidazolium-functionalized receptor 20 (Figure 6) shows dual recognition features because is able to detect $\mathrm{F}^{-}$anion through colour changes and $\mathrm{F}^{-}$and $\mathrm{AcO}^{-}$by fluorescence. Also 20 was used for the chiral recognition of $t$-Boc protected alanine. ${ }^{64}$ The authors reported that acetonitrile-DMSO 9:1 v/v mixtures of receptor 20 are colourless and become yellow upon addition of 50 equivalents of $\mathrm{F}^{-}$and pale yellow upon addition of 50 equivalents of $\mathrm{AcO}^{-}$. No changes were observed upon addition of $\mathrm{Cl}^{-}, \mathrm{Br}^{-}, \mathrm{H}_{2} \mathrm{PO}_{4}{ }^{-}$and $\mathrm{HSO}_{4}{ }^{-}$anions. The distinct chromogenic response of receptor 20 in the presence of $\mathrm{F}^{-}$and $\mathrm{AcO}^{-}$anion was assigned to a deprotonation of the imidazolium moieties by $\mathrm{F}^{-}$anion whereas $\mathrm{AcO}^{-}$was only able to interact with the imidazolium moieties through the formation of $(\mathrm{C}-\mathrm{H})^{+} \cdots \mathrm{X}^{-}$hydrogen bonds. In relation to fluorescence, 20 showed an emission band at $370 \mathrm{~nm}$ in acetonitrile that suffers a bathochromic shift to 474 and $454 \mathrm{~nm}$ upon addition of $\mathrm{F}^{-}$and $\mathrm{AcO}^{-}$respectively. No shifts were observed with other selected anions.

The cleft-like receptor $\mathbf{2 1}$ (Figure 6) is able to selectively recognize $\mathrm{F}^{-}$anion by colour changes and emission intensity enhancements. ${ }^{65}$ DMSO solutions of receptor 21 show an ICT band at $326 \mathrm{~nm}$ due to the presence in the molecule of the electron-rich Schiff-base and the electron deficient isophthaloyl moiety. Addition of $\mathrm{Cl}^{-}, \mathrm{Br}^{-}, \mathrm{I}^{-}$, $\mathrm{H}_{2} \mathrm{PO}_{4}^{-}, \mathrm{HSO}_{4}{ }^{-}$and $\mathrm{NO}_{3}{ }^{-}$anion induced negligible changes in the ICT band whereas addition of $\mathrm{F}^{-}$induced a moderate decrease of the band at $326 \mathrm{~nm}$ (colourless solution) together with the apparition of a new absorption at $425 \mathrm{~nm}$ (yellow-green solution). This new band was ascribed to the formation of 1:1 host-guest complexes through 
multiple hydrogen bonding interactions of $\mathrm{F}^{-}$with the amide and hydroxyl groups of the receptor. Similar spectral changes were observed upon addition of $\mathrm{AcO}^{-}$to $\mathrm{DMSO}$ solutions of receptor 21, but the change in colour was less intense. The authors suggested that the strong affinity of $\mathbf{2 1}$ toward $\mathrm{F}^{-}$was a consequence of its highest electronegativity and the optimal shape complementarity between this spherical anion and the cleft-shaped receptor. Additionally, DMSO solutions of 21 show an emission band at $463 \mathrm{~nm}$ that was shifted to $475 \mathrm{~nm}$ and its intensity enhanced upon addition of $\mathrm{F}^{-}$and $\mathrm{AcO}^{-}$. These emission enhancements were assigned to an excited intramolecular proton transfer (from the $\mathrm{OH}$ to the $\mathrm{NH}$ group) mechanism that was active in the excited state in the presence of anions $\mathrm{F}^{-}$and $\mathrm{AcO}^{-}$. In contrast, no emission enhancements were seen after the addition of the other selected anionic species.

The tripodal receptor functionalized with three catechol subunits 22 (Figure 6) displays a selective chromogenic response to $\mathrm{F}^{-}$anion. ${ }^{66}$ DMSO solutions of receptor 22 show a band centred at $274 \mathrm{~nm}$ and two shoulders at 306 and $353 \mathrm{~nm}$, being the latter an internal charge transfer band involving the imine and the hydroxyl moieties. Of all the anions tested $\left(\mathrm{F}^{-}, \mathrm{Cl}^{-}, \mathrm{Br}^{-}, \mathrm{I}^{-}, \mathrm{NO}_{3}^{-}, \mathrm{CN}^{-}, \mathrm{ClO}_{4}^{-}, \mathrm{AcO}^{-}, \mathrm{HSO}_{4}^{-}\right.$and $\left.\mathrm{H}_{2} \mathrm{PO}_{4}^{-}\right)$only $\mathrm{F}^{-}$was able to induce a slight hypsochromic shift of the highest energy band whereas the shoulder at $353 \mathrm{~nm}$ disappears and, at the same time, a new band appears at $433 \mathrm{~nm}$ (change in colour from pale to deep yellow). ${ }^{1} \mathrm{H}-\mathrm{NMR}$ and UV-visible measurements carried out with tetrabutylammonium hydroxide pointed toward a deprotonation of the hydroxyl moieties of the catechol as the mechanism responsible of the colour change observed. The negative charge generated in the deprotonation process increases the dipole moment and stabilizes the excited state causing the significant red shift of the visible band observed. 
2.1.3.- Functionalized with nitrogen-containing heterocycles.
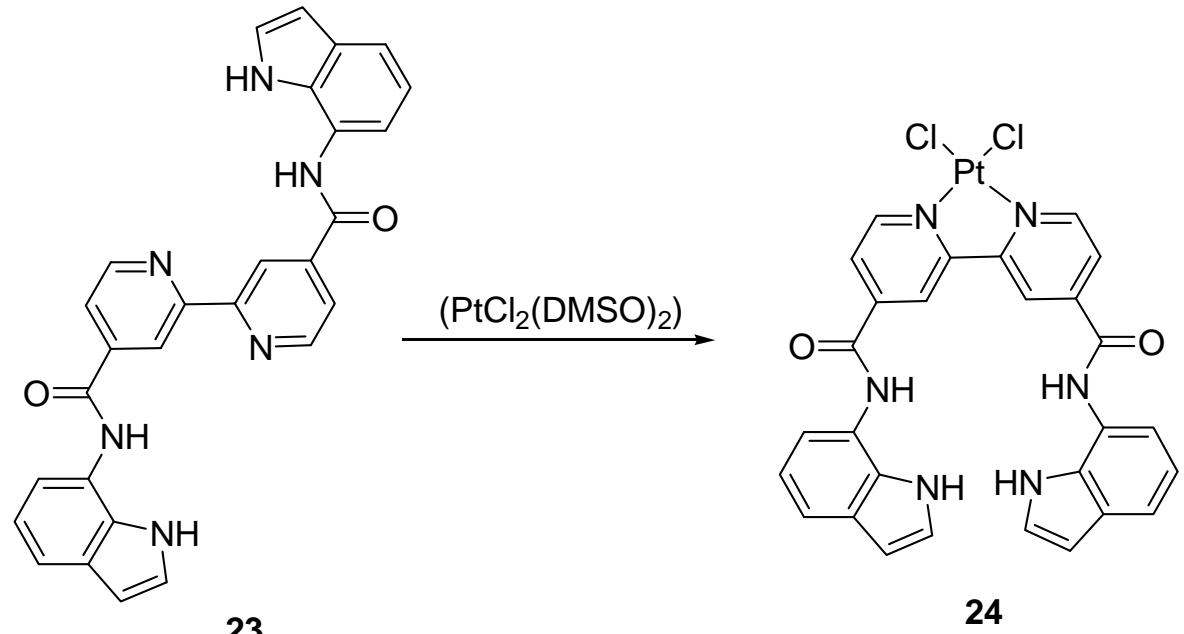

Fig. 7 Structure of 23 and its neutral Pt(II) complex 24.

4,4'-dicarboxamido-di(indol-7-yl)-2,2'-bipyridine, 23, and its neutral $\operatorname{Pt}(\mathrm{II})$ complex 24 (Figure 7) were synthesised to perform anion sensing studies in DMSO$0.5 \%$ water. $^{67}$ The open conformation adopted by the receptor 23 is due to the free rotation of the bipyridine group and could explain the low stability constants determined by solution studies. Moreover, compound $\mathbf{2 4}$ has a significantly higher affinity for anions compared to compound 23. The enhanced anion affinity was attributed to the higher degree of pre-organisation induced by the $\mathrm{Pt}(\mathrm{II})$ centre locking the rotation around the pyridine-pyridine bond. DMSO-water 99.5:0.5 (v/v) solutions of receptor 24 show an absorption band at $400 \mathrm{~nm}$ that was red shifted to $510 \mathrm{~nm}$ upon addition of $\mathrm{F}^{-}$. The absence of isosbestic points in the titration profile indicated the coexistence of more than one reaction between receptor 24 and $\mathrm{F}^{-}$. The changes observed were reflected in colour modulations from yellow (free receptor) to orange-brown (hydrogen bonding interactions of $\mathrm{F}^{-}$with 24) and, finally to purple (deprotonated 24). Other anions tested $\left(\mathrm{H}_{2} \mathrm{PO}_{4}{ }^{-}\right.$included) induced minor changes in the UV-vis spectrum. 


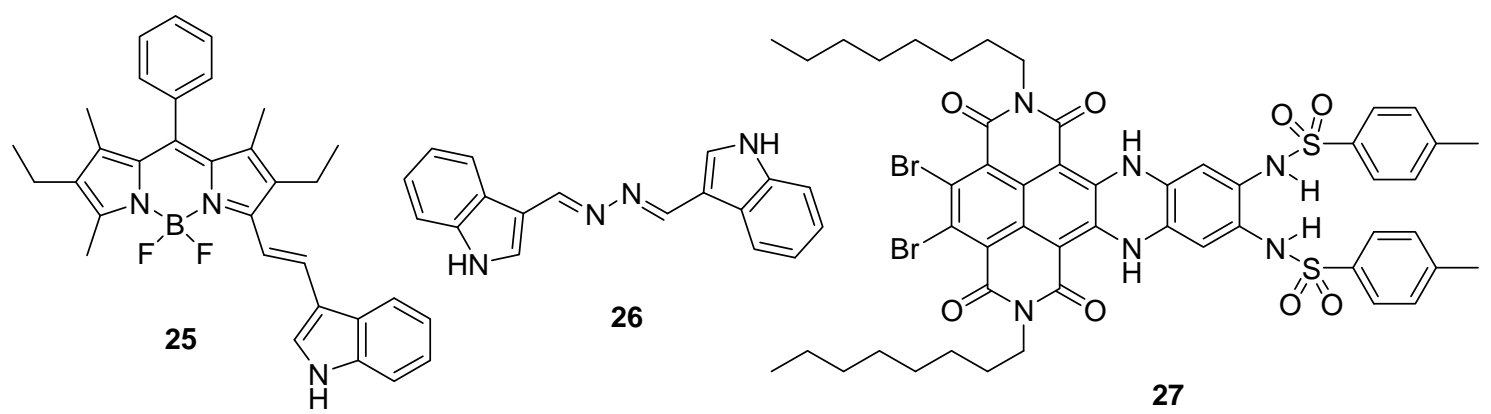

Fig. 8 Structure of receptors 25, 26 and 27.

Receptor 25 (Figure 8) containing the boradiazaindacene (BODIPY) fluorophore as signalling subunit and an indole group as binding site was prepared and tested as dual chromogenic and fluorogenic receptor for anions. ${ }^{68} \mathrm{UV}$-visible spectra of receptor 25 in acetonitrile exhibits a band at $599 \mathrm{~nm}$ that, upon addition of increasing quantities of the anion $\mathrm{F}^{-}$, shifted to $718 \mathrm{~nm}$ with the concomitant colour change from blue to green. In contrast, addition of other anions such as $\mathrm{Cl}^{-}, \mathrm{Br}^{-}, \mathrm{I}^{-}, \mathrm{ClO}_{4}^{-}, \mathrm{H}_{2} \mathrm{PO}_{4}^{-}, \mathrm{HSO}_{4}^{-}, \mathrm{NO}_{3}^{-}, \mathrm{SCN}^{-}$ and $\mathrm{AcO}^{-}$resulted in no colour modulation. The same selectivity was observed when fluorescence studies were carried out. Thus, receptor 25 shows a strong fluorescence emission at $624 \mathrm{~nm}$ in the absence of anions that was strongly and selectively quenched upon addition of $F$. Solutions studies pointed towards the formation of 1:1 complexes between 25 and $\mathrm{F}^{-}$through hydrogen bonding interaction between the $\mathrm{N}-\mathrm{H}$ group of the indole and the anion.

The same research group prepared receptor 26, contains two indole moieties as binding sites, and reported the selectively $\mathrm{F}^{-}$detection by changes in colour and fluorescence (Figure 8). ${ }^{69}$ DMSO solutions of 26 show an absorption band at $352 \mathrm{~nm}$ that, upon addition of $\mathrm{F}^{-}$, disappeared resulting in a new band at $409 \mathrm{~nm}$. This red shift induced a colour change from colourless to yellow. More remarkable was the fluorescent behaviour. DMSO solutions of $\mathbf{2 6}$ show negligible fluorescence (excitation at $420 \mathrm{~nm}$ ) whereas upon addition of increasing quantities of $\mathrm{F}^{-}$anion an emission band at 455 appears. Addition of other anions such as $\mathrm{Cl}^{-}, \mathrm{Br}^{-}, \mathrm{I}^{-}, \mathrm{ClO}_{4}^{-}, \mathrm{H}_{2} \mathrm{PO}_{4}^{-}, \mathrm{HSO}_{4}^{-}, \mathrm{NO}_{3}^{-}$, $\mathrm{SCN}^{-}$and $\mathrm{AcO}^{-}$were not able to induce any noticeable change neither in the UV-visible nor in the fluorescence spectra. Solution studies indicated the formation of 1:2 hostguest complexes. ${ }^{1} \mathrm{H}-\mathrm{NMR}$ experiences and $a b$ initio molecular orbital calculations suggested that the association of $\mathbf{2 6}$ and $\mathrm{F}^{-}$occurs through hydrogen bonding interaction between the $\mathrm{N}-\mathrm{H}$ protons of the indole groups and the anion. 
The receptor 27 contains in its structure a naphthalene diimide signalling subunit and two sulfonamides as binding sites (Figure 8). ${ }^{70}$ Chloroform solutions of receptor 27 show a blue colouration due to the presence of absorptions at 559, 609 and $696 \mathrm{~nm}$. Upon addition of $\mathrm{F}^{-}$the intensity of the bands at 559 and $609 \mathrm{~nm}$ decreased progressively whereas new bands at 570 and 622 appeared being these changes reflected in a colour modulation from blue to green. The response was selective to $\mathrm{F}^{-}$and other anions tested $\left(\mathrm{Cl}^{-}, \mathrm{Br}^{-}, \mathrm{AcO}^{-}, \mathrm{H}_{2} \mathrm{PO}_{4}^{-}\right)$induced negligible changes in the colour of the solution. ${ }^{1} \mathrm{H}-\mathrm{NMR}$ titration profiles of receptor 27 with $\mathrm{F}^{-}$indicated the formation of a 1:2 receptor-fluoride complexes. Addition of $\mathrm{F}^{-}$first results in hydrogen bonding interactions with the N-H moietes of the bis-sulfonamide binding site, while the second $\mathrm{F}^{-}$induced the deprotonation of one of the sulfonamides. Receptor 27 also shows two emission bands at 635 and $696 \mathrm{~nm}$ that suffered a significant quenching (97\%) upon $\mathrm{F}^{-}$ addition. On changing the solvent, from chloroform to the more polar DMSO, a similar $\mathrm{UV}$-visible response was found upon addition of $\mathrm{F}^{-}$.

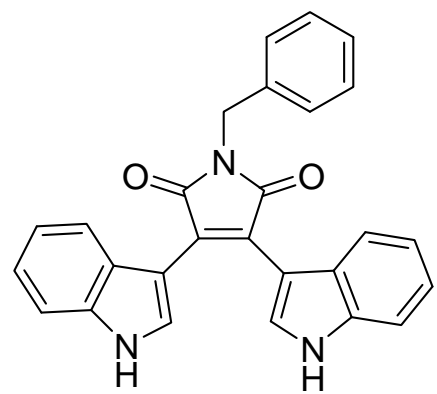

28

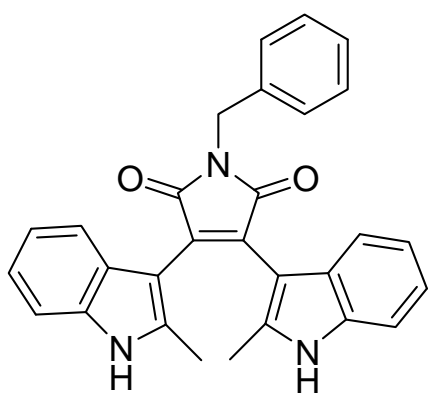

29

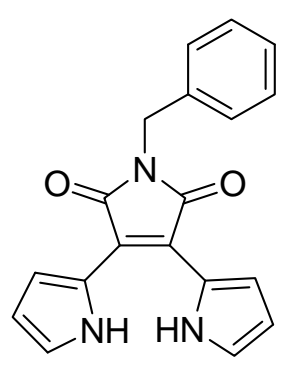

30

Fig. 9 Chemical structures of receptors $\mathbf{2 8 ,} 29$ and 30.

Receptors 28-30 contain a maleimide dye as signalling subunit and indoles (28 and 29) and pyrroles (30) as binding sites (Figure 9). ${ }^{71}$ The chromogenic and fluorogenic behaviour of these molecules in the presence of $\mathrm{F}^{-}, \mathrm{Cl}^{-}, \mathrm{Br}^{-}, \mathrm{I}^{-}, \mathrm{ClO}_{4}^{-}, \mathrm{H}_{2} \mathrm{PO}_{4}^{-}, \mathrm{HSO}_{4}^{-}$, $\mathrm{NO}_{3}{ }^{-}, \mathrm{CN}^{-}$and $\mathrm{AcO}^{-}$in dichloromethane was studied. Receptors 28 and 29 modified their colour from yellow (band at $474 \mathrm{~nm}$ ) to orange (band at $505 \mathrm{~nm}$ ) in the presence of $\mathrm{F}^{-}$and $\mathrm{H}_{2} \mathrm{PO}_{4}{ }^{-}$. Also the emission intensity at $605 \mathrm{~nm}$ was quenched in the presence of the same anions. The formation of 1:1 binding complexes between receptors 28, 29 and the $\mathrm{F}^{-}$and $\mathrm{H}_{2} \mathrm{PO}_{4}{ }^{-}$was suggested to occur using computational models. These studies suggested that the two indolyl N-H groups chelate the anions through hydrogen bonding interactions. The response was clearly different when using receptor $\mathbf{3 0}$. 
Dichloromethane solutions of this chemosensor changed from red (band at $516 \mathrm{~nm}$ ) to blue (band at $580 \mathrm{~nm}$ ) upon addition of increasing quantities of $\mathrm{F}^{-}$and $\mathrm{CN}^{-}$. Also the emission intensity of the receptor at $646 \mathrm{~nm}$ was gradually quenched and shifted to 705 $\mathrm{nm}$ upon addition of $\mathrm{F}^{-}$and $\mathrm{CN}^{-}$. In this case, the observed changes in colour were due to a deprotonation of one of the pyrroles.
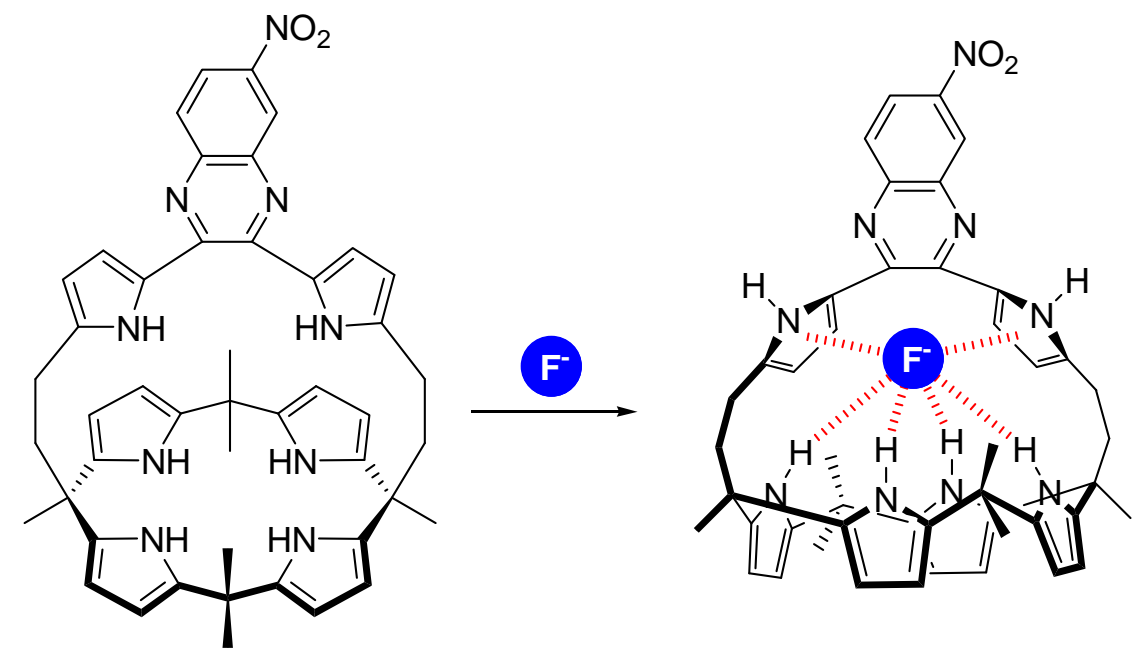

31

Fig. 10 Schematic representation of the binding mode between receptor 31 and $\mathrm{F}^{-}$anion.

The chromogenic behaviour of 31, containing a calix[4]pyrrole binding site strapped with a chromogenic dipyrrolylquinoxaline signalling subunit, was tested against anions (Figure 10). ${ }^{72}$ Acetonitrile-DMSO 97:3 v/v solutions of 31 show an absorption at $460 \mathrm{~nm}$. Addition of the anions $\mathrm{F}^{-}$and $\mathrm{H}_{2} \mathrm{PO}_{4}^{-}$induced a moderate decrease of the band at $460 \mathrm{~nm}$ together with the apparition of a new red-shifted band at 488 and $580 \mathrm{~nm}$ for $\mathrm{F}^{-}$and $\mathrm{H}_{2} \mathrm{PO}_{4}{ }^{-}$respectively, that induced a change of colour to deep red. Detectable changes in colour could also be seen in the presence of $\mathrm{AcO}^{-}$whereas addition of $\mathrm{Cl}^{-}, \mathrm{Br}^{-}, \mathrm{I}^{-}, \mathrm{HSO}_{4}^{-}, \mathrm{NO}_{3}^{-}$and $\mathrm{SCN}^{-}$anions do not induce any noticeable colour change. Colour changes were attributed to $\mathrm{F}^{-}$coordination in the central cavity of the receptor through hydrogen bonding interactions with the $\mathrm{N}-\mathrm{H}$ groups of the calix[4]pyrrole subunit and through anion- $\pi$ interactions with the pyrroles on the strap. 


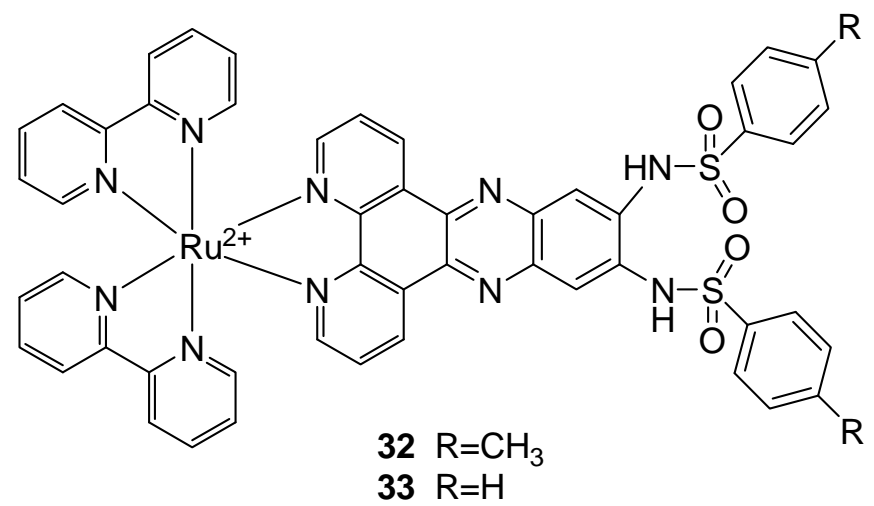

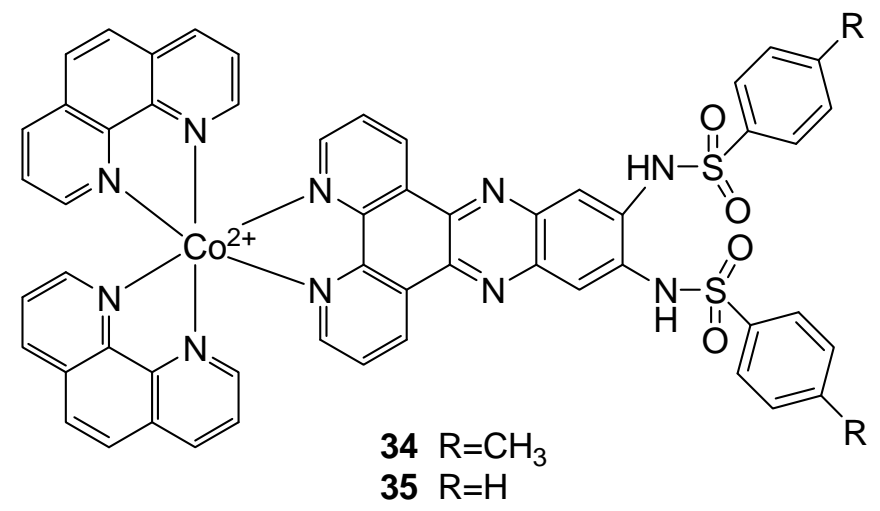

Fig. 11 Structure of receptors 32, 33, 34 and 35.

The interaction with anions of the $\mathrm{Ru}(\mathrm{II})$ and $\mathrm{Co}(\mathrm{II})$-based receptors 32-35 (Figure 11) containing a sulfonamido system, was studied by UV-vis, ${ }^{1} \mathrm{H}-\mathrm{NMR}$ titration and cyclic voltammetry in DMSO. ${ }^{73} 32$ shows an intense absorption band at $340 \mathrm{~nm}$ that, upon addition of the anions $\mathrm{AcO}^{-}$and $\mathrm{F}^{-}$, decreases, whereas three new absorptions at 380, 475 and $500 \mathrm{~nm}$ were developed (change in colour from orange-red to red). Solutions studies demonstrated the formation of 1:1 complexes between 32 and both anions via hydrogen bonding interactions. Nearly the same response was obtained with 33. The anion binding abilities of 32 and 33 follow the order $\mathrm{AcO}^{-}>\mathrm{F}^{-}>\mathrm{H}_{2} \mathrm{PO}_{4}{ }^{-}>>$ $\mathrm{OH}^{-}>\mathrm{Cl}^{-}, \mathrm{Br}^{-}, \mathrm{I}^{-}$. Additionally, DMSO solutions of $\mathbf{3 4}$ show an absorption band at 471 $\mathrm{nm}$ that increased in intensity upon addition of $\mathrm{F}^{-}$and $\mathrm{AcO}^{-}$anions. The binding abilities with 34 and 35 follow the order $\mathrm{F}^{-}>\mathrm{AcO}^{-}>\mathrm{H}_{2} \mathrm{PO}_{4}{ }^{-}>\mathrm{OH}^{-}>>\mathrm{Cl}^{-}, \mathrm{Br}^{-}, \mathrm{I}^{-}$. 


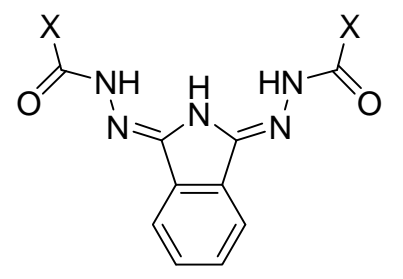

$36 \quad \mathrm{X}=\mathrm{n}-\mathrm{C}_{5} \mathrm{H}_{11}$
$37 \mathrm{X}=\mathrm{Ph}$
$38 \mathrm{X}=2$-pyridine
$39 \mathrm{X}=2$-pyrrole

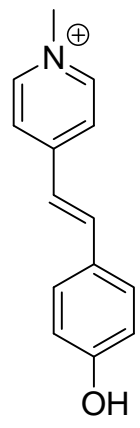

40

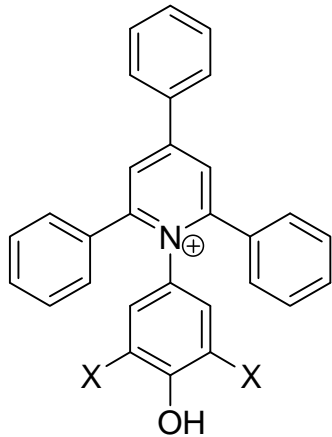

$41 X=\mathrm{C}_{6} \mathrm{H}_{5}$ $42 \mathrm{X}=\mathrm{H}$

Fig. 12 Strutures of receptors 36-39, 40, 41 and 42.

A family of bishydrazide derivatives of isoindolines, compounds 36-39 (Figure 12), was prepared and the anion binding properties investigated by UV-visible studied. ${ }^{74}$ In these receptors the isoindoline moiety acts as signalling subunit and also as binding site together with the hydrazide protons and, in the case of 39, with the protons of the pyrrole ring. DMSO solutions of receptors 36-39 show a visible band around $350 \mathrm{~nm}$ that suffers a bathochromic shift of $40-100 \mathrm{~nm}$ upon addition of $\mathrm{F}^{-}, \mathrm{AcO}^{-}, \mathrm{BzO}^{-}$and $\mathrm{H}_{2} \mathrm{PO}_{4}{ }^{-}$being the final wavelength and intensity of the red shifted band function of the receptor and the added anion. The more selective behaviour was obtained with 36; in this case, addition of $\mathrm{F}^{-}$was able to change the colour of the solution from colourless to yellow. Changes in colour were attributed to an anion-induced deprotonation of the receptors.

Merocyanine dyes 40-42 were used as chromogenic receptors for anions in organic solvents (Figure 12). ${ }^{75}$ Solutions of the free receptors $\mathbf{4 0 - 4 2}$ in chloroform are colourless, however addition of certain anions induced important colour changes. For instance, addition of $\mathrm{CN}^{-}$to $\mathbf{4 0}$ induced the apparition of two bands in the visible region at 579 and $619 \mathrm{~nm}$ coupled with a colour change from colourless to blue. On the other hand, addition of $\mathrm{F}^{-}$induced the apparition of the same bands but to a lesser extent (change in colour from colourless to light blue). The same effect was observed with receptors 41 and 42; i.e. the apparition of bands at $725 \mathrm{~nm}$ and at $609 \mathrm{~nm}$ for each receptor respectively, upon addition of $\mathrm{CN}^{-}$and $\mathrm{F}^{-}$anions. In this case, addition of $\mathrm{H}_{2} \mathrm{PO}_{4}{ }^{-}$to solutions of $\mathbf{4 1}$ and $\mathbf{4 2}$ induced the apparition of the same bands but also to a lesser extent. These changes in colour were assigned to a deprotonation of the receptors by the anions that generated a charge-transfer band from the donor phenolate group to 
the acceptor pyridinium moiety. The final intensity of the band was related with the basicity of the anion $\left(\mathrm{CN}^{-}>\mathrm{F}^{-}>\mathrm{H}_{2} \mathrm{PO}_{4}^{-}\right)$. It is remarkable that the receptor 42 was used as a chromogenic chemosensor for $\mathrm{CN}^{-}$in a biphasic system. In the experiment, chloroform solutions of receptor 42 were put in contact with aqueous solutions of $\mathrm{CN}^{-}$. A change in colour in the organic phase from colourless to magenta was observed that was assigned to the deprotonation of receptor $\mathbf{4 2}$ by $\mathrm{CN}^{-}$anion.<smiles></smiles>

43

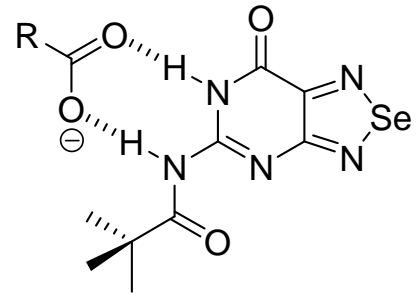

Fig. 13 Binding mode of receptor 43 with carboxylates.

The compound 5-pivaloylamino-1,2,5-selenodiazolo[3,4-d]pyrimidin-7-(6H)one, 43, (Figure 13) was prepared and its chromogenic and fluorogenic response in the presence of selected carboxylates was tested. ${ }^{76}$ Solutions of receptor $\mathbf{4 3}$ in chloroform present a band at $356 \mathrm{~nm}$ that gradually decreases with the concomitant increase of the bands at 304 and $396 \mathrm{~nm}$ upon addition of adamantane-1-carboxylate, pivalate, $\mathrm{AcO}^{-}$ and phenyl acetate anions. The presence of isosbestic points in the titration profiles of receptor 43 with the selected carboxylates indicated the formation of 1:1 host-guest complexes. The carboxylates bind with the two $\mathrm{N}-\mathrm{H}$ protons of receptor 43 then breaking the intramolecular hydrogen bonding between the pivaloyl amide $\mathrm{C}=\mathrm{O}$ and the lactam N-H. The decrease of the band at 356 and the increase of the new band at 396 was more intense upon addition of the bulky anions adamantane-1-carboxylate and pivalate than upon the addition of $\mathrm{AcO}^{-}$and phenyl acetate. The red shift of the absorption maxima upon addition of anions were reflected in colour changes from colourless to yellow. Receptor $\mathbf{4 3}$ is also fluorescent in chloroform. Upon addition of carboxylates the emission band at $412 \mathrm{~nm}$ suffers a bathochromic shift to $445 \mathrm{~nm}$ in the presence of $\mathrm{AcO}^{-}$and phenyl acetate and to $459 \mathrm{~nm}$, with an important enhancement in intensity, in the presence of adamantane-1-carboxylate and pivalate. 


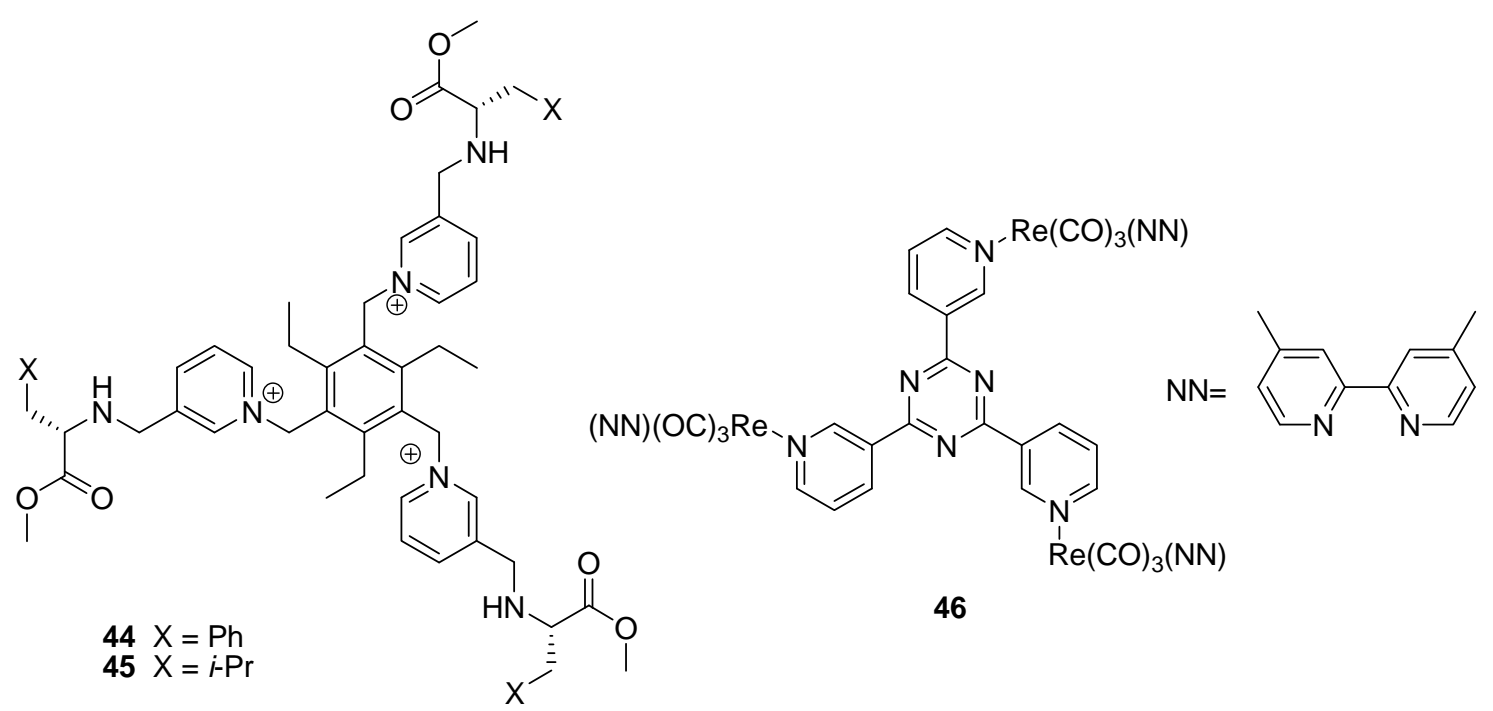

Fig. 14 Chemical structures of receptors 44,45 and 46.

The chiral tripodal receptors 44 and 45 (Figure 14) contain a homochiral anion binding pocket that is able to coordinate with moderate selectivity D-lactate versus Llactate anions. ${ }^{77}$ However chromogenic differentiation was not accomplished and addition of racemic lactate and $\mathrm{AcO}^{-}$to acetonitrile solutions of $\mathbf{4 4}$ or $\mathbf{4 5}$ induced the same visual colour change from colourless to orange-red. This red colour comes from the growth of a broad shoulder at around $350 \mathrm{~nm}$ extended to the visible region that was tentatively assigned to an anion- $\pi^{*}$ charge transfer state involving the pyridinium acceptor and the hydrogen-bonded complexed anion. Both lactate enantiomers coordinated with 44 and 45 through electrostatic and hydrogen bonding (with the $\mathrm{N}-\mathrm{H}$ moieties) interactions.

The trinuclear star-shaped organometallic host 46, containing a $\pi$-acidic interior cavity, was able to colorimetrically sense $\mathrm{F}^{-}$anion (Figure 14). ${ }^{78}$ Acetonitrile solutions of receptor 46 showed intense ligand localized $\pi-\pi^{*}$ transitions at 250-310 nm and a weak MLCT band at $320 \mathrm{~nm}$. Addition of increasing quantities of $\mathrm{F}^{-}$anion induced the apparition of a band at $470 \mathrm{~nm}$ (change in colour from yellow to orange) with clear isosbestic points indicating the formation of 1:1 complexes. Other common inorganic anions tested $\left(\mathrm{Cl}^{-}, \mathrm{Br}^{-}, \mathrm{AcO}^{-}, \mathrm{H}_{2} \mathrm{PO}_{4}^{-}, \mathrm{HSO}_{4}^{-}, \mathrm{ClO}_{4}^{-}\right.$and $\left.\mathrm{NO}_{3}^{-}\right)$induced negligible changes in the UV-vis spectra. The colour changes were ascribed to binding of $\mathrm{F}^{-}$with the $\pi$ electron-deficient triazine moiety that induced a perturbation of the electronic properties of $\mathbf{4 6}$ inducing the response observed. Also the emission intensity of $\mathbf{4 6}$ (at $574 \mathrm{~nm}$ upon excitation at $355 \mathrm{~nm}$ ) was selectively quenched in the presence of $\mathrm{F}^{-}$. 


\section{2.- The displacement assay approach.}

Displacement assays have been extensively used for the development of chromogenic sensors for anions since the pioneering work of authors such as of Anslyn $^{79-85}$ and Fabbrizzi. ${ }^{86-88}$ This approach is somehow inspired in displacement reactions in immunoassay protocols. Traditionally in this paradigm the selected receptor (usually a metallic complex) forms an inclusion complex with a dye, upon addition of the target anion a displacement occurs; i.e. the receptor binds to the anion and releases the dye to the solution. Perhaps the most interesting feature of this approach is that the non-covalent anchoring of binding sites and indicator groups allows testing a large number of combinations in order to obtain tuned sensing systems. Additionally, most of the designed ensembles usually display sensing features in water or organic-aqueous mixed solutions allowing the design of realistic sensing protocols. The used dyes (vide infra) in the development of chromogenic displacement assays for anion sensing are depicted in Figure 15.<smiles>O=C1OC2(c3ccc(O)cc3Oc3cc(O)ccc32)c2ccccc21</smiles>

Fluorescein (F)<smiles></smiles>

Celestine blue (CB)<smiles>[R]c1cc2c(c(O)c1O)C(=O)c1ccccc1C2=O</smiles>

Alizarin $\mathrm{R}=\mathrm{H}$ Alizarin complexone $\mathrm{R}=\mathrm{CH}_{2} \mathrm{~N}\left(\mathrm{CH}_{2} \mathrm{COOH}\right)_{2}$<smiles>O=C1C=CC(=C(c2ccc(O)c(O)c2)c2ccccc2S)C=C1</smiles>

Pyrocatechol violet (PV)<smiles>C[N+](C)=c1ccc2nc3c(C(=O)[O-])cc(O)c(O)c3oc-2c1</smiles>

Gallocyanine (G)<smiles>CS(=O)(=O)c1cc2cc(S(=O)(=O)O)c(N=Nc3ccccc3[As](=O)(O)O)c(O)c2c(O)c1N=Nc1ccccc1S(=O)(=O)O</smiles>

Arsenazo III<smiles>[R]OC(=O)CN(CC(N)=O)Cc1cc(C2=C(C=CC(=O)C(CC(=O)O)CN(CC(N)=O)C(=O)O)C2)cc(C)c1O</smiles>

Xylenol orange tetrasodium salt $\mathrm{R}^{1}=\mathrm{H}, \mathrm{R}^{2}=\mathrm{Na}$ or $\mathrm{R}^{1}=\mathrm{Na}, \mathrm{R}^{2}=\mathrm{H}$

Fig. 15 Dyes employed in displacement assays for the chromogenic and fluorogenic sensing of anions. 


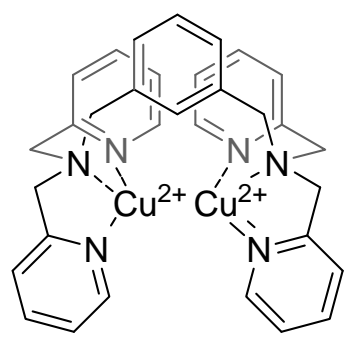

47

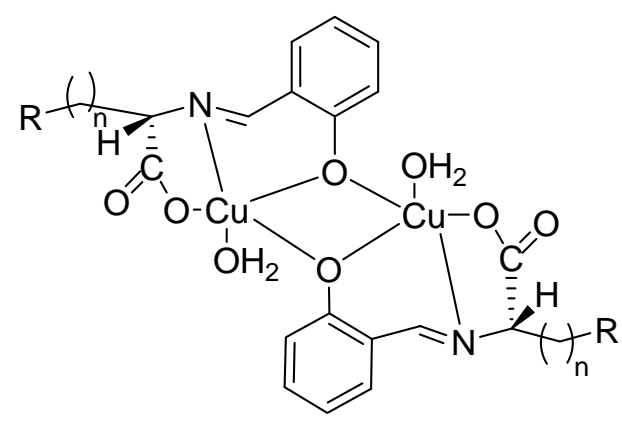

$48 \mathrm{R}=\mathrm{NH}_{2} ; \mathrm{n}=4$

$49 \mathrm{R}=\mathrm{NH}_{3}{ }^{+} ; \mathrm{n}=3$

Fig. 16 Structure of receptors 47,48 and 49.

The following examples employ the traditional displacement approach. The first example uses the coordinating ability of the $\mathrm{Cu}$ (II) ion to design chromogenic and fluorogenic ensembles based on complex 47 for detection of $\mathrm{P}_{2} \mathrm{O}_{7}{ }^{4-}$ in water (Figure 16). ${ }^{89}$ Reaction of $\mathbf{4 7}$ with two indicators: pyrocatechol violet (47-PV) and fluorescein disodium salts (47-F) leads to the formation of two different sensing ensembles. When $\mathrm{P}_{2} \mathrm{O}_{7}{ }^{4-}$ was gradually added to $47-\mathbf{P V}$, the absorption band at $441 \mathrm{~nm}$ increased and the absorption at $663 \mathrm{~nm}$ decreased with a colour change from sky blue (ensemble 47-PV) to pale yellow (free PV). Upon addition of ATP, 47-PV turned form sky blue to pale green, while the addition of other anions, such as $\mathrm{F}^{-}, \mathrm{Cl}^{-}, \mathrm{Br}^{-}, \mathrm{I}^{-}, \mathrm{NO}_{3}^{-}, \mathrm{AcO}^{-}, \mathrm{HPO}_{4}{ }^{2-}$, ADP and AMP, did not introduce any colour changes. Also, the fluorescence of the ensemble 47-F, upon addition of various anions, was studied. The emission at $514 \mathrm{~nm}$ increased (due to dye delivery) by addition of: $\mathrm{P}_{2} \mathrm{O}_{7}{ }^{4-}$ (5.7-fold), ATP (3.6-fold), ADP (3.2-fold), AMP (2-fold) and Pi (1.9-fold), while other anions ( $\mathrm{F}^{-}, \mathrm{Cl}^{-}, \mathrm{Br}^{-}, \mathrm{I}^{-}, \mathrm{NO}_{3}{ }^{-}$and $\left.\mathrm{AcO}^{-}\right)$showed no noticeable changes.

Two dinuclear water soluble $\mathrm{Cu}(\mathrm{II})$ complexes 48 and 49 (Figure 16) were prepared and their capacity to selectively sense citrate at physiological $\mathrm{pH}$ via displacement of pyrocatechol violet (PV) as colorimetric indicator was reported. ${ }^{90}$ Other anions such as $\mathrm{C}_{2} \mathrm{O}_{4}{ }^{2-}$, malonate, glutarate, succinate and adipate were tested, but only citrate was able to release PV from the ensemble. This is reflected in a decrease of the intensity of the band at $597 \mathrm{~nm}$ (PV-49) and the progressive growth of an absorption centred at $434 \mathrm{~nm}$ (arising from free PV). Complex 48 showed the same response towards citrate anion but with a lower sensitivity. 

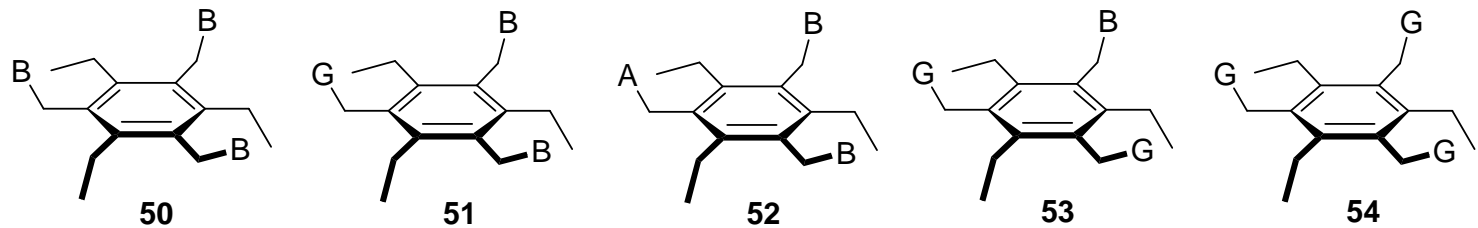<smiles>[B]=C1C=CC=C(Br)C1CNC</smiles><smiles>C=C1CNC(NC)=N1</smiles>

$$
\mathrm{A}=\stackrel{\oplus}{\stackrel{\oplus}{\mathrm{N}}-}
$$<smiles>Cc1nccc(-c2cccc(-c3ccnc(C)n3)n2)n1</smiles>

55 with $\mathrm{ZnCl}_{2}$ 56 with $\mathrm{CuCl}_{2}$

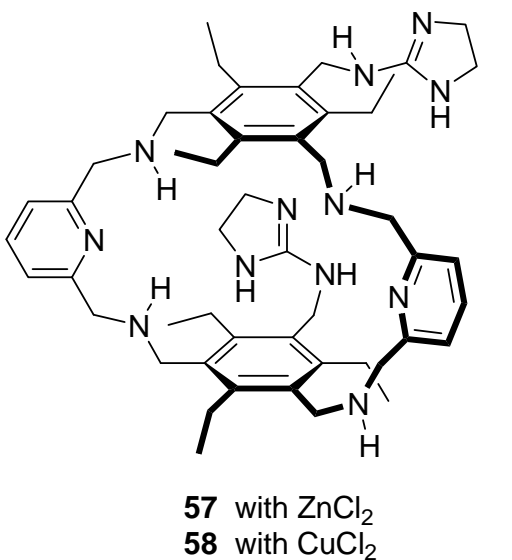

Fig. 17 Structure of receptors 50-58.

The following example uses a displacement approach combined with pattern recognition tools. In fact patter recognition using chromogenic differential receptors has become an active research field in the last years. ${ }^{91}$ In this example the authors developed an array of complex-dye ensembles to test the potential detection of certain carboxylates. $^{92}$ As sensing systems the authors combined ligands 50-58 (Figure 17) and metal salts $\left(\mathrm{ZnCl}_{2}, \mathrm{CuCl}_{2}, \mathrm{CdCl}_{2}, \mathrm{MnSO}_{4}, \mathrm{LaCl}_{3}\right)$. Then to these complexes the indicators alizarin, alizarin complexone, pyrocatechol violet, xylenol orange tetrasodium salt, fluorescein, arsenazo III and gallocyanine were added in order to form the corresponding sensing ensembles that were used for pattern recognition assays of certain $\alpha$-hydroxycarboxylic acids, phenolic acids and $\alpha$-amino acids that are components of wine. Principal component analysis (PCA) was used for data treatment and discrimination of the target analytes. 


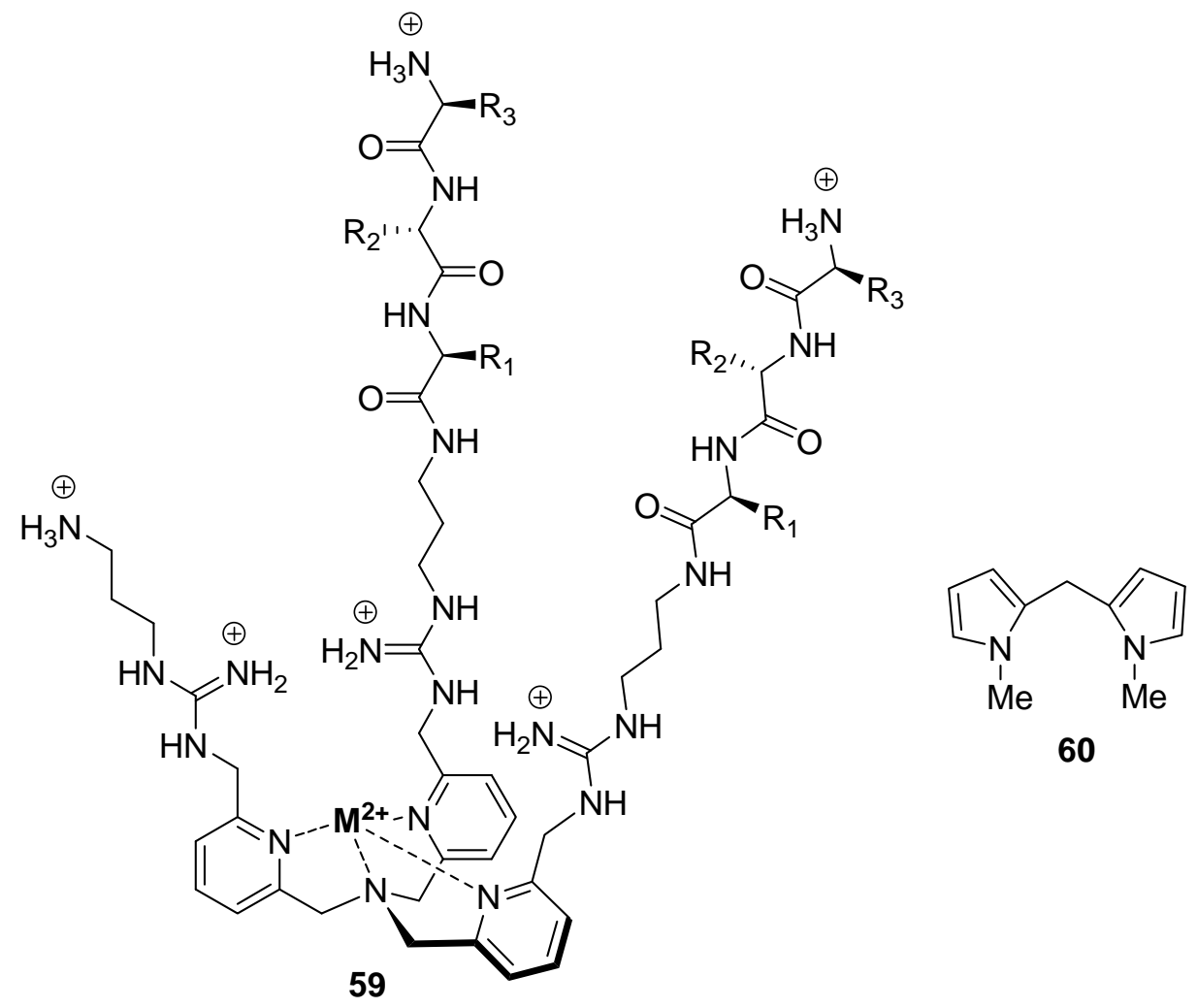

Fig. 18 Chemical structure of receptors 59 and 60.

The same research group used a similar concept for the differential recognition of small peptides and their phosphorylated analogues. ${ }^{93}$ For this task, five different receptors containing two tripeptide arms (59) (Figure 18), synthesized through combinatorial chemistry, three metal cations $\left(\mathrm{Ni}^{2+}, \mathrm{Co}^{2+}\right.$ and $\left.\mathrm{Cu}^{2+}\right)$ and three indicators (pyrocatechol violet, celestine blue and gallocyanine) were used to create an array of 45 metal/receptor/indicator combinations that was used for pattern recognition of Pro-SerGlu, Ser-Glu-Glu, Pro-pSer-Glu and pSer-Glu-Glu tripeptides.

The following two examples use a conceptual modification of the traditional displacement assay (vide ante). In this case the signalling system is a coordination metal complex and the signalling protocol is based in an anion-induced demetallation. The fist example uses ligand $\mathbf{6 0}$ (Figure 18) that is able to form a 2:3 metal-to-ligand complex with $\mathrm{Cu}^{2+}$. Addition of $\mathrm{CN}^{-}$to this complex resulted in a bleaching of the solution that was ascribed to the rupture of the $\mathrm{Cu}^{2+} \mathbf{- 6 0}$ system and the formation of $\mathrm{CuCN}$ species (the low oxidation state of copper being stabilized by $\mathrm{CN}^{-}$which is a strong $\pi$-acceptor). No visual changes were observed upon addition of other anions such as $\mathrm{NO}_{3}^{-}, \mathrm{F}^{-}, \mathrm{Cl}^{-}$, $\mathrm{Br}^{-}, \mathrm{I}^{-}, \mathrm{SO}_{4}{ }^{2-}, \mathrm{HSO}_{4}{ }^{-}, \mathrm{PO}_{4}{ }^{3-}, \mathrm{HPO}_{4}{ }^{2-}, \mathrm{H}_{2} \mathrm{PO}_{4}{ }^{-}$, and $\mathrm{SO}_{3}{ }^{2-}$. 


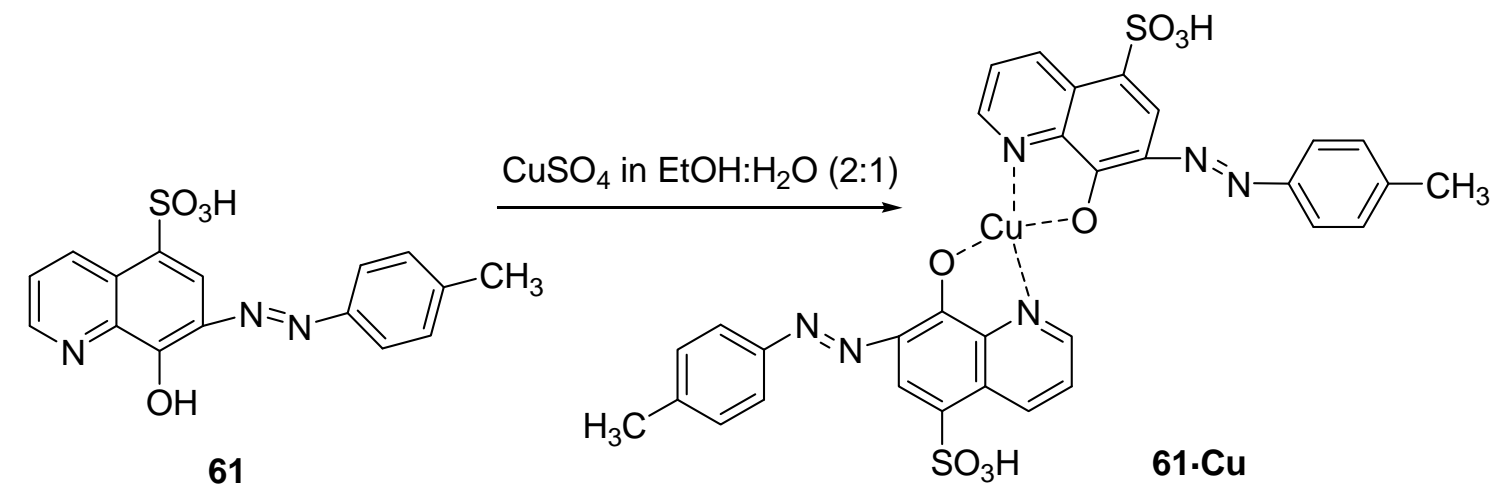

Fig. 19 Structure of compound $\mathbf{6 1}$ and its $\mathrm{Cu}(\mathrm{II})$ complex $\mathbf{6 1} \cdot \mathrm{Cu}^{2+}$.

Using a similar approach complex $\mathbf{6 1} \cdot \mathrm{Cu}^{2+}$ (Figure 19) was used as a colorimetric probe for the detection of cysteine (Cys) and homocysteine (Hcy) in water. ${ }^{94}$ Complex $\mathbf{6 1} \cdot \mathrm{Cu}^{2+}$ shows a band at $421 \mathrm{~nm}$. Upon addition of Cys and Hcy to aqueous solutions of $\mathbf{6 1} \cdot \mathrm{Cu}^{2+}$ at $\mathrm{pH} 7.0$ a clear reduction in the intensity of this band and a concomitant increase of an absorption at $497 \mathrm{~nm}$ was observed (colour change from yellow to red). These changes were ascribed to a demetallation process that induced the release of dye $\mathbf{6 1}$ from complex $\mathbf{6 1} \cdot \mathrm{Cu}^{2+}$ and the formation of $\mathrm{Cu}^{2+}$-aminoacids aducts. The absorption spectra of $\mathbf{6 1} \cdot \mathrm{Cu}^{2+}$ in the presence of other amino acids (Phe, Thr, Arg, His, Asn, Leu, Ala, Pro, Val, Gly, Lys, Gln, Met, Ser, Ile, Tyr, Trp, Glu and Asp) showed no important changes.
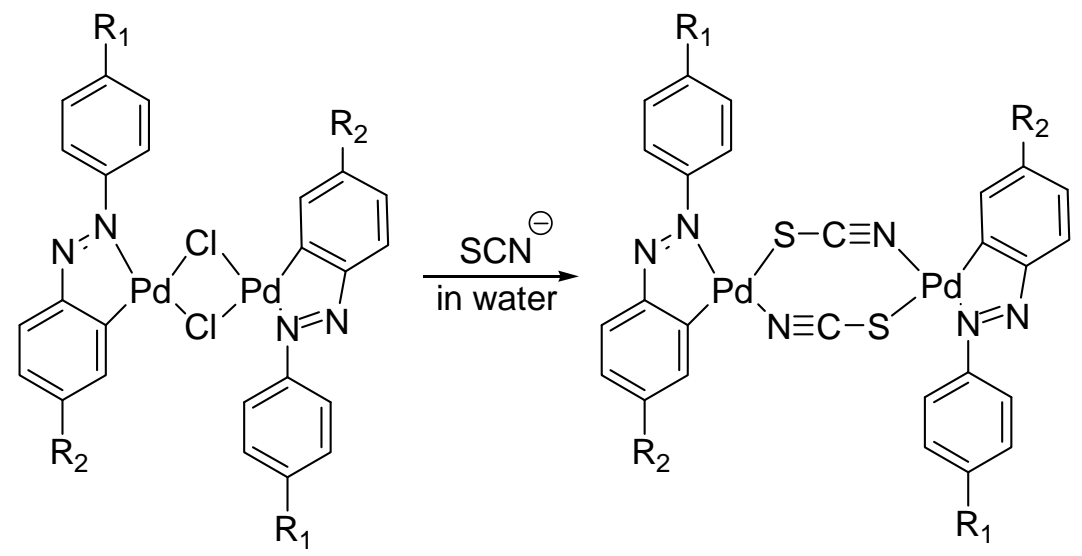

$62 \mathrm{R}_{1}=\mathrm{SO}_{3} \mathrm{H}, \mathrm{R}_{2}=\mathrm{N}\left(\mathrm{CH}_{3}\right)_{2}$

$63 \mathrm{R}_{1}=\mathrm{R}_{2}=\mathrm{OH}$

Fig. 20 Proposed binding mechanism of receptors 62 and 63 with $\mathrm{SCN}^{-}$anion.

Whereas in the last two examples there was an anion-induced demetallation in the two following cases a displacement of a simple ligand (not a dye) was used as 
sensing protocol. The dinuclear cyclopalladated azobencene (CPAB) complexes 62 and 63 show a sensitive and selective chromogenic response towards $\mathrm{SCN}^{-}$in aqueous solution at physiological $\mathrm{pH}$ (see Figure 20). ${ }^{95}$ Addition of $\mathrm{SCN}^{-}$to solutions of 62 at $\mathrm{pH} 7.4$ resulted in a remarkable colour modulation from red to yellow, whereas negligible changes were observed upon addition of other anions such as $\mathrm{F}^{-}, \mathrm{Cl}^{-}, \mathrm{Br}^{-}, \mathrm{I}^{-}$, $\mathrm{NO}_{3}{ }^{-}, \mathrm{NO}_{2}{ }^{-}, \mathrm{SO}_{4}{ }^{2-}, \mathrm{HCO}_{3}{ }^{-}, \mathrm{PhCO}_{2}{ }^{-}, \mathrm{CH}_{3} \mathrm{CO}_{2}{ }^{-}, \mathrm{CN}^{-}, \mathrm{S}^{2-}$ and $\mathrm{SO}_{3}{ }^{2-}$. Both, Jot plots and an IR spectra analysis confirmed the formation of 1:2 62:SCN species. On the other hand, solutions of 63 change from purple $\left(\lambda_{\max }=530 \mathrm{~nm}\right)$ to yellow $\left(\lambda_{\max }=360 \mathrm{~nm}\right)$, orange $\left(\lambda_{\max }=495 \mathrm{~nm}\right)$ and colourless upon addition of $\mathrm{S}_{2}^{-}, \mathrm{SO}_{3}{ }^{2-}$ and $\mathrm{SCN}^{-}$anions, respectively.

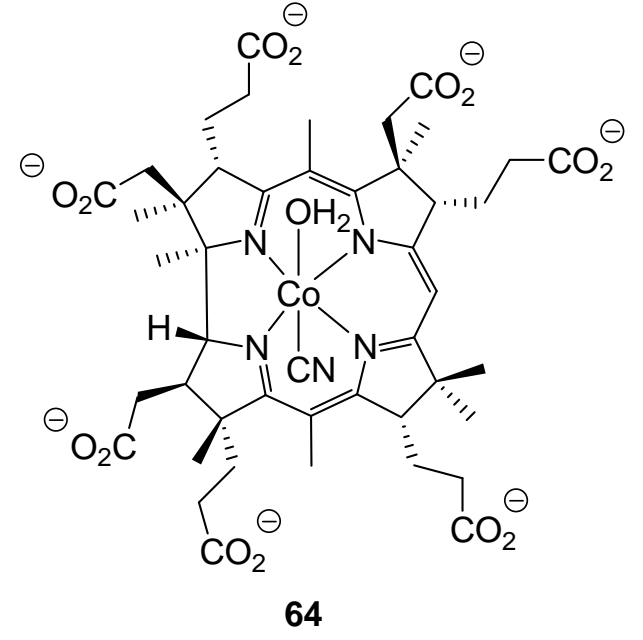

64

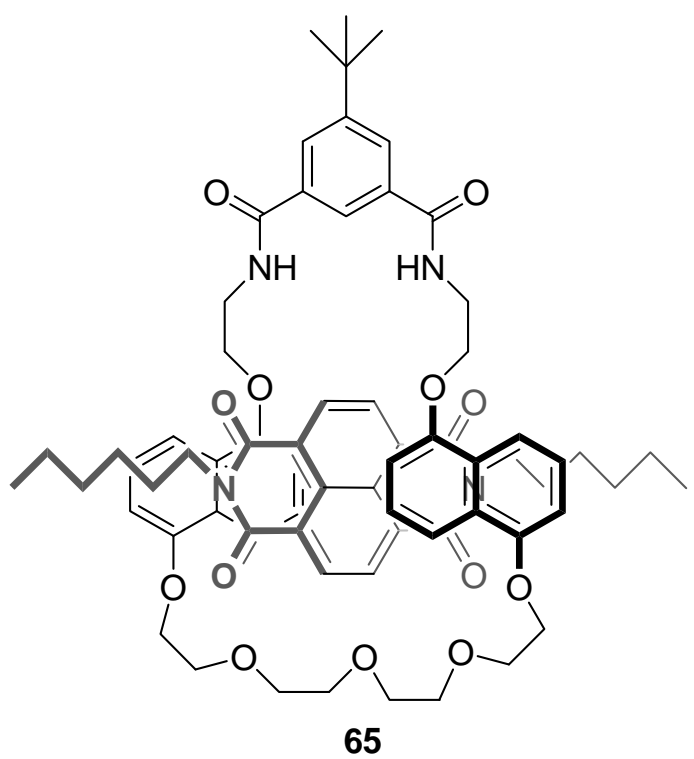

65

Fig. 21 Structure of receptors 64 and 65.

The aquocyanocobyrinic acid 64 (Figure 21) was used as a colorimetric sensor for $\mathrm{CN}^{-}$anion. ${ }^{96}$ Water solutions (HEPES pH 7.5) of $\mathbf{6 4}$ show an absorption band at 530 $\mathrm{nm}$ (orange colour) that suffers a bathochromic shift to $580 \mathrm{~nm}$ upon addition of $\mathrm{CN}^{-}$ (violet colour). This shift of the visible band was selective for $\mathrm{CN}^{-}$and other anions tested $\left(\mathrm{F}^{-}, \mathrm{Cl}^{-}, \mathrm{Br}^{-}, \mathrm{I}^{-}, \mathrm{SCN}^{-}, \mathrm{NO}_{3}{ }^{-}, \mathrm{HCO}_{3}{ }^{-}, \mathrm{C}_{2} \mathrm{O}_{4}{ }^{2-}, \mathrm{SO}_{4}{ }^{2-}, \mathrm{H}_{2} \mathrm{PO}_{4}{ }^{-}, \mathrm{ClO}_{4}^{-}, \mathrm{AcO}^{-}\right.$and $\left.\mathrm{CN}^{-}\right)$ induced negligible changes in the UV-vis spectra. The changes in colour observed were ascribed to the substitution of the water molecule axially coordinated with the Co by one $\mathrm{CN}^{-}$anion.

The new pseudorotaxane 65 was described and tested as system capable of sensing anions through displacement assays. ${ }^{97} 65$ (Figure 21) has a dark pink colour 
arising from a charge transfer interaction between the macrocycle and the diimide. The addition of $\mathrm{SO}_{4}{ }^{2-}, \mathrm{BzO}^{-}, \mathrm{F}^{-}, \mathrm{Cl}^{-}$and $\mathrm{H}_{2} \mathrm{PO}_{4}{ }^{-}$anions to 65 in $\mathrm{CHCl}_{3}$ resulted in a visible colour change from dark pink to colourless. The decrease in absorbance of the charged transfer band at $510 \mathrm{~nm}$ was indicative of the diimide being expelled from the cavity of the macrocycle. The largest change in absorbance was observed upon $\mathrm{SO}_{4}{ }^{2-}$ addition indicating that the dethreading process was more effective when using a dianion.

\section{3.- The chemodosimeter approach.}

Among the three classical approaches mentioned above for the chromofluorogenic signalling of anions, probably the chemodosimeter approach has been the one that has been growing more in number of examples in the last years. ${ }^{98-104}$ Whereas this approach was marginal some years ago, today is a well established procedure for the design of probes for anion signalling. As stated above, chemodosimeters or reagents, take advantage of specific anion-induced reactions that are generally irreversible and commonly involve the rupture and formation of several covalent bonds. In general there is a remarkable chemical modification of the molecular probe to which the anion in reactive and therefore this approach is usually associated with remarkable spectroscopic modulations. The design of new chemodisimeters involves the finding of reactions with anions that ideally have (i) to be selective, (ii) to occur preferably in water or mixed organic-aqueous solutions and (iii) to be rather quick.

The use of the chemodosimeter approach shows some advantages, when compared with the other two protocols, such as the usually high selectivity reached and also an accumulative effect. Most of the reported colorimetric reagents in the last year have been developed for the signalling of $\mathrm{CN}^{-}$and $\mathrm{F}^{-}$. Also, we have included in this section examples designed for the detection of thiol-containing amino acids. In most cases the probes take advantage of the nucleophilic attack of these species to electron deficient atoms or functional groups that results in a re-organization of the electron density in the whole molecule and colour changes.

The following two examples use the nucleophilic reactivity of thiol groups for the preparation of probes for the colorimetric detection of thiol-containing amino acids and small peptides. 


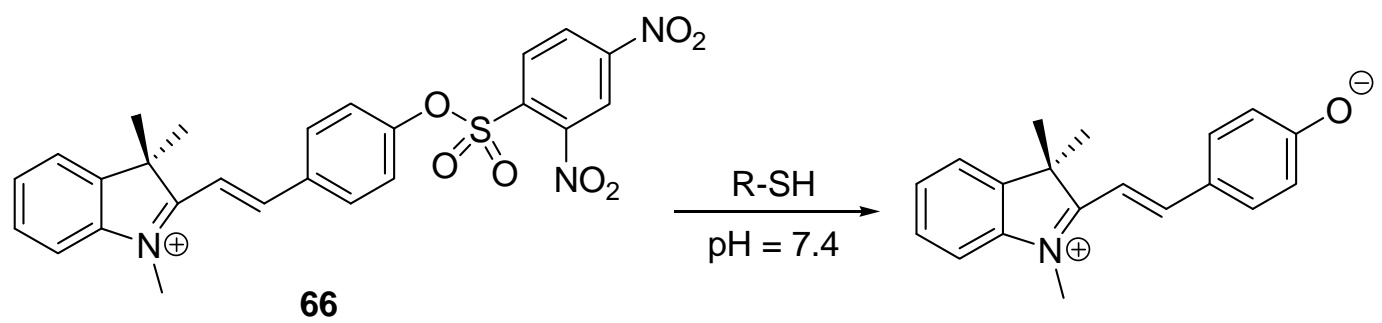

Fig. 22 Proposed signalling mechanism of thiols using 66.

The first example is a merocyanine derivative functionalized with a dinitrobenzenesulfonyl moiety (66) (Figure 22) that has been successfully employed for the chromogenic and fluorogenic sensing of cysteine (Cys), homocysteine (Hcy) and glutathione $(\mathrm{GSH})$ in methanol-water $3: 7 \mathrm{v} / \mathrm{v}$ (PBS buffer, $\mathrm{pH} 7.4$ ) via a modulation in colour from yellow to magenta. ${ }^{105}$ The bathochromic shift of the absorption band was explained by a thiol-mediated cleavage of the electron-withdrawing sulfonyl group of 66 that yields a chromophore with an intense ICT band. The addition of other amino acids (Gly, Ser, Asp, Met, Asn, Lys, Tyr, Trp, Arg and His) induced negligible changes in the UV-visible profile. Also the emission of chromoreactand 66 at $553 \mathrm{~nm}$ was greatly enhanced upon addition of Cys, Hcy and GSH.

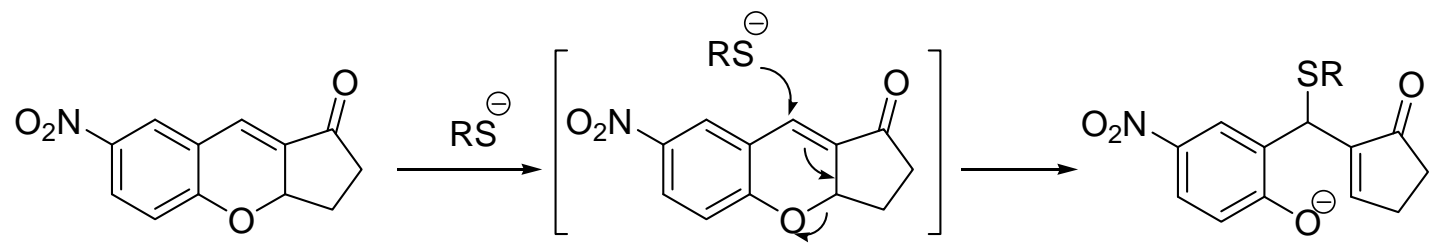

67

Fig. 23 Proposed signalling mechanism of thiolates using 67.

The second example uses a chromene derivative (67) (Figure 23). ${ }^{106}$ In the presence of cysteine (HEPES, pH 7.0), the absorption peak at $292 \mathrm{~nm}$ of probe 67 decreases and a new peak appeared at $405 \mathrm{~nm}$ (change in colour from colourless to yellow). The effect caused by Cys was highly selective and for instance the authors report that solutions containing other amino acids (Ala, Arg, Asn, Asp, Gln, Glu, Gly, His, Ile, Leu, Lys, Met, Phe, Pro, Ser, Thr, Trp, Tyr and Val) remained unchanged. Also the addition of anions with physiological functions $\left(\mathrm{F}^{-}, \mathrm{Cl}^{-}, \mathrm{Br}^{-}, \mathrm{I}^{-}, \mathrm{AcO}^{-}, \mathrm{SCN}^{-}, \mathrm{NO}_{3}^{-}\right.$, $\mathrm{SO}_{4}{ }^{2-}, \mathrm{CO}_{3}{ }^{2-}, \mathrm{C}_{2} \mathrm{O}_{4}{ }^{2-}$ and $\left.\mathrm{PO}_{4}{ }^{3-}\right)$ and common metal ions $\left(\mathrm{Na}^{+}, \mathrm{K}^{+}, \mathrm{Mg}^{2+}, \mathrm{Ca}^{2+}, \mathrm{Ba}^{2+}\right.$, 
$\mathrm{V}^{4+}, \mathrm{Cr}^{3+}, \mathrm{Mn}^{2+}, \mathrm{Fe}^{3+}, \mathrm{Al}^{3+}, \mathrm{Ga}^{3+}, \mathrm{Sn}^{2+}, \mathrm{Zr}^{4+}, \mathrm{Ce}^{3+}, \mathrm{Nd}^{3+}, \mathrm{Sm}^{3+}, \mathrm{Eu}^{3+}, \mathrm{Er}^{3+}, \mathrm{Tb}^{3+}, \mathrm{Ho}^{3+}$ and $\mathrm{Yb}^{3+}$ ) did not induce any noticeable change in colour. However, the probe was partly or completely inhibited in the presence of equimolar concentrations of $\mathrm{Co}^{2+}, \mathrm{Ni}^{2+}$, $\mathrm{Zn}^{2+}, \mathrm{Cd}^{2+}, \mathrm{Pb}^{2+}, \mathrm{Cu}^{2+}$ or $\mathrm{Hg}^{2+}$ due to the formation of complexes between these cations and cysteine. In presence of a strong chelator such as EDTA, only $\mathrm{Hg}^{2+}$ remained able to inhibit the reaction of $\mathbf{6 7}$ with thiols. Under the same conditions, probe $\mathbf{6 7}$ exhibited a similar response to other thiol-containing compounds such as Hcy and GSH. The mechanism of the colorimetric response was determined by ${ }^{1} \mathrm{H}-\mathrm{NMR}$; the nucleophilic attack of the thiol group to the carbonyl conjugated double bond of 67 induced the opening of the chromene ring with the subsequent formation of a nitrophenolate chromophore.

An anion for which several interesting chromogenic probes have been reported using the chemodosimeter approach is for $\mathrm{CN}^{-}{ }^{46}$ In all cases, the examples shown below take advantage of the nucleophilic character of $\mathrm{CN}^{-} . \mathrm{CN}^{-}$is an anion of environmental interest, is highly toxic to living organisms and different groups have been working in the preparation of selective and sensitive probes for the undemanding and rapid detection of this anion. ${ }^{107-114}$

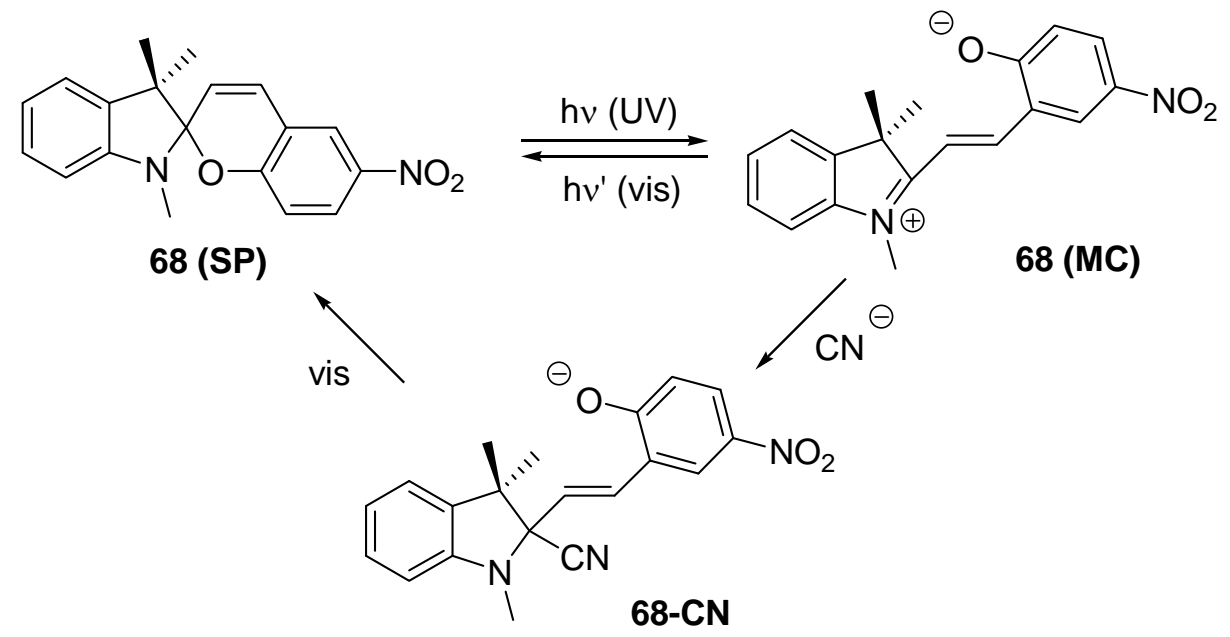

Fig. 24 Proposed signalling mechanism of $\mathrm{CN}^{-}$using 68.

The spiropyran 68 (Figure 24) has been used as chemoreactand for $\mathrm{CN}^{-}$ detection in buffered water-acetonitrile 1:1 v/v mixtures ( $\mathrm{pH} 9.3, \mathrm{CHES}) .{ }^{115}$ Without anion and no UV irradiation, the chromoreactand 68(SP) displays almost no absorption in the visible zone whereas upon UV irradiation shows a distinctive absorption band at $519 \mathrm{~nm}$ assigned to the generated merocyanine form 68(MC). Addition of $\mathrm{CN}^{-}$anion, 
upon UV irradiation, induced a significant decrease of the visible band along with the appearance of a new absorption at $421 \mathrm{~nm}$. This blue shift was observed only in the presence of $\mathrm{CN}^{-}$and other anions such as $\mathrm{F}^{-}, \mathrm{Cl}^{-}, \mathrm{Br}^{-}, \mathrm{I}^{-}, \mathrm{AcO}^{-}, \mathrm{H}_{2} \mathrm{PO}_{4}^{-}, \mathrm{HSO}_{4}^{-}, \mathrm{ClO}_{4}^{-}$, $\mathrm{NO}_{3}{ }^{-}$and $\mathrm{SCN}^{-}$anions were unable to induce any change in the visible spectra. The absorption change was assigned to the addition of the nucleophilic $\mathrm{CN}^{-}$anion to the spirocarbon of chromoreactand 68, leading to the formation of the $68-\mathbf{C N}$ derivative. 68 allows the ratiometric determination of $\mathrm{CN}^{-}$with a detection limit as low as $1.7 \mu \mathrm{M}$, Interestingly, the chromoreactand $\mathbf{6 8}$ can be regenerated from 68-CN by irradiation with visible light.

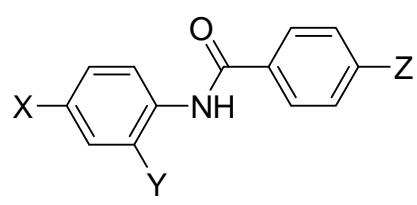

69 X. Y, Z $=\mathrm{NO}_{2}$

$70 \quad \mathrm{X}, \mathrm{Y}=\mathrm{NO}_{2} \mathrm{Z}=\mathrm{Cl}$

$71 \mathrm{X}, \mathrm{Y}=\mathrm{NO}_{2} \mathrm{Z}=\mathrm{H}$

$72 \quad X=\mathrm{NO}_{2} \quad \mathrm{Y}=\mathrm{H} \quad \mathrm{Z}=\mathrm{NO}_{2}$

$73 \quad X=H \quad Y=N_{2} \quad Z=N_{2}$

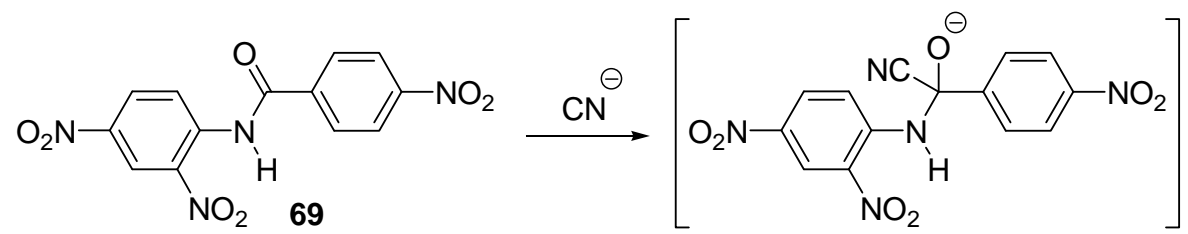

$\downarrow$ Proton transfer

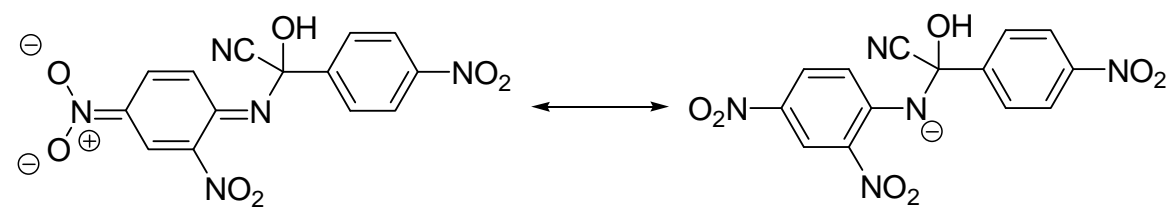

Fig. 25 Structures of receptors 69-73 and proposed signalling mechanims of $\mathrm{CN}^{-}$using 69.

The strong affinity of $\mathrm{CN}^{-}$toward acyl carbonyl moieties was employed to develop a family of $N$-nitrophenyl benzamide derivatives (69-73) that were used for the chromogenic sensing of this anion (Figure 25). ${ }^{116}$ The band at $305 \mathrm{~nm}$ of 69 in DMSOwater $1: 1 \mathrm{v} / \mathrm{v}$ mixtures was red shifted to $405 \mathrm{~nm}$ in the presence of $\mathrm{CN}^{-}$(colour modulation from colourless to yellow), whereas no changes were observed upon addition of $\mathrm{Cl}^{-}, \mathrm{Br}^{-}, \mathrm{I}^{-}, \mathrm{ClO}_{4}^{-}, \mathrm{H}_{2} \mathrm{PO}_{4}^{-}, \mathrm{NO}_{3}{ }^{-}$and $\mathrm{N}_{3}^{-}$anions. The change in colour was due to an addition reaction of $\mathrm{CN}^{-}$anion to the carbonyl carbon atom that induced the 
formation of the corresponding alcoxyde derivative. This alcoxide suffers a proton transfer from the amide hydrogen, leading to the formation of a negative charge into the nitrogen atom directly linked to the 2,4-dinitrobencene ring that shows a strong ICT band in the visible region. The authors reported a limit of detection for $\mathrm{CN}^{-}$of $1.74 \mu \mathrm{M}$ using 69. Probes 70-73 showed a similar behaviour but with lower sensitivities.
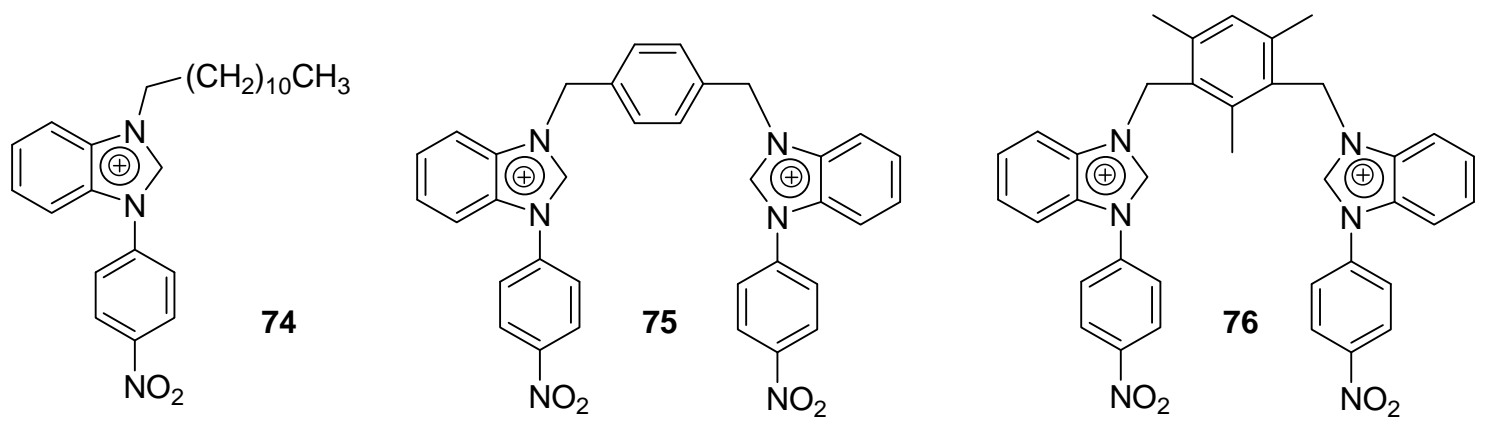

Fig. 26 Structure of receptors 74, 75 and 76.

Chromoreactands 74-76 (Figure 26), containing 1-(4-nitrophenyl)benzimidazolium moieties, showed a selective colour change in the presence of $\mathrm{CN}^{-}$in methanol from colourless (band at $270 \mathrm{~nm}$ ) to yellow (band at $376 \mathrm{~nm}$ ). ${ }^{117}$ Other anions such as $\mathrm{AcO}^{-}, \mathrm{F}^{-}, \mathrm{Cl}^{-}, \mathrm{Br}^{-}, \mathrm{I}^{-}, \mathrm{H}_{2} \mathrm{PO}_{4}{ }^{-}, \mathrm{HSO}_{4}{ }^{-}, \mathrm{NO}_{3}{ }^{-}, \mathrm{ClO}_{4}{ }^{-}$and $\mathrm{SCN}^{-}$were also tested but gave no colour modulations. The response to $\mathrm{CN}^{-}$arises from the nucleophilic addition of this anion at $\mathrm{C}-2$ of the benzimidazolium groups in 74-76 that results in the formation 1,2-dihydrobenzimidazole moieties. Nearly the same selectivity and colour changes were observed for the three chromoreactands when using methanol-water 1:1 v/v mixtures.

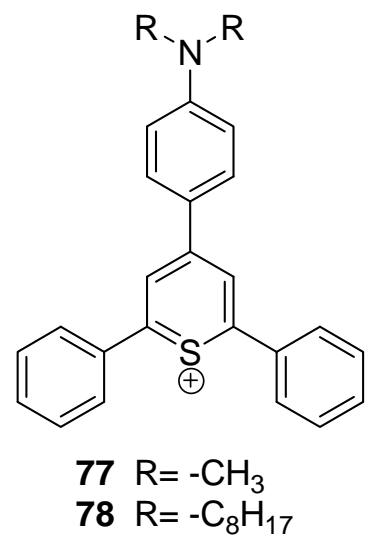

Fig. 27 Structure of receptors 77 and $\mathbf{7 8 .}$ 
Anilinium-thiopyrylium receptors 77 and 78 (Figure 27) have been used as probes for the colorimetric detection of $\mathrm{CN}^{-}{ }^{118}$ In this case the addition of anions $\mathrm{Cl}^{-}$, $\mathrm{Br}^{-}, \mathrm{I}^{-}, \mathrm{NO}_{3}^{-}, \mathrm{H}_{2} \mathrm{PO}_{4}^{-}, \mathrm{HSO}_{4}^{-}, \mathrm{AcO}^{-}$and $\mathrm{NCS}^{-}$to acetonitrile blue solutions of $77\left(\lambda_{\max }=\right.$ $575 \mathrm{~nm}$ ) induced negligible changes in the UV-visible spectra, whereas the addition of $\mathrm{CN}^{-}$anion resulted in a complete bleaching. This decolouration was assigned to an attack of $\mathrm{CN}^{-}$to the aromatic thiopyrylium ring, which results in the rupture of the electronic delocalization. As a negative feature compound $\mathbf{7 7}$ did not display sensing features in water. In an attempt to avoid this problem the derivative $\mathbf{7 8}$ was prepared by funcionalization of the aniline group with highly hydrophobic $n$-octyl chains. This probe was then used for the detection of $\mathrm{CN}^{-}$in water in the presence of the surfactant Triton X-100.

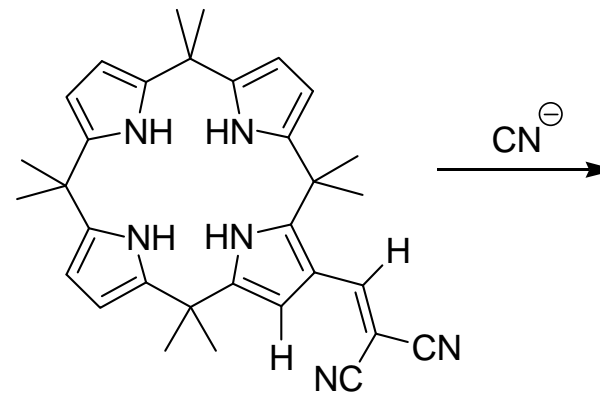

79

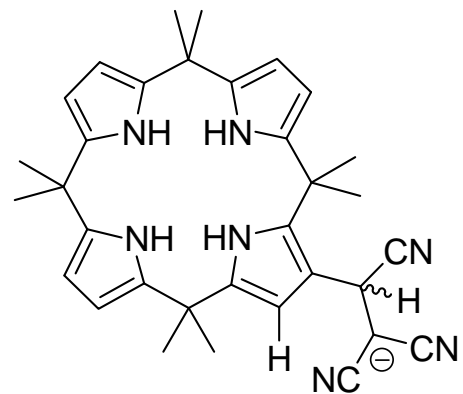

79-CN

Fig. 28 Reaction of receptor 79 with $\mathrm{CN}^{-}$.

The functionalized calix[4]pyrrole 79 (Figure 28) was reported to be a suitable selective probe for $\mathrm{CN}^{-}$in $\mathrm{CH}_{3} \mathrm{CN}-\mathrm{DMSO}(3 \%) .{ }^{119}$ Solutions of 79 in this misture display a yellow colouration due to the presence of an absorption band at $374 \mathrm{~nm}$. Addition of $\mathrm{F}^{-}, \mathrm{Cl}^{-}, \mathrm{Br}^{-}, \mathrm{NO}_{3}^{-}, \mathrm{SCN}^{-}, \mathrm{HP}_{2} \mathrm{O}_{7}{ }^{3-}, \mathrm{H}_{2} \mathrm{PO}_{4}^{-}, \mathrm{AcO}^{-}$induced characteristic spectral shifts associated of coordination, through hydrogen bonding interactions, with the N-H moieties of the calix[4]pyrrole subunit. Only $\mathrm{CN}^{-}$anion was able to induce a complete bleaching of the solution due the nucleophilic addition into the tricyanovinyl moiety and formation of 79-CN. The presence of 79-CN was verified by high resolution MALDI-TOF MS and proton NMR spectroscopy. 
<smiles>CCN=C1C=CC(=C(c2ccc(N(CC)CC)cc2)c2cc(S(N)(=O)=O)cc3cc(S(=O)(=O)[O-])ccc23)C=C1</smiles>

80

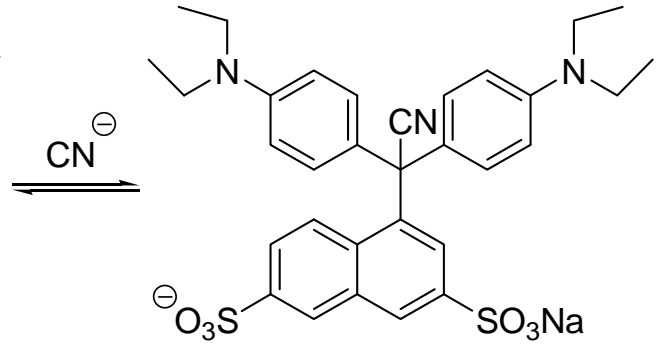

80-CN

Fig. 29 Proposed signalling mechanism of $\mathrm{CN}^{-}$using 80.

The authors report that when a buffered aqueous solution of $\mathrm{CN}^{-}$was added to the quaternized triarylmethane dye $\mathbf{8 0}$ (Figure 29) in $\mathrm{CH}_{3} \mathrm{CN}$, the three absorption bands at 634,453 and $308 \mathrm{~nm}$ in the spectrum of $\mathbf{8 0}$ disappeared with the concomitant appearance of a new band at $280 \mathrm{~nm}$ and bleaching of the solution. ${ }^{120}$ However, when titrations using other anions such as $\mathrm{CO}_{3}{ }^{2-}, \mathrm{HCO}_{3}{ }^{-}, \mathrm{PO}_{4}{ }^{3-}, \mathrm{H}_{2} \mathrm{PO}_{4}^{-}, \mathrm{HPO}_{4}{ }^{2-}, \mathrm{F}^{-}, \mathrm{Cl}^{-}, \mathrm{Br}^{-}$, $\mathrm{NO}_{3}{ }^{-}, \mathrm{NO}_{2}^{-}, \mathrm{SO}_{4}{ }^{2-}, \mathrm{HSO}_{4}^{-}, \mathrm{SO}_{3}{ }^{2-}, \mathrm{HSO}_{3}{ }^{-}, \mathrm{CH}_{3} \mathrm{COO}^{-}$and citrate were conducted under similar conditions, no change either in the intensity or the position of the absorption bands of $\mathbf{8 0}$ was found. It was envisaged that the observed colour change arises from the addition reaction of $\mathrm{CN}^{-}$at the methine carbon of $\mathbf{8 0}$, resulting in the formation of the corresponding colourless leuconitrile derivative 80-CN.

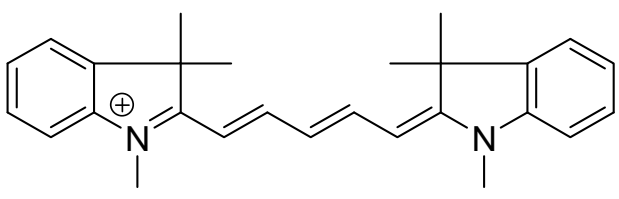

81

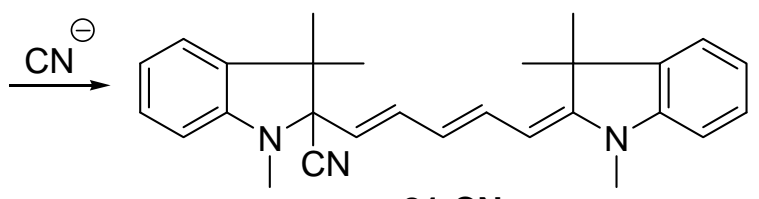

81-CN

Fig. 30 Reaction between receptor 81 and $\mathrm{CN}^{-}$anion.

A commercially available NIR dye $\mathbf{8 1}$ (Figure 30) was used for the selective chromogenic detection of $\mathrm{CN}^{-}{ }^{121}$ The absorption spectrum of $\mathbf{8 1}$ in $\mathrm{CH}_{3} \mathrm{CN}$ exhibited a band at $637 \mathrm{~nm}$, which faded gradually upon addition of increasing amounts of $\mathrm{CN}^{-}$ followed by the concomitant appearance of a new absorption at $375 \mathrm{~nm}$. These spectral changes were reflected in a colour change from pale blue to colourless that suggested a rupture of the $\pi$-conjugation of the dye. The mechanism was confirmed by ${ }^{1} \mathrm{H}-\mathrm{NMR}$ titration experiments that indicated the formation of 81-CN by a nucleophilic addition of $\mathrm{CN}^{-}$to 81. The presence of other anions $\left(\mathrm{F}^{-}, \mathrm{Cl}^{-}, \mathrm{Br}^{-}, \mathrm{AcO}^{-}, \mathrm{H}_{2} \mathrm{PO}_{4}^{-}, \mathrm{HSO}_{4}^{-}, \mathrm{NO}_{3}^{-}\right.$, 
$\mathrm{ClO}_{4}{ }^{-}$and $\mathrm{SCN}^{-}$) induced no obvious changes in the absorption spectra even when added in large excess. It was also found that a complete quenching of the fluorescence of 81 (emission band at $658 \mathrm{~nm}$ ) occurred in the presence of $\mathrm{CN}^{-}$.

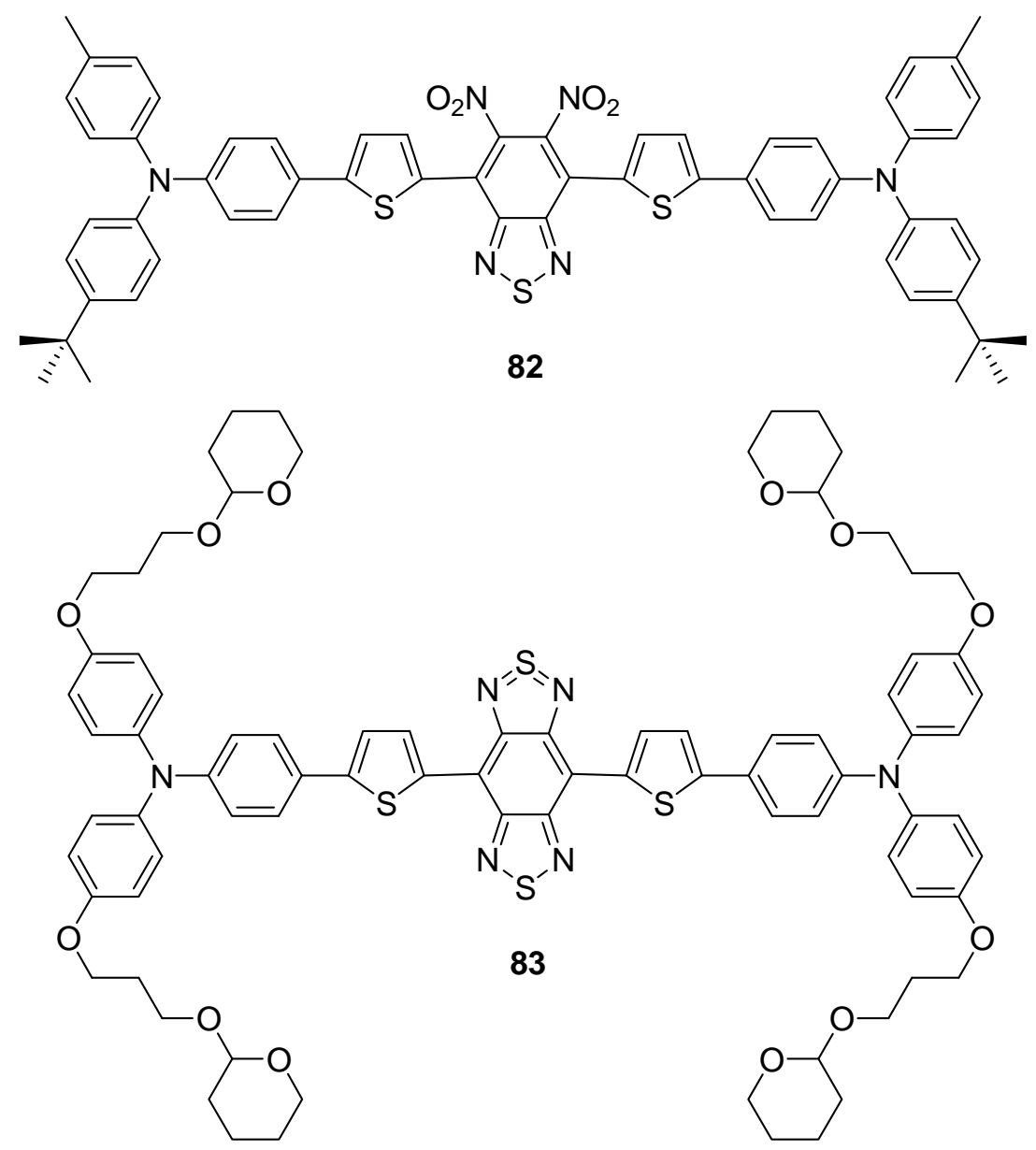

Fig. 31 Structure of receptors 82 and 83.

The chromogenic receptors $\mathbf{8 2}$ and $\mathbf{8 3}$ (Figure 31) have also been used for the colorimetric detection of $\mathrm{CN}^{-122}$ DMF-water 99:1 v/v solutions of $\mathbf{8 2}$ show an intense charge-transfer band at $568 \mathrm{~nm}$ (purple-blue colour solution). Of all the anions tested $\left(\mathrm{CN}^{-}, \mathrm{F}^{-}, \mathrm{Cl}^{-}, \mathrm{Br}^{-}, \mathrm{I}^{-}, \mathrm{AcO}^{-}, \mathrm{H}_{2} \mathrm{PO}_{4}^{-}, \mathrm{HSO}_{4}{ }^{2-}, \mathrm{NO}_{3}{ }^{-}\right)$only $\mathrm{CN}^{-}$induced a blue shift of this band to $460 \mathrm{~nm}$ with a colour modulation to yellowish-orange. Nearly the same response was observed with 83 in DMF-water 99:1 v/v solutions. In this case the band at $890 \mathrm{~nm}$ in the NIR region completely disappeared being substituted by an absorption band at $500 \mathrm{~nm}$ upon addition of $\mathrm{CN}^{-}$. The changes in colour observed were assigned to a chemical reaction of $\mathrm{CN}^{-}$with the sulphur atoms of the benzothiadiazole rings. Finally, receptor 82 was non-fluorescent but 83 can also be used for the fluogenic recognition of $\mathrm{CN}^{-}$anion. The authors found that the emission band at $1280 \mathrm{~nm}$ of $\mathbf{8 3}$ 
was quenched upon addition of $\mathrm{CN}^{-}$whereas the intensity of the emission band at 600 nm was enhanced.

The following examples were designed for the colorimetric detection of $\mathrm{F}^{-}$. Some of the examples are based in the high fluorophilicity of organoboranes, that additionally, in most cases, are additionally functionalized with aromatic substituents that are conjugated via the vacant boron $\pi$-orbital. $\mathrm{F}^{-}$binding with the boron atom leads to a modulation of the electronic properties of the chromophore resulting in changes in colour and/or fluorescence emission. ${ }^{123}$ In these studies it was observed that the introduction of cationic boranes favours the binding of $\mathrm{F}^{-}$in aqueous solutions due to the presence of coulombic attractive interactions.

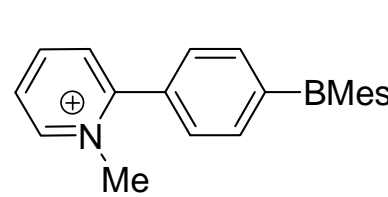

84

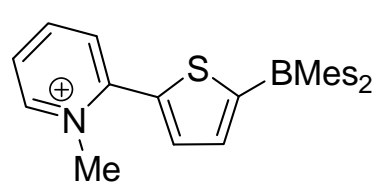

85

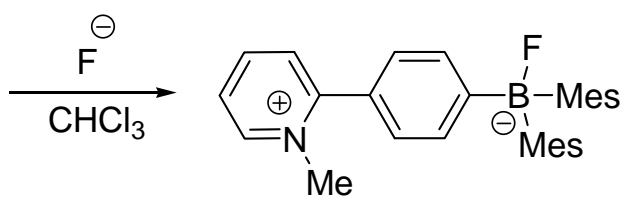

84-F
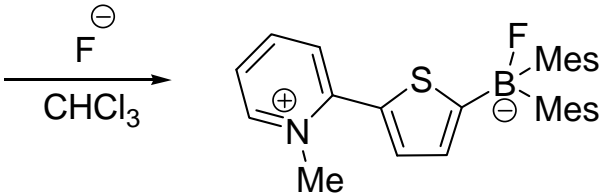

85-F

Fig. 32 Proposed binding mode of 84 and 85 with $\mathrm{F}^{-}$anion.

Using this approach the cationic pyridinium boranes $\mathbf{8 4}$ and $\mathbf{8 5}$ were synthesized and tested as $\mathrm{F}^{-}$probes (Figure 32). ${ }^{124}$ Both derivatives were quantitatively converted into the corresponding zwitterionic fluoroborate adducts 84-F and 85-F upon addition of tetrabutylammonium fluoride (TBAF) in $\mathrm{CDCl}_{3}$. This conversion was accompanied by the appearance of an intense yellow colour in solution. The origin of this colorimetric response is attributed to an intramolecular charge transfer involving the triorganofluoroborate moiety as the donor and the pyridinium moiety as the acceptor. The authors observed that when $\mathrm{CDCl}_{3}$ solutions of 84 and 85 were mixed with $\mathrm{F}^{-}$ solutions in $\mathrm{D}_{2} \mathrm{O}$, the organic layer quickly developed a yellow colour indicative of the formation of fluoroborate species. The response observed was selective and for instance addition of $\mathrm{Cl}^{-}, \mathrm{Br}^{-}$and $\mathrm{I}^{-}$induced negligible changes in the $\mathrm{UV}$-vis spectra of receptors 84 and 85. 


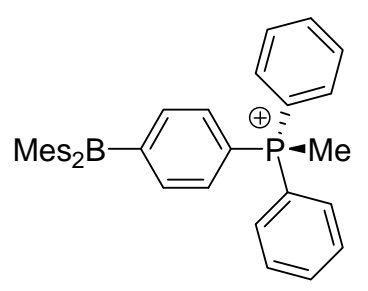

86

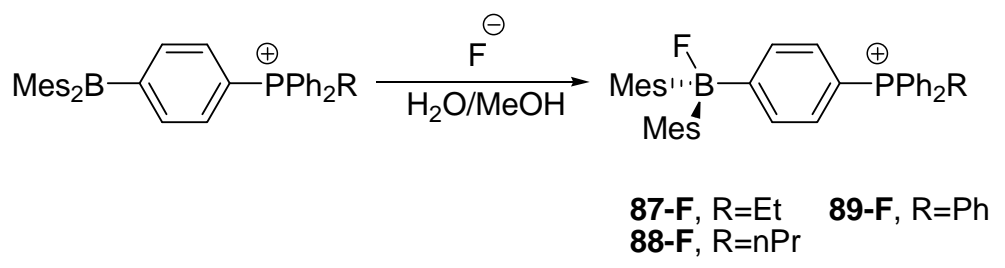

Fig. 33 Structure of receptors $\mathbf{8 6 - 8 9}$ and their reaction with $\mathrm{F}^{-}$.

Following with the study of cationic boranes for the complexation of $\mathrm{F}^{-}$ions a series of phosphonium boranes, 86-89, of varying hydrophobicity were synthesized (Figure 33). ${ }^{125}$ These compounds were found to be water stable and reversibly formed the corresponding hydroxide complexes under basic conditions. It was also showed, by spectrophotometric acid-base titrations carried out in water-methanol 9:1 v/v, that the Lewis acidity of these cationic boranes depend on the nature of the phosphorus substituents and readily increased with the hydrophobic character of the phosphorium unit $(\mathbf{8 6}<\mathbf{8 7}<\mathbf{8 8}<\mathbf{8 9})$. These derivatives forms the corresponding fluoride derivatives upon addition of $\mathrm{F}^{-}$to water-methanol 9:1 v/v solutions (buffered at $\mathrm{pH} 4.9$ for 86-88 and at $\mathrm{pH} 4.6$ for 89 ), whereas addition of other inorganic anions such as $\mathrm{Cl}^{-}, \mathrm{Br}^{-}, \mathrm{I}^{-}$, $\mathrm{NO}_{3}{ }^{-}, \mathrm{H}_{2} \mathrm{PO}_{4}{ }^{-}$and $\mathrm{HSO}_{4}{ }^{-}$results in no reaction. UV-vis titration studies indicated that the $\mathrm{F}^{-}$binding constant increased with the hydrophobicity of the borane. Interesingly 89 was used to detect $\mathrm{F}^{-}$in water-methanol 9:1 v/v solutions. With this compound a detection limit for $\mathrm{F}^{-}$of 2 ppm was determined. 


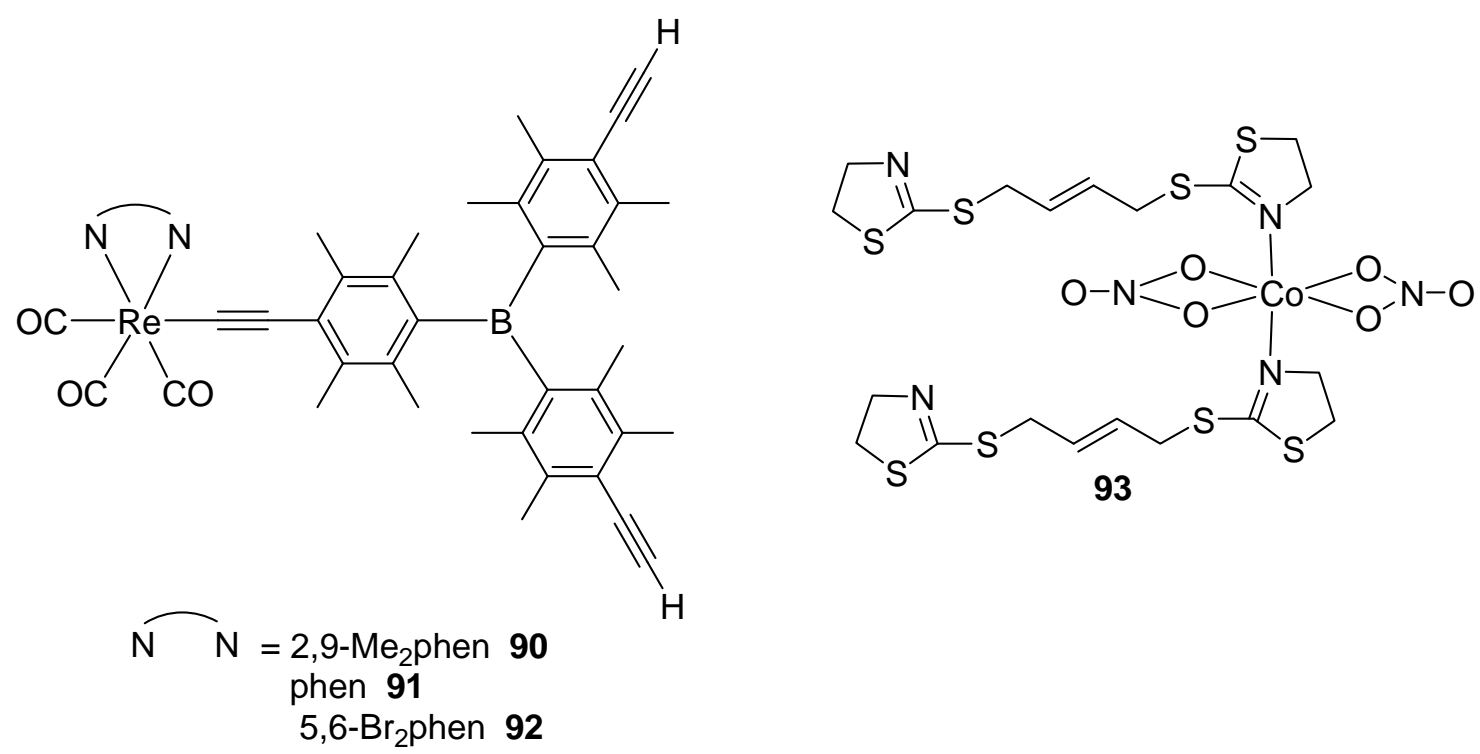

Fig. 34 Chemical structure of receptors 90-93.

The $\mathrm{F}^{-}$binding properties of a series of alkylnylrhenium(I) tricarbonyl diimine complexes 90-92 (Figure 34) with a triarylboron moiety were studied using UV-vis and emission spectrophotometry. ${ }^{126}$ Upon addition of $\mathrm{F}^{-}$to $\mathbf{9 0}$ in acetonitrile a red shift of the absorption band was observed with a concomitant colour change from yellow to dark red. The red shift was consistent with the binding of the negatively charged $\mathrm{F}^{-}$ion to the empty $\mathrm{p}$ orbital of the boron atom that results in an increased electron-donating ability of the alkynyl ligand. The changes in the luminescence response of $\mathbf{9 0}$ toward $\mathrm{F}^{-}$ were also studied in degassed acetonitrile. A quenching of the emission band centred at $625 \mathrm{~nm}$ upon addition of $\mathrm{F}^{-}$was observed. Similar findings were observed for complexes 91 and 92.

The thiazoline-containing cobalt(II) complex 93, was prepared and used as colorimetric and fluorescent "turn-on" probe for $\mathrm{F}^{-}$in DMF-water (HEPES pH 9.5) 9:1 v/v mixtures (Figure 34). ${ }^{127}$ Complex 93 shows a charge transfer absorption band (from the thiazoline donor ligand to the cobalt metal cation) at $543 \mathrm{~nm}$ that is the responsible of its pink colour. Upon addition of $\mathrm{F}^{-}$, the colour of the solution changes to dark blue and additionally the emission intensity at $570 \mathrm{~nm}$ was greatly enhanced. Other anions such as $\mathrm{F}^{-}, \mathrm{Cl}^{-} \mathrm{Br}^{-}, \mathrm{I}^{-}, \mathrm{CN}^{-}, \mathrm{CO}_{3}{ }^{2-}, \mathrm{CH}_{3} \mathrm{COO}^{-}, \mathrm{NO}_{3}{ }^{-}, \mathrm{SO}_{4}{ }^{2-}$ and $\mathrm{H}_{2} \mathrm{PO}_{4}{ }^{-}$did not interfere in the selective detection of $\mathrm{F}^{-}$. The changes in colour and in fluorescence were ascribed to variations in the extent of the charge transfer upon $\mathrm{F}^{-}$binding with the metal centre. 
<smiles>O=C(c1cc([N+](=O)[O-])cc([N+](=O)[O-])c1)N1[CH]OC(C(F)(F)F)c2ccccc21</smiles>

94<smiles>O=C(Nc1ccccc1)c1cc([N+](=O)[O-])cc([N+](=O)[O-])c1</smiles>

95<smiles>CCOCCC(=O)OCCOCCC(=O)c1ccc(C(=O)C(F)(F)F)c(NC(=O)c2cc([N+](=O)[O-])cc([N+](=O)[O-])c2)c1</smiles>

peg-94<smiles>O=C(Nc1ccc(C(=O)C(F)(F)F)cc1)c1cc([N+](=O)[O-])cc([N+](=O)[O-])c1</smiles>

Fig. 35 Structure of 94, peg-94, 95 and 96.

The chromogenic probe 94 was designed by linking a simple 3,4-dinitrophenyl chromophore with a $o$-(carboxamido)trifluoroacetophenone (o-CATFA) group (Figure 35). ${ }^{128}$ Acetonitrile solutions of $\mathbf{9 4}$ show an absorption band at $360 \mathrm{~nm}$. When 94 was treated with $\mathrm{CN}^{-}$two new peaks at 433 and $533 \mathrm{~nm}$ appeared (colour change from colourless to orange). Other basic anions such as $\mathrm{F}^{-}, \mathrm{AcO}^{-}, \mathrm{OH}^{-}$and $\mathrm{H}_{2} \mathrm{PO}_{4}{ }^{2-}$ showed less important absorption changes and a light orange colouration, whereas the anions $\mathrm{HSO}_{4}^{-}, \mathrm{SCN}^{-}, \mathrm{Cl}^{-}$, and $\mathrm{Br}^{-}$did not induce any noticeable colour modulation. In contrast, when acetonitrile solutions of 95 (colourless) were treated with $\mathrm{CN}^{-}$and $\mathrm{F}^{-}$changes to light purple and light yellow were observed, respectively. Additionally the authors carried similar experiments in methanol-water 10:1 v/v mixtures in order to enhance selectivity. In this medium, only the addition of $\mathrm{CN}^{-}$induced a colour change of $\mathbf{9 4}$ from colourless to orange, whereas 95 is completely insensitive to the presence of the selected anions. The changes in colour observed for 94 in water-methanol mixtures in the presence of $\mathrm{CN}^{-}$were ascribed to a nucleophilic addition reaction of the anion to the carbonyl of the trifluoroacetophenone moiety. Moreover, the critical role of the intramolecular H-bond stabilization in 94 was evident from the sensing behaviour observed with its $p$-analogue 96. Acetonitrile solutions of 96 turned yellow upon addition of $\mathrm{F}^{-}, \mathrm{AcO}^{-}$and $\mathrm{CN}^{-}$. No colour changes were observed for 96 in methanolwater 10:1 v/v upon addition of all the anions selected. Finally, the water-soluble peg94 was synthesized introducing a poly(ethyleneglycol) unit into the structure of receptor 
94. This receptor showed a selective change in colour from colourless to orange in the presence of $\mathrm{CN}^{-}$anion in aqueous TRIS solution at $\mathrm{pH}$ 8.2.

\section{4.- Hybrid sensing materials.}

Most of the examples detailed above are based on molecular systems and on the simple interaction of target anions with a binding site or reactive centre. An attractive recent alternative to molecular probes is the use of functionalised pre-organised nanoscopic solid structures in sensing protocols. In most cases the subjacent concept that the combination of solid scaffoldings and molecular or supramolecular ideas may result in the development of novel sensing systems with enhanced capabilities and synergic effects. ${ }^{129-130}$ Using this approach some interesting examples have been reported involving hybrid materials for the chromogenic sensing of cations and anions. ${ }^{131}$ As inorganic scaffoldings gold/silica nanoparticles and mesoporous supports have been used. However, despite these examples, the use of hybrid functional supports for anion signalling is still very scarce. ${ }^{132-142}$

A significant feature of the following examples is that in most cases there is not a simple anchoring of certain molecular entities on a solid support but there is a search of new signalling effects where the solid scaffolding itself plays a significant role in the recognition/sensing protocol.

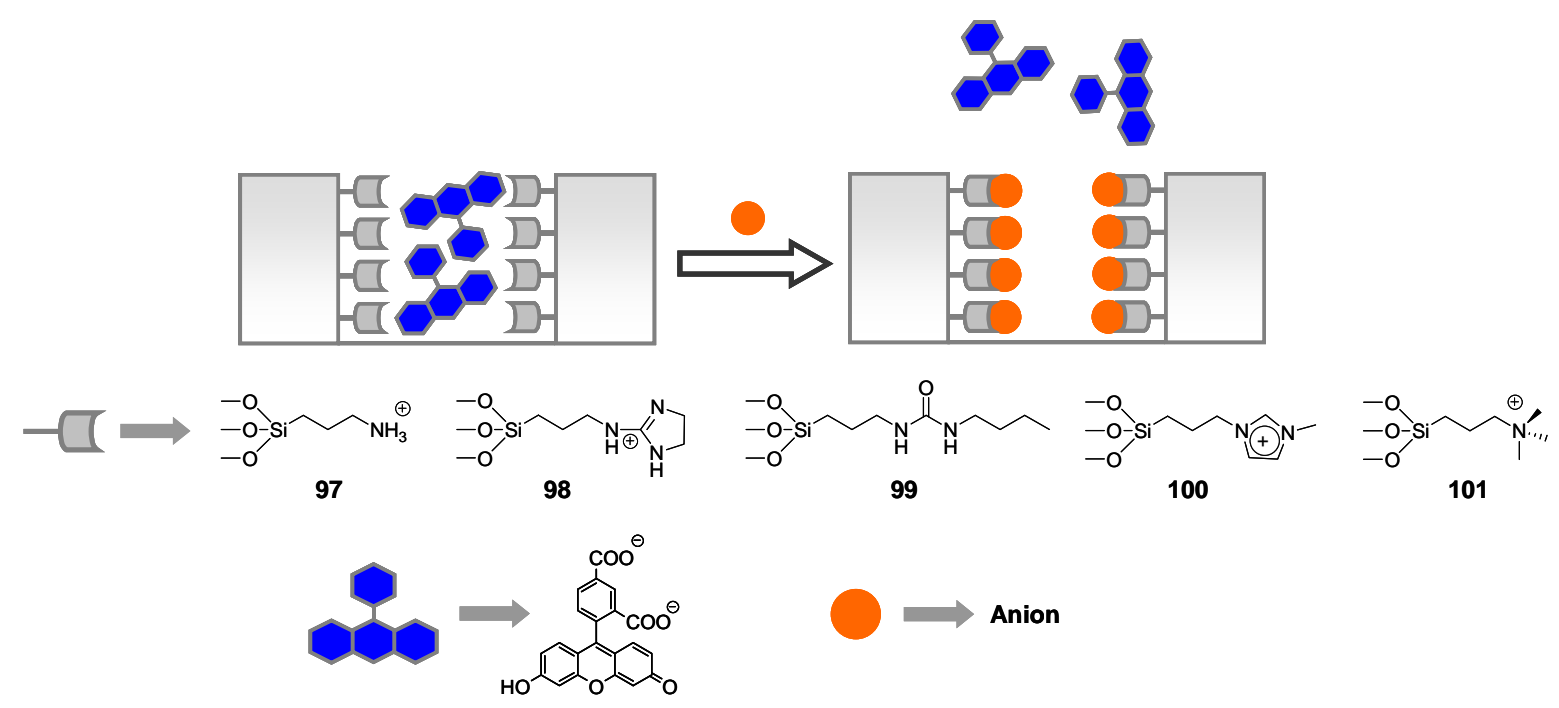

Fig. 36 Schematic representation of hybrid materials 97-101 used in displacement assays for the colorimetric detection of anions. 
The first example uses a mesoporous support of the MCM41-type family (Figure 36). Thes solid shows a narrow and controlled pore size distribution in ordered hexagonal channels with comparatively large pore openings of ca. $25 \AA$. The functionalization of the inner pore surface can be obtained by co-condensation or postsynthetic covalent grafting of organic groups leading to the formation of nanoscopic binding pockets. Using this approach mesoporous silica supports were used for the preparation of hybrid organic-inorganic sensing material for displacement assays in aqueous media. ${ }^{143}$ The inorganic support was functionalized with different coordinating groups; i.e. amines (solid 97), guanidinium salts (solid 98), ureas (solid 99), imidazolates (solid 100) and quaternary ammonium salts (solid 101). Additionally, the five solids were loaded with 5-carboxyfluorescein. Addition of certain carboxylates to water suspensions (HEPES pH 7.5) of the hybrid sensory materials induced different degrees of dye release and a colorimetric response. Solids 100 and 101 (whose binding sites could only display electrostatic interactions) showed a significant dye displacement in presence of citrate anion. The same citrate selective behaviour was observed with solid 97. The response of solid 99 was less selective because all the carboxylates tested $\left(\mathrm{AcO}^{-}\right.$, citrate, lactate, succinate, $\mathrm{C}_{2} \mathrm{O}_{4}{ }^{2-}$, tartrate, malate, mandelate and glutamate) were able to displace the dye in some extent. Also displacement assays were carried out in the presence of ATP, ADP and GMP. For solid 97 the response followed the order ATP $>$ ADP $>$ GMP $\sim$ citrate suggesting that the main force between the functionalized pores (positively charged amines) and the anions are electrostatic interactions. In contrast, solid 99 showed displacement of the dye in the order citrate $>$ $\mathrm{ATP}=\mathrm{ADP}=\mathrm{GMP}$, indicating that the main force in this case are hydrogen-bonding interactions between the anions and the urea groups of the solid.
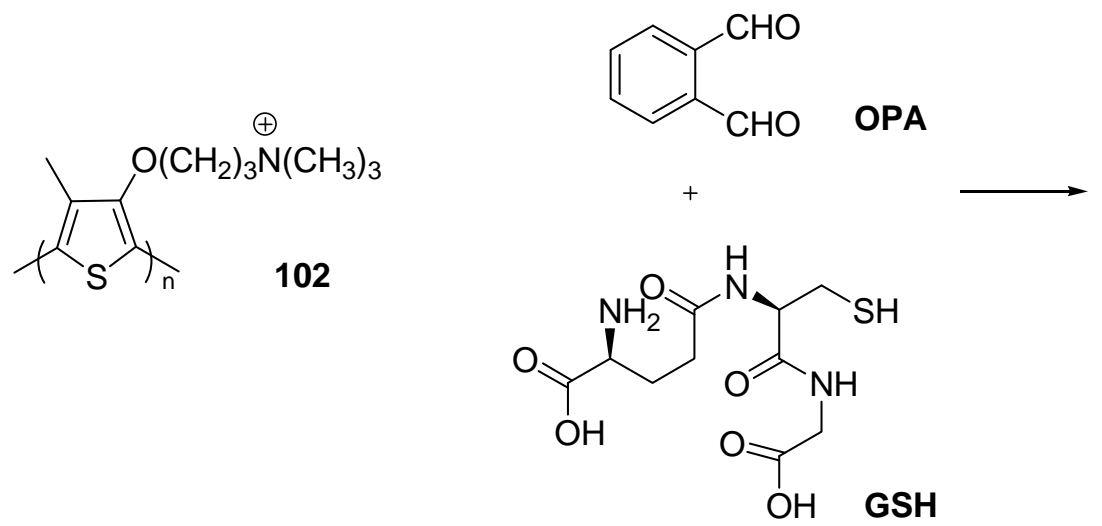<smiles>CCCCCCCCCCCCCCCCCC(=O)NC(CCC(=O)NCC(=O)O)C(C(=O)O)n1cc2ccccc2c1SC</smiles>

Fig. 37 Structure of receptor 102 and the reaction between OPA and GSH. 
Yao et al. reported a chromo-fluorogenic approach for the detection of glutathione (GSH) in aqueous media by using an organic polymer (Figure 37). ${ }^{144}$ The sensing mechanism is through an analyte-induced aggregation of charged polythiophene 102 by combining it with an in situ pre-modified reaction of GSH. The absorption maximum of 102 in borate buffer ( $\mathrm{pH} \mathrm{9.0)} \mathrm{is} \mathrm{at} 407 \mathrm{~nm}$, which is attributed to a random-coiled conformation of the polythiophene backbone. Upon addition of GSH the absorption maximum is slightly red-shifted to $419 \mathrm{~nm}$, whereas upon addition of both OPA and GSH (and generation of isoindole-GSH) the absorption maximum of 102 was red-shifted to $545 \mathrm{~nm}$ with a colour change from yellow to pink-red. It was found that addition of 20 natural amino acids ot thiol-containing molecules (homocysteine and bovine serum albumin) resulted in poor changes in colour $\left(\lambda_{\max }<420 \mathrm{~nm}\right)$. The selectivity of 102 toward GSH was also probed by emission measurements; when increasing amounts of GSH were added to solutions of 102, the emission intensity at $557 \mathrm{~nm}$ was quenched along with a red-shift of the emission maximum.

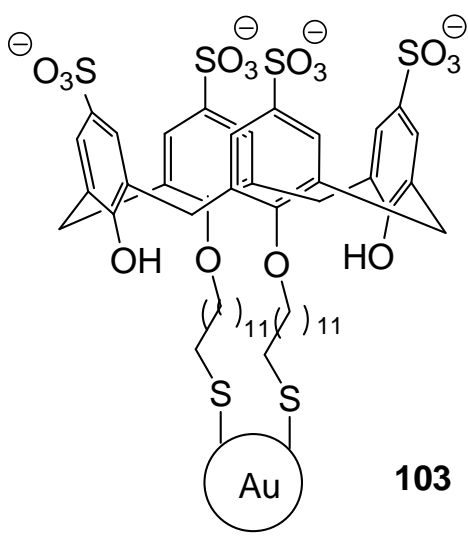

Fig. 38 Structure of receptor 103 based on AuNPs.

The following example in this section relies on the ability of functionalized gold nanoparticles (AuNPs) to show remarkable optical changes upon guest-induced aggregation processes. This color modulation upon aggregation is due to a coupling of the dipoles that result in shifts of the plasmon band to the red when the interparticle distances in the aggregates decrease to less than the average particle radius. ${ }^{145,146}$ Based in this phenomenon several sensing protocols have been described in recent years for both anion and cations and in the field of biomacromolecule analysis. ${ }^{147,148}$ The AuNPs containing a novel $p$-sulfonatocalix[4]arene derivative attached to the gold surface via thiol groups (103, Figure 38) were used as colorimetric probe for the detection of 
certain amino acids in water. ${ }^{149}$ Aqueous suspensions of the calix-capped AuNPs show an absorption maximum at $524 \mathrm{~nm}$. Different aqueous solutions of amino acids in PBS buffer were added to 103. A visible colour change from red $\left(\lambda_{\max }=524 \mathrm{~nm}\right)$ to purple $\left(\lambda_{\max }=550 \mathrm{~nm}\right)$ was induced selectively after adding Lys, Arg and His solutions. This colour change was assigned to an amino acid-induced aggregation process of the AuNPs. Other amino acids added (Gly, Ala, Leu, Val, Pro, Ser, Asp and Glu) had no effect on the colour of 103. The selectivity observed arises from the fact that AuNPs were functionalized with calixarenes, which possesses an electron-rich cyclic cavity able to form inclusion complexes with the positively charged $\mathrm{NH}_{3}{ }^{+}$moieties or imidazole groups of Lys, Arg or His.

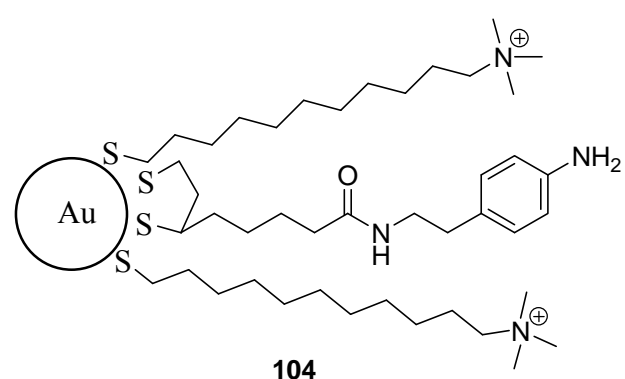

104
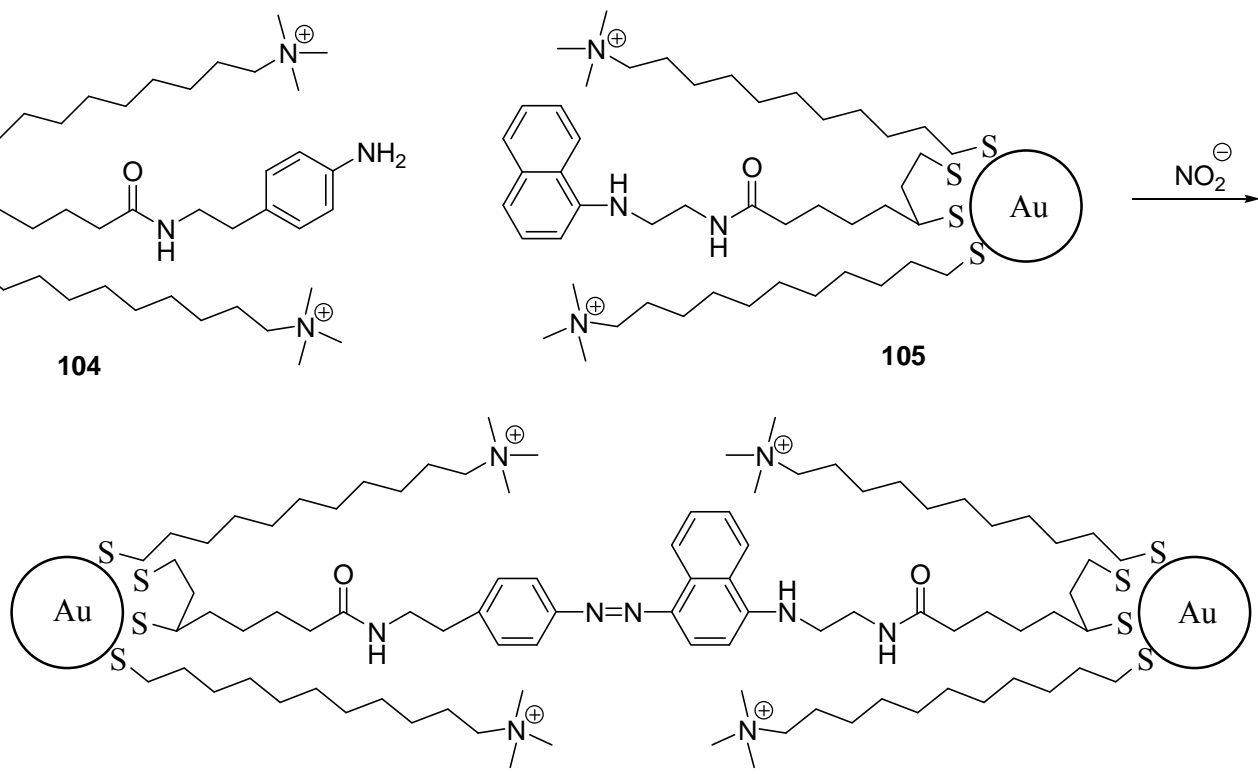

Fig. 39 Structure of AuNPs 104 and 105 and the proposed reaction with $\mathrm{NO}_{2}{ }^{-}$anion.

A second example that uses selective aggregation of AuNPs is based on the Griess reaction for the selective detection of $\mathrm{NO}_{2}{ }^{-}$anion (Figure 39). ${ }^{150}$ Two types of AuNPs were prepared, AuNPs containing aniline groups (104) and AuNPs containing naphthalene moieties (105). The aniline- and naphthalene-capped AuNPs are red when dispersed in aqueous solution due to an intense surface plasmon resonance at $520 \mathrm{~nm}$. In the presence of $\mathrm{NO}_{2}^{-}$ion under acidic conditions, the amine groups on the anilinecapped AuNPs are converted to a diazonium salt, which then couples with the naphthalene-capped AuNPs. This reaction causes the formation of crosslinked particle networks which precipitate rapidly, causing the solution to change from red to 
colourless. The authors found no aggregation in the presence of $\mathrm{NO}_{3}^{-}, \mathrm{F}^{-}, \mathrm{SO}_{4}^{-}, \mathrm{Br}^{-}$, $\mathrm{ClO}_{4}{ }^{-}, \mathrm{CH}_{3} \mathrm{COO}^{-}, \mathrm{S}_{2} \mathrm{O}_{3}{ }^{2-}, \mathrm{C}_{2} \mathrm{O}_{4}{ }^{2-}, \mathrm{N}_{3}{ }^{-}$or $\mathrm{HCO}_{3}{ }^{-}$.
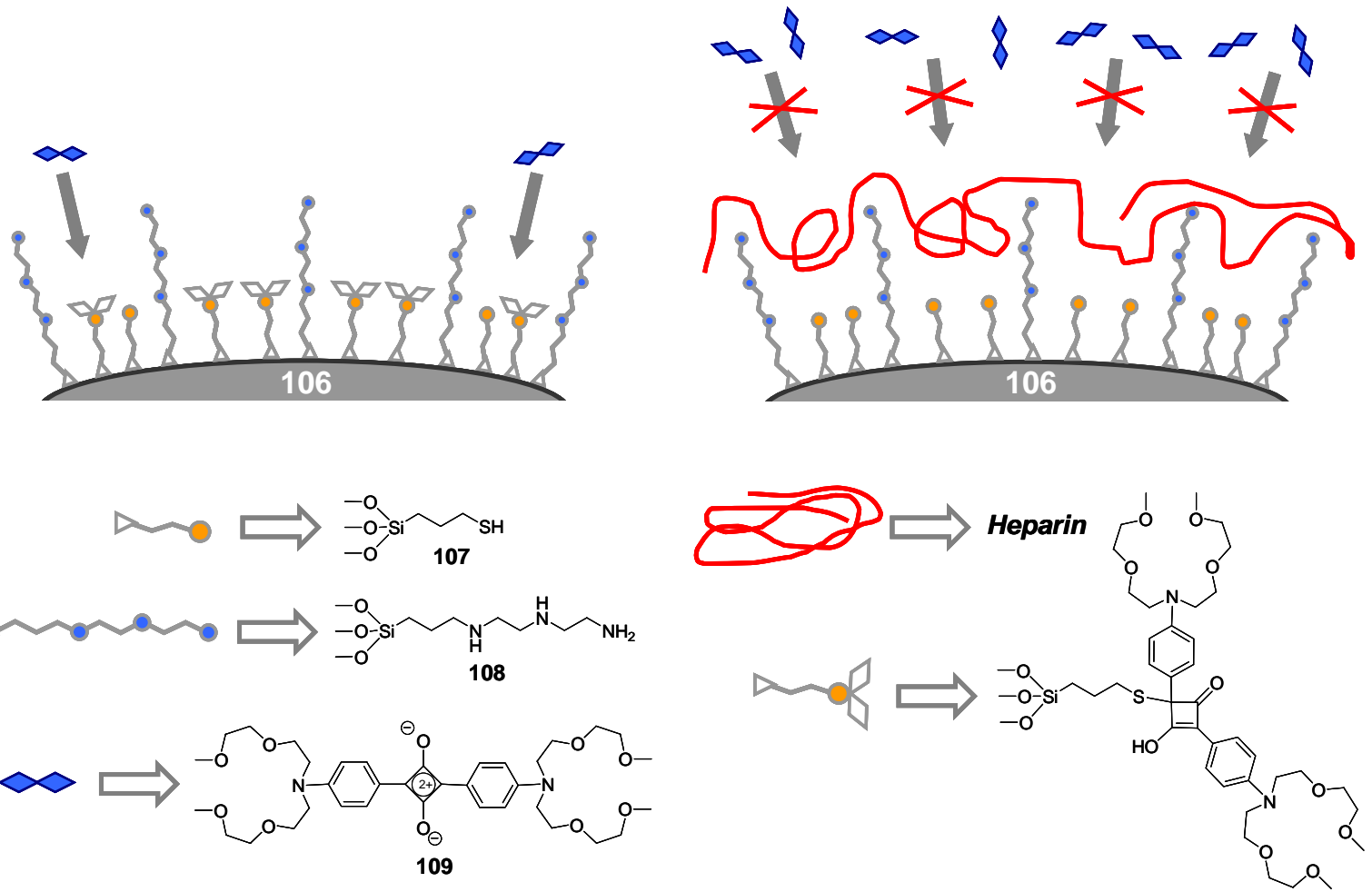

Fig. 40 Structure of the hybrid silica nanoparticles 106 fucntionalized with a thiol derivative 107 and a polyamine binding site 108. The interaction of 106 with heparin controlled the access of squaraine (109) to the thiol groups on the surface.

The following approach develops a chromogenic sensing system for heparin via mass transport control to the surface of bi-functionalised silica nanoparticles (Figure 40). Coated silica nanoparticles 106 were prepared by using two trialcoxysilyl derivatives; 107 (containing a thiol group) and 108 (with a polyamine group). ${ }^{151}$ The role of $\mathbf{1 0 7}$ is to react with squaraine dye $\mathbf{1 0 9}$ through the nucleophilic attack of the thiol group to the electron deficient, central, four-member ring of the squaraine scaffolding. ${ }^{152}$ This is known to result in the bleaching of blue squaraine solutions. The sensing protocol relies in the concept that interaction of $\mathbf{1 0 8}$ with a suitable guest would inhibit of the reaction between 107 and 109, resulting in a chromo-fluorogenic signalling. Addition of $\mathbf{1 0 9}$ to water/DMSO/acetonitrile $(45: 45: 10, \mathrm{v} / \mathrm{v} / \mathrm{v})$ suspensions of 106 induced the disappearance of the squaraine band centred at $643 \mathrm{~nm}$ and due to the reaction of the thiols and the squaraine dye. When the same experience was carried out in the presence of heparin, the solution remained blue due to the inhibition of the 107- 
109 reaction as a consequence of the strong coordination between the polianion and 108. The reaction was also partially hindered by the addition of chondroitin-4-sulfate, whereas the presence of anions $\left(\mathrm{F}^{-}, \mathrm{Cl}^{-}, \mathrm{Br}^{-}, \mathrm{I}^{-}, \mathrm{SO}_{4}{ }^{2-}, \mathrm{PO}_{4}{ }^{3-}, \mathrm{NO}_{3}{ }^{-}\right)$, monosaccharides (sucrose, glucose, fructose, arabinose) and charged disaccharides (calcium lactobionate) do not induce any effect in the absorbance of the 109. The degree of inhibition (heparine $>$ chondroitin-4-sulfate) was clearly related to the anionic charge density of the respective polysaccharide, which suggested that the electrostatic interactions played a dominant role in binding with the polyamine network. The same colorimetric recognition mechanism was used in developing similar bi-functionalised silica surfaces for sensing $\mathrm{P}_{2} \mathrm{O}_{7}{ }^{4-}$ in aqueous media. ${ }^{153}$

The following sensing approach uses a gated hybrid architecture that consists of a mesoporous MCM-41 silica support containing suitable molecules at the pore outlets and a dye in the pore voids. The sensing protocol is based on the idea that the addition of a certain "key" guest may "close" (or "open") the gate and inhibits (or enhances) the delivery of the dye from the pores into the bulk solution. ${ }^{154-158}$ These systems show distinctive features when compared with the classical paradigms detailed above; in these hybrid systems the complexation of relatively few guests at the external gate may inhibit/enhance the liberation of a large number of dye molecules, thus showing clear features of signal amplification. This approach also detaches the recognition protocol from the signalling event, making signalling independent of the stoichiometry of the guest-binding site complex as usually happens in classical signalling procedures.

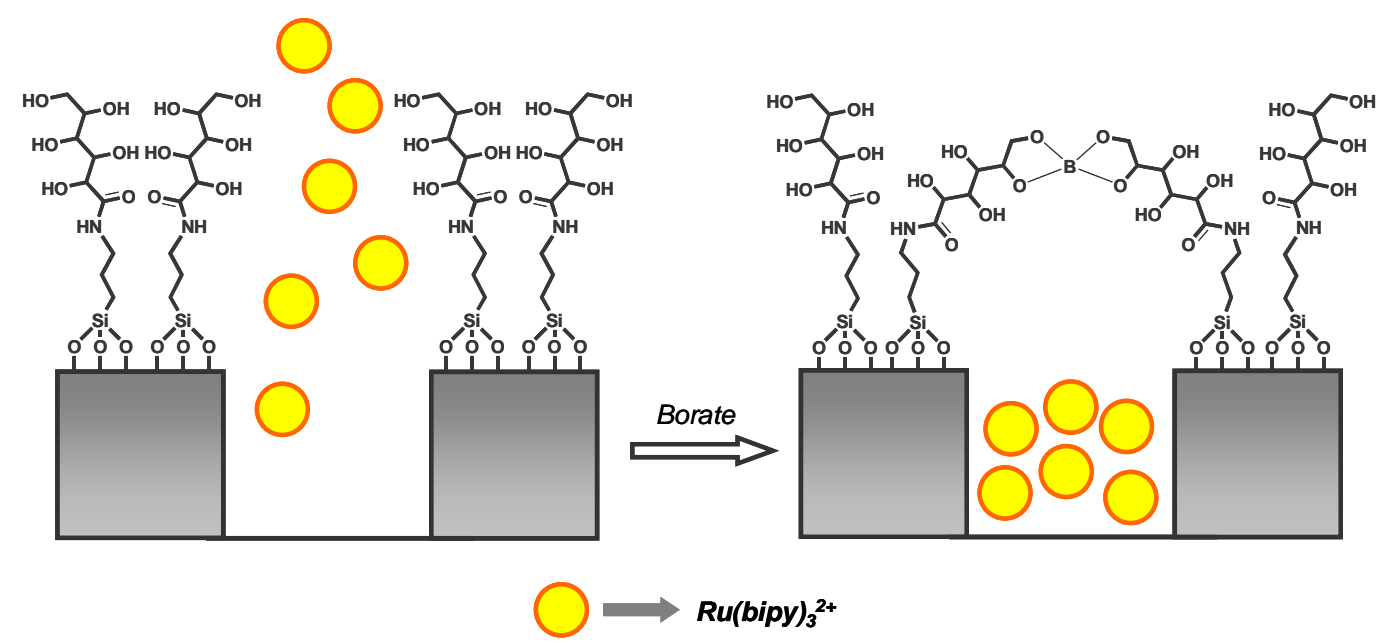

Fig. 41 Schematic representation of a hybrid material with a gate-like scaffolding for the colorimetric sensing of $\mathrm{BO}_{3}{ }^{3-}$ anion. 
Following this concept, a mesoporous MCM-41 support was functionalised with a saccharide derivative in the external surface and the dye $\left[\mathrm{Ru}(\mathrm{bipy})_{3}\right]^{2+}$ was loaded on the inner mesopores (Figure 41). This gated solid was used for the colorimetic sensing of $\mathrm{BO}_{3}{ }^{3-159}$ The effectiveness of the delivery of the $\left[\mathrm{Ru}(\text { bipy })_{3}\right]^{2+}$ complex from the pore voids of the hybrid material to the bulk solution was studied in water in at $\mathrm{pH} 7$ in the presence of anions such as $\mathrm{BO}_{3}{ }^{3-}, \mathrm{CO}_{3}{ }^{2-}, \mathrm{Cl}^{-}, \mathrm{SO}_{4}{ }^{2-}, \mathrm{NO}_{3}{ }^{-}, \mathrm{Br}^{-}$and $\mathrm{PO}_{4}{ }^{3-}$. It was found that whereas the presence of $\mathrm{BO}_{3}{ }^{3-}$ strongly inhibited $\left[\mathrm{Ru}(\text { bipy })_{3}\right]^{2+}$ complex delivery (solution remained colourless), the rest of anions displayed no control in the release of the dye (the solution turned yellow).
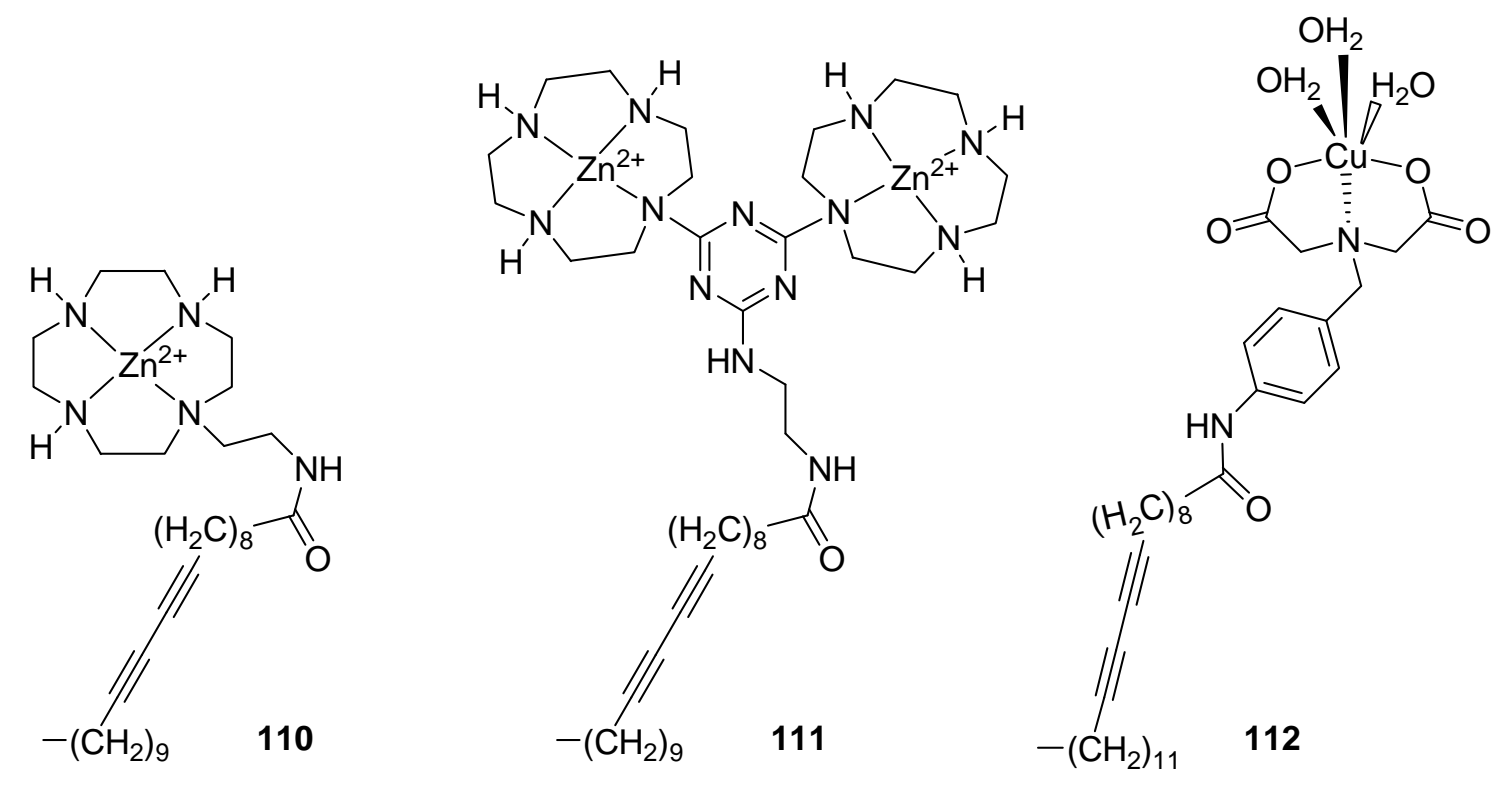

Fig. 42 Structure of receptors 110, 111 and 112.

Self-assembled polydiacetylene vesicles with amphiphilic metal zinc(II)-cyclen (110 and 111) complexes and the $\mathrm{Cu}(\mathrm{II})$-iminodiacetato (112) complex were tested as $\mathrm{PO}_{4}{ }^{3-}$ ion recognition receptors in aqueous solutions (Figure 42). ${ }^{160}$ Addition of these molecules to water resulted in the formation of the corresponding liposomes; i.e. LP110, LP-111 and LP-112. These vesicular receptors responded to the presence of ATP, $\mathrm{P}_{2} \mathrm{O}_{7}{ }^{4-}$ and $\mathrm{CN}^{-}$in buffered aqueous solution (HEPES, $\mathrm{pH}$ 7.2) at milimolar concentrations. Thus, aqueous solutions of LP-110 and LP-111 show an absorption band at $640 \mathrm{~nm}$ that disappeared completely at the same time that two new bands at 489 and 543 grew in intensity upon addition of increasing quantities of $\mathrm{ATP}, \mathrm{P}_{2} \mathrm{O}_{7}{ }^{4-}$ and $\mathrm{CN}^{-}$ 
anions (change in colour from dark blue to red). No colour changes were observed upon addition of other anions such as $\mathrm{F}^{-}, \mathrm{Cl}^{-}, \mathrm{Br}^{-}, \mathrm{I}^{-}, \mathrm{H}_{2} \mathrm{PO}_{4}{ }^{-}, \mathrm{CH}_{3} \mathrm{COO}^{-}$, AMP or ADP under similar conditions. The dinuclear Zn(II)-cyclen system LP-111 showed a higher affinity to ATP and $\mathrm{P}_{2} \mathrm{O}_{7}{ }^{4-}$ ions than the mononuclear LP-110. The same absorption spectra changes were found for $\mathbf{L P - 1 1 2}$ in the presence of $\mathrm{P}_{2} \mathrm{O}_{7}{ }^{4-}$ whereas other anions gave no change. Thus LP-112 was suitable for selective detection of $\mathrm{P}_{2} \mathrm{O}_{7}{ }^{4-}$ over ATP. The authors indicated that the observed colour modulations were due to a distortion of the conjugated p-orbitals in the main chain of the polydiacetylene polymers and not due to displacement of zinc ions. By emission studies the detection of ATP and $\mathrm{P}_{2} \mathrm{O}_{7}{ }^{4-}$ was achieved with LP-110 and LP-111, while $\mathrm{P}_{2} \mathrm{O}_{7}{ }^{4-}$ was the unique anion able to induce an emission enhancement of LP-112. All these receptors were used to design a test paper strip, which allowed the simple detection of ATP and $\mathrm{P}_{2} \mathrm{O}_{7}{ }^{4-}$ at milimolar concentrations in water.

\section{3.- Fluorogenic anion chemosensors and reagents.}

The use of fluorescent signalling subunits in the development of chemosensors for anions has been extensively used and signal transduction procedures are in general well known. ${ }^{34,40}$ However, a detailed list of fluorescence signalling mechanisms will not be detailed here. As in the cases shown above for chromogenic systems, most fluorogenic chemosensors and reagents for anions contain binding or reactive sites and signalling subunits. The two units can be electronically connected or not. In the later case only changes in fluorescence are observed, whereas in the former anion coordination may also induce a colour modulation. The inclusion of these examples in this section (fluorogenic) or in the above section (chromogenic) is subjective and depends on the importance of the colour or emission modulations.

\section{1.- Binding site-signalling subunit approach.}

\subsection{1.- Containing polycyclic aromatic hydrocarbons derivatives.}

Polycyclic aromatic hydrocarbons are very popular units used in the development of fluorescent chemosensors for anion signalling. In particular anthracene, but also naphthalene and pyrene, have been extensively employed as fluorescent moieties. Part of this popularity deals, among other reasons, with their quite well-known photo-physical properties, their relatively large quantum yield, the possibility of act as 
binding groups via $\pi$-interactions, their ability to form excimers, their easy functionalization and the relatively large number of commercially available derivatives that can be used as starting materials. Probably the main drawback in their use is that they show emission near the UV region where serious matrix interferences may be found in real samples.

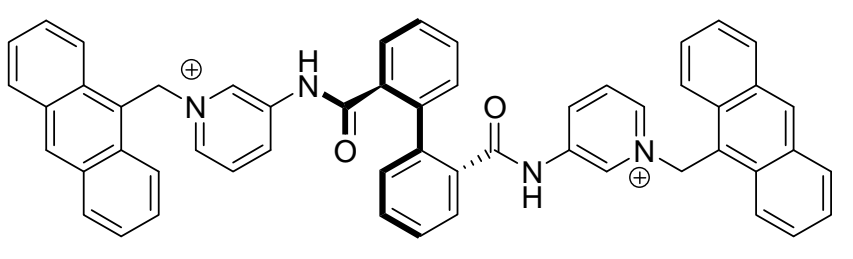

113

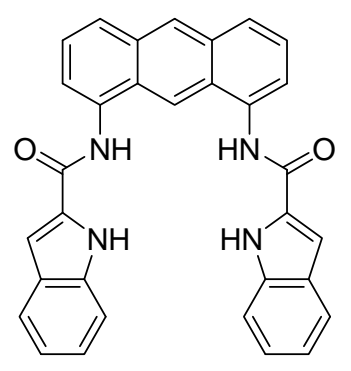

114

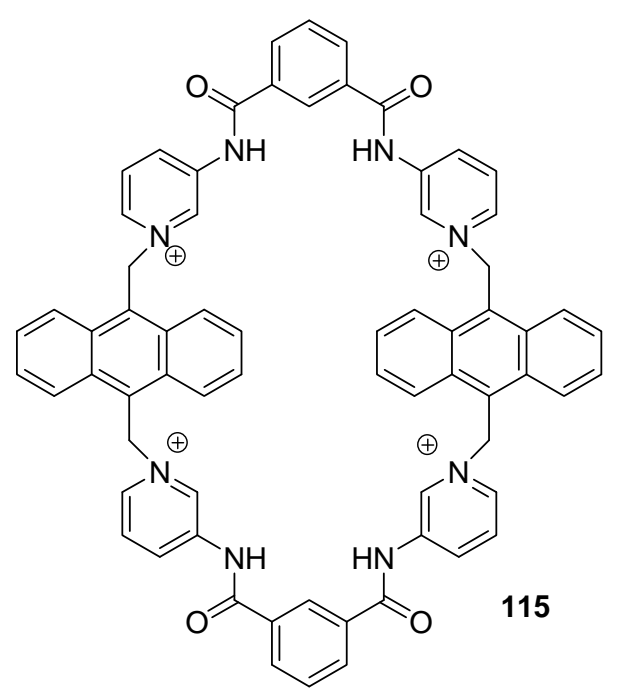

Fig. 43 Structure of 113, 114 and 115.

113 uses anthracene moieties as signalling subunit and pyridinium amides as binding sites in a cleft geometry imposed by the central biphenyl moiety (Figure 43). ${ }^{161}$ Chloroform-acetonitrile 98:2 v/v solutions of 113 show two bands at 413 (anthracene monomer emission) and $513 \mathrm{~nm}$ (excimer emission due to the close proximity of both anthracene moieties in 113). Addition of $\mathrm{H}_{2} \mathrm{PO}_{4}{ }^{-}$to this solution induced negligible changes in the monomer emission whereas the excimer band increased significantly. This was attributed to a fit of the tetrahedral $\mathrm{H}_{2} \mathrm{PO}_{4}{ }^{-}$anion in the cleft of the receptor giving hydrogen bonding and electrostatic interactions with the amide protons and the charged pyridinium moieties. This coordination results in an inhibition of a PET process between the photo-excited anthracene and the pyridinium-amide that leads to the observed emission enhancement. Addition of terephthalate, $\mathrm{HSO}_{4}{ }^{-}$and isosphthalate induced moderate increase of the excimer emission, whereas $\mathrm{ClO}_{4}^{-}, \mathrm{AcO}^{-}$, succinate, glutarate, malonate and phthalate induced negligible changes.

114 (Figure 43) contains an anthracene fluorophore attached through amide linkages to two indole units. ${ }^{162}$ Dichloromethane-DMSO $(9: 1 \mathrm{v} / \mathrm{v})$ solutions of 114 
show an emission band centred at $429 \mathrm{~nm}$. Addition of 5 equivalents of $\mathrm{F}^{-}$induced an emission intensity enhancement with a red shift of $7 \mathrm{~nm}$ whereas addition of $\mathrm{AcO}^{-}, \mathrm{Cl}^{-}$, $\mathrm{Br}^{-}, \mathrm{I}^{-}, \mathrm{HSO}_{4}{ }^{-}, \mathrm{H}_{2} \mathrm{PO}_{4}{ }^{-}$and $\mathrm{NO}_{3}{ }^{-}$induced negligible changes in the emission intensity. ${ }^{1} \mathrm{H}$ NMR studies show that receptor 114 forms 1:1 complexes with $\mathrm{F}^{-}$via hydrogen bonding interactios with the $\mathrm{N}-\mathrm{H}$ groups of the amide and the indole, and with a $\mathrm{C}-\mathrm{H}$ moiety from anthracene. The authors suggested that the formation of the complex induces an increase in the rigidity of the receptor that leads to the suppression of a PET process that is active in the receptor alone.

The macrocyclic receptor 115, bearing two anthracene fluorophores, four pyridinium groups and four amides, was synthesized and its behaviour in the presence of certain dicarboxylates tested (Figure 43). ${ }^{163}$ Acetonitrile solutions of 115 show a broad emission band at $419 \mathrm{~nm}$ due to the anthracene moieties. Addition of monocarboxylates such as $\mathrm{AcO}^{-}$and $\mathrm{BzO}^{-}$resulted in negligible changes in the emission profile whereas the presence of dicarboxylates (1,4-phenyldiacetate, adipate, pimelate and terephthalate) induced enhancements of different degrees in the emission at $419 \mathrm{~nm}$ with the additional development of a new strong band centred at $500 \mathrm{~nm}$ that was attributed to the formation of an excimer. Other dicarboxylates tested $\left(\mathrm{C}_{2} \mathrm{O}_{4}{ }^{2-}\right.$, malonate, succinate and glutarate) induced an increase of the band intensity at $419 \mathrm{~nm}$ but a poor enhancement of the emission at $500 \mathrm{~nm}$. All the dicarboxylates form 1:1 complexes with receptor 115 through hydrogen bonding interactions with the isophthaloyldiamide moieties and electrostatic interactions with the pyridinium cations. The fluorescence enhancements observed in the presence of dicarboxylates were ascribed to the inhibition of a photo-induced electron transfer from the binding sites to the photo-excited anthracene. 


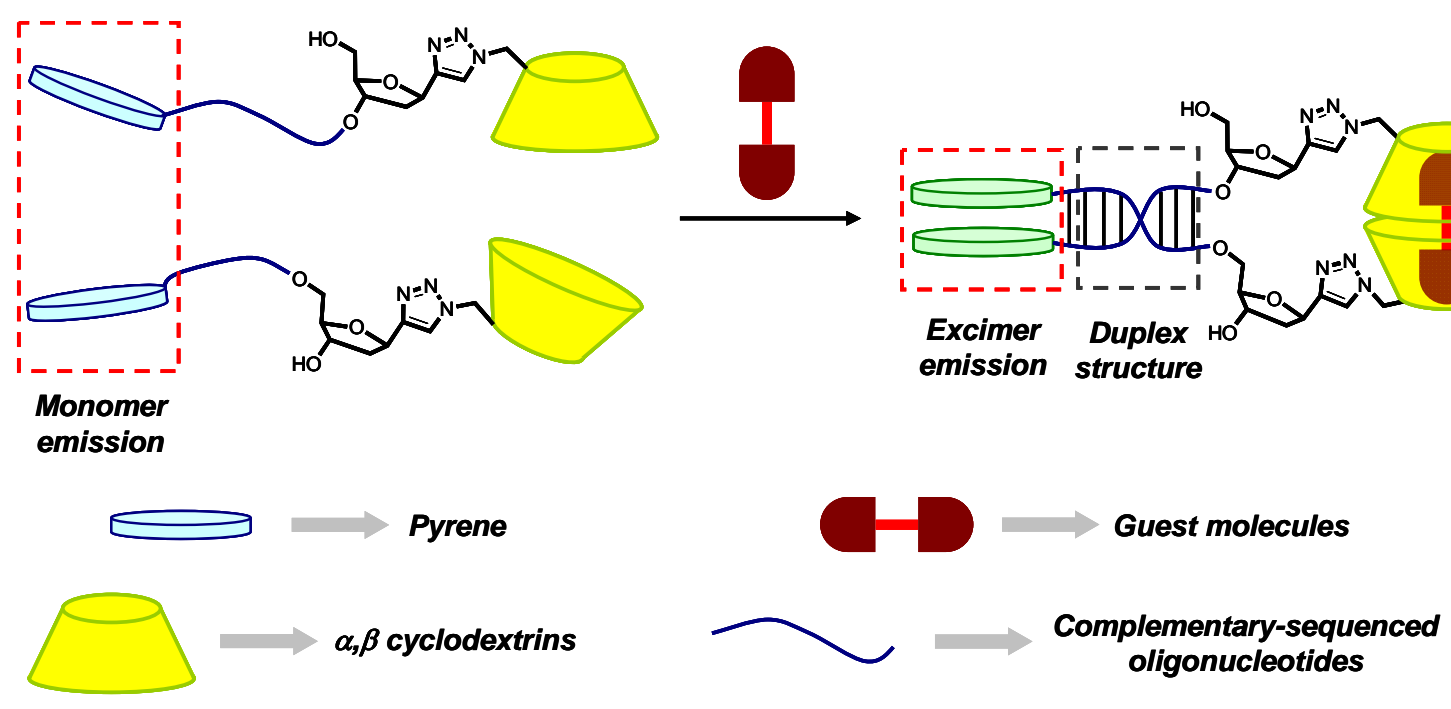

Fig. 44 Schematic representation of a cyclodextrin-oligonucleotide-pyrene receptor for the fluorogenic recognition of fatty carboxylates.

The following three examples use pyrene as signalling subunit. In the first one, two complementary-sequenced oligonucleotides (ODN) were functionalized with pyrene as signalling unit and cyclodextrins as binding site and used for the fluorescent recognition of fatty acids (Figure 44). ${ }^{164}$ Aqueous solutions buffered at pH 10.0 (Gly$\mathrm{NaOH}$ ) of two ODN functionalized with $\beta$-cyclodextrins showed the typical broad emission band of the pyrene monomer in the 350-450 $\mathrm{nm}$ interval (excitation at 345 $\mathrm{nm})$. Addition of oleic, elaidic and arachidonic acids induced a moderate quenching of the monomer emission with the appearance of an excimer emission band centred at 500 nm. Solution studies suggested the formation of 2:1 host-guest complexes. The formation of inclusion complexes between $\beta$-cyclodextrin and the carboxylic acids induced the hybridization of the ODN chains. This induced a spatial proximity between two pyrene fluorophores that leads to the switch-on of the excimer emission. The selectivity toward oleic and elaidic acid can be modulated by changing $\beta$-cyclodextrin to $\alpha$-cyclodextrin. 

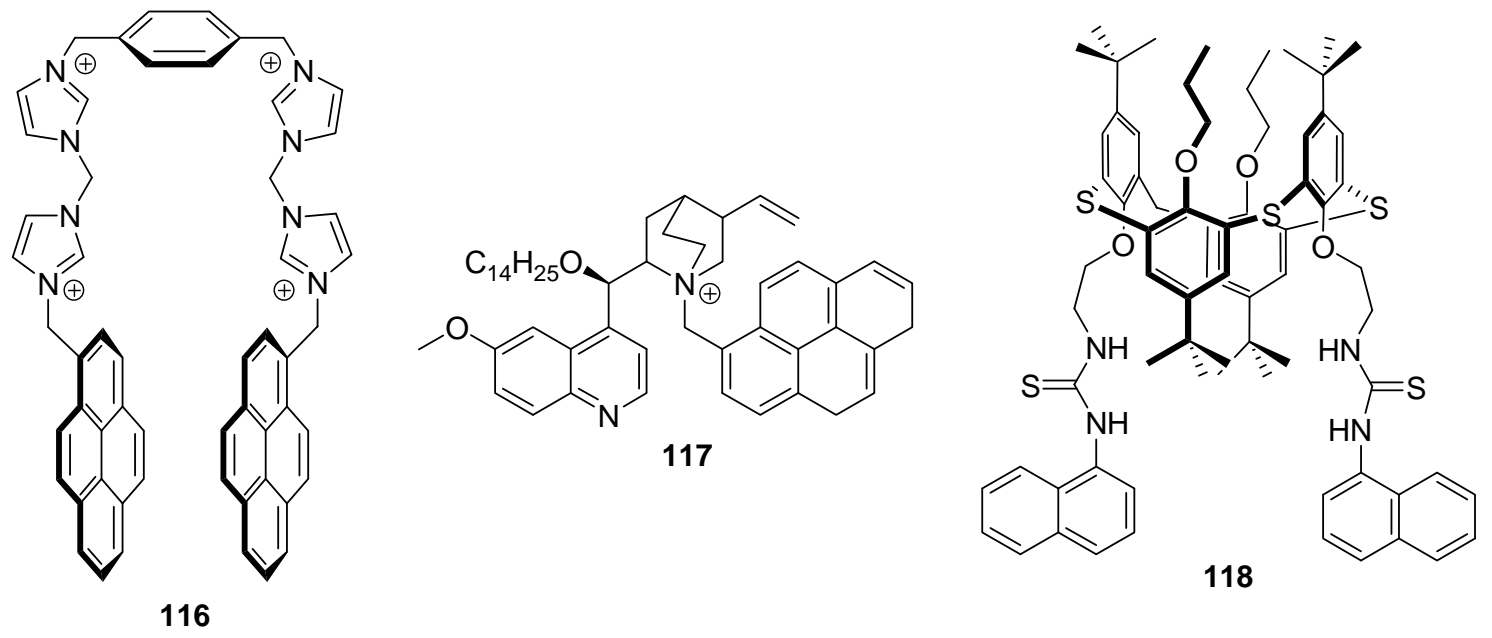

Fig. 45 Structures of receptors 116, 117 and 118.

Receptor 116, functionalized with pyrene as fluorogenic unit and imidazolium cationic groups as binding sites, was able to selectively recognize ATP in aqueous solutions (Figure 45). ${ }^{165}$ Water solutions of 116 (HEPES, pH 7.4) display two emission bands at 375 and $478 \mathrm{~nm}$ that were assigned to the monomer and excimer emission of the pyrene fluorophore, respectively. Addition of nucleoside triphosphates (CTP, UTP, TTP, GTP and ATP) induced quenching of the excimer emission whereas addition of $\mathrm{PO}_{4}{ }^{3-}$ and $\mathrm{P}_{2} \mathrm{O}_{7}{ }^{4-}$ induced negligible changes in the excimer band. However, the unique anion able to induce an enhancement in the emission monomer band centred at $375 \mathrm{~nm}$ was ATP. The $\mathrm{PO}_{4}{ }^{3-}$ groups of ATP interact, through hydrogen bonding and electrostatic attractive forces, with the imidazolium groups of 116. As a consequence, the authors suggest that the adenine base is inserted in between both pyrenes inducing a quenching of the excimer band and an enhancement of the monomer emission. The receptor was also able to distinguish between ATP, ADP and AMP by measuring the ratio of the monomer/excimer emission intensity $\left(\mathrm{I}_{375} / \mathrm{I}_{478}\right)$; AMP induces negligible changes in both emission bands whereas ADP displays small excimer emission quenching and relatively large enhancement of the monomer emission.

A quinine derivative functionalised with pyrene, 117, was prepared and its ability to recognize heparin, a common used anticoagulant, in aqueous environments tested (Figure 45). ${ }^{166}$ Water solutions of receptor 117 (HEPES, pH 7.4) show the typical pyrene monomer emission in the 350-425 $\mathrm{nm}$ range. Addition of heparin induced the 
appearance of a broad structureless emission band centred at 489 that was assigned to the formation of a pyrene excimer. The authors attributed excimer formation to coordination of pyrenyl ammonium cation of receptor 117 with the $\mathrm{SO}_{4}{ }^{2-}$ and carboxylate moieties in the pyranosyluronic acid moiety of heparin that results in a close proximity of the fluorophores. The response observed was highly selective; i.e. the presence of other species such as adenosine, AMP, ATP, $\mathrm{PO}_{4}{ }^{3-}, \mathrm{P}_{2} \mathrm{O}_{7}{ }^{4-}, \mathrm{UMP}, \mathrm{DNA}$, glucose, $\mathrm{SO}_{4}{ }^{2-}$, bovine serum albumin, globulin, Glu, Asp, hyaluronic acid and chondroitin sulfate induced negligible changes in the intensity of the excimer emission.

The following case is the only example reported in 2009 that used naphthyl groups as signalling reporters. THF solutions of the thiacalix[4]arene receptor 118 (Figure 45) show no fluorescence, ${ }^{167}$ however addition of $\mathrm{F}^{-}$induced a significant increase in the emission at $385 \mathrm{~nm}$. The response is highly selective and the addition of $\mathrm{Cl}^{-}, \mathrm{Br}^{-}, \mathrm{I}^{-}, \mathrm{AcO}^{-}, \mathrm{HSO}_{4}^{-}, \mathrm{NO}_{3}^{-}, \mathrm{H}_{2} \mathrm{PO}_{4}^{-}$, malonate, fumarate, succinate, tartrate, adipate and phthalate induced negligible emission changes. The authors suggested that coordination of $\mathrm{F}^{-}$with thiourea moieties of receptor 118, through the formation of hydrogen bonds, trigger an intramolecular $\pi-\pi$ interaction between both naphthyl groups that is the responsible of the emission band at $385 \mathrm{~nm}$.

In the following examples the polycyclic aromatic hydrocarbon signalling groups are further incorporated in the structure of metal cation complexes.<smiles>c1ccc2c(Cn3ccnc3)c3ccccc3c(Cn3ccnc3)c2c1</smiles>

119

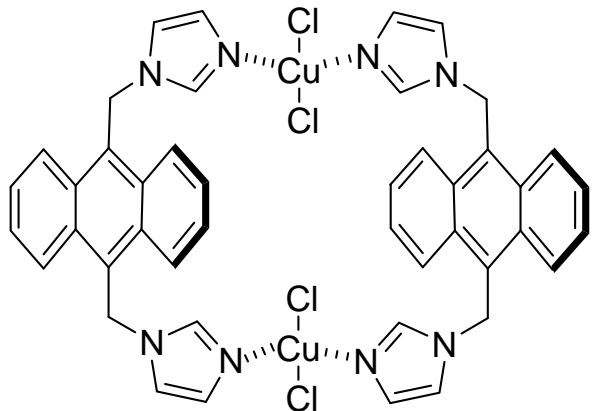

$\left[119 \cdot \mathrm{CuCl}_{2}\right]_{2}$

Fig. 46 Structure of 119 and its dicopper complex.

The anthracene-imidazole conjugate 119 (Figure 46) forms the metallacyclophane $\left[\mathbf{1 1 9} \cdot \mathrm{CuCl}_{2}\right]_{2}$ which is able to recognize 5'-GMP over other nucleotides by changes in emission intensity. ${ }^{168}$ DMSO-water 8:2 v/v solutions of receptor 119 show the typical emission bands of anthracene in the 380-500 $\mathrm{nm}$ range. Upon addition of increasing quantities of $\mathrm{CuCl}_{2}$ a partial quenching of the emission 
intensity was observed. MALDI-TOF MS studies suggested the formation of the complex $\left[\mathbf{1 1 9} \cdot \mathrm{CuCl}_{2}\right]_{2}$ whereas ${ }^{1} \mathrm{H}-\mathrm{NMR}$ spectra additionally indicated that $\mathrm{Cu}^{2+}$ ions coordinated with the imidazole moieties of 119. Gradual addition of 5'-GMP to DMSOwater $8: 2 \mathrm{v} / \mathrm{v}$ solutions of $\left[\mathbf{1 1 9} \cdot \mathrm{CuCl}_{2}\right]_{2}$ induced a remarkable quenching of the anthracene emission whereas addition of adenosine, guanosine, 5'-AMP, 5'-ADP, 5'GDP, 5'-GTP and 3',5'-cGMP induced negligible changes in the emission spectra. The authors indicated that the selectivity of the metallacyclophane arises from a preferential coordination of $5^{\prime}$-GMP in the pre-organized cavity of $\left[\mathbf{1 1 9} \cdot \mathrm{CuCl}_{2}\right]_{2}$ via a combination of various interactions that include (i) electrostatic attractive forces between $\mathrm{Cu}^{2+}$ ions and the phosphate group of 5'-GMP, (ii) coordinative interactions between $\mathrm{Cu}^{2+}$ ions and the nitrogen atoms of guanine base and, (iii) $\pi$-stacking interactions between the anthracene moieties and the aromatic heterocycles of 5'-GMP. The formation of this inclusion complex allowed an electron transfer from the nucleobase to the excited state of the anthracene fluorophore that induced the observed quenching.

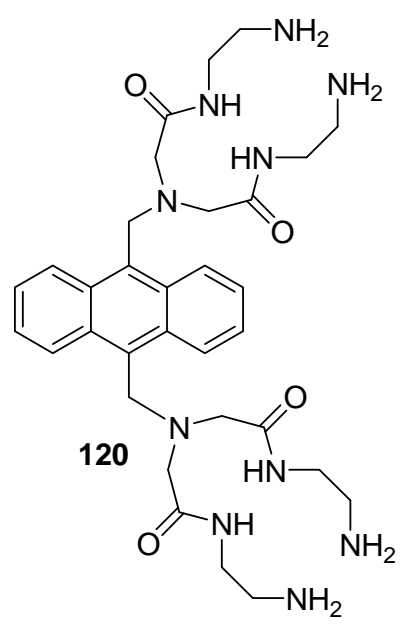

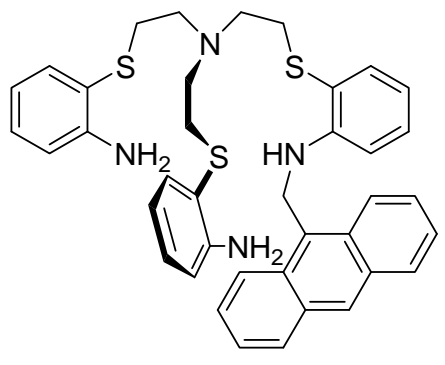

121

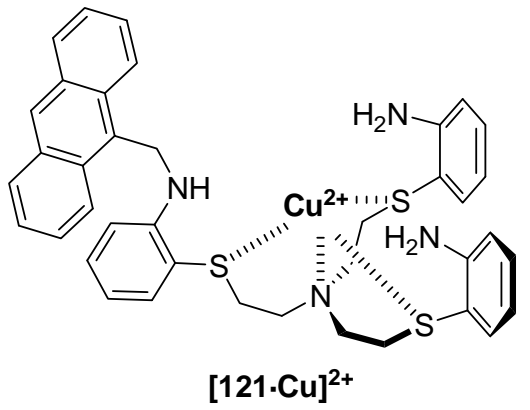

Fig. 47 Structure of 120, 121 and 121·Cu.

Ligand 120 forms a complex with two $\mathrm{Zn}(\mathrm{II})$ cations that was used as fluorogenic receptor (Figure 47). ${ }^{169}$ Water solutions (HEPES, $\mathrm{pH}=7.4$ ) of the $\left[120 \cdot \mathrm{Zn}_{2}\right]^{4+}$ complex show three well defined emission bands at 411, 432 and $457 \mathrm{~nm}$ typical of the anthracene fluorophore. Upon addition of $\mathrm{H}_{2} \mathrm{PO}_{4}{ }^{-}$anion the emission bands at 411 and $432 \mathrm{~nm}$ were slightly quenched whereas the band centred at 457 suffers a red-shift to $490 \mathrm{~nm}$ together with a remarkable enhancement in intensity. Under the same experimental conditions addition of $\mathrm{NO}_{3}^{-}, \mathrm{HCO}_{3}^{-}, \mathrm{AcO}^{-}, \mathrm{F}^{-}, \mathrm{Cl}^{-}, \mathrm{Br}^{-}, \mathrm{I}^{-}$ and $\mathrm{HSO}_{4}{ }^{-}$induced negligible changes in the emission profile of $\left[\mathbf{1 2 0} \cdot \mathrm{Zn}_{2}\right]^{4+}$ complex. 
From the least square treatment of the titration profiles with $\mathrm{H}_{2} \mathrm{PO}_{4}^{-}$, the formation of 1:1 complexes was determined. In these adducts two $\mathrm{H}_{2} \mathrm{PO}_{4}{ }^{-}$anions bind with the $\mathrm{Zn}(\mathrm{II})$ centres of two $\left[\mathbf{1 2 0} \cdot \mathrm{Zn}_{2}\right]^{4+}$ complexes leading to a conformation in which the two anthracene moieties are in close proximity inducing the apparition of an excimer emission band at $490 \mathrm{~nm}$

The anthracene-containing tripodal receptor 121 (Figure 47) forms a 1:1 complex with $\mathrm{Cu}^{2+}$. The complex contains a preorganized cavity formed by the vacant axial position of the copper atom and by a hydrogen bonding array of the amine groups. ${ }^{170}$ Acetonitrile-water $95: 5 \mathrm{v} / \mathrm{v}$ solutions of complex $[\mathbf{1 2 1} \cdot \mathrm{Cu}]^{2+}$ show the typical broad structured band of the anthracene moiety centred at $412 \mathrm{~nm}$. Addition of $\mathrm{F}^{-}, \mathrm{Cl}^{-}$, $\mathrm{Br}^{-}, \mathrm{NO}_{3}^{-}, \mathrm{AcO}^{-}$and $\mathrm{H}_{2} \mathrm{PO}_{4}^{-}$induced negligible changes in the emission intensity, whereas addition of $\mathrm{I}^{-}$induced a significant quenching. From the titration profiles the formation of $1: 1$ adducts between $\mathrm{I}^{-}$and the $[\mathbf{1 2 1} \cdot \mathrm{Cu}]^{2+}$ complex was suggested. The authors indicated that $\mathrm{I}^{-}$binds with the $[\mathbf{1 2 1} \cdot \mathrm{Cu}]^{2+}$ complex through the formation of hydrogen bonds with the aniline N-H protons. The observed quenching in the presence of $\mathrm{I}^{-}$was assigned to a photo-induced electron transfer process that is active upon anion binding.<smiles></smiles>

122<smiles>C[Si](C)(C)O[Si](C)(C)CCCSCCCN1C(=O)c2cccc3c(NCCNC(=S)Nc4ccccc4)ccc(c23)C1=O</smiles>

Fig. 48 Structure of receptors 122 and 123.

The last example in this section (product 122, see Figure 48) contains two pyrene signalling subunits and a cyclen core able to form a complex with $\mathrm{Zn}^{2+}$. ${ }^{171}$ 
Acetonitrile-water 1:9 v/v (HEPES buffered, $\mathrm{pH} 7.4$ ) solutions of $[\mathbf{1 2 2} \cdot \mathrm{Zn}]^{2+}$ show typical bands of the pyrene monomer emission centred at $375 \mathrm{~nm}$ and a weak broad band at 470 typical of the pyrene excimer emission. Addition of 20 equivalents of TMP, TDP and TTP induced a strong enhancement of the pyrene excimer band and a decrease of the pyrene monomer emission. The enhancement observed was greater for TTP (10fold) than for TDP (6-fold) and TMP (5-fold). On the other hand addition of thymine, adenine, cytosine, guanine, AMP, ADP, ATP, CMP, CDP, CTP, GMP, GDP, GTP, triphosphate, $\mathrm{P}_{2} \mathrm{O}_{7}{ }^{4-}, \mathrm{PO}_{4}{ }^{3-}, \mathrm{F}^{-}$and $\mathrm{Cl}^{-}$induced negligible changes in the emission profile. The enhancement in the emission intensity observed upon addition of TTP, TDP and TMP was a direct consequence of the binding mode. For instance it was found that the $[122 \cdot \mathrm{Zn}]^{2+}$ complex and thymidine nucleotides form 1:1 aducts in which $\mathrm{Zn}$ (II) cation binds with the deprotonated thymine heterocycle forming a Zinc-N bond. Additionally, hydrogen bonding interactions between the protonated nitrogen atoms of the receptor and the phosphate groups of the nucleotides also occurs. This host-guest ensemble adopts a conformation that brings the pyrene moieties into close proximity leading to strong excimer emission.

\subsection{2.- Containing aromatic heterocycles.}

Several aromatic heterocycles have been used as signalling subunits in the development of fluorogenic receptors for anions following the binding site-signalling subunit approach. Polysiloxane 123 (Figure 48) contains a 1,8-naphthalimide fluorophore as signalling subunit coupled with thiourea binding sites. ${ }^{172} \mathrm{UV}$-visible spectra of 123 in DMSO shows two bands at 270 and $444 \mathrm{~nm}$ assigned to the phenyl and naphthalimide moieties respectively. When the DMSO solution was excited at 450 $\mathrm{nm}$ a broad emission band at $540 \mathrm{~nm}$, characteristic of the naphthalimide fluorophore, was observed. This emission was quenched upon addition of anions. For instance, $\mathrm{Cl}^{-}$ and $\mathrm{Br}^{-}$induced a $12 \%$ quenching whereas addition of $\mathrm{HSO}_{4}^{-}$induced a $22 \%$ quenching. However the more important reductions were observed upon addition of $\mathrm{AcO}^{-}, \mathrm{HPO}_{4}{ }^{2-}$ (about $40 \%$ quenching) and $\mathrm{F}^{-}$(53\% quenching). The quenching of the emission intensity was ascribed, in all cases, to an increase in the reduction potential of the receptor upon anion binding resulting in a more effective PET process. 

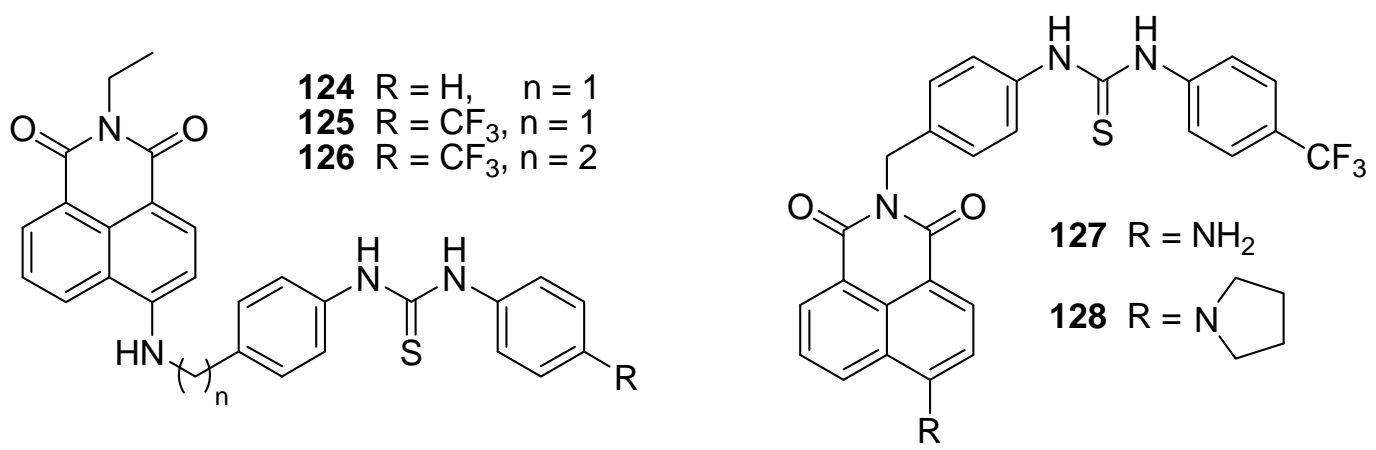

Fig. 49 Chemical structures of receptors 124-128.

Thiourea-based receptors 124-128 (Figure 49) were functionalized with naphthalimide fluorophores and their recognition properties toward anions studied in DMSO. ${ }^{173}$ The absorption spectra of these receptors showed ICT bands at 444 (for 124126), 438 (for 127) and $454 \mathrm{~nm}$ (for 128) that upon excitation gave intense emission bands at 527 (for 124-127) and $533 \mathrm{~nm}$ (for 128). Addition of basic anions such as $\mathrm{F}^{-}$ and $\mathrm{H}_{2} \mathrm{PO}_{4}{ }^{-}$to DMSO solutions of receptors 124-126 induced several quenching degrees whereas addition of $\mathrm{Cl}^{-}$and $\mathrm{Br}^{-}$did not induce any significant change in the emission profiles of the three receptors. The observed quenching was ascribed to a PET process from the coordinated anion (that forms hydrogen bonding interactions with the thiourea protons) to the photo-excited fluorophore. Addition of small quantities of $\mathrm{AcO}^{-}$to DMSO solutions of $\mathbf{1 2 5}$ and $\mathbf{1 2 6}$ induced an initial quenching followed by an important enhancement upon addition of higher concentration of anion. Nearly the same response was observed for receptors 127 and 128.

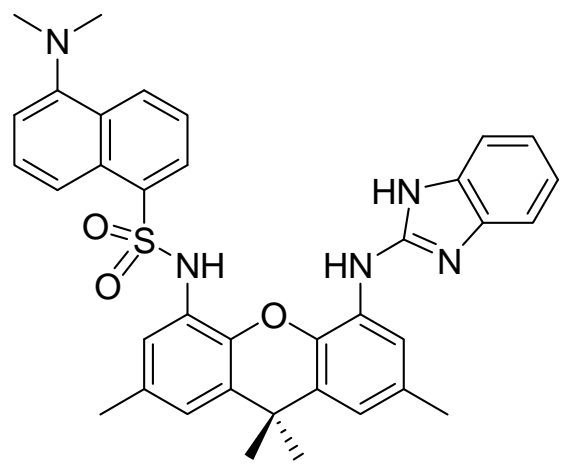

129

Fig. 50 Structure of receptor 129. 
Chloroform solutions of probe 129 (Figure 50) display a broad emission at 516 $\mathrm{nm}$ typical of the dansyl signalling subunit. ${ }^{174}$ Addition of basic anions $\mathrm{AcO}^{-}$and $\mathrm{F}^{-}$ induced large fluorescence quenching due to a deprotonation of the sulphonamide group whereas addition of $\mathrm{I}^{-}$induced a moderate quenching (20\% in intensity). Addition of other anions such as $\mathrm{Cl}^{-}, \mathrm{Br}^{-}, \mathrm{ClO}_{4}{ }^{-}$and sulphonate induced negligible changes in the emission of the dansyl fluorophore. Also receptor 129 forms a 1:1 complex with 3,5dinitrobenzoic acid resulting in a strong quenching of the emission of $\mathbf{1 2 9}$ due to an electron transfer process from the excited dansyl fluorophore to the nitro groups of the acid. This complex has been additionally used in a displacement-like assay protocol for the fluorescent detection of $\mathrm{Cl}^{-}$anion. At this respect, addition of $\mathrm{Cl}^{-}$anion restored the dansyl emission due to a rupture of the complex between 129 and 3,5-dinitrobenzoic acid. $\mathrm{Br}^{-}$anion showed a small effect whereas $\mathrm{I}^{-}$was unable to disrupt the complex.

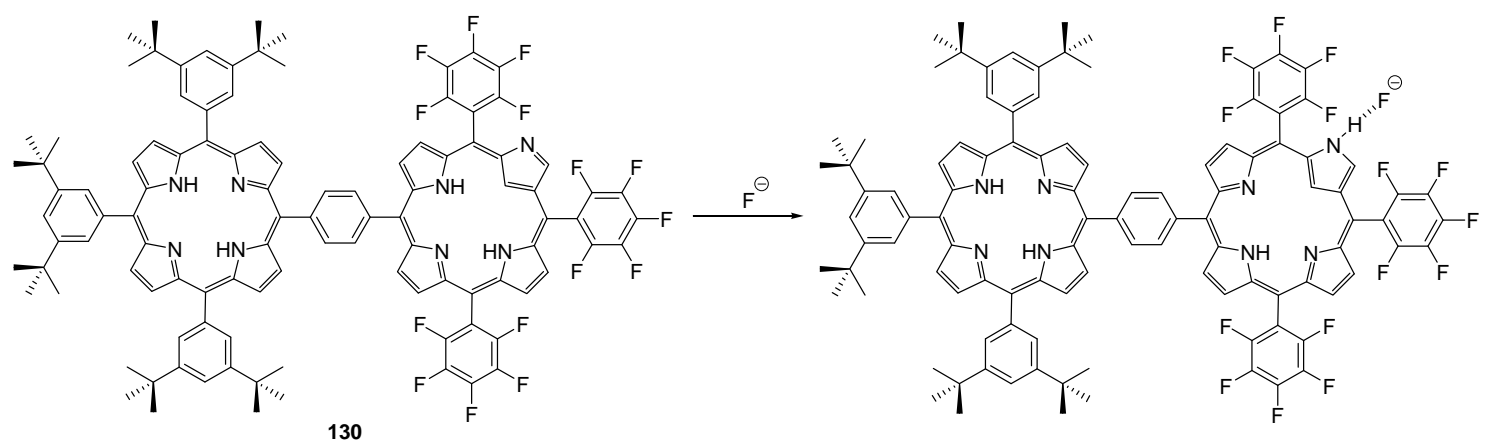

Fig. 51 Structure of $N$-confused porphyrin 130 and the proposed binding mode with $\mathrm{F}^{-}$.

The porphyrin and $N$-confused porphyrin dyad 130 (Figure 51) shows an enhancement in the emission quantum yield in the presence of $\mathrm{Cl}^{-}$and $\mathrm{F}^{-}$anions. ${ }^{175}$ Upon excitation of acetonitrile solutions of $\mathbf{1 3 0}$ at $421 \mathrm{~nm}$ the light was mainly absorbed by the porphyrin moiety and then there was a energy transfer process to the $N$ confused porphyrin that emits radiation at 730 and $803 \mathrm{~nm}$. Addition of $\mathrm{F}^{-}$and $\mathrm{Cl}^{-}$ anions induced an enhancement of the emission intensity together with a red shift of the emission bands from 730 and $803 \mathrm{~nm}$ to 703 and $765 \mathrm{~nm}$ respectively. These observations were assigned to a $\mathrm{NH}$-tautomerism process in the $\mathrm{N}$-confused porphyrin core induced by anion binding. 


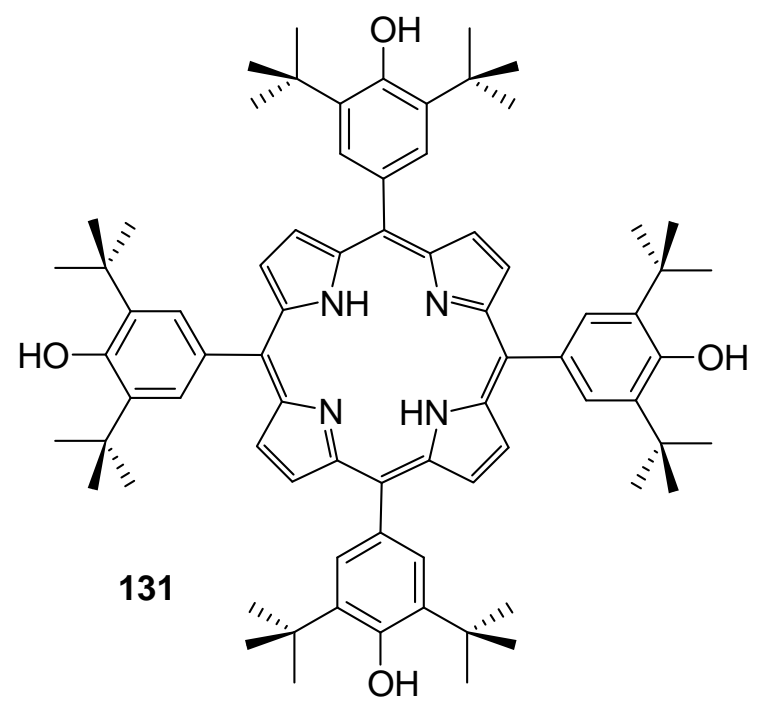<smiles></smiles>

132<smiles>C[C@H](NC(=O)Nc1ccc2c(c1)C(=O)N(Cc1ccccc1)C2=O)c1ccccc1</smiles>

133

Fig. 52 Receptors 131, 132 and 133.

Dichloromethane solutions of receptor 131 (Figure 52) show the typical emission band of the porphyrin core centred at ca. $660 \mathrm{~nm}$ that was quenched upon addition of $\mathrm{F}^{-}$anion. ${ }^{176}$ This quenching was ascribed to a deprotonation of the phenolic groups induced by $\mathrm{F}^{-}$, subsequent oxidation to an oxoporphyrinogen derivative and formation of a fluoride-oxoporphyrinogen complex. Additionally, addition of ascorbic acid induced the recovery of the emission of 131. Addition of $\mathrm{Cl}^{-}, \mathrm{Br}^{-}, \mathrm{I}^{-}, \mathrm{NO}_{3}{ }^{-}, \mathrm{BF}_{4}{ }^{-}$and $\mathrm{PF}_{6}^{-}$induced negligible changes in the emission intensity of 131. In spite of these features, the authors did not explore the possible use of the receptor as fluorescent sensor for $\mathrm{F}^{-}$detection but used the porphyrin derivative $\mathbf{1 3 1}$ as a fluoride-writable memory system based on its easy oxidizability in the presence of $\mathrm{F}^{-}$anion.

132 (Figure 52) was proved to be a selective fluoride-sensing compound in $\mathrm{CH}_{3} \mathrm{CN}$ operating in the "turn-on" mode. ${ }^{177} 132$ exhibits an absorption band at $330 \mathrm{~nm}$. Upon addition of increasing concentrations of $\mathrm{F}^{-}$, a yellow coloration became apparent, due to the development of an absorption band at $414 \mathrm{~nm}$. Moreover, the addition of $\mathrm{F}^{-}$to solutions of 132, which had initially a barely detectable fluorescence, caused the emergence of a distinct emission at $489 \mathrm{~nm}$. The recognition process was selective for $\mathrm{F}^{-}$since in the presence of other anions, including $\mathrm{Cl}^{-}, \mathrm{Br}^{-}, \mathrm{I}^{-}, \mathrm{AcO}^{-}, \mathrm{NO}_{2}^{-}$and $\mathrm{HSO}_{4}{ }^{-}$do not induce significant changes in the fluorescence spectra. Complete fluorescence 
quenching was noted however in the presence of water $(>20 \%)$. Based on proton NMR titration experiments it was suggested that the initial coordination of $\mathrm{F}^{-}$to the indole $\mathrm{NH}$ hydrogen induces a rotation of $180^{\circ}$ of the benzylic ring. Upon addition of further aliquots of $\mathrm{F}^{-}$, significant deprotonation occurs and the deprotonated indole is then stabilized by an intramolecular H-bond with the amide NH group. A locked coplanar disposition of the indole and quinoline rings ensued with consequent fluorescence enhancement and UV-vis bathochromic shift.

The phthalimide-urea chemosensor 133 (Figure 52) displays a selective fluorescent response to $\mathrm{F}^{-}{ }^{178}$ Acetonitrile solutions of $\mathbf{1 3 3}$ show an intense emission band at $430 \mathrm{~nm}$ attributed to the phthalimide fluorophore. Addition of $\mathrm{F}^{-}$induced a significant quenching with the appearance of a weak red-shifted band in the 520-550 nm range, whereas addition of $\mathrm{Cl}^{-}, \mathrm{Br}^{-}$and $\mathrm{I}^{-}$induced negligible changes. ${ }^{1} \mathrm{H}-\mathrm{NMR}$ studies indicated the formation of complexes between 133 and $\mathrm{F}^{-}$through hydrogen bonding interactions.
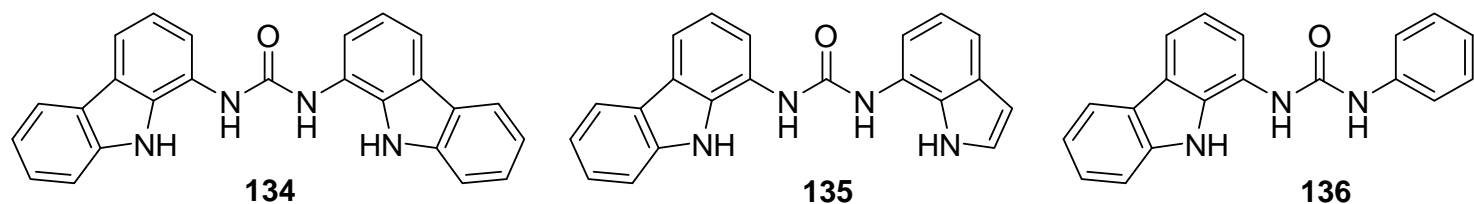

Fig. 53 Structure of urea-functionalized receptors 134-136.

DMSO-water $(99.5-0.5 \mathrm{v} / \mathrm{v})$ solutions of receptor 134 (Figure 53) display an intense emission band with maxima at 363 and $376 \mathrm{~nm}$ upon excitation at $270 \mathrm{~nm} .^{179}$ Addition of increasing quantities of $\mathrm{BzO}^{-}$induced a significant $90 \%$ quenching of the emission whereas addition of other anions induced moderate deactivations; for instance a 50, 32 and $27 \%$ quenching was found with $\mathrm{AcO}^{-}, \mathrm{H}_{2} \mathrm{PO}_{4}{ }^{-}$, and $\mathrm{HCO}_{3}{ }^{-}$respectively. Similar effects were observed with receptors 135 and 136. The quenching was ascribed to $\pi-\pi$ interactions in the excited state between the aromatic electrons of the carbazole moieties and the anions. 


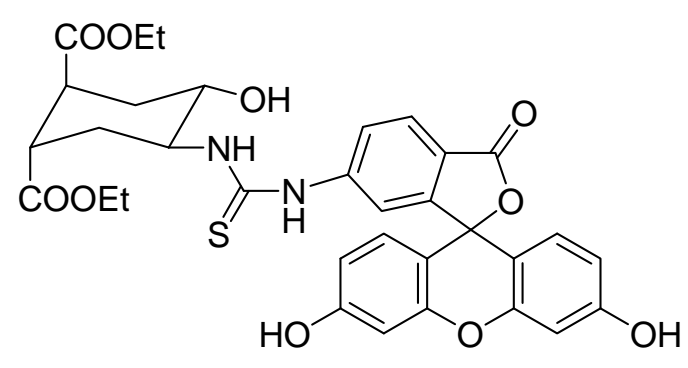

137

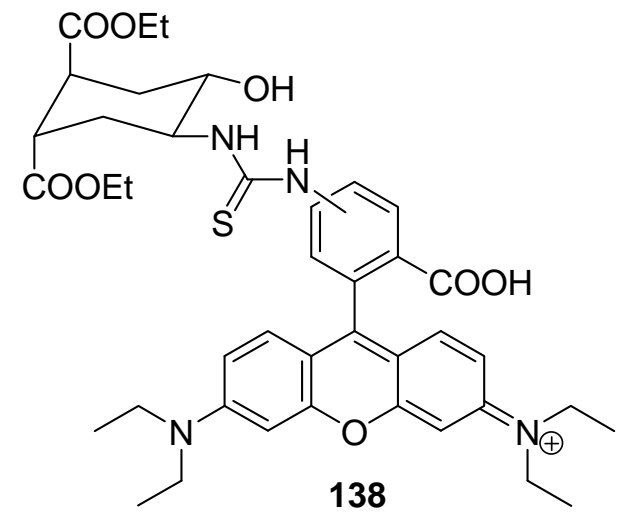

138

Fig. 54 Structure of fluorescein and rhodamine B based receptors 137 and 138.

Fluorescein and rhodamine B functionalized receptors 137 and 138 were used for the fluorescent recognition of dicarboxylate anions in DMSO-water 2:1 v/v mixtures (Figure 54). ${ }^{180}$ Receptor 137 shows an intense broad band at $520 \mathrm{~nm}$ when excited at $488 \mathrm{~nm}$, whereas 138 shows an emission band at $585 \mathrm{~nm}$ when excited at $540 \mathrm{~nm}$. The fact that the emission band of receptor 137 overlaps with the absorption band of 138, allowed their use as fluorescent chemosensors with a FRET transduction mechanism. DMSO-water 2:1 v/v solutions containing equimolecular quantities of both receptors showed an intense emission band centred at $588 \mathrm{~nm}$ upon excitation at $488 \mathrm{~nm}$. This behaviour was related with the formation of aggregates between 137 and 138 that induced the FRET process in which the energy absorbed by 137 was transferred to 138 which emits at its characteristic wavelength. Addition of $\mathrm{C}_{2} \mathrm{O}_{4}{ }^{2-}$, succinate, glutarate and adipate induced negligible changes in the emission profile which suggests that the FRET process was still operative after formation of the $\mathbf{1 3 7 \cdot 1 3 8} \cdot$ dicarboxylate complex. However, a striking result was obtained upon malonate addition that induced the development of an emission band centred at 520. This recovery of the emission of $\mathbf{1 3 7}$ was assigned to an inhibition of the FRET process due to complexation of $\mathbf{1 3 7}$ and 138 with malonate that located both fluorophores in almost orthogonal planes. 

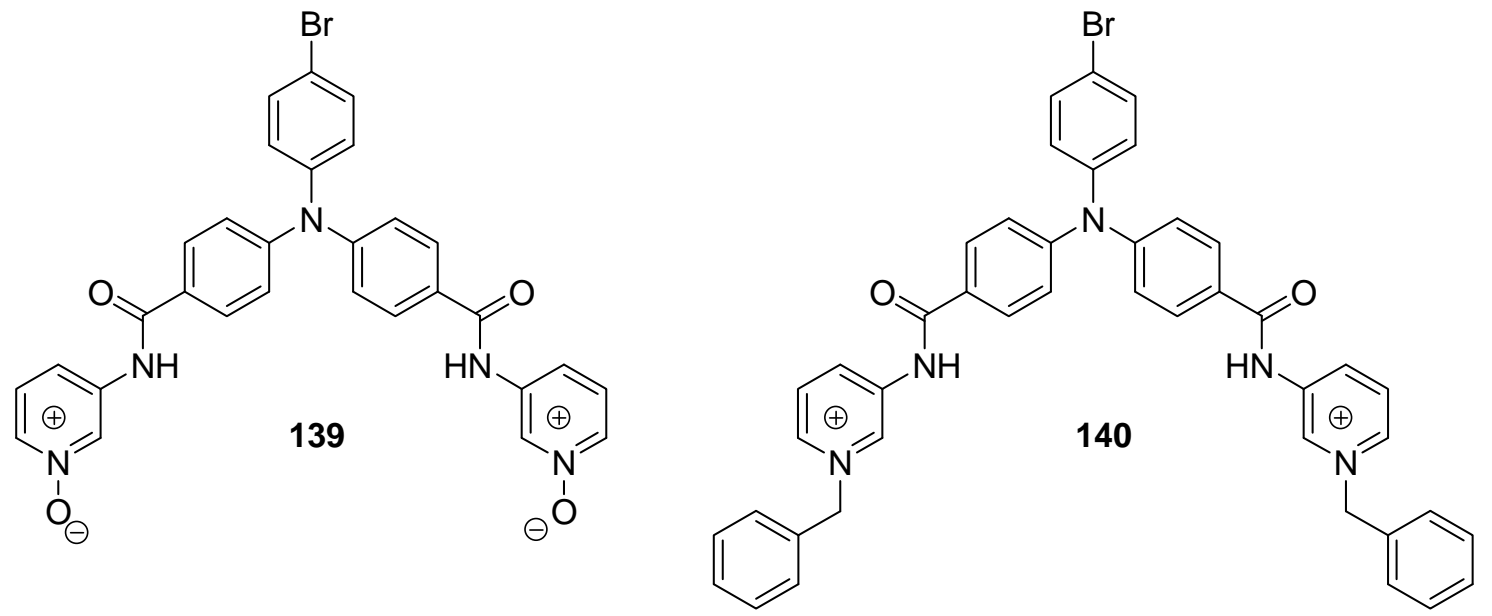

Fig. 55 Structure of receptors 139 and 140.

Triphenylamine-based receptor 139 and 140 (Figure 55) were synthesized and used for the fluorescent recognition of dicarboxylate anions. ${ }^{181}$ Both receptors contain a triphenylamine fluorophore. DMSO solutions of receptor 139 and 140 show emissions at $447 \mathrm{~nm}$ and at $443 \mathrm{~nm}$, respectively. The emission intensity of both receptors was quenched upon addition of dicarboxylates (malonate, succinate, glutarate, adipate, pimelate and suberate). For 139 the stronger deactivation was observed with shorter dicarboxylates (malonate, succinate and glutarate) that formed 1:2 host-guest complexes whereas for 140 the stronger quenching was observed for the larger dicarboxylates (pimelate and suberate) that formed 1:1 host-guest species. The formation of the complexes induced changes in the dihedral angle around the $\mathrm{N}$ atom of the triphenylamine moiety that accounted for the quenching observed.<smiles>O=c1cc(C(F)(F)F)c2ccc(/N=C/c3ccccc3O)cc2o1</smiles>

141<smiles></smiles>

142<smiles>O=C(Nc1nc2ccccc2s1)c1cccc(C(=O)Nc2nc3ccccc3s2)c1</smiles>

143

Fig. 56 Chemical structure of 141, 142 and 143.

Acetonitrile-water 1:1 v/v solutions of coumarin-based receptor 141 (Figure 56) show a weak fluorescence band at $485 \mathrm{~nm}$ due to the existence of a PET process involving the lone electron pair of the imine nitrogen and the photo-excited coumarin 
fluorophore. ${ }^{182}$ Addition of $\mathrm{HSO}_{4}{ }^{-}$anion to acetonitrile-water $1: 1 \mathrm{v} / \mathrm{v}$ solutions of $\mathbf{1 4 1}$ induced a 13-fold emission enhancement at $485 \mathrm{~nm}$ that was assigned to a suppression of the PET by the formation of hydrogen bonding interactions between the anion and the phenolic hydroxyl and the imine nitrogen of the receptor. This emission enhancement is selective and the addition of $\mathrm{F}^{-}, \mathrm{Cl}^{-}, \mathrm{Br}^{-}, \mathrm{I}^{-}, \mathrm{AcO}^{-}, \mathrm{H}_{2} \mathrm{PO}_{4}^{-}, \mathrm{NO}_{3}{ }^{-}$and $\mathrm{OH}^{-}$ anions induced no changes in the emission profile. The response of the pyrene-based receptor 142 is the same than that shown by 141; selective emission enhancement in the presence of $\mathrm{HSO}_{4}{ }^{-}$anion.

Acetonitrile-DMSO-water $(98: 1: 1 \quad \mathrm{v} / \mathrm{v} / \mathrm{v})$ solutions of benzthiazole-based receptor 143 (Figure 56) show an emission band at $452 \mathrm{~nm} .{ }^{183}$ Addition of certain anions $\left(\mathrm{F}^{-}, \mathrm{AcO}^{-}, \mathrm{HSO}_{4}^{-}, \mathrm{I}^{-}, \mathrm{Br}^{-}, \mathrm{Cl}^{-}, \mathrm{NO}_{3}{ }^{-}, \mathrm{PO}_{4}{ }^{3-}, \mathrm{HPO}_{4}{ }^{2-}\right)$ resulted in negligible changes in the emission profile whereas $\mathrm{H}_{2} \mathrm{PO}_{4}{ }^{-}$induced quenching of the emission intensity. Receptor 143 forms 1:1 complexes with $\mathrm{H}_{2} \mathrm{PO}_{4}{ }^{-}$via hydrogen bonding interactions with the amide and the nitrogen atom of the benzthiazole fluorophore.
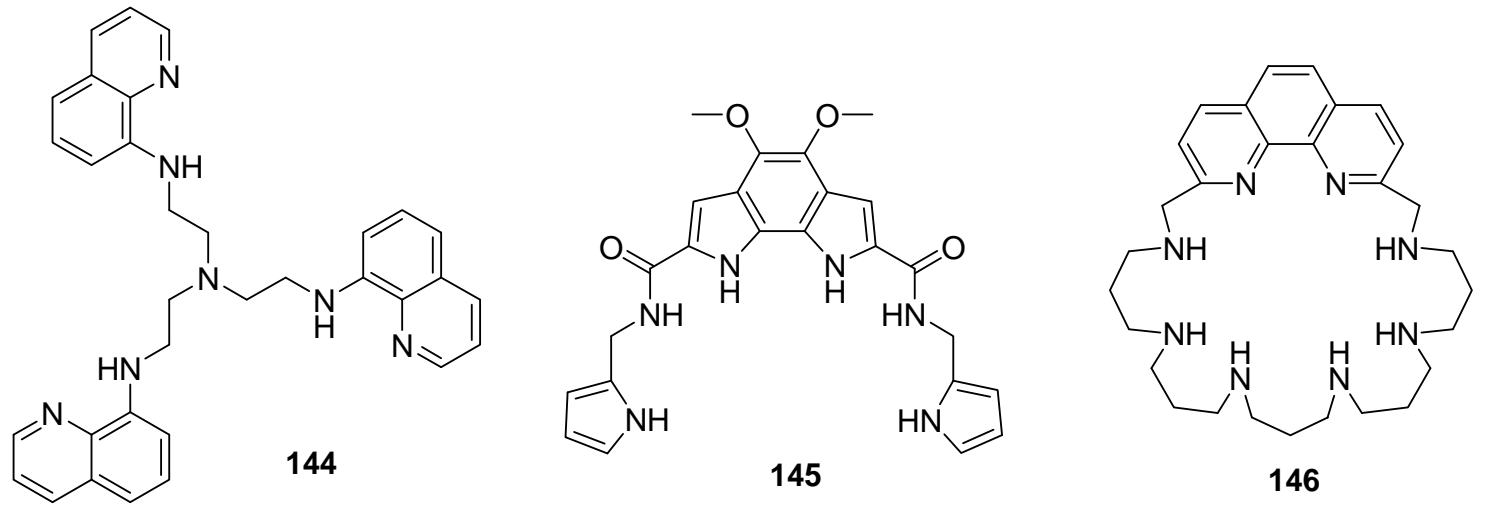

Fig. 57 Structures of receptors 144, 145 and 146.

THF solutions of the quinoline based tripodal probe 144 (Figure 57) show two emission bands at 310 (monomer) and $475 \mathrm{~nm}$ (excimer). ${ }^{184}$ Upon addition of $\mathrm{PO}_{4}{ }^{3-}$ anion a quenching of the excimer band was observed whereas the monomer band remained unaltered. Addition of $\mathrm{AcO}^{-}, \mathrm{NO}_{3}{ }^{-}, \mathrm{SO}_{4}{ }^{2-}, \mathrm{F}^{-}, \mathrm{Cl}^{-}$and $\mathrm{Br}^{-}$induced negligible changes in both emission bands. $\mathrm{PO}_{4}{ }^{3-}$ anion forms a 1:1 inclusion complex with receptor 144 which leads to the quenching of the excimer emission.

The fluorescence behaviour of the benzodipyrrole derivative 145 (Figure 57) against anions was studied in acetone-water (5\% v/v) solutions. ${ }^{185} 145$ displays an emission band at $500 \mathrm{~nm}$ whose intensity was enhanced selectively in the presence of 
$\mathrm{HP}_{2} \mathrm{O}_{7}{ }^{3-}$ whereas the addition of $\mathrm{AcO}^{-}, \mathrm{BzO}^{-}$and $\mathrm{H}_{2} \mathrm{PO}_{4}^{-}$induced negligible changes. The authors suggest that $\mathbf{1 4 5}$ have a pre-organised cavity that was able to accommodate selectively the $\mathrm{HP}_{2} \mathrm{O}_{7}{ }^{3-}$ anion through the formation of several hydrogen bonds with the $\mathrm{N}-\mathrm{H}$ moieties. The emission intensity enhancement was thus related with a rigidifying effect that the formation of the complex exerts over the structure of the receptor, which decrease the probability of a non-radiative decay.

Aqueous solutions of the phenanthroline-based polyammonium receptor 146 (Figure 57) at $\mathrm{pH} 6.0$ show an intense emission at $365 \mathrm{~nm}$ due the protonation of the six aliphatic amine nitrogen atoms that induced a suppression of a PET process that is active in the deprotonated receptor. ${ }^{186}$ Of all the nucleotide triphosphates tested (ATP, CTP, TTP and GTP) only the presence of ATP was able to include a complete quenching. A 1:1 host-guest complex is formed via strong $\pi$-stacking, charge-charge and hydrogen bonding interactions that accounts for the selectivity observed. The authors demonstrated thorough ${ }^{1} \mathrm{H}-\mathrm{NMR}$ experiments that a partial proton transfer from the benzylic amines to the phosphate chain of ATP was the responsible of the emission deactivation observed.
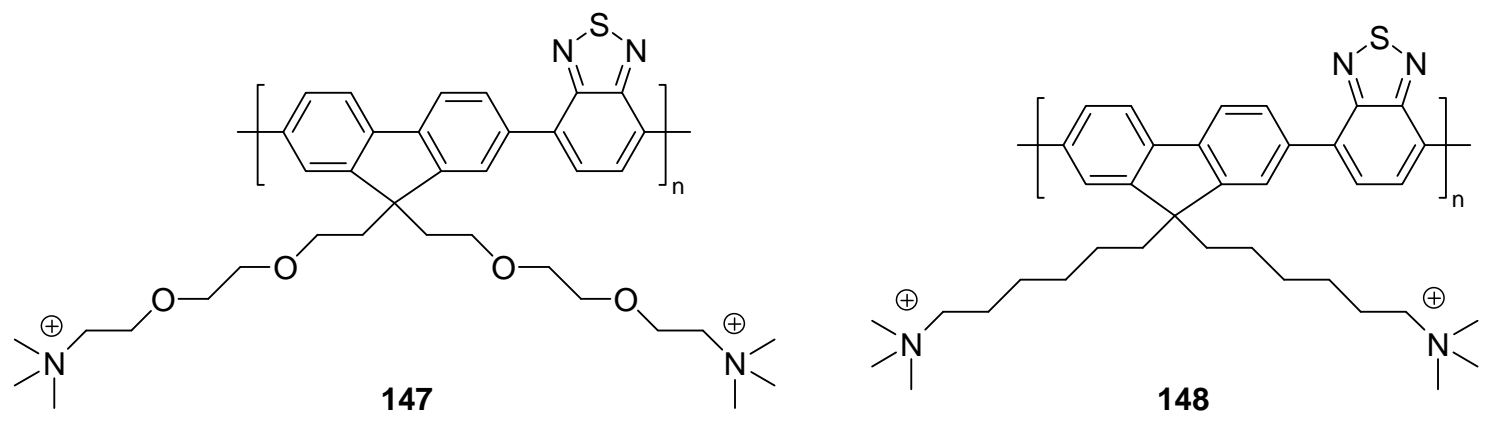

Fig. 58 Structure of sensory polymers 147 and 148.

Two cationic poly(fluorine-alt-benzothiadiazole) polymers, 147 and 148, were prepared and their sensing ability toward heparin and hyaluronic acid tested (Figure 58). ${ }^{187}$ Both polymers show a weak emission band centred at $598 \mathrm{~nm}$ in PBS at $\mathrm{pH}$ 7.4. The weak emission was due to an effective quenching of the benzothiadiazole fluorescence by water molecules. Upon addition of increasing quantities of heparin both polymers display a progressive increase in the emission intensity (22- and 6-fold for 147 and 148 respectively) that was assigned to a complexation between the polymer and the heparin which creates an hydrophobic environment that minimizes the contact between 
the polymer and water molecules. The higher enhancement observed with 147 was related with its improved water solubility due to the presence of oligo(ethylene oxide) chains. Hyaluronic acid also gave emission enhancement upon coordination but of less importance due to the fact that heparin has four negative charged side groups per repeat unit whereas hyaluronic acid only contain one negative charged group per repeat unit.

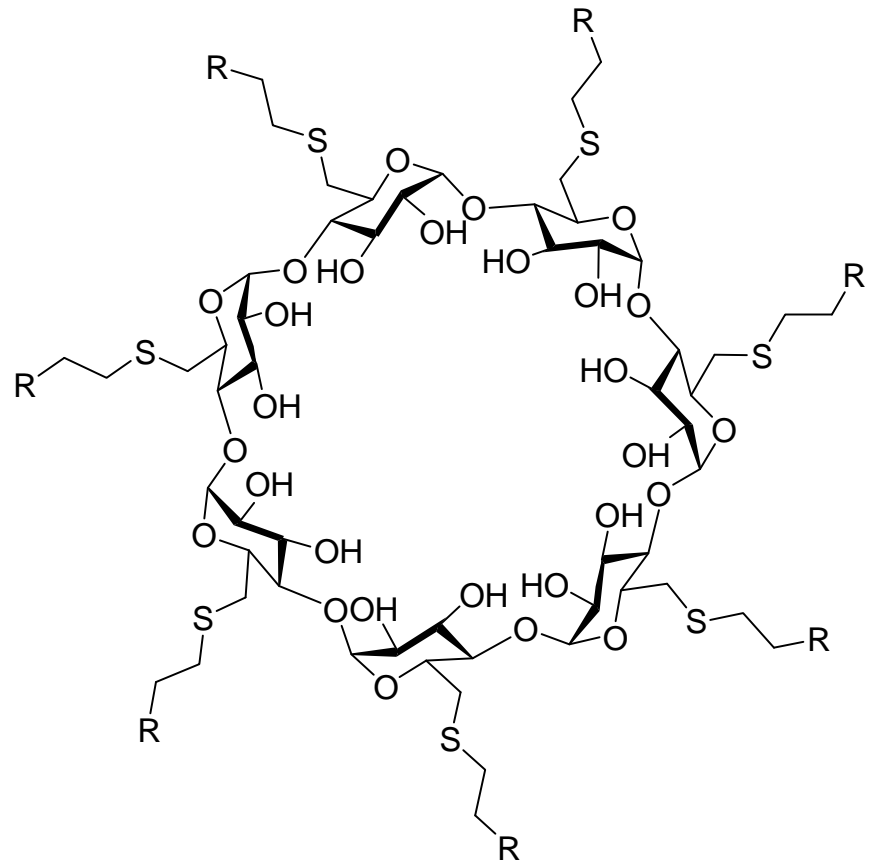

149a $\mathrm{R}=-\mathrm{NH}_{3}^{\oplus}$

$149 b$<smiles>[R]NC([NH2+])=[NH2+]</smiles>

$149 \mathrm{C}$

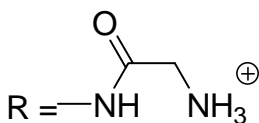

149d

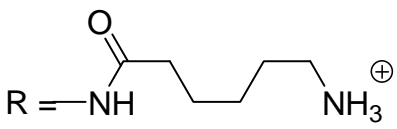

$149 \mathrm{e}$<smiles>[R]NC(=O)C(N)CCC[NH3+]</smiles>

$150 \mathrm{a} X=-\left(\mathrm{CH}_{2}\right)_{2}-$

150b $\mathrm{X}=-\left(\mathrm{CH}_{2}\right)_{4}-$

150c $\mathrm{X}=-\left(\left(\mathrm{CH}_{2}\right)_{2} \mathrm{O}\right)_{2}\left(\mathrm{CH}_{2}\right)_{2}-$

Fig. 59 Structures of $\beta$-cyclodextrin derivatives 149 and quinolinium fluorophores 150.

A modular receptor array for the recognition of negatively charged biopolymers has been developed (Figure 59) based on positively charged $\beta$-cyclodextrins (149a149e) and lithocholic acid functionalized with a quinolinium fluorophore (150a150c). ${ }^{188}$ The idea relies in the fact that lithocholic acid forms inclusion complexes with the $\beta$-cyclodextrin placing the quinolinium near the positively charged heads of 149a149e. Upon addition of the negatively charged biopolymers a binding event occurs that 
changes the environment of the fluorophore leading to a modulation of its emission. For instance, aqueous solutions (PBS buffered, 7.4) of 149a-150 complexes show weak emission that increases linearly upon addition of unfractionated heparin sulfate (UFH). The most important enhancements were obtained for 149a-150a indicating that the shorter tether brings the fluorophore closer to the polycationic binding site and thus maximizing the change in the environment experienced by the fluorophore upon UFH binding. These fluorescent receptors were used for pattern-based recognition of unfractionated and low-molecular weight heparin (UFH and LMWH), heparin sulfate (HS), dermatan sulfate (DS), chondroitin sulfate (CS), oversulfated chondroitin sulfate (OSCS), polyglutamic acid (PGA) and polyacrylic acid (PAA). The most notably result obtained with the array is the different profile for OSCS when compared to that obtained for the other polyanions. UFH and LMWH give a nearly equal response and the less charged analytes (HS, DS and PGA) also give similar patterns between them. Finally, this array was used for the accurate discrimination between heparin and common potential contaminants in a sample.

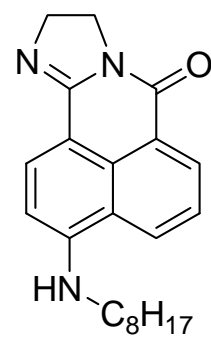

151<smiles>CCCCCCCCNc1ccc2c(=O)n3c(c4cccc1c24)=NCC3</smiles>

152
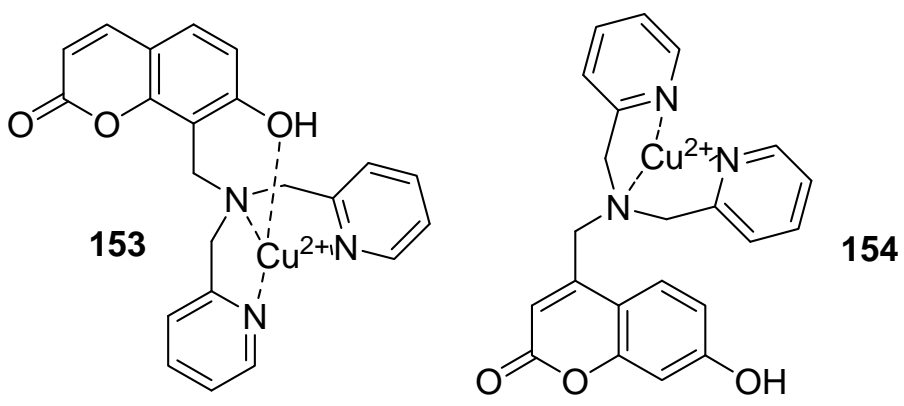

Fig. 60 Structure of receptors 151, 152 and complexes 153 and 154.

Receptors 151 and 152 (Figure 60) bearing a dihydrogen imidazo[2,1$a]$ benz $[d, e]$ isoquinolin-7-one fluorophore were prepared and used for the selective fluorogenic recognition of anionic surfactants. ${ }^{189}$ Aqueous solutions of receptor 151 buffered at $\mathrm{pH} 6.5$ show an emission band at $526 \mathrm{~nm}$. Addition of sodium dodecyl sulfate (SDS) induced a quenching of the emission intensity that reached a $91 \%$ upon addition of 3.6 mM SDS followed by an emission enhancement upon addition of larger SDS quantities. This fluorescence behaviour could be rationalised bearing in mind that at $\mathrm{pH} 6.5$ receptor 151 was protonated to some extent. The first decrease in the emission intensity was attributed to the formation of 1:1 host-guest complexes in which there is 
(i) an electrostatic interaction between the protonated nitrogen atom of $\mathbf{1 5 1}$ and the sulfate group of SDS and (ii) an hydrophobic interactions between the alkyl chains of 151 and SDS. As a consequence of this complexation, a PET process from the negatively charged sulfate group of SDS to the excited fluorophore occurs. The enhancement in the emission intensity observed upon addition of more SDS was assigned to the rupture of the 1:1 complex and inclusion of the fluorophore into the micelles formed by SDS (an hydrophobic environment that account for the intensity enhancement). Addition of cationic (cetyl trimethyl ammonium bromide) and neutral (Triton X-100) surfactants induced negligible changes in the emission profiles. Nearly the same response was obtained with receptor 152 in the presence of SDS.

The last examples of this section include the use of metal complexes to enhance selectivity and anion-host interactions. Most of the following examples display sensing features in water or mixed organic-aqueous environments. For instance the simple coumarin derivatives bearing a $\mathrm{Cu}^{2+}$ cation, 153 and 154, are able to distinguish $\mathrm{P}_{2} \mathrm{O}_{7}{ }^{4-}$ from other anions and $\mathrm{PO}_{4}{ }^{3-}$ containing compounds by changes in fluoresecence (Figure 60). ${ }^{190}$ Water solutions of complex 153 buffered at $\mathrm{pH} 7.4$ (HEPES) display a weak emission band at $450 \mathrm{~nm}$ that suffers a 3-fold intensity enhancement upon addition of $\mathrm{P}_{2} \mathrm{O}_{7}{ }^{4-}$ anion. The response was quite selective and for instance the addition of $\mathrm{PO}_{4}{ }^{3-}$, ATP, ADP, AMP, AcO $, \mathrm{HSO}_{4}^{-}, \mathrm{F}^{-}, \mathrm{Cl}^{-}, \mathrm{Br}^{-}$and $\mathrm{I}^{-}$(up to 100 equivalents) induced negligible changes in the emission band. When using complex 154 a larger fluorescence enhancement (emission band at $475 \mathrm{~nm}$ ) in the presence of $\mathrm{P}_{2} \mathrm{O}_{7}{ }^{4-}$ was observed (over 20 -fold) maintaining the same selectivity. The emission enhancement was attributed to a weakening of the $\mathrm{Cu}^{2+}$ cation - coumarin fluorophore interaction upon metal-anion coordination. 


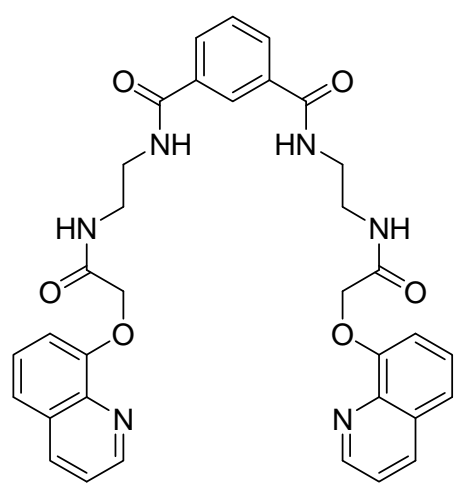

155
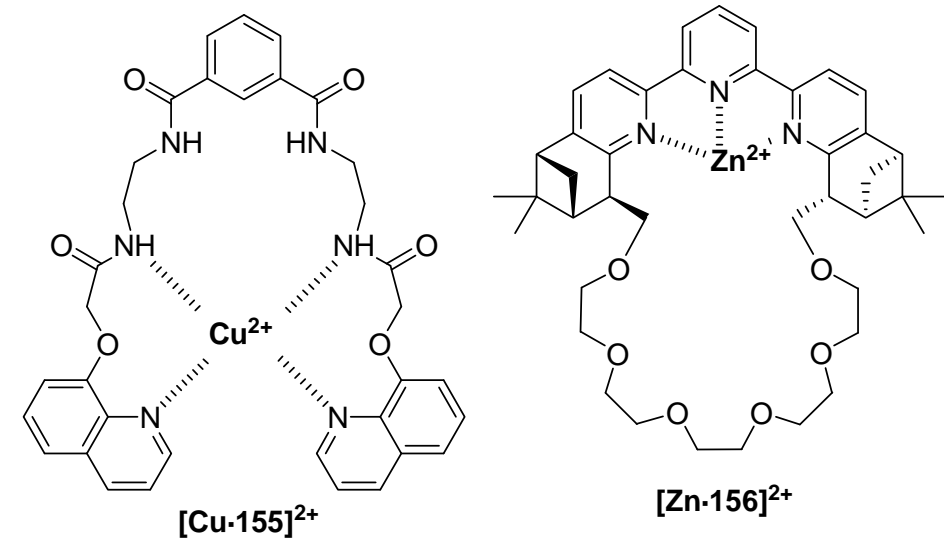

Fig. 61 Structures of $155,155 \cdot \mathrm{Cu}$ and $156 \cdot \mathrm{Zn}$.

The $[\mathrm{Cu} \cdot \mathbf{1 5 5}]^{2+}$ complex containing quinoline fluorophores was prepared and its emission behaviour studies in the presence of selected anions (Figure 61). ${ }^{191}$ Acetonitrile-water $(95: 5 \mathrm{v} / \mathrm{v})$ solutions of the $[\mathrm{Cu} \cdot 155]^{2+}$ complex show an emission band at $390 \mathrm{~nm}$. The most significant response was obtained upon addition of $\mathrm{AcO}^{-}$that resulted in an important enhancement of the emission intensity. Addition of $\mathrm{I}^{-}$, DLmalate, DL-mandelate, $\mathrm{BzO}^{-}$, isophthalate and $\mathrm{NO}_{3}{ }^{-}$induced moderate enhancements, whereas addition of $\mathrm{F}^{-}, \mathrm{Cl}^{-}, \mathrm{Br}^{-}, \mathrm{H}_{2} \mathrm{PO}_{4}^{-}$and $\mathrm{HSO}_{4}^{-}$induced weak deactivation. The authors suggested that the presence of a pre-organised cavity in the $[\mathrm{Cu} \cdot \mathbf{1 5 5}]^{2+}$ complex was the responsible of the selectivity. $\mathrm{AcO}^{-}$anion fits well in the cavity, due to its size and shape, and forms 1:1 host-guest adducts. As a consequence of this inclusion the non-radiative deactivation pathways were blocked and an emission intensity enhancement was observed.

Complex $[\mathrm{Zn} \cdot 156]^{2+}$, containing a $\mathrm{Zn}(\mathrm{II})$-terpyridine core and a crown-like ether moiety, was used for the fluorescent recognition of amino acids (Figure 61). ${ }^{192}$ DMFwater $3: 1 \mathrm{v} / \mathrm{v}$ (HEPES, pH 7.4) solutions of $[\mathrm{Zn} \cdot \mathbf{1 5 6}]^{2+}$ shows an emission band at 383 $\mathrm{nm}$ that was assigned to the terpyridine fluorophore. Addition of selected L-amino acids (phenylglycine, Phe, Val, Pro, Asp, Glu, ornithine, Ser, Cys and Asn) induced several quenching degrees in the emission, being the most important these obtained in the presence of L-aspartate and L-cysteine. The quenching of the emission intensity was ascribed to the formation of 1:1 adducts in which the carboxylate group of amino acids binds with the $\mathrm{Zn}(\mathrm{II})$ centre through electrostatic interactions, whereas the ammonium moiety coordinates with the crown ether fragment. 


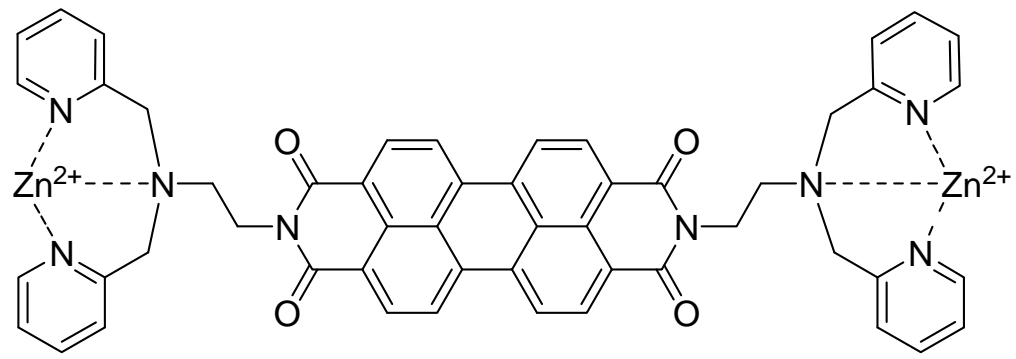

157

Fig. 62 Structure of receptor 157.

Acetonitrile-water 0.05:99.95 v/v (HEPES, pH 7.4) solutions of complex 157 (Figure 62) showed a weak emission band at $550 \mathrm{~nm} .{ }^{193}$ Addition of 100 equivalents of UTP and UDP induced remarkable enhancements in the emission intensity (more intense for UDP than for UTP), whereas CTP, $\mathrm{PO}_{4}{ }^{3-}, \mathrm{P}_{2} \mathrm{O}_{7}{ }^{4-}$, ATP, GTP, ADP, AMP and UMP induced negligible changes in the emission profiles. The authors suggest that the fluorescence enhancement of $\mathbf{1 5 7}$ is associated with the fact that binding of UTP/UDP promoted strengthening of the $\mathrm{Zn}^{2+}$ coordination with the nitrogen atoms in the tertiary amine moieties of bis(2-pyridylmethyl)amine. In fact the complex 157 shows a weak emission that the authors attributed to the predominant existence in solution of the mononuclear $\mathrm{Zn}^{2+}$ complex. Addition of UTP/UDP induced a second $\mathrm{Zn}^{2+}$ complexation, probably due to an electrostatic and coordination assistance, to give 157-UDP and 157-UTP adducts. This binding mode can induce inhibition of the electron transfer process from tertiary amine donors to the perylene singlet excited state that results in an enhancement on the emission intensity. In 157-UDP and 157-UTP adducts, one of the $\mathrm{Zn}$ (II) centres binds specifically to the uridine group while the other $\mathrm{Zn}$ (II) centre binds the phosphate groups. Finally, 157 was successfully applied to fluorimetric monitoring of a enzyme-catalyzed glycosylation process. 
<smiles>CC1=NN(CN2c3cccc4cccc(c34)N(Cn3nc(C)cc3C)C2c2ccccc2)C(C)C1</smiles>

158

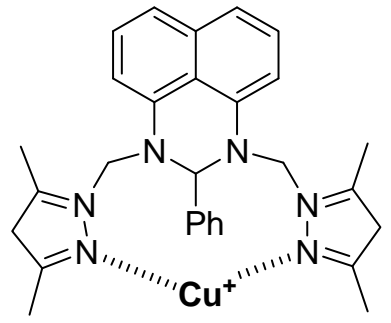

$[158 \cdot \mathrm{Cu}]^{+}$

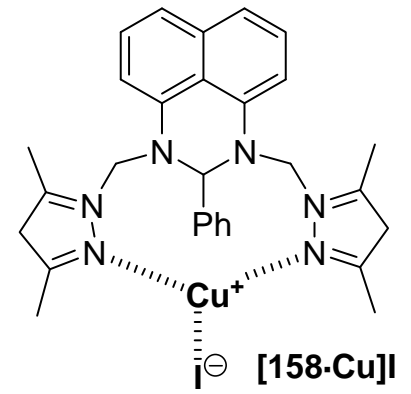

Fig. 63 Structure of receptor 158, its $\mathrm{Cu}(\mathrm{I})$ complex and the binding interaction between complex and $\mathrm{I}^{-}$anion.

Receptor 158 contains two pyrazolyl derivatives as cation binding sites and a perimidine fluorescent group as signalling subunit (Figure 63). ${ }^{194}$ Dichloromethane solutions of 158 show a broad emission band centred at $394 \mathrm{~nm}$ that was severely quenched and blue shifted $(14 \mathrm{~nm})$ upon addition of one equivalent of $\mathrm{Cu}^{+}$. The quenching observed was ascribed to the formation of the $[158 \cdot \mathrm{Cu}]^{+}$complex; the interaction of the $\mathrm{Cu}^{+}$cation with the nitrogen atoms of the pyrazolyl subunits induces an electronic perturbation in the $\pi$ network of the fluorophore. Addition of $\mathrm{I}^{-}$anion to dichloromethane solutions of the $[\mathbf{1 5 8} \cdot \mathrm{Cu}]^{+}$complex induced a moderate enhancement of the emission band and a red shift of $14 \mathrm{~nm}$. The author suggested that the formation of the $[158 \cdot \mathrm{Cu}] \mathrm{I}$ complex weakened the $\mathrm{Cu}(\mathrm{I})-\mathrm{N}$ interactions resulting in a partial enhancement of the emission.
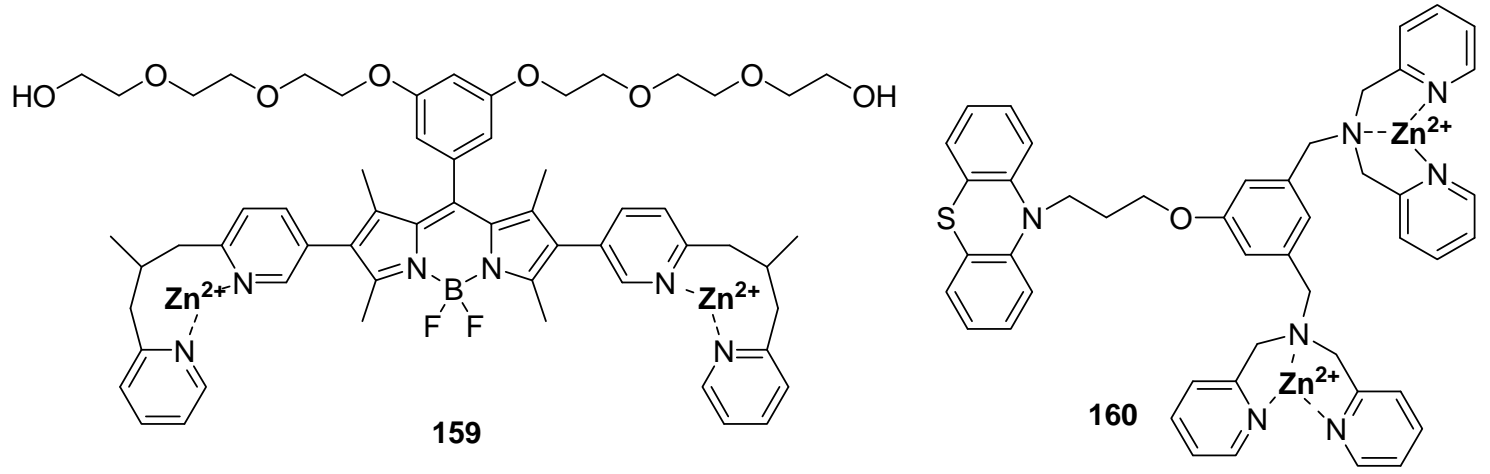

Fig. 64 Structure of fluorescent complexes 159 and 160.

159 incorporates a fluorescent BODIPY unit and two Zn(II)-2,2'-dipicolylamine groups as binding sites and was used for the detection of phosphorylated peptide fragments (Figure 64). ${ }^{195}$ Aqueous solutions (HEPES, pH 7.2) of 159 display an intense 
emission at $547 \mathrm{~nm}$ typical of the BODIPY fluorophore. Addition of phosphorylated peptides derived from the hyper-phosphorilated human tau protein induced changes in the emission intensity profile. For instance, the addition of tau(227-238)-2P peptide, with phosphor-treonine and phosphor-serine residues at $(i, i+4)$ positions, induced an increase of 1.5-fold of the emission intensity. Receptor 159 also was able to detect the bis-phosphorylated peptides $\operatorname{tau}(394-403)-2 \mathrm{P}$ and $\operatorname{tau}(204-217)-2 \mathrm{~Pa}$ and the trisphosphorylated tau(204-216)-3P all of which possesses phosphorylated residues at (i, i+4) positions. However, 159 was unable to detect tau(227-238)-1P (monophosphorylated peptide), tau(227-238)-0P (nonphosphorylated peptide) and tau(231-238)-2P and tau(204-217)-2Pb peptides, which possess two phosphorylated residues but at $(i, i+2)$ and $(i, i+6)$ positions respectively. These results indicated the preferential binding of 159 with bis-phosphorylated $(i, i+4)$ peptides giving 1:1 hostguest complexes. Finally receptor 159 was used for the in vivo detection of phosphorylated tau protein that accumulated in the neurofibrillary tangles in Alzhemimer's disease brain tissues.

160, containing two $\mathrm{Zn}(\mathrm{II})-2,2^{2}$-dipicolylamine groups as phosphate binding sites and a phenothiazine fluorophore, was used as fluorescent chemosensor for flavins (see Figure 64). ${ }^{196}$ Complex 160 FAD was non fluorescent due to a PET process from the phenothiazine donor group of $\mathbf{1 6 0}$ to the isoalloxacine ring of FAD. However, $\mathbf{1 6 0}$ was able to hydrolyze FAD to cyclic Flavin mononucleotide (cFMN) that was released to the solution resulting in a recovery of the emission band of the isoalloxacine fluorophore at $525 \mathrm{~nm}$. Flavin mononucleotide (FMN) also binds with 160 but in this case the quenching of the isoalloxacine ring was observed. Finally, riboflavin (RF) induced negligible changes in the emission intensity of the isoalloxacine because the lack of phosphate groups disables coordination with 160. This receptor was applied to the fluorescence monitoring of riboflavin kinase, alkaline phosphatase and FAD synthetase enzymes.

\subsection{3.- Lanthanide and ruthenium complexes.}

It is known that the direct excitation of the lanthanide ions is a very inefficient process and therefore emissive lanthadicde complexes usually contain an "anthena". The antenna is regularly an organic chromophore that is able, upon excitation, to transfer energy to the metal that finally emits. Related with the use of lanthanide complexes in anion signaling two basic mechanism have been reported (i) perturbation, 
upon anion binding, of the rate of the energy transfer from the antenna to the lanthanide center and (ii) the displacement of water molecules from the coordination sphere of the lanthanide centre by anions, in both cases resulting in changes in the emission intensity of the lanthanide complex. ${ }^{197,198}$

The lanthanide heteropentanuclear complexes $\left[\mathrm{Al}_{3}(\mathrm{Mq})_{4}(\mathrm{HMq})\left(\mu_{3}-\mathrm{OH}\right)_{2}(\mu-\right.$ $\left.\mathrm{OH})_{3}\left\{\mathrm{Ln}(\mathrm{hfac})_{3}\right\}_{2}\right], 14(\mathrm{Ln}=\mathrm{Nd}), 15(\mathrm{Ln}=\mathrm{Eu}), 16(\mathrm{Ln}=\mathrm{Yb})$ in which $\mathrm{Mq}=2$-methyl8-hydroxyquinolinate and $\mathrm{hfac}=$ hexafluoroacetylacetonate, have been used as luminescent sensors for $\mathrm{F}^{-}{ }^{199}$ Dichloromethane solutions of these complexes show the typical lanthanide line-like luminescence bands in the 550-1100 nm interval (upon excitation at $250<\lambda_{\text {exc }}<420 \mathrm{~nm}$ ). The intensity of the luminescence bands were enhanced upon addition of up to 0.6 equivalents of $\mathrm{F}^{-}$anion due to the formation of $\mathrm{O}$ $\mathrm{H} \cdots \mathrm{F}^{-}$bonds that minimize the nonradiative processes that were active in the complex alone. If more than 0.6 equivalents were added to dichloromethane solutions of 14-16 the lanthanide emission gradually disappear because the structure of the complex was destroyed by $\mathrm{F}^{-}$.
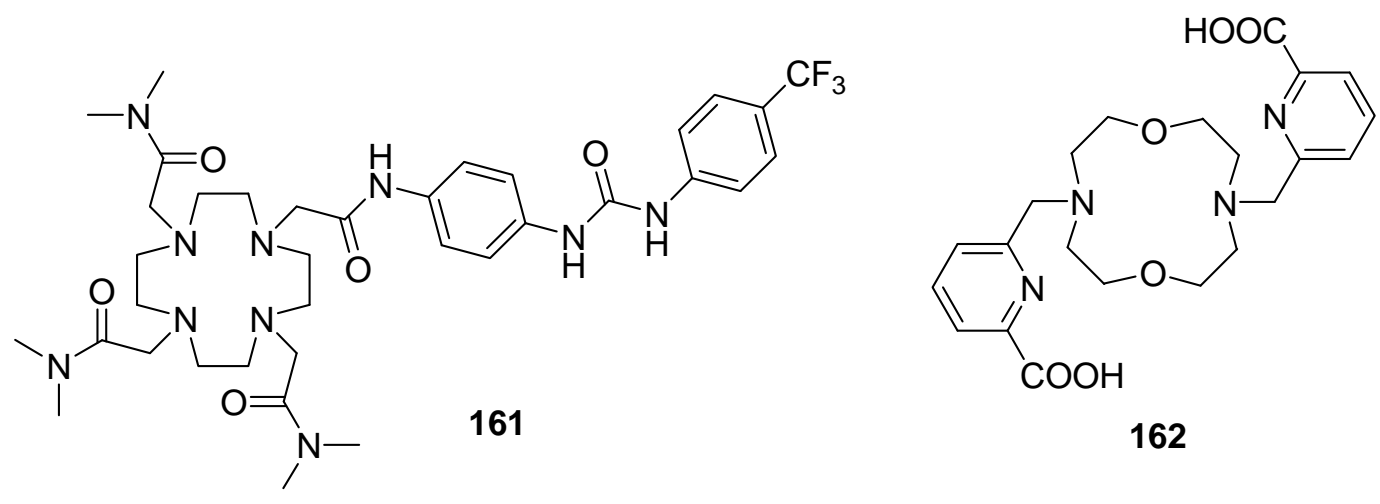

Fig. 65 Receptors 161 and 162.

Receptor 161 (Figure 65) contains a cyclen binding site and forms a luminescent complex with $\mathrm{Tb}{ }^{200}$ The 161· $\mathrm{Tb}$ complex shows three binding sites for anions namely (i) an urea group, (ii) an amide moiety and (iii) the metal centre. Acetonitrile solutions of complex 161· $\mathrm{Tb}$ showed an absorption band centred at $280 \mathrm{~nm}$ at was assigned to a $\pi-\pi *$ transition of the di-aryl amidourea antenna. Excitation at $280 \mathrm{~nm}$ gives rise to the appearance of lanthanide emission bands centred at 490, 546, 586 and $622 \mathrm{~nm}$ corresponding to the deactivation of ${ }^{5} \mathrm{D}_{4}$ to the ground states ${ }^{7} \mathrm{~F}_{J}(J=6, J=5, J=4, J=$ 3 , respectively). The fine emission bands observed were affected by the presence of anions. Addition of $\mathrm{AcO}^{-}$and $\mathrm{Cl}^{-}$induced a moderate quenching of the emission (about 
$50 \%$ ). $\mathrm{Cl}^{-}$forms 1:1 complexes through hydrogen bonding interactions with the urea moiety whereas $\mathrm{AcO}^{-}$forms $1: 1$ and $2: 1$ anion-161 ${ }^{-} \mathrm{Tb}$ complexes through hydrogen bonding interactions with the urea and amide moieties. Addition of $\mathrm{H}_{2} \mathrm{PO}_{4}{ }^{-}$induced an initial quenching of the emission intensity (70 \%) followed by a significant 14 -fold enhancement of the emission at higher anion concentration. Again the initial quenching of the emission intensity was ascribed to the formation of $1: 1$ and $2: 1$ anion-161 $\mathrm{Tb}$ complexes (through hydrogen bonding interactions with the urea and amide binding sites) whereas the enhancement was assigned to the formation of a 3:1 anion-161·Tb complex in which the third anion coordinates with $\mathrm{Tb}$ causing displacement of a water molecule from the metal coordination sphere. The behaviour of the emission intensity in the presence of $\mathrm{P}_{2} \mathrm{O}_{7}^{4-}$ and $\mathrm{F}^{-}$resembles those observed with $\mathrm{H}_{2} \mathrm{PO}_{4}^{-}$but with less prominent changes.

The europium complex of ligand 162 (Figure 65) forms ternary adducts with $\mathrm{HCO}_{3}{ }^{-}$and citrate anions. ${ }^{201}$ Water solutions of complex $\left[(\mathrm{Eu} \cdot \mathbf{1 6 2})\left(\mathrm{H}_{2} \mathrm{O}\right)_{\mathrm{q}}\right]^{+}(\mathrm{HEPES}$, $\mathrm{pH}$ 7.4) show the typical metal centred ${ }^{5} \mathrm{D}_{0} \rightarrow{ }^{7} \mathrm{~F}_{J}$ transitions $(J=0-4)$ upon excitation at $272 \mathrm{~nm}$. Addition of $\mathrm{HCO}_{3}{ }^{-}$and citrate induced an important increase in the hypersensitive ${ }^{5} \mathrm{D}_{0} \rightarrow{ }^{7} \mathrm{~F}_{2}$ transition while the intensity of the remaining transitions increased to a lesser extent. These enhancements in intensity where ascribed to the substitution of coordinated water molecules by the anions.
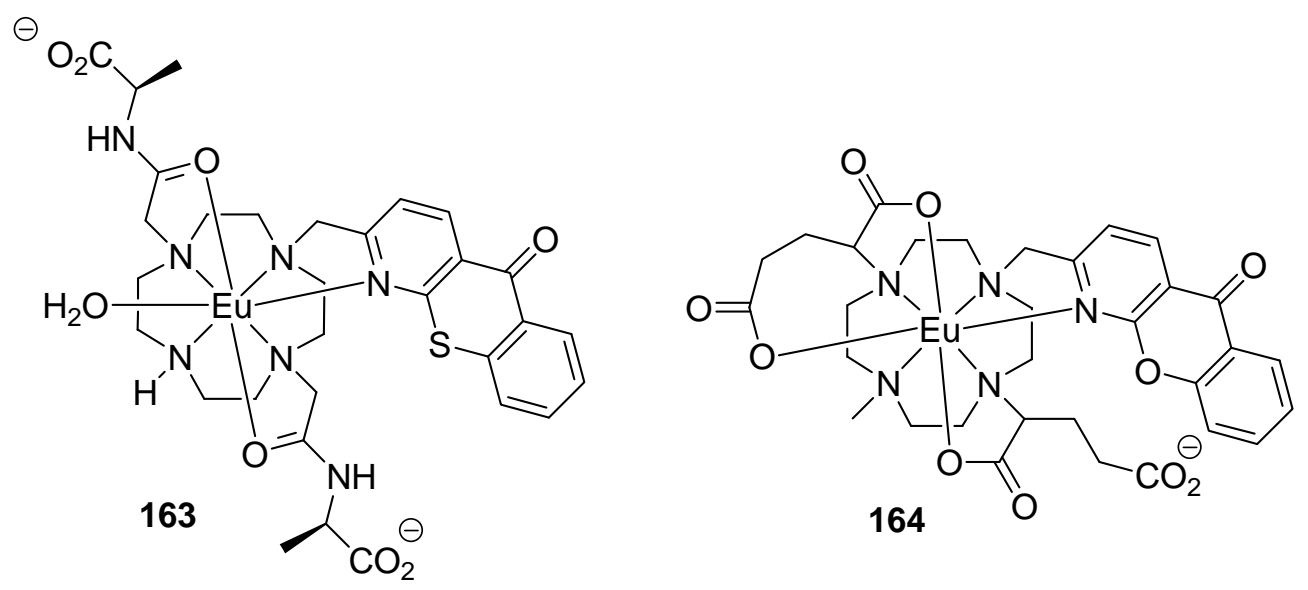

Fig. 66 Structure of europium complexes 163 and 164.

Costello et al. prepared nine europium luminescent complexes and tested their ability to sense lactate and citrate in biological fluids. ${ }^{202}$ The best results in terms of selectivity were obtained with 163 and 164 (Figure 66). A water solution (HEPES, pH 6.5) of receptor $\mathbf{1 6 3}$ displays the typical fine bands of the europium sensitized emission 
(excitation to the azathiaxanthone antenna at $380 \mathrm{~nm}$ ). Addition of increasing quantities of citrate induced a selective moderate quenching with a $42: 1$ ratio in the affinity constants for the binding of citrate vs. lactate. The reverse selectivity was observed with 164 in water (HEPES, pH 6.5) upon excitation in the azaxanthone chromophore at 337 $\mathrm{nm}$; i.e. the ratio in the affinity constants for lactate vs. citrate amounts to 30:1. The observed deactivation of the luminescence arises from the competitive displacement of the intramolecularly bound carboxylates by the added oxyanions that induced changes in the coordination environment of the $\mathrm{Eu}(\mathrm{III})$ centre.

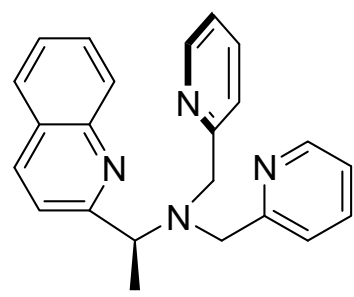

165

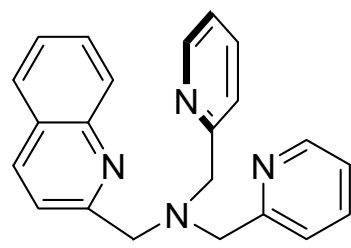

166

Fig. 67 Structure of tripodal receptors 165 and 166.

The tripodal ligands 165 and $\mathbf{1 6 6}$ form lanthanum and europium complexes that were able to recognize anions (Figure 67). ${ }^{203}$ Acetonitrile solutions of [La·165] ${ }^{3+}$ show an emission band at 375 (excitation at $316 \mathrm{~nm}$ ) that was ascribed to the quinoline fluorophore. Addition of $\mathrm{NO}_{3}^{-}$to acetonitrile solutions of the $[\mathrm{La} \cdot 165]^{3+}$ complex induced a remarkable emission enhancement (13-fold) whereas $\mathrm{Cl}^{-}, \mathrm{Br}^{-}, \mathrm{I}^{-}, \mathrm{SCN}^{-}, \mathrm{HSO}_{4}^{-}$ , $\mathrm{H}_{2} \mathrm{PO}_{4}{ }^{-}$and $\mathrm{AcO}^{-}$induced moderate enhancements. Nearly the same emission response was obtained with $[\mathrm{La} \cdot \mathbf{1 6 6}]^{3+}$ but in this case the enhancement in the presence of $\mathrm{NO}_{3}{ }^{-}$ was modest (1.4-fold). The selectivity was reversed when using $[\mathrm{Eu} \cdot 165]^{3+}$. Acetonitrile solutions of $[\mathrm{Eu} \cdot \mathbf{1 6 5}]^{3+}$ show the emission band at $613 \mathrm{~nm}$ when excited at $316 \mathrm{~nm}$. This emission suffers a 70-fold enhancement upon addition of $\mathrm{Cl}^{-}$anion whereas addition of $\mathrm{NO}_{3}{ }^{-}$induced a 25 -fold enhancement. This remarkable selectivity was not observed in $[\mathrm{Eu} \cdot 166]^{3+}$; the presence of $\mathrm{Cl}^{-}$and $\mathrm{NO}_{3}{ }^{-}$induced both a 20 -fold enhancement of the intensity of the luminescence band centred at $613 \mathrm{~nm}$. 


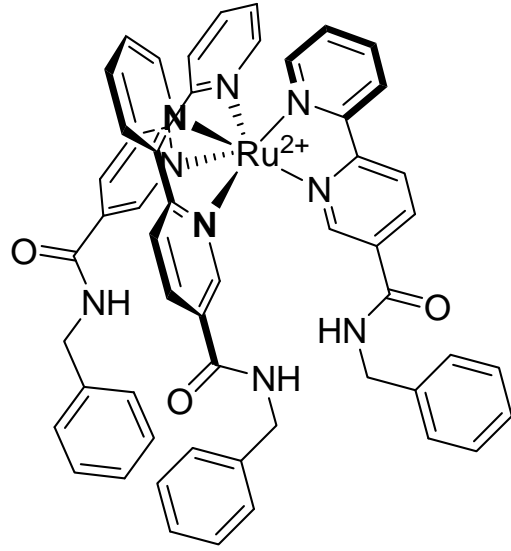

167

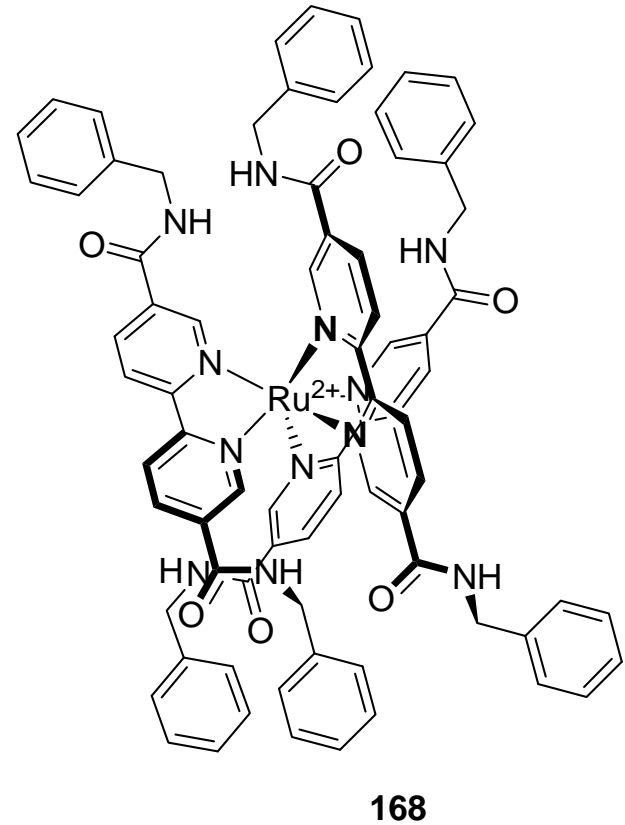

Fig. 68 Structure of ruthenium complexes 167 and 168.

The Ru(bipy) ${ }_{3}{ }^{2+}$ moiety has been widely used in the development of fluorogenic anion sensors. The photochemistry of the $\mathrm{Ru}$ (bipy) ${ }_{3}{ }^{2+}$ metal complex framework is very well known. The lowest energy absorption band in this core is due to a Metal-to-Ligand Charge Transfer (MLCT) transition that appears at ca. $450 \mathrm{~nm}$. Excitation to this band gave emission usually in the $600-700 \mathrm{~nm}$ range. Acetonitrile solutions of receptors 167 and 168 show a weak broad emission band centred at 630 and $650 \mathrm{~nm}$ respectively, upon excitation at $450 \mathrm{~nm}$ (Figure 68). ${ }^{204}$ Addition of $\mathrm{Cl}^{-}, \mathrm{Br}^{-}$and $\mathrm{NO}_{3}{ }^{-}$anions induced no significant changes in the luminescence profile whereas addition of $\mathrm{H}_{2} \mathrm{PO}_{4}{ }^{-}$and $\mathrm{HSO}_{4}{ }^{-}$induced a more complex response. Both anions display the same behaviour; namely negligible changes upon the addition of one equivalent of anion followed by a substantial quenching and a bathochromic shift upon addition of more equivalents. Coordination of both anions with the amide subunits, through the formation of hydrogen bonds, induced a distortion in the receptor around the metal centre that encourages the spin forbidden relaxation from the excited triplet state. 

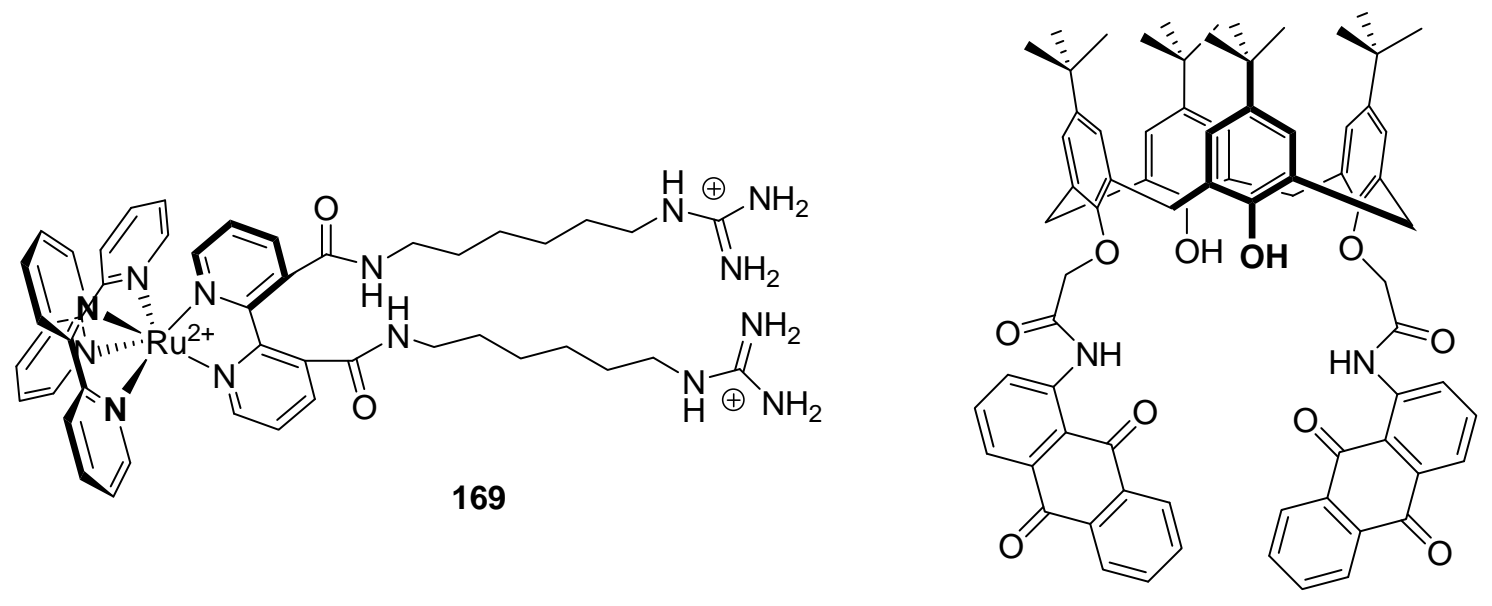

170

Fig. 69 Structure of 169 and 170.

Receptor 169 (Figure 69) is a bipyridylruthenium(II) complex functionalised with two guanidinium binding sites that is able to display anion analysis using photoluminescence and electrochemiluminescence. ${ }^{205}$ Acetonitrile solutions of 169 show a broad MLCT emission band at $712 \mathrm{~nm}$ upon excitation at $490 \mathrm{~nm}$. Addition of L-Glu induced a significant 4-fold increase in the emission intensity coupled with a hypsochromic shift in the maximum emission wavelength. The same response but with a lower enhancement (3-fold) was observed upon addition of $\mathrm{H}_{2} \mathrm{PO}_{4}^{-}$, whereas addition of $\mathrm{AcO}^{-}, \mathrm{Cl}^{-}$and $\mathrm{I}^{-}$induced negligible changes. The emission enhancements observed upon addition of L-Glu and $\mathrm{H}_{2} \mathrm{PO}_{4}{ }^{-}$were ascribed to a rigidification of the receptor upon coordination of the anions with the guanidinium moieties through electrostatic and hydrogen bonding interactions. The selectivity was reversed in electrochemiluminescence measurements and in this case only the addition of $\mathrm{H}_{2} \mathrm{PO}_{4}{ }^{-}$to acetonitrile solutions of $\mathbf{1 6 9}$ containing $n$-tripropylamine (used as co-reactand) was able to induce an increase in intensity. Such behaviour is related to the different oxidation potentials of $\mathrm{H}_{2} \mathrm{PO}_{4}{ }^{-}$and L-Glu.

\subsection{4.- Miscellaneous.}

New chemosensor 170 (Figure 69), with two aminoanthraquinone groups linked to the lower rim of a $p$-tert-butylalix[4]arene, exhibited a selective fluorescence response to $\mathrm{F}^{-}{ }^{206}$ The solvent dependency (polarity changed absorption spectra of 170) was the first evidence to show that ESIPT (state intramolecular proton transfer) took 
place with the transfer of the amide NH hydrogen to the neighbouring oxygen atom in the excited state. Variations of UV-vis and fluorescence spectra of $\mathbf{1 7 0}$ in the presence of various anions including $\mathrm{F}^{-}, \mathrm{Cl}^{-}, \mathrm{Br}^{-}, \mathrm{I}^{-}, \mathrm{CH}_{3} \mathrm{COO}^{-}, \mathrm{HSO}_{4}^{-}, \mathrm{H}_{2} \mathrm{PO}_{4}^{-}$and $\mathrm{OH}^{-}$in $\mathrm{CH}_{3} \mathrm{CN}$ led to conclude that both significant absorption change in the visible region (from paleyellow to deep-yellow, appearing a new red-shifted absorption band at $510 \mathrm{~nm}$ ) and "off-on" fluorescence changes (emission peaks at 527 and $560 \mathrm{~nm}$ ) only occurred upon $\mathrm{F}^{-}$addition. Finally some comparison experiments with a similar chemosensor with only one amidoanthraquinone group led to the conclusion that two amido $\mathrm{NH}$ functional linkers-1-amidoanthraquinone are needed for selectivity.

\section{2.- The displacement approach.}

This approach has also been widely used for the development of probes for the fluorogenic detection of anions. ${ }^{207-210}$ Most of the reported systems involve the formation of an ensemble between a certain metal complex and a fluorophore. Addition of a target anion, for which the metal complex has a high affinity, results in a displacement of the fluorophore. Also some few examples use anion-induced "displacements" of coordinated metals as signalling protocols.

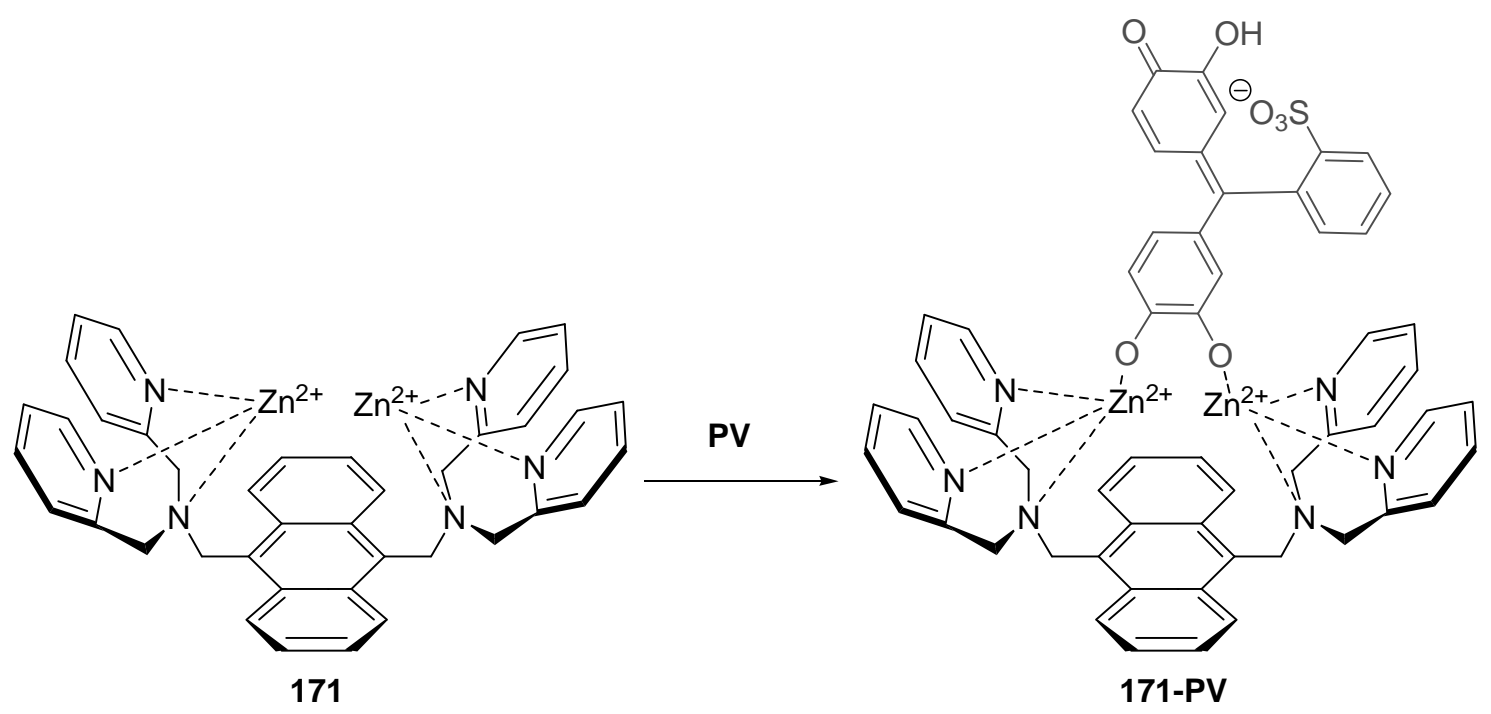

Fig. 70 Structure of complex $\mathbf{1 7 1}$ and its sensing ensemble with PV.

The first example in this section reports the formation of the ensemble 171-PV for the detection of ATP (Figure 70). ${ }^{211}$ Fluorescence changes of the ensemble 171-PV in water (Trizma buffer at $\mathrm{pH}$ 7.2) in the presence of various amounts of ATP were examined, resulting in a large enhancement of fluorescence with a noteworthy detection 
range. Another remarkable behaviour of the chemosensing ensemble 171-PV was its selectivity towards ATP over other anions such as ADP.

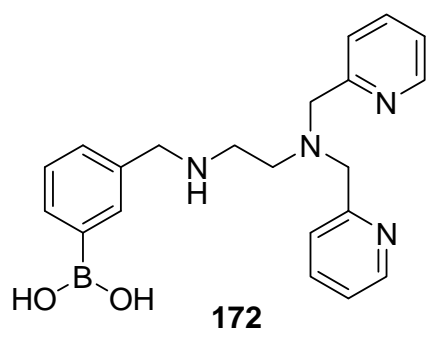

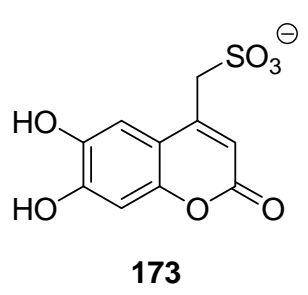

173

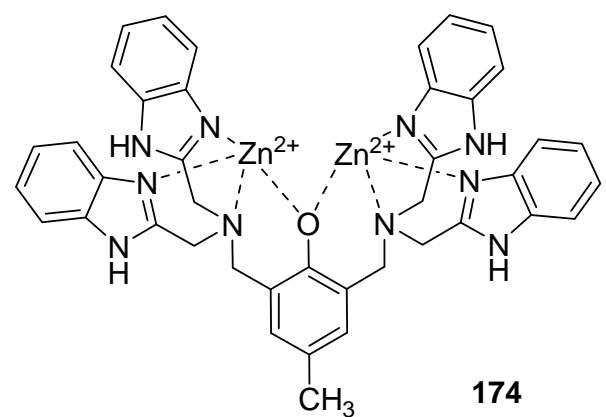

Fig. 71 Structure of receptor 172, coumarin derivative 173 and complex 174.

Receptor 172 bearing boronic acid and dipicolylamine fragments forms a complex with $\mathrm{Zn}^{2+}$ that was used together with the fluorophore 6,7-dihydroxycoumarin4-methanesulfonate (173) in an displacement assay for the fluorescent sensing of phosphosugars (Figure 71). ${ }^{212} \mathbf{1 7 3}$ in buffered water at $\mathrm{pH} 7.4$ shows an emission at 485 $\mathrm{nm}$. This emission band increased in intensity upon addition of the $\mathbf{1 7 2} \cdot \mathrm{Zn}$ complex due to the formation of the $\mathbf{1 7 3 - 1 7 2 \cdot} \mathrm{Zn}$ ensemble via boronate esterification of $172 \cdot \mathrm{Zn}$ with the dihydroxy moieties of $\mathbf{1 7 3}$ and electrostatic interactions between the $\mathrm{Zn}^{2+}$ cation and the sulfonate group of 173. Addition of D-fructose-6-phosphate (F6P) to 173-172-Zn induced a decrease in the emission intensity due to the formation of the corresponding F6P-172. $\mathrm{Zn}$ complex and release of fluorophore 173 to the solution. D-ribose-5phosphate (R5P) and D-fructose-1,6-diphosphate (F1,6P) induced nearly the same quenching than that observed with F6P, whereas D-glucose-6-phosphate (G6P) and $\alpha$ D-glucose-1-phosphate (G1P) induced weak emission changes.

The dinuclear $\mathrm{Zn}$ complex, 174, (as receptor) and fluorescein (as indicator) formed an ensemble for $\mathrm{P}_{2} \mathrm{O}_{7}{ }^{4-}$ recognition in water at physiological $\mathrm{pH}$ (Figure 71). ${ }^{213}$ The fluorescence emission of 1:1, 174-fluorescein, solutions (HEPES at $7.4 \mathrm{pH}$ ), that were completely quenched in origin, was studied upon addition of $(\mathrm{COO})_{2}{ }^{2-}, \mathrm{HSO}_{4}^{-}$, $\mathrm{PO}_{4}{ }^{2-}, \mathrm{CH}_{3} \mathrm{COO}^{-}, \mathrm{I}^{-}, \mathrm{Br}^{-}, \mathrm{Cl}^{-}, \mathrm{F}^{-}$and $\mathrm{P}_{2} \mathrm{O}_{7}{ }^{4-}$. Only $\mathrm{P}_{2} \mathrm{O}_{7}{ }^{4-}$ was able to displace the indicator from the ensemble and caused significant fluorescence revival. 


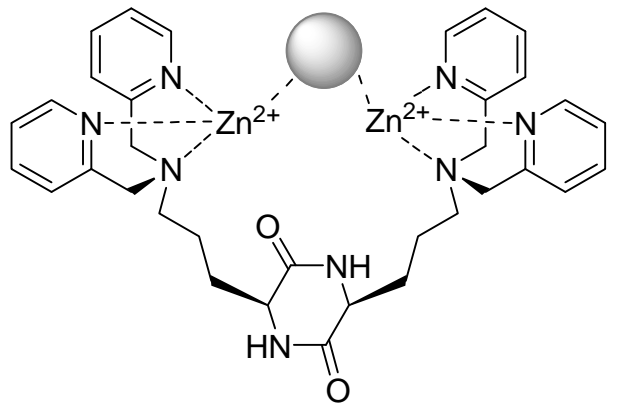

175

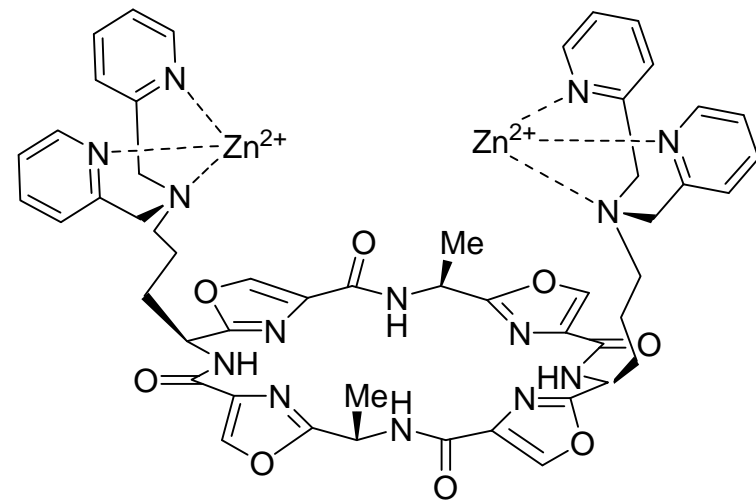

pre-175

Fig. 72 Structures of 175 and pre-175.

Anion binding capabilities of a diketopiperazine-based receptor 175 bearing two $\mathrm{Zn}$ (II) dipicolylamino binding sites was studied by using an indicator displacement assay with a fluorescent coumarin derivative (Figure 72). ${ }^{214} \mathbf{1 7 5}$ was able to quench the fluorescence emission of coumarin at $37^{\circ} \mathrm{C}$ in water (HEPES, $\mathrm{pH} 7.4$ and $\mathrm{NaCl}$ to mimic physiological $\mathrm{pH}$ and ionic strength). The titration profiles indicated the formation of a 1:1 complex between 175 and coumarin. An equimolar solution of $\mathbf{1 7 5}$ and coumarin $\left(10 \mu \mathrm{M}\right.$ each) was then titrated with aliquots of the anions $\mathrm{NO}_{3}{ }^{-}, \mathrm{SO}_{4}{ }^{2-}$, $\mathrm{Br}^{-}, \mathrm{I}^{-}, \mathrm{AcO}^{-},(+)$-tartrate, citrate, $\mathrm{HPO}_{4}{ }^{2-}, \mathrm{P}_{2} \mathrm{O}_{7}{ }^{4-}$, phosphotyrosine, phosphothreonine, AMP, cAMP, ADP, ATP and GTP. Selectivity fluorescence enhancement for di- and triphosphate oxoanions over all other anions was observed in the order: $\mathrm{P}_{2} \mathrm{O}_{7}{ }^{4-}>\mathrm{ATP} \approx$ GTP $>$ ADP. These results are not as selective as the ones obtained in a previously study using receptor pre-175, ${ }^{215}$ which better matches to $\mathrm{P}_{2} \mathrm{O}_{7}{ }^{4-}$ due to the larger distance between the two $\mathrm{Zn}(\mathrm{II})$ metal centres. The work points towards the importance of the correct scaffold choice in the design of receptors for phosphate oxoanions.

The two following examples use $\mathrm{Zn}$ complexes that act themselves as fluorogenic chemosensors and additionally have also been used in displacement protocols. 

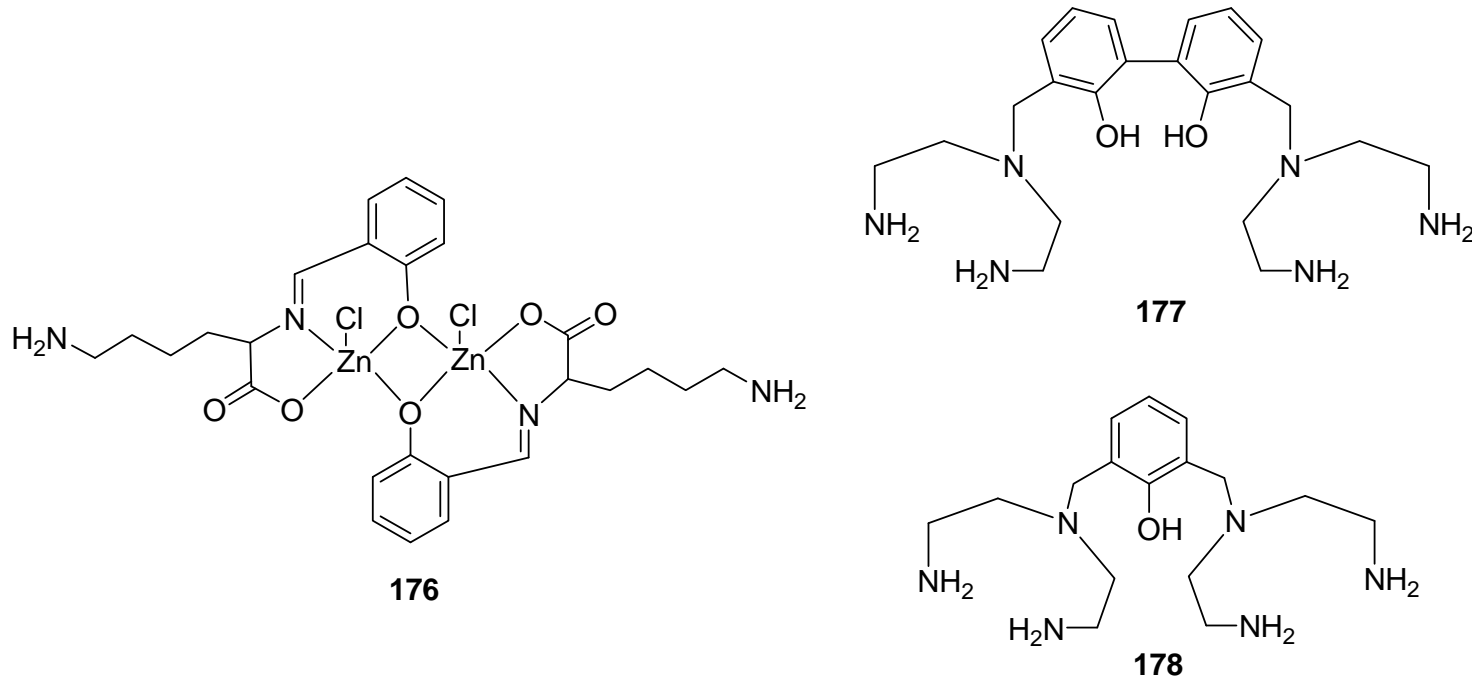

Fig. 73 Structure of receptors 176, 177 and 178.

Fluorimetric and colorimetric sensing of phosphate ions by the fluorescent dinuclear chiral $\mathrm{Zn}$ complex 176 (Figure 73) in water at physiological pH was reported. ${ }^{216}$ Compound 176 exhibits an intense blue fluorescence $\left(\lambda_{\mathrm{em}}=453 \mathrm{~nm}\right)$ in neutral aqueous conditions (HEPES buffer, $\mathrm{pH}$ 7.4) due to the 2-hydroxybenzylidene amino group in which $\mathrm{C}=\mathrm{N}$ isomerisation was inhibited because of $\mathrm{Zn}^{2+}$ complexation. After addition of $\mathrm{P}_{2} \mathrm{O}_{7}^{4-}$ the fluorescence intensity decreased. This quenching was ascribed to the fact that anion binding with the $\mathrm{Zn}$ centres induced a weakening in the $\mathrm{Zn}-\mathrm{N}$ and $\mathrm{Zn}-\mathrm{O}$ bonds. As a consequence the $\mathrm{C}=\mathrm{N}$ isomerisation was allowed thus inducing fluorescence quenching. Comparatively small fluorescence quenching was observed for ATP and ADP. Colorimetric sensing was also studied in a displacement assay using pyrocatechol violet (PV). Titration of $\mathbf{1 7 6}$ with PV led to a gradual decrease of the intense absorption at $440 \mathrm{~nm}$, while a band at $601 \mathrm{~nm}$ concomitantly increased. Reversibility was proved when 2 equiv. of $\mathrm{P}_{2} \mathrm{O}_{7}{ }^{4-}$, ATP and ADP were added and the yellow colour of PV was restored (a binding tendency $\mathrm{P}_{2} \mathrm{O}_{7}{ }^{4-} \geq$ ATP $>$ ADP was observed). Other anions (halides, $\mathrm{CO}_{3}{ }^{2-}, \mathrm{AcO}^{-}$and $\mathrm{PO}_{4}{ }^{3-}$ ) did not induce colour recovery.

Two $\mathrm{Zn}(\mathrm{II})$-dinuclear complexes prepared with the aza-phenolic ligands $\mathbf{1 7 7}$ and 178 were used as inorganic phosphate fluorescent receptors (see Figure 73). ${ }^{217}$ Water solutions (TAPS, $\mathrm{pH} \mathrm{8.3)}$ ) of the Zn-177 complex show an emission band at $379 \mathrm{~nm}$ that was quenched (4-fold) upon addition of increasing quantities of $\mathrm{PO}_{4}{ }^{3-}$, whereas addition of $\mathrm{P}_{2} \mathrm{O}_{7}{ }^{4-}$ induced a moderate emission enhancement with a red shift from 379 to 395 
nm. On changing to the $\mathrm{Zn-178}$ complex, $\mathrm{P}_{2} \mathrm{O}_{7}{ }^{4-}$ basically does not affect the emission of the system while $\mathrm{PO}_{4}{ }^{3-}$ slightly decreased the emission and shifted the $\lambda_{\text {em }}$ from 308 to $313 \mathrm{~nm}$. This different behaviour were ascribed to the different $\mathrm{Zn}$ (II)- $\mathrm{Zn}$ (II) distances between the two metal centres when using 177 or 178 as ligands. Moreover, with the aid of an external dye pyrocatechol violet (PV), the receptors were used to produce the simple signalling systems 177-PV and 178-PV for phosphates at physiological $\mathrm{pH}$ based on a displacement method and preserving the selectivity between $\mathrm{PO}_{4}{ }^{3-}$ and $\mathrm{P}_{2} \mathrm{O}_{7}{ }^{4-}$ and extending it to G6P and ATP. All titrations were carried out in a buffered HEPES aqueous solution at $\mathrm{pH} 7.4$ by UV-vis experiments. When phosphate derivatives were added to solutions of 178-CV a change from blue to yellow was observed, due to PV release. Further studies concluded that ATP was better recognized by the 178-PV while 177-PV better bound G6P; due to a selective fit with the $\mathrm{Zn}-\mathrm{Zn}$ distance. Finally, no interaction was observed with the common inorganic anions tested $\mathrm{Cl}^{-}, \mathrm{Br}^{-}, \mathrm{ClO}_{4}^{-}, \mathrm{NO}_{3}{ }^{-}$, and $\mathrm{SO}_{4}{ }^{2-}$.<smiles>O=C(O)CN(CC(=O)O)CC(=O)O</smiles><smiles>O=C([O-])CN(CC(=O)[O-])Cc1c2oc3c(CN(CC(=O)[O-])CC(=O)[O-])c(O)c(Cl)cc3c(-c3ccccc3C(=O)[O-])c-2cc(Cl)c1=O</smiles>

Fluorescent a pH 7.4

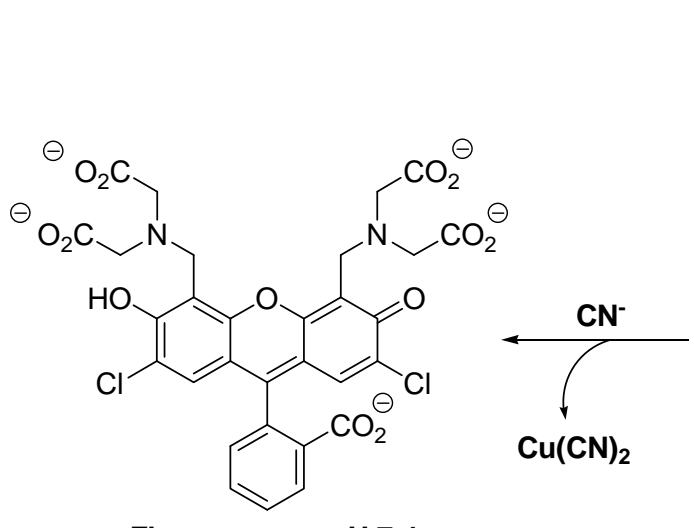

Fluorescent a pH 7.4

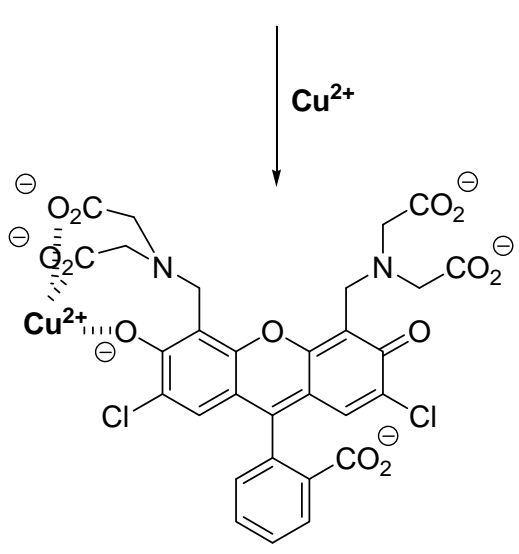

Less fluorescent a pH 7.4

Fig. 74 Structure of 179 and the binding modes with $\mathrm{Cu}(\mathrm{II})$ and $\mathrm{CN}^{-}$. 
The following displacement examples are related with the use of anion-induced metallatation procedures. The first example is based on the use of receptor 179 that at pH 7.4 (HEPES) shows an intense emission band at $522 \mathrm{~nm}$ (Figure 74). ${ }^{218}$ When 1 equivalent of $\mathrm{Cu}^{2+}$ was added a large fluorescent quenching was observed due to the formation of a non-emissive 1:1 complex between $\mathrm{Cu}^{2+}$ and 179. This ensemble was then used as fluorogenic probe for $\mathrm{CN}^{-}$. From a number of anions tested $\left(\mathrm{CN}^{-}, \mathrm{SCN}^{-}\right.$, $\mathrm{AcO}^{-}, \mathrm{F}^{-}, \mathrm{Cl}^{-}, \mathrm{Br}^{-}, \mathrm{I}^{-}, \mathrm{H}_{2} \mathrm{PO}_{4}^{-}, \mathrm{HSO}_{4}^{-}, \mathrm{NO}_{3}{ }^{-}$and $\mathrm{ClO}_{4}{ }^{-}$), only $\mathrm{CN}^{-}$induced a fluorescence enhancement that was assigned to a displacement of the $\mathrm{Cu}^{2+}$ cation and formation of the corresponding $\mathrm{Cu}(\mathrm{CN})_{2}$ complex. This sensing system was applied by the authors in a microfluidic platform and for in vivo imaging of $\mathrm{CN}^{-}$in C. elegans.

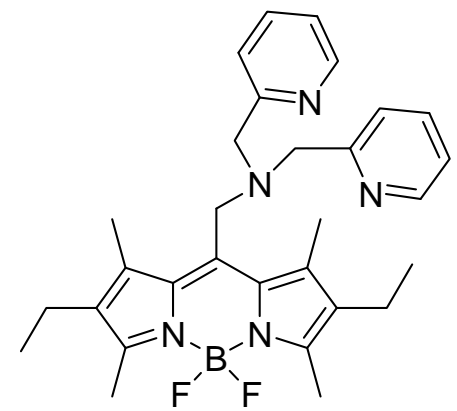

180

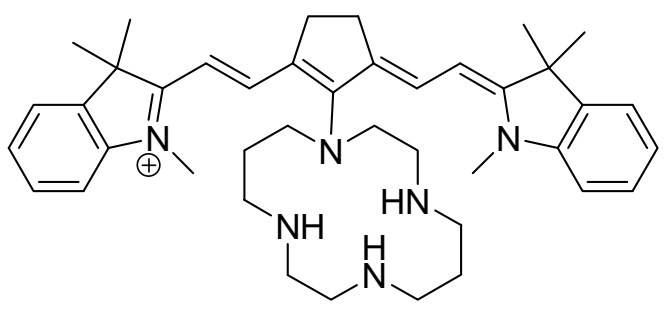

182

Fig. 75 Structure of receptors 180 and 182.

The following example senses $\mathrm{CN}^{-}$in THF-water 98:2 v/v mixtures via metal ion removal from the fluorogenic BODIPY (boradiazaindacene) complex 180-Cu(II) (Figure 75). ${ }^{219}$ Fluorescence response of $\mathbf{1 8 0}$ was completely quenched upon addition of $\mathrm{Cu}(\mathrm{II})$ due to formation of the corresponding 180-Cu(II) complex. Addition of $\mathrm{CN}^{-}$to 180-Cu(II) solutions resulted in a release of 180. In order to ascertain the selectivity response of the $180-\mathbf{C u}(\mathrm{II})$ complex system for $\mathrm{CN}^{-}$, titration experiments were repeated with other potentially interfering anions including $\mathrm{F}^{-}, \mathrm{Cl}^{-}, \mathrm{Br}^{-}, \mathrm{I}^{-}, \mathrm{AcO}^{-}, \mathrm{NO}_{3}^{-}$, $\mathrm{ClO}_{4}{ }^{-}, \mathrm{HSO}_{4}{ }^{-}$and $\mathrm{OH}^{-}$. Neither $\mathrm{I}^{-}$nor $\mathrm{NO}_{3}{ }^{-}$interfered significantly with the selective sensing of $\mathrm{CN}^{-}$, despite their addition resulted in some degree of emission recovery. 


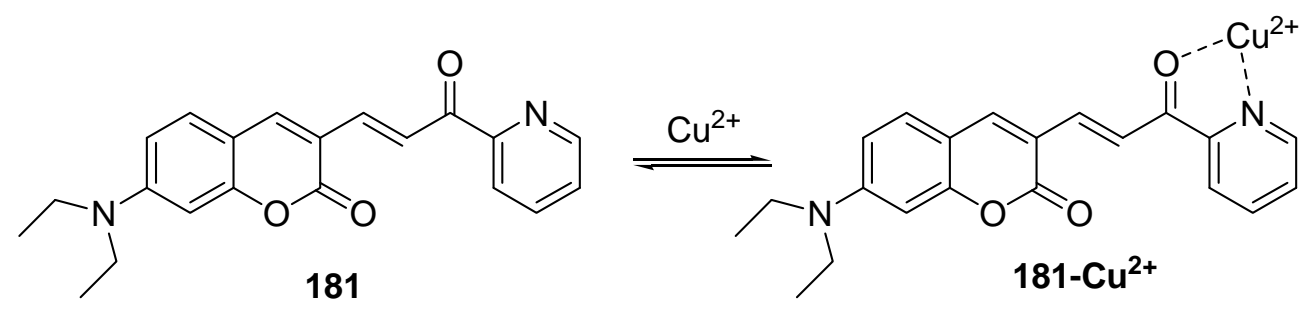

Fig. 76 Chemical structure of $\mathbf{1 8 1}$ and its $\mathrm{Cu}(\mathrm{II})$ complex.

A fluorescence turn-on probe, $181-\mathrm{Cu}^{2+}$, for $\mathrm{I}^{-}$based on the redox reaction between the cupric cation and $\mathrm{I}^{-}$was reported (Figure 76). ${ }^{220}$ The authors reported that the addition of $\mathrm{Cu}^{2+}$ to solutions of $\mathbf{1 8 1}$ resulted in a large red-shift, from 463 to 585 $\mathrm{nm}$, in the UV-vis spectrum while the fluorescence emission was strongly quenched. Addition of increasing quantities of $\mathrm{I}^{-}$to the $\mathbf{1 8 1 - \mathbf { C u } ^ { 2 + }}$ ensemble, resulted in the rupture of the complex and the solution immediately turned yellow (the colour of free 181). The system exhibits also a drastic fluorescent enhancement at $551 \mathrm{~nm}$ in the presence of $\mathrm{I}^{-}$. The selectivity of 181- $\mathbf{C u}^{2+}$ to I' was evaluated by studying the effect of other anions such as $\mathrm{F}^{-}, \mathrm{SO}_{3}{ }^{2-}, \mathrm{SO}_{4}{ }^{2-}, \mathrm{CO}_{3}{ }^{2-}, \mathrm{HCO}_{3}{ }^{-}, \mathrm{HPO}_{4}{ }^{2-}, \mathrm{BF}_{4}{ }^{-}, \mathrm{ClO}_{3}{ }^{-}$or $\mathrm{NO}_{3}{ }^{-}$. Although $\mathrm{Br}^{-}$and $\mathrm{Cl}^{-}$elicit a small fluorescence-enhanced response, they did not interfere with fluorescence detection of $\mathrm{I}^{-}$.

The heptamethine cyanine dye 182 (Figure 75) forms a $\mathrm{Cu}^{2+}$ complex that was used for the fluorescence sensing of the anion citrate. ${ }^{221}$ Aqueous solutions of receptor 182 buffered at $\mathrm{pH} 7.0$ (HEPES) show an absorption band at $707 \mathrm{~nm}$ with a shoulder at $794 \mathrm{~nm}$ (indicative of partial association of the receptor). Upon addition of $\mathrm{Cu}^{2+}$ the maximum of the main band suffers a red shift of $20 \mathrm{~nm}$ whereas the shoulder at $794 \mathrm{~nm}$ gains intensity. This behaviour was assigned to a metal-ion-mediated aggregation process. Also the formation of the aggregates induced a quenching of the emission intensity at $782 \mathrm{~nm} \cdot \mathbf{1 8 2} \cdot \mathrm{Cu}^{2+}$ aggregates were used for the chromogenic and fluorogenic sensing of citrate anion. Thus, the addition of citrate to solutions of $182 \cdot \mathrm{Cu}^{2+}$ leads to the disruption of the aggregates due to the formation of citrate- $\mathrm{Cu}^{2+}$ complexes, reflected in a decrease of the band at $794 \mathrm{~nm}$ and in an enhancement of the emission at $782 \mathrm{~nm}$. The deaggregation process is selective for citrate and other anions such as $\mathrm{AcO}^{-}, \mathrm{Cl}^{-}, \mathrm{Br}^{-}, \mathrm{SO}_{4}{ }^{2-}, \mathrm{H}_{2} \mathrm{PO}_{4}{ }^{-}$and malonate induced negligible changes in the absorption and in the emission bands. 


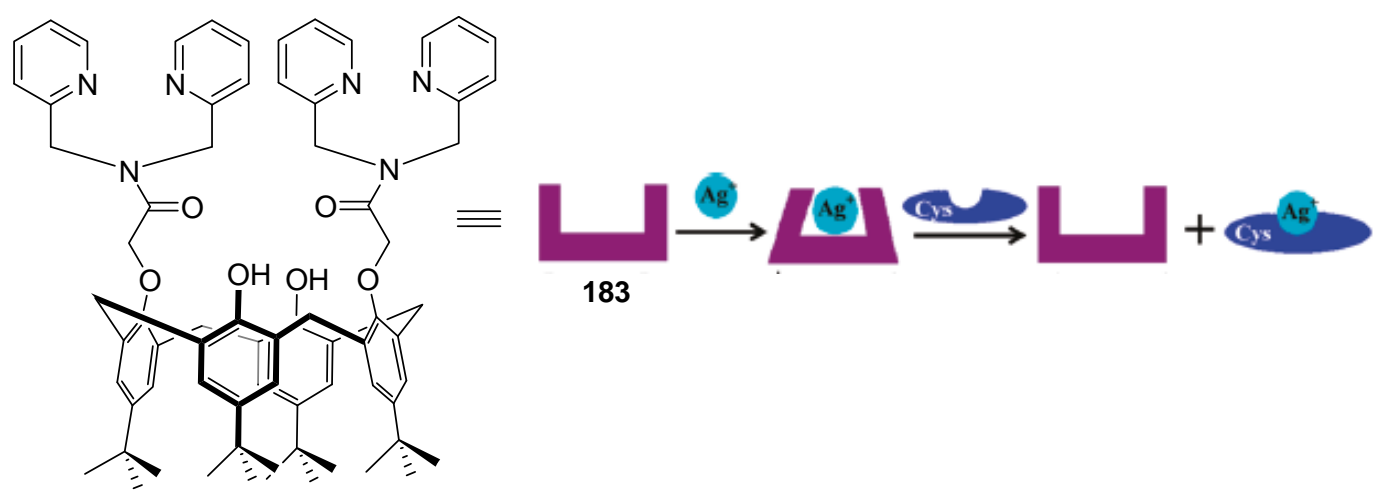

Fig. 77 Structure of calix[4]arene $\mathbf{1 8 3}$ and the displacement assay with $\mathrm{Ag}(\mathrm{I})$ and Cys.

The lower rim functionalized calix[4]arene containing dipicolyl moieties connected through an amide linkage, 183, exhibited ratiometric silver-sensing properties and the recognition of Cys via the use of the corresponding 183-silver complex (Figure 77). ${ }^{222}$ Excitation at $285 \mathrm{~nm}$ of methanol solutions of receptor 183 gives an intense emission at $315 \mathrm{~nm}$ that was severely quenched upon addition of increasing quantities of $\mathrm{Ag}^{+}$cation. Apart from the deactivation of the $315 \mathrm{~nm}$ emission a new band centred at $445 \mathrm{~nm}$ grows in intensity. This new band was ascribed to an excimer state suggesting that coordination of silver ion with 183 bring the pyridyl moieties in close proximity. Titration analysis revealed the formation of 2:1 $\mathrm{Ag}(\mathrm{I})-\mathbf{1 8 3}$ complexes. Upon addition of Cys to methanolic solutions of the $\mathrm{Ag}(\mathrm{I}) \mathbf{- 1 8 3}$ ensemble, the emission centred at $445 \mathrm{~nm}$ was gradually quenched and an emission at $315 \mathrm{~nm}$ progressively appeared. These changes were ascribed to a disruption of the $\operatorname{Ag}(\mathrm{I})-\mathbf{1 8 3}$ complex that releases free 183 to the solution. The authors demonstrate that the silver complex is able to selectively detect Cys in a ratiometric fashion with a detection limit of 514 ppb.

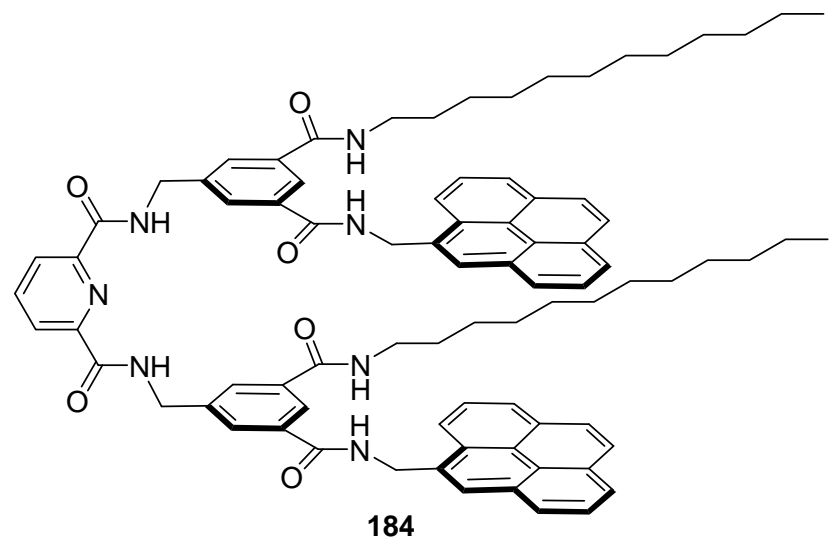<smiles>CCN(CC)c1ccc2cc(C(=O)NCCCCOP(=O)(O)O)c(=O)oc2c1</smiles>

Fig. 78 Chemical structures of 184, 185 and GFP. 
The two following examples do not use a metallic complex but ensembles built with organic receptors. In the first case, the hexaamide receptor 184, containing a pseudotetrahedral cavity, forms a host-guest complex with the coumarin phosphate 185 (Figure 78). The ensemble was used for the fluorimetric signalling of geranyl pyrophosphate (GPP). ${ }^{223}$ DMSO solutions of 184 display the typical pyrene monomer emission bands at 377 and $397 \mathrm{~nm}$ and a red-shifted excimer band at $477 \mathrm{~nm}$. Upon addition of increasing quantities of coumarin phosphate 185, the monomer emission of the pyrene decreases regularly with a concomitant increase in the coumarin emission at $470 \mathrm{~nm}$ as consequence of the formation of 1:1 host-guest complexes between $\mathbf{1 8 4}$ and 185 that induced a FRET process involving the photo-excited pyrene and the coumarin group on 185. When GPP was added to the ensemble the monomer pyrene emission is recovered. This strongly suggests the interaction of $\mathbf{1 8 4}$ with GPP and release of $\mathbf{1 8 5}$ to the solution. Addition of $\mathrm{PO}_{4}{ }^{3-}$ and $\mathrm{P}_{2} \mathrm{O}_{7}{ }^{4-}$ induced a low response, whereas addition of $\mathrm{F}^{-}, \mathrm{Cl}^{-}, \mathrm{Br}^{-}, \mathrm{SCN}^{-}, \mathrm{AcO}^{-}, \mathrm{NO}_{3}{ }^{-}, \mathrm{ClO}_{4}{ }^{-}$and certain fatty carboxylates induced no changes in the emission profile. The high affinity for GPP most likely arises from the formation of multiple hydrogen bonds between this polyanion and $\mathbf{1 8 4}$ and by the hydrophobic interactions between the geranyl groups and the aliphatic chains of the receptor.

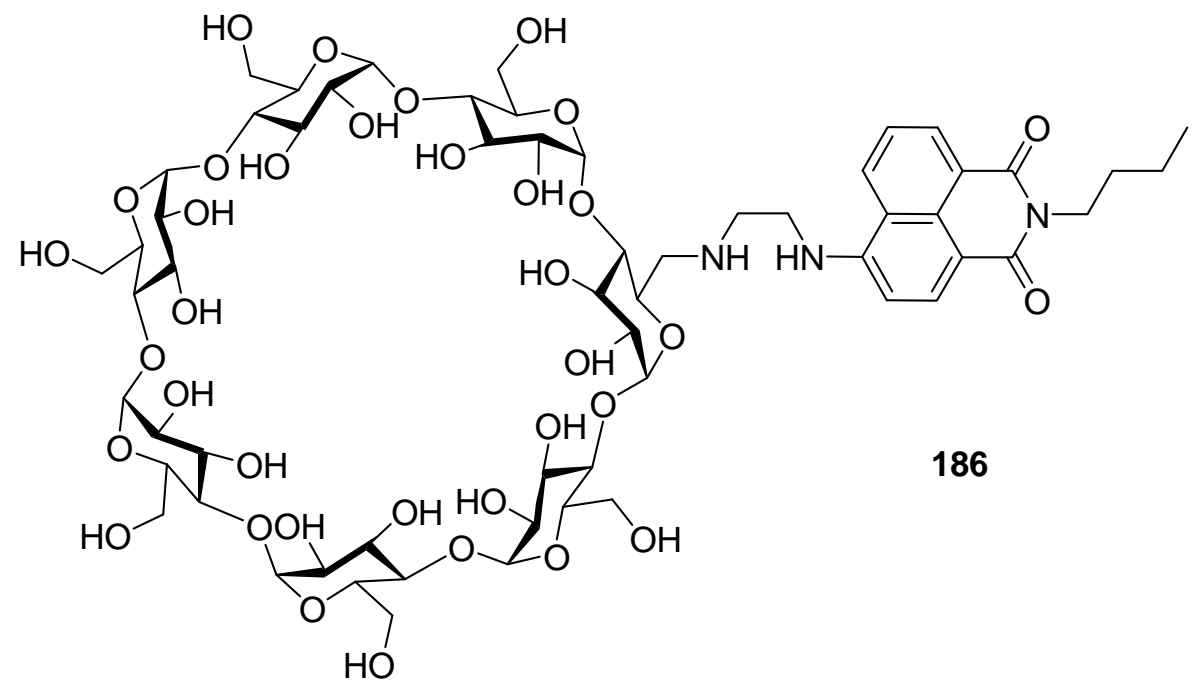

Fig. 79 Structure of $\beta$-cyclodextrin derivative 186.

The second example uses an intramolecular displacement assay. 186 (Figure 79) consists of a $\beta$-cyclodextrin binding site and a $N$-butyl-4-(2-aminoethylamino)-1,8naphthalimide fluorophore. ${ }^{224}$ Aqueous solutions of receptor 186 buffered at $\mathrm{pH} 7.4$ 
(Tris- $\mathrm{HCl}$ ) show a weak emission at $540 \mathrm{~nm}$ due to the fact that the 1,8-naphthalimide fluorophore was included in the hydrophobic cavity of the $\beta$-cyclodextrin. Upon addition of adamantane-1-carboxylate anion a 8-fold enhancement of the emission intensity was observed due to the preferential inclusion of the adamantane moiety into the cavity of the cyclodextrin and the subsequent displacement of the 1,8-naphthalimide fluorophore. This sensing mechanism was confirmed with circular dichroism and NOESY NMR experiments. Deoxycholate, decanoate, nonanoate, octanoate, heptanoate and hexanoate anions also form inclusion complexes with $\beta$-cyclodextrin and induced different enhancements in the emission intensity. It was suggested that $\mathbf{1 8 6}$ is a good candidate to distinguish between acyclic carboxylates because the larger the alkyl chain, the greater the enhancement in the emission intensity.

\section{3.- The chemodosimeter approach.}

As it was found in chromogenic systems, there are also an increasing number of examples dealing with the use of the chemodosimeter approach for the fluorogenic detection of anions. ${ }^{225-234}$ Most of the examples are related with the detection of $\mathrm{F}^{-}, \mathrm{CN}^{-}$ and thiol-containing amino acids. Also interesting examples for $\mathrm{ClO}^{-}, \mathrm{ONOO}^{-}$and $\mathrm{SO}_{3}{ }^{2-}$ have been reported.

The following examples use the nucleophilic reactivity of thiol groups for the preparation of probes for the fluorogenic detection of thiol-containing amino acids.

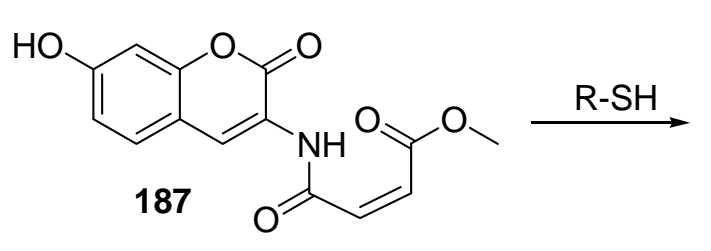<smiles>[R]SC(CC(=O)OC)C(=O)Nc1cc2ccc(O)cc2oc1=O</smiles>

Fig. 80 Fluorogenic probe $\mathbf{1 8 7}$ and the reaction with thiol derivatives.

Aqueous (TRIS, pH 7.4) solutions of chemodosimeter 187, containing a coumarin fluorophore and a maleimide group as reactive site, show a very weak emission at $465 \mathrm{~nm}$ (Figure 80). ${ }^{235}$ This weak fluorescence was ascribed to a photoelectron transfer process from the double bond of the maleimide moiety to the coumarin fluorophore. Addition of gluthathione and Cys induced a dramatic turn-on fluorescent response (470-fold emission enhancement with gluthathione) due to a Michael addition 
reaction between the thiol groups and the cis double bond in the maleimide subunit that results in an inhibition the PET process. The response was selective for thiol-containing amino acids. Based in this selective response, the authors used reactand $\mathbf{1 8 7}$ for the development of high-throughput fluorescence assay for enzyme gluthathione reductase.

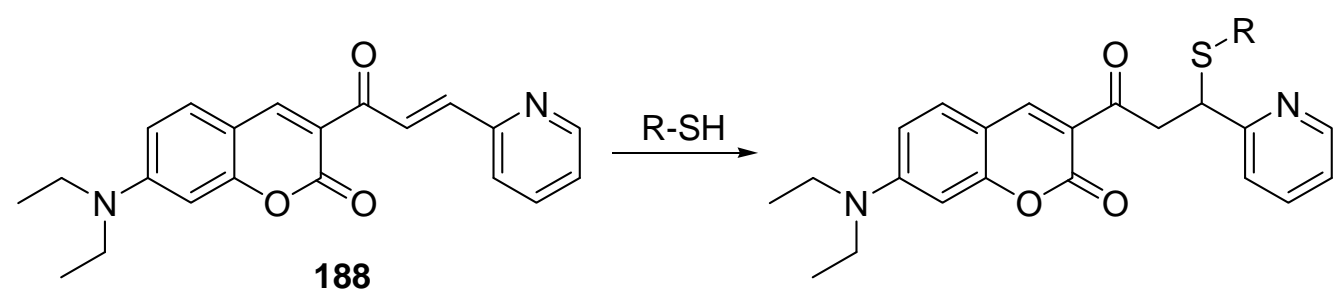

Fig. $\mathbf{8 1}$ Fluorogenic probe $\mathbf{1 8 8}$ and the reaction with thiol derivatives.

Probe 188 consists of a $N, N$-diethylaminocoumarin fluorophore linked, through an $\alpha, \beta$-unsaturated ketone, to a pyridine ring (Figure 81$).{ }^{236}$ Water-acetonitrile 99:1 v/v solutions of 188 buffered at $\mathrm{pH} 7.4$ showed an intense intramolecular charge transfer (ICT) absorption band (from the electron-donor $N, N$-diethylaminocoumarin to the electron-acceptor pyridine moiety) at $466 \mathrm{~nm}$ and almost no fluorescence. The low emission of 188 was explained by the formation of a non-emissive ICT state. However, addition of Cys induced the apparition of a strong emission at $496 \mathrm{~nm}$ (211-fold of enhancement). This was assigned to a 1,4-addition reaction between the thiol moiety of the Cys and the $\alpha, \beta$-unsaturated ketone. As a consequence of this reaction the intramolecular charge transfer was interrupted and the fluorescence of the coumarin restored. Nearly the same results, namely enhancement in the emission intensity at 496 $\mathrm{nm}$, were obtained with homocysteine (180-fold) and with glutathione (35-fold) whereas no noticeable changes were found in the presence of other amino acids, metal ions, reactive oxygen species, reducing agents, nucleosides or glucose. 

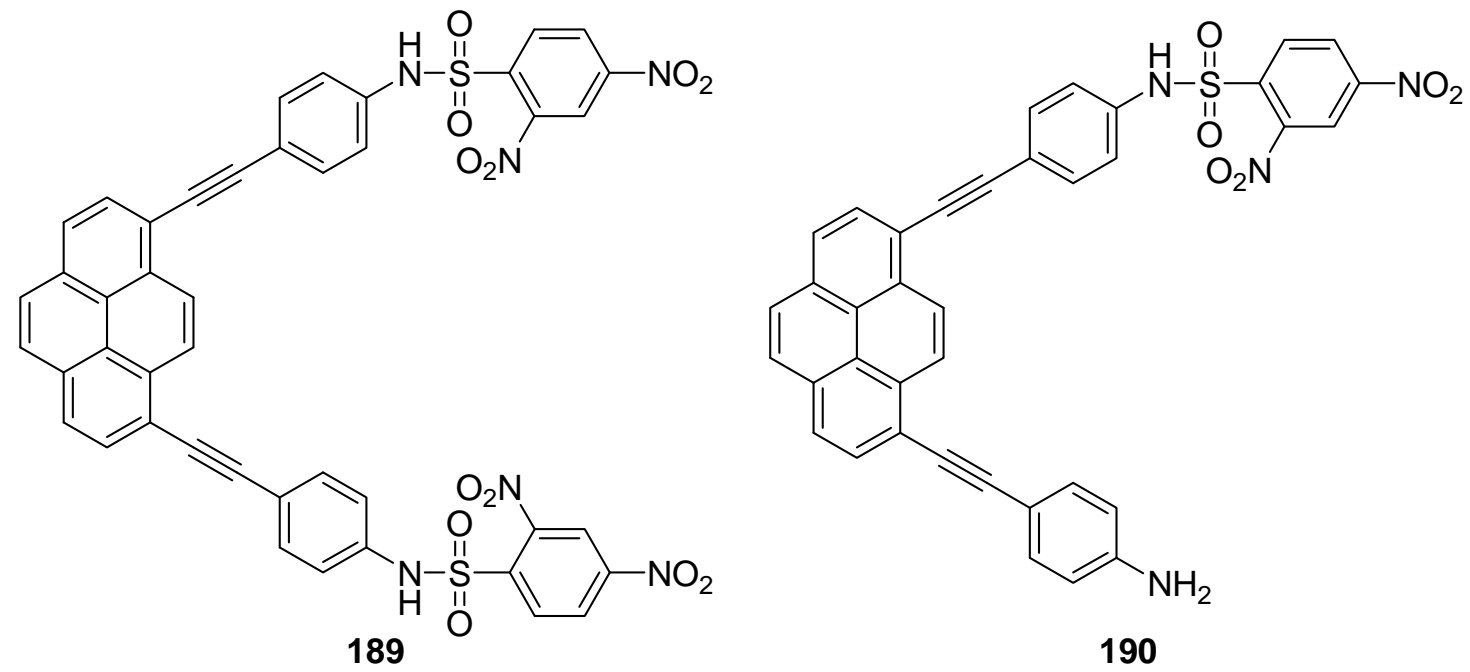

Fig. 82 Structure of pyrene-based receptors 189 and 190.

189 and 190 (Figure 82) were designed for the selective determination of biorelevant thiols in a chemodosimeter fashion. ${ }^{237}$ Methanol-water 4:1 v/v (buffered at $\mathrm{pH}$ 7.4) solutions of probe 189 showed negligible fluorescence because the 2,4dinitrosulfonyl electron acceptor group quenches the pyrene emission. Addition of LCys induced the apparition of an emission band at $562 \mathrm{~nm}$ (53-fold fluorescence enhancement) that was assigned to an elimination of the quenching process by a reaction of the thiol moiety of Cys with the 2,4-dinitrosulfonyl group that resulted in a release of the 2,4-dinitrosulfonyl quencher. Also addition of gluthathione and 3mercaptopropionic acid induced the recovery of the emission but in a lesser extent. Nearly the same response, but with weak enhancements, were obtained with receptor 190 in the presence of thiol-containing compounds.

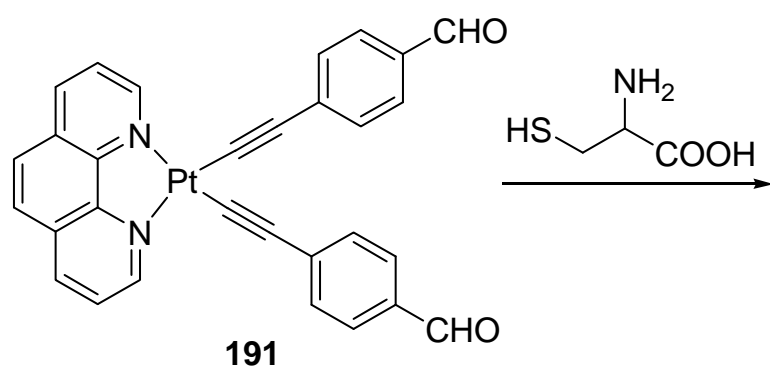<smiles></smiles>

Fig. 83 Proposed reaction between the Pt(II) complex 191 and cysteine. 
The platinum (II) complex 191 was found to be a highly selective phosphorescent chemodosimeter for Cys and Hcy (Figure 83). ${ }^{238}$ Addition of Hcy and Cys to acetonitrile-water $4: 1 \mathrm{v} / \mathrm{v}(\mathrm{pH} 7.2)$ solutions of 191 led to a gradual decrease of the band at $330 \mathrm{~nm}$ and an increase of the band centred at $270 \mathrm{~nm}$. On the other hand, the emission band of 191 was red-shifted from 510 to $555 \mathrm{~nm}$ in the presence of Cys and Hcy. To validate the selectivity of 191 besides Cys/Hcy, various other natural amino acids including His, Leu, Asp, Arg, Tyr, Thr, Pro, IsoLeu, Try, Met, Val, Ala, Phe, Glu-ine, Glu, Ser, Hyd, Lys and Gly were added to acetonitrile-water solution of 191 resulting in no obvious changes in the emission spectra. Finally, ${ }^{1} \mathrm{H}$ NMR studies indicated that the observed spectral shifts should be ascribed to the reaction between the aldehyde in $\mathbf{1 9 1}$ and Cys/Hcy leading to the formation of a thiazinane ring.
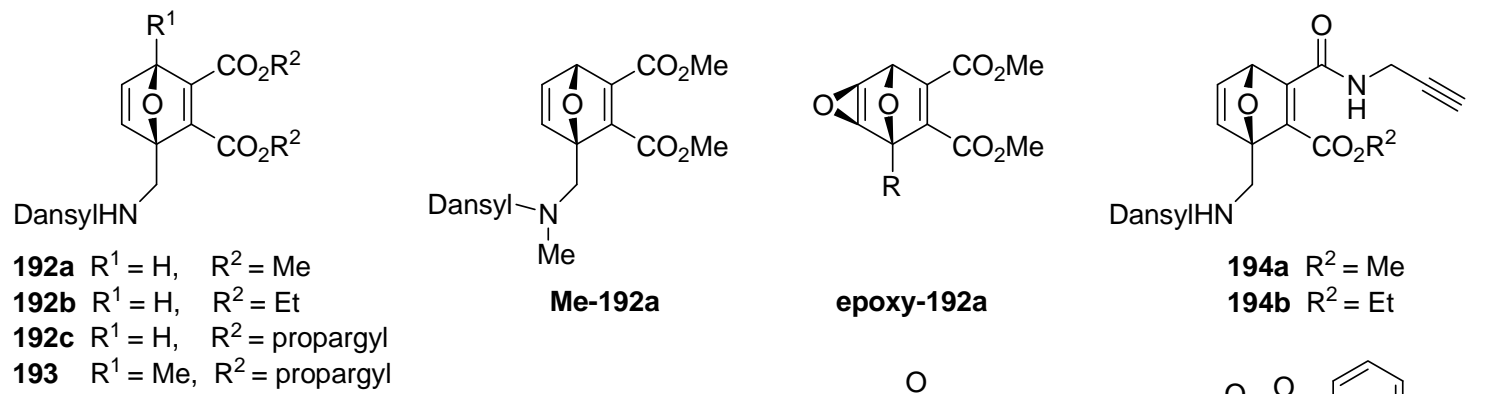

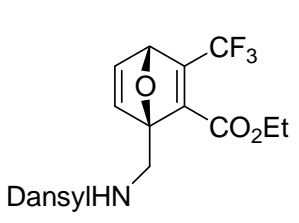

195

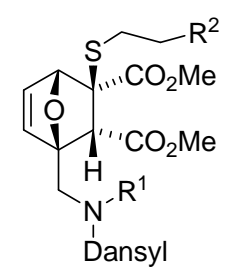

$196 a$

196b Me-196a $R^{1}=M e, R^{2}=O H$

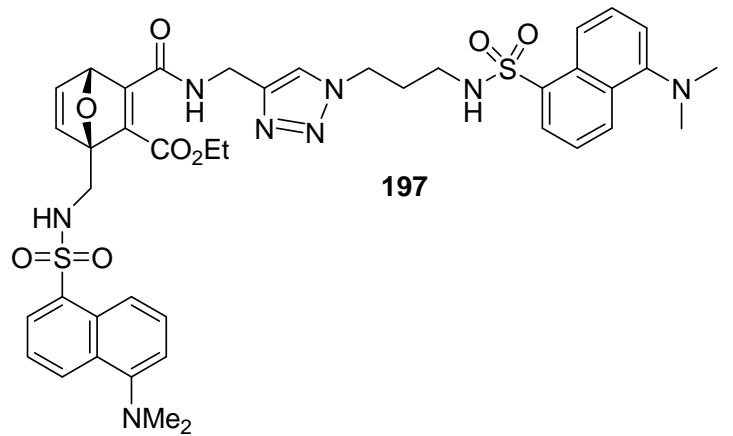

Fig. 84 Structure of oxanorbornadiene-based receptors 192-197.

A new class of highly selective fluorogenic probes for thiols in small molecules, peptides and proteins based on the 7-oxanorbornadiene (OND) framework was reported (Figure 84). ${ }^{239}$ The fluorescence of compounds 192-197 was significantly low due to a photoinduced electron transfer from the fluorophore excited state to the LUMO of the maleate moiety. Compound 192a was used as a representative electrophile in reactions with a selection of potentially nucleophilic amino acids at pH 7 in water-DMSO 9:1 v/v. Addition of Lys and Hys to 192a gave a very small $(<2 \%)$ increase in fluorescence (emission band at $550 \mathrm{~nm}$ ), whereas the other amino acids tested induced even a lower 
enhancement. In contrast, the addition of glutathione to 192a gave rise to an immediate and strong increase in fluorescence. The enhancement in emission intensity was ascribed to an addition reaction of glutathione to the maleate moiety of 192a and subsequent retro Diels-Alder reaction of the formed adduct. The same selectivity toward thiol containing amino acids was found for 192-197 receptors. Finally, receptors 192a, 194a and 194b were used for labelling a nonapeptide (KCIRGDTFG containing amine, carboxylate, guanidine, alkyl and thiol functional groups) with the observation of a strong fluorescence emission at $550 \mathrm{~nm}$ upon reaction. Also BSA was labelled with receptors 192b, 194b and 197.

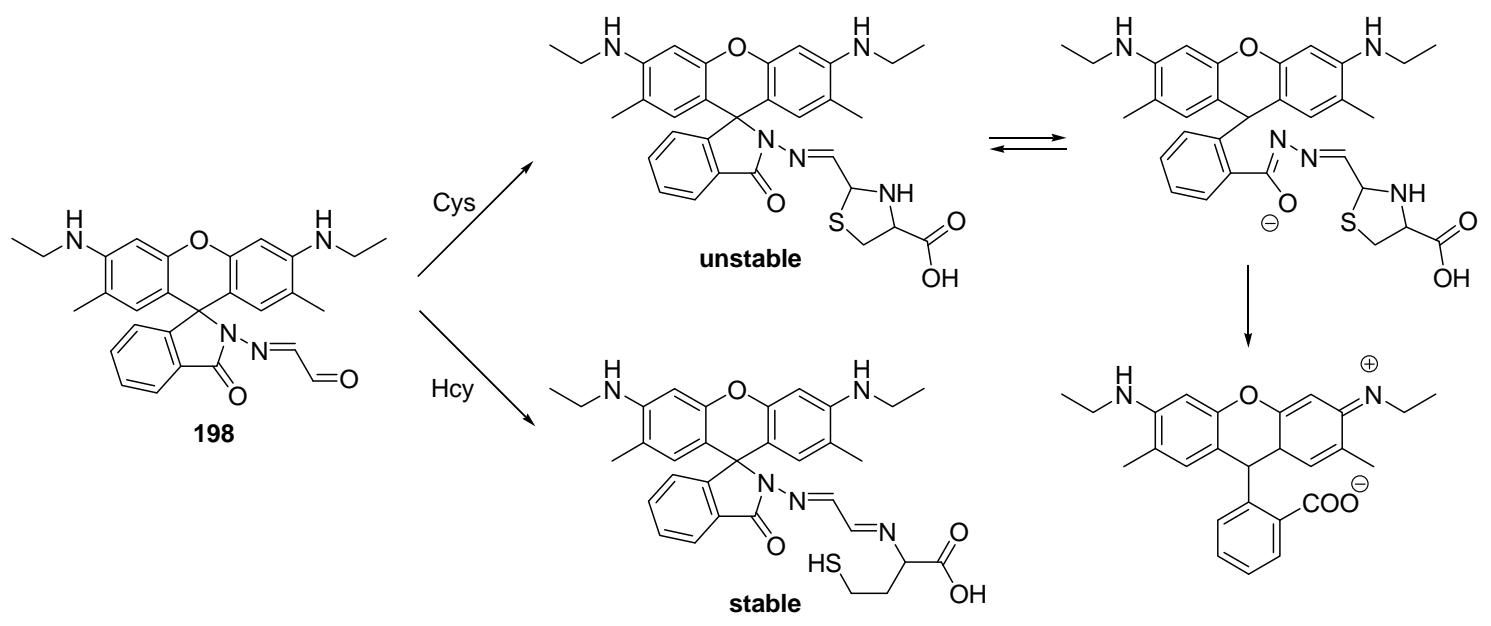

Fig. 85 Chemodosimeter 198 and the reaction with cysteine and homocysteine.

Chemodosimeter 198, derived from rhodamine-6G, shows an excellent selectivity for Cys over other thiol containing amino acids such as Hcy and gluthathione (Figure 85). ${ }^{240}$ Solutions of 198 in ethanol-PBS 3:7 v/v at pH 7.0 were colourless and weakly fluorescent with an emission at $552 \mathrm{~nm}$. Upon addition of Cys the intensity at $552 \mathrm{~nm}$ increased (20-fold enhancement). Other amino acids, including the related Hcy and gluthathione induced no changes in the intensity profile. This remarkable recognition of Cys over Hcy was related with the formation of an unstable thiazolidine derivative upon reaction of 198 with Cys. This thiazolidine gives a ring opening reaction yielding an open derivative that hydrolizes to release a free rhodamine-6G fluorophore with the subsequent change in colour to pink and enhancement in the emission intensity. In the case of the reaction between 198 and Hcy the intermediate 
product formed is colourless and non-fluorescent. Finally, this chemodosimeter was used to visualize changes of Cys concentrations in living cells.
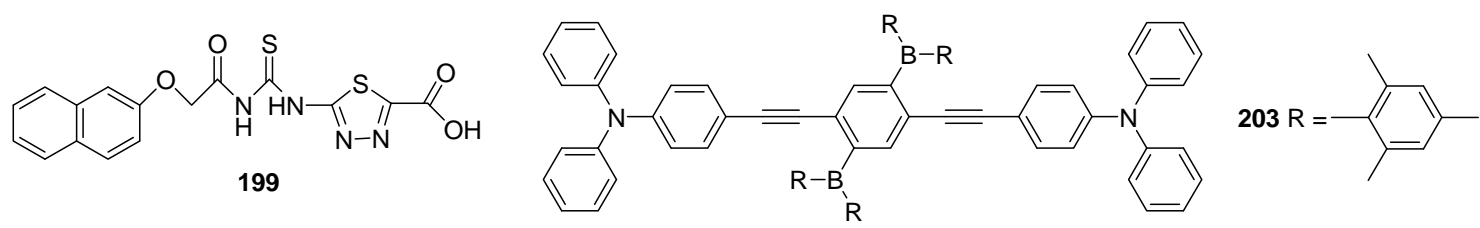

Fig. 86 Structure of receptors 199 and 203.

A novel method for the ratiometric fluorescent determination of cysteine was developed based on the use of naphthalene-thiourea-thiadiazole derivative 199 (Figure $86)$ in the form of fluorescent organic nanoparticles (199-FONs). ${ }^{241}$ Molecules of receptor 199 self-assembled into colloidal nanoparticles (199-FONs) as a result of reprecipitation when a THF solution of 199 was added to water. The spectrum of 199FONs in THF-water 1:1 v/v mixtures display the typical naphthalene emission band at $356 \mathrm{~nm}$ but when Cys was added a moderate decrease in the intensity at $356 \mathrm{~nm}$ and the formation of a red-shifted emission band at $430 \mathrm{~nm}$ was observed. However, 199-FONs did not show any obvious spectral change upon addition of other amino acids as Ala, Met, Ser, Leu, Glu, Thr, Val, Arg, Pro, Asp, Phe, Pry and Apc. Changes in optical properties of 199-FONs were attributed to FONs aggregation linked by Cys. Competition experiments concluded that 199-FONs could be used as a potential candidate for Cys detection with very high degree of selectivity.
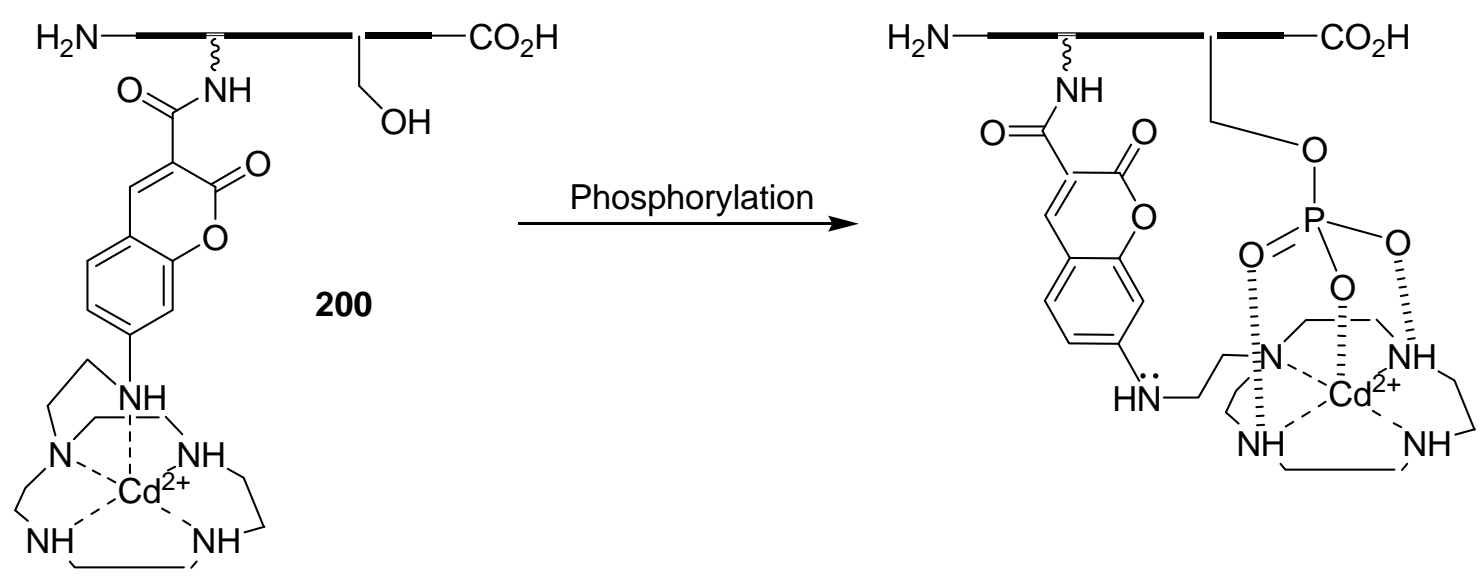

Fig. 87 Peptidic receptor 200 and its phosphorylation process. 
A new probe for protein kinases (PKA) based on a peptide containing an appended Cd(II)-cyclen 7-aminocoumarin (200, Figure 87) was reported. ${ }^{242}$ Aqueous solutions of 200 (HEPES, pH 7.4) show the typical coumarin emission at $460 \mathrm{~nm}$ upon excitation at $360 \mathrm{~nm}$. Addition of $\mathrm{PO}_{4}{ }^{3-}$ induced the phosphorylation of the hydroxyl moiety of the peptide with the subsequent $\mathrm{PO}_{4}{ }^{3-}$ coordination to the metal centre. This changes the excitation wavelength from 360 to $410 \mathrm{~nm}$ without any shift in the emission wavelength. This change in the excitation wavelength could be used for the ratiometric recognition of $\mathrm{PO}_{4}{ }^{3-}$ anion. Additionally, to prove the utility of $\mathbf{2 0 0}$ as a fluorescent probe for protein kinases, the time-dependent change of its excitation spectrum when treated with ATP and the PKA catalytic subunit was studied. The phosphorylation reaction was initiated by addition of ATP to a mixture of $\mathbf{2 0 0}$ and PKA in HEPES at pH 7.4. Although ATP strongly coordinated to $\mathrm{Cd}^{\mathrm{II}}$ complex of $\mathbf{2 0 0}$ no significant changes on the excitation spectrum was observed. However, the ratio of the excitation intensity $(410 / 360 \mathrm{~nm})$ increased 1.7 fold after $30 \mathrm{~min}$ of reaction. This result indicated that the ratiometric spectral change was caused by PKA-mediated phosphorylation of 200.

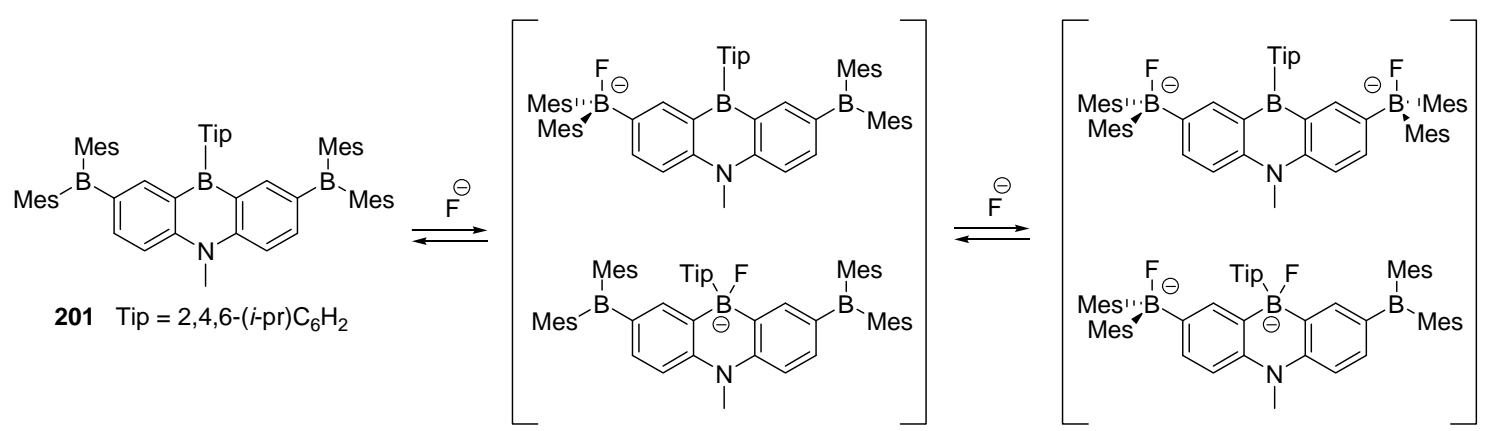

Fig. 88 Bis(dimesitylboryl)azaborine receptor 201 and the proposed reactions with $\mathrm{F}^{-}$ anion.

Most of the systems for the fluorogenic detection of $\mathrm{F}^{-}$and some for $\mathrm{CN}^{-}$are based on the addition of these anions to boron atoms. ${ }^{122}$ Whereas signalling features are observed for $\mathrm{F}^{-}$in organic solvents, the examples with $\mathrm{CN}^{-}$display signalling features in aqueous environments. The first example uses a bis(dimesitylboryl)azaborine derivative (201) for $\mathrm{F}^{-}$signalling in THF (Figure 88). ${ }^{243} 201$ shows an emission band centred at $402 \mathrm{~nm}$ that is quenched upon addition of 2 equivalents of $\mathrm{F}^{-}$while a new broad emission at $460 \mathrm{~nm}$ appeared. This new emission band was assigned to the formation of a fluoroborate derivative which results from the addition of one $\mathrm{F}^{-}$to the boron atoms. Further addition of $\mathrm{F}^{-}$induced a blue shift of the emission band centred at $460 \mathrm{~nm}$ in 
accordance with a second $\mathrm{F}^{-}$addition. These $\mathrm{F}^{-}$anchoring were also reflected in the UVvisible spectra of 201.

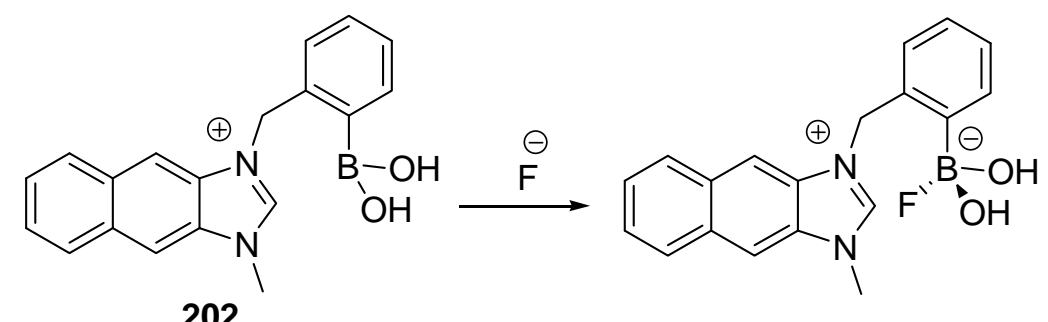

202

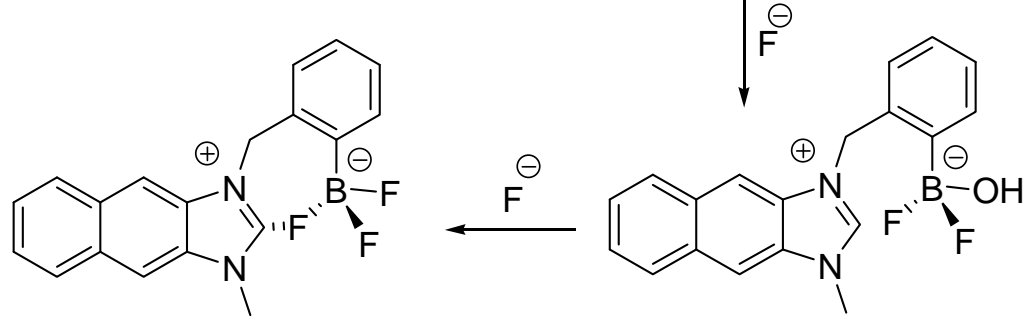

Fig. 89 Structure of receptor 202 and the proposed reaction with $\mathrm{F}^{-}$.

Receptor 202 (Figure 89) contains two binding sites, i.e. a boronic acid and an imidazolium group, and was used for selective $\mathrm{F}^{-}$recognition. ${ }^{244}$ Acetonitrile solutions of 202 show a broad emission at $440 \mathrm{~nm}$ due to the naphthoimidazolium fluorophore. When $\mathrm{F}^{-}$anion was added a significant decrease in the emission band at $440 \mathrm{~nm}$ together with the appearance of a blue-shifted emission at 372 was observed. This effect allowed the ratiometric fluorescent sensing of $\mathrm{F}^{-} .{ }^{19} \mathrm{~F}-\mathrm{NMR}$ titration profiles suggested the formation of a trifluoroboronate derivative and the subsequent formation of a $(\mathrm{C}$ $\mathrm{H})^{+} \cdots \mathrm{F}^{-}$hydrogen bond between imidazolium and the $-\mathrm{BF}_{3}{ }^{-}$moiety as the mechanism that governed the observed response.

THF solutions of receptor 203 (Figure 86) show an intense absorption band at $442 \mathrm{~nm}$ of charge transfer nature that involves the HOMO delocalized over the whole $\pi$ conjugated framework and the LUMO mainly located on the diborylphenylene moiety. ${ }^{245}$ Upon excitation of THF solutions at $390 \mathrm{~nm}$ a broad emission band was observed at $601 \mathrm{~nm}$. Addition of increasing quantities of $\mathrm{F}^{-}$induced a decrease of the emission at $601 \mathrm{~nm}$ with the appearance of a blue-shifted band at $477 \mathrm{~nm}$. Further addition of a large excess of $\mathrm{F}^{-}$caused the appearance of a blue-shifted band at $412 \mathrm{~nm}$ that was assigned to the reaction with a second $\mathrm{F}^{-}$anion. The blue-shifted bands were ascribed to the reaction of $\mathrm{F}^{-}$with the boron atoms that interrupted the charge transfer 
transition and activated a $\pi-\pi^{*}$ emission based on the bis(arylethynyl)benzene framework.

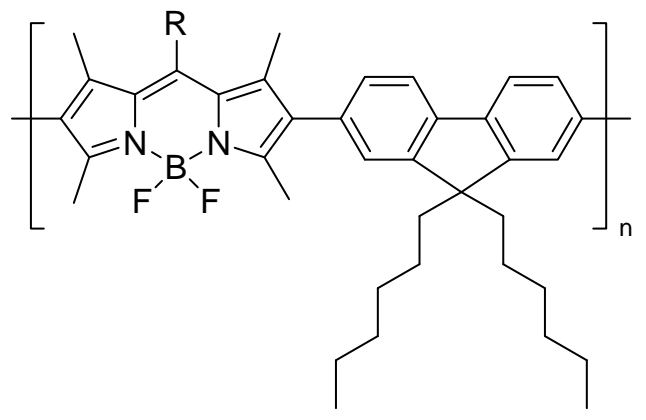

204<smiles>[R]=Cc1ccc(OC)cc1OC</smiles>

206<smiles></smiles>

Fig. 90 Structure of sensory polymers 204-206.

The conjugated copolymers of fluorene and BODIPY units, 204-206, have been used as sensory materials for the fluorogenic detection of $\mathrm{F}^{-}$and also $\mathrm{CN}^{-}$anions (Figure 90). ${ }^{246}$ DMF solutions of the three polymers show an intense fluorescence at ca. $590 \mathrm{~nm}$ that arises from the emission of the BODIPY moiety. Addition of $\mathrm{Cl}^{-}, \mathrm{Br}^{-}$and $\mathrm{I}^{-}$anions to DMF solutions of the three polymers induced negligible changes in the emission intensity whereas $\mathrm{F}^{-}$and $\mathrm{CN}^{-}$induced a significant quenching. The quenching in the presence of $\mathrm{F}^{-}$was ascribed to a chemical reaction of this anion which induced the breaking of a B-N bond resulting in the formation of a B-F bond. The authors suggested that $\mathrm{CN}^{-}$interacts with the BODIPY in a different manner but the mechanistic details remained unclear.

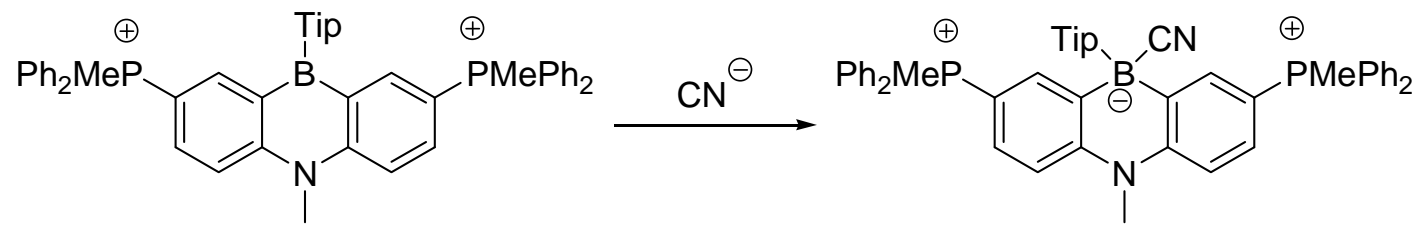

207 Tip $=2,4,6-(i-p r) \mathrm{C}_{6} \mathrm{H}_{2}$

Fig. 91 Proposed reaction between receptor 207 and $\mathrm{CN}^{-}$anion.

The cationic triarylborane, bearing phosphonio groups, 207 (Figure 91) was used for the fluorimetric recognition of $\mathrm{CN}^{-}{ }^{247}$ DMSO-water 4:6 v/v (buffered at $\mathrm{pH} 7.0$ ) solutions of receptor 207 show an absorption band at ca $335 \mathrm{~nm}$ that suffers a bathochromic shift to $369 \mathrm{~nm}$ upon addition of $\mathrm{CN}^{-}$. This response is highly selective 
and the addition of other anions such as $\mathrm{F}^{-}, \mathrm{Cl}^{-}, \mathrm{Br}^{-}, \mathrm{I}^{-}, \mathrm{HSO}_{4}^{-}, \mathrm{NO}_{3}{ }^{-}, \mathrm{AcO}^{-}$and $\mathrm{N}_{3}^{-}$ induced negligible changes in the UV-vis profile. Also the emission band centred at 407 $\mathrm{nm}$ (excitation at $369 \mathrm{~nm}$ ) was gradually quenched upon addition of $\mathrm{CN}^{-}$. The absorption and emission changes in the presence of $\mathrm{CN}^{-}$were ascribed to the addition of $\mathrm{CN}^{-}$to the electrophilic boron atom.

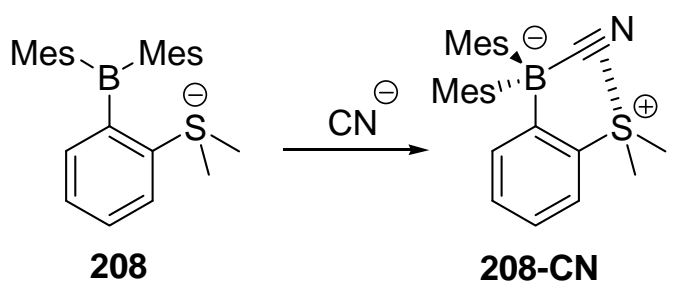

Fig. 92 Chemodosimeter 208 and the product of the reaction with $\mathrm{CN}^{-}$anion.

Chemodosimenter $\mathbf{2 0 8}$ is a cationic borane consisting of adjacent sulfonium and boryl moieties connected by an $o$-phenylene linker (Figure 92). ${ }^{248}$ Water solutions of receptor 208 buffered at pH 7.0 (HEPES) showed a broad emission band at $460 \mathrm{~nm}$. Addition of $\mathrm{F}^{-}, \mathrm{Cl}^{-}, \mathrm{Br}^{-}, \mathrm{I}^{-}, \mathrm{HSO}_{4}^{-}, \mathrm{NO}_{3}{ }^{-}, \mathrm{AcO}^{-}$and $\mathrm{H}_{2} \mathrm{PO}_{4}^{-}$to 208 in water induced negligible change in the emission intensity whereas addition of $\mathrm{CN}^{-}$produced a clear fluorescence quenching that is complete upon addition of $0.2 \mathrm{ppm}$. The $\mathrm{CN}^{-}$anion reacted with the boryl moiety leading to the formation of the product $208 \cdot \mathrm{CN}$ in which there is a $\pi(\mathrm{C} \equiv \mathrm{N}) \rightarrow \sigma^{*}(\mathrm{~S}-\mathrm{C})$ donor-acceptor interaction. This complex is insoluble in water and its precipitation accounts for the quenching of the emission observed.

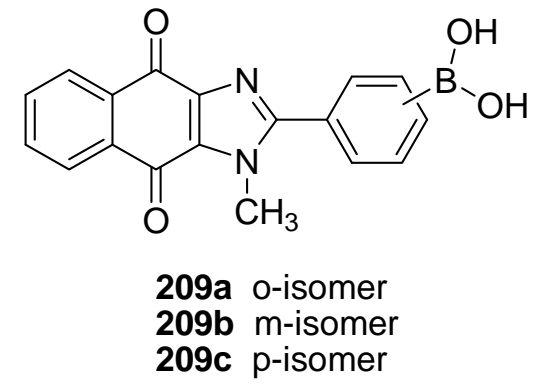

Fig. 93 Structure of fluorescent probe 209.

The fluorescent probes 209a-c, based on naphthoquinoneimidazole and boronic acid groups, are acceptor-donor-acceptor systems that display a remarkable selectivity towards $\mathrm{CN}^{-}$, as turn-on probes (Figure 93). ${ }^{249}$ DMSO:water (HEPES, pH 7.4) 1:1 v/v 
solutions of 209a-c are yellow and show characteristic emission bands at $562 \mathrm{~nm}$ (209a), $565 \mathrm{~nm}(209 \mathrm{~b})$ and $572 \mathrm{~nm}(209 \mathrm{c})$. Addition of $\mathrm{CN}^{-}$to 209b and 209c induced the apparition of an intense emission band at $460 \mathrm{~nm}$ whereas the ortho isomer 209a gave a poor response. The observed emission enhancement in the presence of $\mathrm{CN}^{-}$is highly selective and except $\mathrm{F}^{-}$, that gave certain response, the receptors remained silent in the presence of $\mathrm{AcO}^{-}, \mathrm{BzO}^{-}, \mathrm{NO}_{3}^{-}, \mathrm{ClO}_{4}^{-}, \mathrm{Cl}^{-}, \mathrm{Br}^{-}, \mathrm{SCN}^{-}$or $\mathrm{I}^{-}$. The new emission band arises from an ICT state that was switched on upon reaction of $\mathrm{CN}^{-}$with the boron atom of the receptors. The authors demonstrated that, compounds 209b and 209c could be incorporated into a CTAB micellar system for the detection of $\mathrm{CN}^{-}$at low concentrations $(50 \mu \mathrm{M})$.

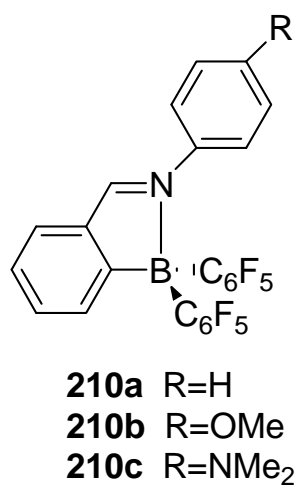

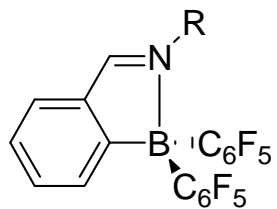

$211 \mathrm{R}=\mathrm{n}-\mathrm{Bu}$

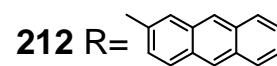

$213 \mathrm{R}=\mathrm{OMe}$

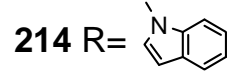

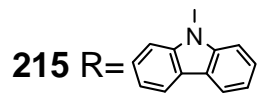

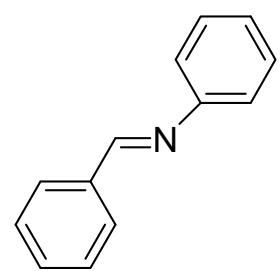

216

Fig. 94 Boron-substituted imine derivatives 210-216.

The following examples are based on the nucleophilic addition of $\mathrm{CN}^{-}$to other reactive organic groups. Several boron-substituted imine derivatives, 210a-216, were synthesized and their emission behaviour in the presence of $\mathrm{CN}^{-}$tested (Figure 94). ${ }^{250}$ DMF solutions of receptor 210c show an absorption band at $440 \mathrm{~nm}$ that disappears in the presence of $\mathrm{CN}^{-}$with the simultaneous growth of two new bands at 328 and $302 \mathrm{~nm}$. 210c also shows an intense emission at $575 \mathrm{~nm}$ that was quenched upon addition of $\mathrm{CN}^{-}$ . The large blue shift observed in the UV-vis experiments suggested a disconnection of the $\pi$-conjugated system. In fact ${ }^{19} \mathrm{~F}$ and ${ }^{13} \mathrm{C}$-NMR experiments with $210 \mathrm{c}$ indicated that $\mathrm{CN}^{-}$addition to the carbon atom of the imine double bond moiety occurs. In this case no reaction with the boron atom takes place. 
<smiles>C[O+]=Cc1ccccc1C#Cc1cc(CO)ccc1N(C)C(=O)C[NH3+]</smiles>

217<smiles>CN(C(=O)CNC(=O)OC(C)(C)C)c1ccc(CO)cc1C#Cc1ccccc1C=O</smiles>

218<smiles>O=Cc1ccccc1C#Cc1cccc(CO)c1</smiles>

219<smiles>OCc1cccc(C#Cc2ccccc2)c1</smiles>

220

Fig. 95 Structure of receptors 217-220.

Receptor 217 was found to respond by fluorescence enhancement with fast response kinetics exclusively to $\mu \mathrm{M}$-level of $\mathrm{CN}^{-}$anion in neutral aqueous solutions, with no interference from other common anions (Figure 95). ${ }^{251}$ Probe 217 displays a strong electronic transition at $350 \mathrm{~nm}$ but was only weakly fluorescent. Addition of $\mathrm{CN}^{-}$ elicited a significant ( $>7$-fold) enhancement of the emission at $375 \mathrm{~nm}$, with only a slight decrease in absorption intensity. Solution studies indicated the formation 1:1 complexes between 217 and $\mathrm{CN}^{-}$. The authors suggested that a nucleophilic attack of $\mathrm{CN}^{-}$on the aldehyde group of $\mathbf{2 1 7}$ to form a cyanohydrin derivative occurs. Moreover, the functional role of intramolecular hydrogen bonds in this bimolecular reaction was additionally studied by using compounds 218 and 219 in acetonitrile. The efficiency of $\mathrm{CN}^{-}$detection upon introduction of the same amount of $\mathrm{NaCN}$ to the solution of the probes followed the trend of $\mathbf{2 1 7}>\mathbf{2 1 8}>>\mathbf{2 1 9}$. This suggests that the larger net turn-on response of $\mathbf{2 1 7}$ was due to the additional structural rigidity of the fluorogenic $\pi$ backbone provided by the tight H-bonding network. Finally, among different anions screened, including $\mathrm{F}^{-}, \mathrm{Cl}^{-}, \mathrm{Br}^{-}, \mathrm{I}^{-}, \mathrm{HSO}_{4}^{-}, \mathrm{N}_{3}^{-}, \mathrm{HCO}_{3}^{-}, \mathrm{PF}_{6}^{-}, \mathrm{H}_{2} \mathrm{PO}_{4}^{-}, \mathrm{OH}^{-}, \mathrm{ClO}_{4}^{-}, \mathrm{AcO}^{-}$, $\mathrm{NO}_{3}{ }^{-}$, and $\mathrm{SCN}^{-}, 217$ responded exclusively to $\mathrm{CN}^{-}$in water at $\mathrm{pH}=7.0$ (HEPES). This excellent selectivity was further highlighted by competition experiments. 

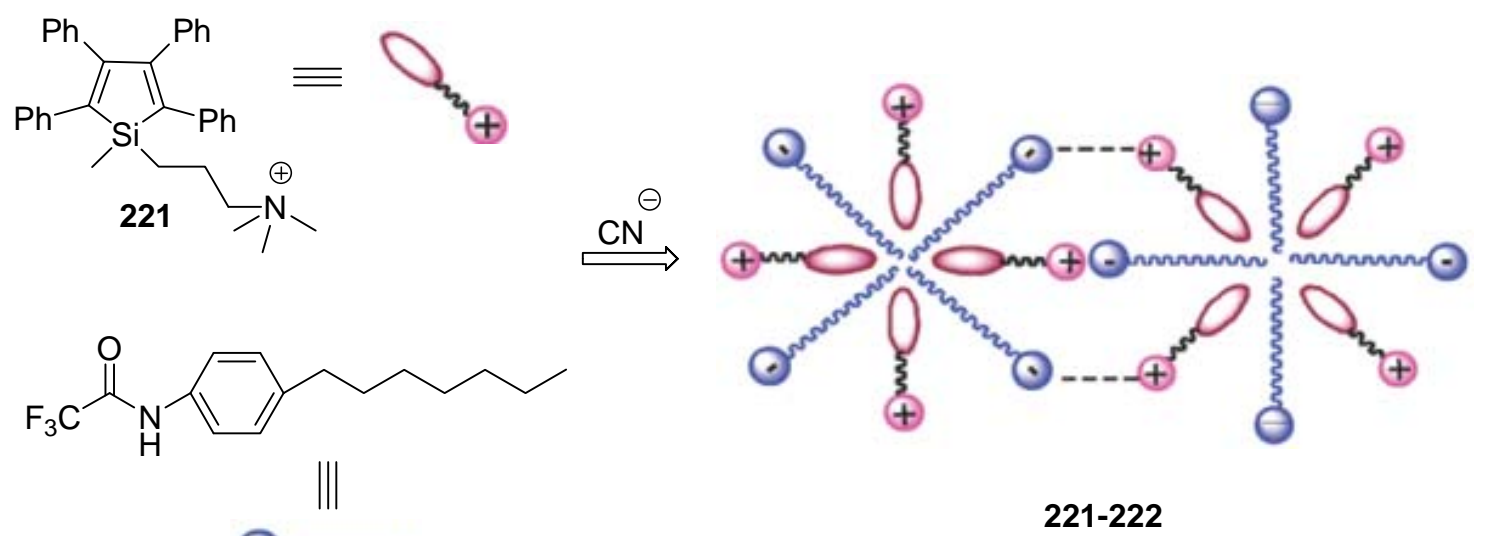

Fig. 96 Proposed cyanide-induced reaction between silole derivative 221 and compound 222.

A fluorescence turn-on detection of $\mathrm{CN}^{-}$anion in aqueous solution was established with the ensemble of silole 221 and compound 222 containing a trifluoroacetylamino group (Figure 96). ${ }^{252}$ Solutions of 221 and 222 in DMSO-water 1:75 v/v mixtures show negligible fluorescence, while addition of increasing quantities of $\mathrm{CN}^{-}$induced the apparition of an intense (8-fold enhancement) emission band at 476 nm. ${ }^{1} \mathrm{H}-\mathrm{NMR}$, dynamic light scattering, ${ }^{13} \mathrm{C}-\mathrm{NMR},{ }^{19} \mathrm{~F}-\mathrm{NMR}$ and mass spectroscopic experiments concluded that the addition of $\mathrm{CN}^{-}$to the trifluoroacetylamino group in compound 222 led to the formation of an amphiphilic derivative with a negative headgroup. This induced the co-aggregation of silole 221 and the new amphiphilic compound resulting in an enhancement of the silole 221 fluorescence. Other anions $\left(\mathrm{AcO}^{-}, \mathrm{Br}^{-}, \mathrm{Cl}^{-}, \mathrm{F}^{-}, \mathrm{H}_{2} \mathrm{PO}_{4}^{-}, \mathrm{HSO}_{4}^{-}, \mathrm{N}_{3}^{-}\right.$and $\mathrm{NO}_{3}^{-}$) gave no response.<smiles>O=Cc1ccc(-c2nc3c4ccccc4c4ccccc4c3[nH]2)cc1</smiles>

Fig. 97 Reaction of chemodosimeter 223 with $\mathrm{ClO}^{-}$anion.

The last examples in this section deal with the fluorogenic detection of $\mathrm{ClO}^{-}$, $\mathrm{ONOO}^{-}$and $\mathrm{SO}_{3}{ }^{2-}$ using the chemodosimeter approach. In the first example a deoximation reaction of $\mathbf{2 2 3}$ induced by $\mathrm{ClO}^{-}$was used for the fluorescent recognition 
of this anion (Figure 97). ${ }^{253}$ The detection was carried out using water -DMF 1:4 v/v (phosphate buffer, pH 9.0) mixtures. In this medium 223 shows an emission band at 439 $\mathrm{nm}$. Upon addition of $\mathrm{ClO}^{-}$anion, the intensity of the emission gradually decreased with the simultaneous appearance of a new red-shifted emission at $509 \mathrm{~nm}$ that was assigned to the aldehyde functionalized derivative obtained from 223. The new red-shifted band is a direct consequence of the fact that the electron-withdrawing ability of the aldehyde group is stronger than that of the oxime moiety. The changes in the emission intensity allowed a ratiometric detection of $\mathrm{ClO}^{-}$. The addition of metal cations, anions $\left(\mathrm{Cl}^{-}, \mathrm{AcO}^{-}\right.$ , $\mathrm{SO}_{4}{ }^{2-}, \mathrm{NO}_{3}{ }^{-}, \mathrm{ClO}_{3}{ }^{-}$and $\mathrm{ClO}_{4}{ }^{-}$) and $\mathrm{H}_{2} \mathrm{O}_{2}$ induced negligible changes in the emission profile of 223.
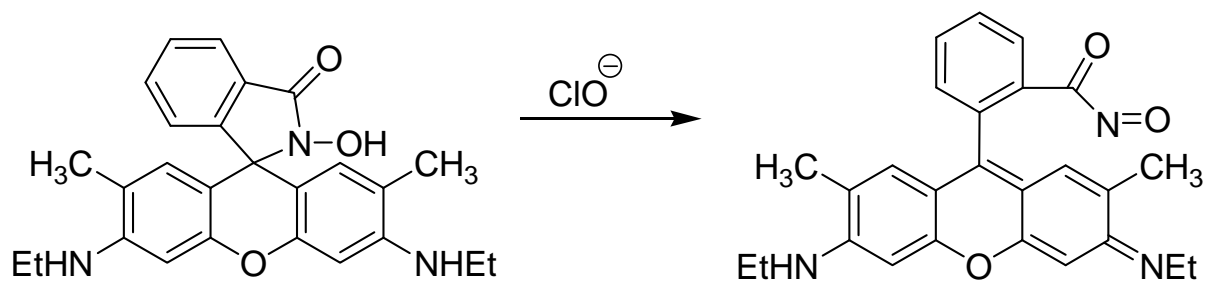

224

Fig. 98 Mechanism of the reaction of rhodamine-based chemosensor 224 with $\mathrm{ClO}^{-}$ anion.

A new rhodamine-hydroxamic acid-based fluorescent chemosensor for the rapid detection of $\mathrm{ClO}^{-}$in aqueous media was developed (Figure 98). ${ }^{254}$ Addition of $\mathrm{ClO}^{-}(10$ equiv.) to aqueous solutions (PBS, $\mathrm{pH}$ 7.4) of 224 (which was initially colourless as it existed in the spirocyclic form) resulted in the instantaneous development of a pink colour. Also a very remarkable fluorescence band at $547 \mathrm{~nm}$ was observed. These changes are attributed to the $\mathrm{ClO}^{-}$-induced irreversible oxidation of 224 that yields the corresponding ring-opened acyl nitroso derivative. $\mathrm{ClO}^{-}$was the only product which dramatically enhanced the fluorescent intensity of $\mathbf{2 2 4}$ whereas other reactive oxygen species $\left(\mathrm{H}_{2} \mathrm{O}_{2}, \mathrm{NO}, \mathrm{OH}, \mathrm{ROO}, \mathrm{O}_{2}^{-}\right)$gave no response. In addition, 224 was studied for the $\mathrm{ClO}^{-}$detection in biological systems. 
<smiles>CCNC(=O)c1ccc2n1B(F)[N+]1=C(C(=O)OCC)C=CC1=C2c1cc(CCC(=O)C(F)(F)F)ccc1O</smiles>

225

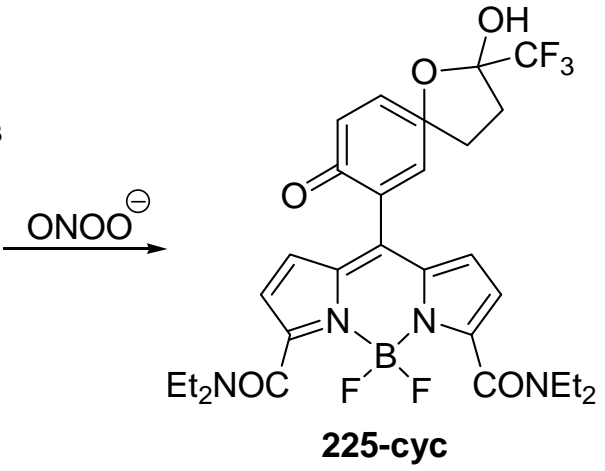

225-cyc

Fig. 99 Reaction of BODIPY-functionalized receptor 225 with $\mathrm{ONOO}^{-}$anion.

BODIPY functionalized receptor 225 was designed as a suitable probe for $\mathrm{ONOO}^{-}$detection (Figure 99). ${ }^{255}$ The probe was non-fluorescent prior to its reaction with $\mathrm{ONOO}^{-}$which induced a dramatic 69-fold increase in the fluorescence intensity of 225. The intensity enhancement was ascribed to the formation of compound 225-cyc that was confirmed through ESI-MS. A much weaker response was observed upon reaction with other reactive oxygen and nitrogen species such as $\mathrm{HClO}, \cdot \mathrm{OH}, \mathrm{H}_{2} \mathrm{O}_{2},{ }^{1} \mathrm{O}_{2}$, $\mathrm{NO}_{2}{ }^{-}, \mathrm{NO}_{3}{ }^{-}, \mathrm{NO}, \mathrm{O}_{2}{ }^{-}$and $\mathrm{ROO}$. Moreover, 225 was used to detect $\mathrm{ONOO}^{-}$endogenous production in cells under physiological conditions.

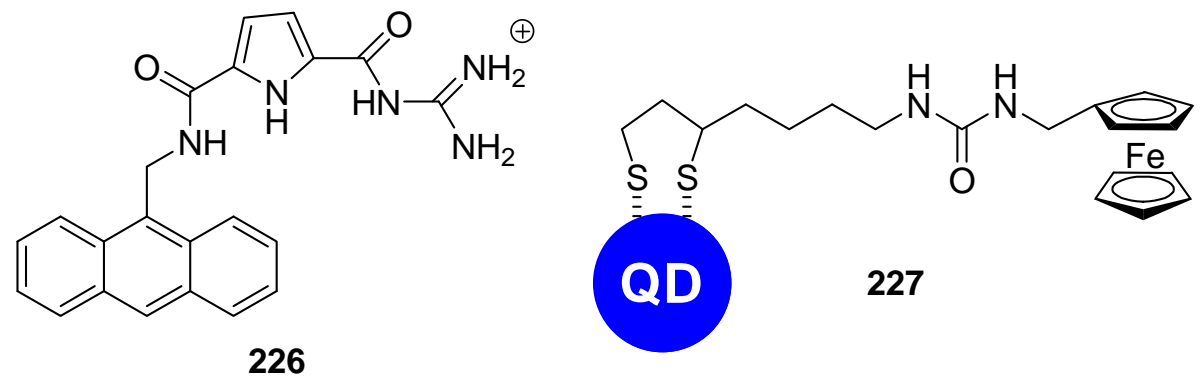

Fig. 100 Structure of receptors 226 and 227.

Receptor 226 is a new FRET-based ratiometric fluorescent chemodosimeter for $\mathrm{SO}_{3}{ }^{2-}$, that consists of a guanidiniocarbonyl pyrrole moiety covalently attached to a 9(aminomethyl)anthracene group (Figure 100). ${ }^{256}$ In water-DMSO 9:1 v/v solutions (Tris buffer, $\mathrm{pH}$ 7.2) 226 display the typical anthracene emission bands centred at $417 \mathrm{~nm}$ upon excitation at $290 \mathrm{~nm}$ due to the existence of a FRET process between the guanidiniocarbonyl pyrrole (excitation at $290 \mathrm{~nm}$, emission at $350 \mathrm{~nm}$ ) and the anthracene. Addition of $\mathrm{SO}_{3}{ }^{2-}$ anion to solutions of $\mathbf{2 2 6}$ leads first to the formation of 2:2 complexes in which the anion interacts through a combination of ion pairing and 
multiple hydrogen bonds with the receptor. In the final ensemble two anthracenes were located closely. This adducts, upon irradiation, gives an intermolecular $[4 \pi+4 \pi]$ photodimerization of the anthracene moieties. This photodimerization minimized the spectral overlap between the donor (guanidiniocarbonyl pyrrole) emission and the acceptor (anthracene) absorption bands, resulting in the cancellation of the FRET effect between the two fluorophores. This allows a ratiometric detection of $\mathrm{SO}_{3}{ }^{2-}$. Other anions tested $\left(\mathrm{F}^{-}, \mathrm{Cl}^{-}, \mathrm{Br}^{-}, \mathrm{I}^{-}, \mathrm{AcO}^{-}, \mathrm{SO}_{4}{ }^{2-}, \mathrm{HCO}_{3}{ }^{-}, \mathrm{HPO}_{4}{ }^{2-}, \mathrm{P}_{2} \mathrm{O}_{7}{ }^{4-}, \mathrm{NO}_{3}{ }^{-}\right.$and $\left.\mathrm{NO}_{2}{ }^{-}\right)$ induced negligible changes in the emission profiles.

\section{4.- Hybrid sensory materials.}

Several interesting examples have been reported using hybrid materials for the fluorogenic sensing of anions. For instance receptor 227 contains a urea binding site and uses a CdSe/ZnS quantum dot as signalling moiety (Figure 100). ${ }^{257}$ Chloroform solutions of receptor 227 are poorly fluorescent at $540 \mathrm{~nm}$ due to an electron transfer process between the ferrocene and the excited QD. Addition of $\mathrm{Cl}^{-}, \mathrm{Br}^{-}, \mathrm{HSO}_{4}{ }^{-}$and $\mathrm{ClO}_{4}{ }^{-}$induced negligible changes in the emission intensity at $540 \mathrm{~nm}$, whereas addition of $\mathrm{AcO}^{-}$and $\mathrm{H}_{2} \mathrm{PO}_{4}^{-}$induced a moderate enhancement of the emission (5-fold). However the more striking effect was observed upon addition of $\mathrm{F}^{-}$, in this case a 25 fold enhancement in the emission intensity at $540 \mathrm{~nm}$ was observed. The authors attributed the changes in emission to the formation of fluoride-urea complexes that alters the rate of the electron transfer leading to an enhancement in the emission.
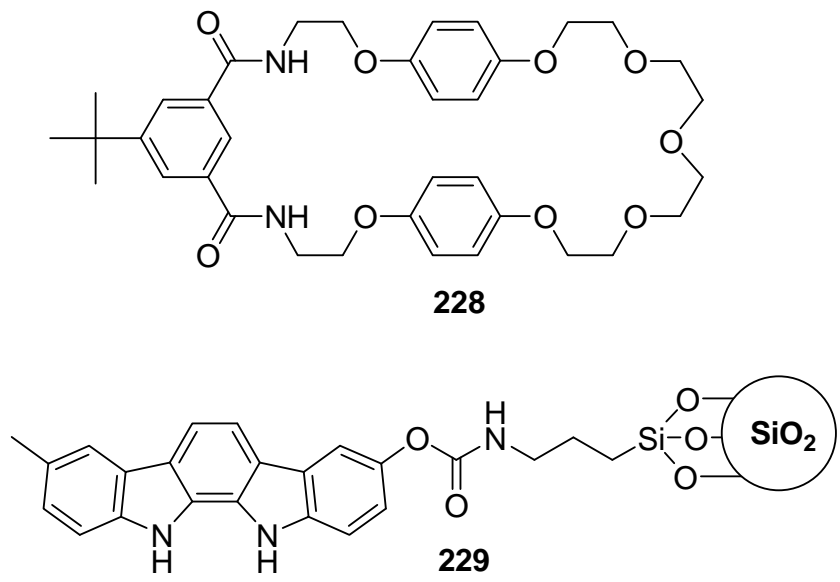

Fig. 101 Structure of macrocycle 228 and indolocarbazole functionalized silica nanoparticles 229. 
Acetonitrile suspensions of the indolocarbazole functionalized silica nanoparticles 229 show a broad emission band at $387 \mathrm{~nm}$ (see Figure 101). ${ }^{258}$ Addition of $\mathrm{SO}_{4}{ }^{2-}$ and $\mathrm{F}^{-}$anions induced an emission intensity decrease together with a $6 \mathrm{~nm}$ bathochromic shift indicative of anion coordination with the indolocarbazole subunit through hydrogen bonding interactions. Further addition of macrocycle 228 induced another emission intensity decrease ascribed to the anion-templated formation of a pseudorotaxane in the nanoparticle surface. The threading of the pseudorotaxane was carried out only in the presence of $\mathrm{SO}_{4}{ }^{2-}$ and for instance addition of $\mathrm{HSO}_{4}{ }^{-}$and $\mathrm{Cl}^{-}$did not induce changes in the emission intensity. The same results were obtained when the indolocarbazole derivative was anchored onto TentaGel polystyrene beads. However, the authors do not fully explore the use of these materials as fluorescent probes for anions.

Dealing with the use of materials for the development of fluorescent systems for anion sensing, Zeller et al prepared a tetrazole-based microporous metal-organic framework (MOF) that exhibits a selective response towards $\mathrm{NO}_{2}{ }^{-259}$ Ligand 5-methyl$1 H$-tetrazole $(5-\mathrm{MT})$ yields a highly symmetric $\left[\mathrm{Cd}\left(\mu_{2}-\mathrm{Cl}\right)\left(\mu_{4}-5 \mathrm{MT}\right)\right]_{\mathrm{n}}$ MOF that showed an emission band centred at $370 \mathrm{~nm}$ in DMF solutions assigned to an intraligand transition. The effect of selected anions in DMF solutions on the MOF was studied. Addition of $\mathrm{Cl}^{-}, \mathrm{I}^{-}, \mathrm{ClO}_{4}{ }^{-}$and $\mathrm{NO}_{3}{ }^{-}$induced negligible changes in the emission intensity whereas the presence of $\mathrm{NO}_{2}^{-}$induced a continuous decrease of the emission. This quenching was ascribed to an energy transfer though $\mathrm{C}-\mathrm{H} \cdots \mathrm{O}$ hydrogen bonding interactions between methyl groups and the $\mathrm{NO}_{2}^{-}$ions.

Citrate-stabilized gold nanoparticles (AuNPs) were used for the development of a chemodosimeter assay for the selective turn-on fluorescent detection of $\mathrm{CN}^{-}{ }^{260}$ The fluorescent photostable rhodamine B was selected as fluorophore and it was adsorbed on the surface of citrate-stabilized AuNPs through electrostatic interactions. Aqueous solutions of these nanoparticles show a weakly emission band at $577 \mathrm{~nm}$ due to the presence of an efficient energy transfer from the fluorophore to the AuNPs. Of all the anions tested $\left(\mathrm{B}_{4} \mathrm{O}_{7}{ }^{2-}, \mathrm{F}^{-}, \mathrm{Cl}^{-}, \mathrm{Br}^{-}, \mathrm{I}^{-}, \mathrm{BrO}_{3}{ }^{-}, \mathrm{ClO}_{4}{ }^{-}, \mathrm{CO}_{3}{ }^{2-}, \mathrm{C}_{2} \mathrm{O}_{4}{ }^{2-}, \mathrm{IO}_{3}{ }^{-}, \mathrm{NO}_{2}{ }^{-}, \mathrm{NO}_{3}{ }^{-}, \mathrm{PO}_{4}{ }^{3-}\right.$ , $\mathrm{SO}_{3}{ }^{2-}, \mathrm{SO}_{4}{ }^{2-}, \mathrm{S}_{2} \mathrm{O}_{8}{ }^{2-}, \mathrm{S}^{2-}$ and $\mathrm{SCN}^{-}$), only $\mathrm{CN}^{-}$induced a progressive enhancement of the emission intensity. The etching of gold nanoparticles induced by $\mathrm{CN}^{-}$was suggested as the mechanism that modulated the emission intensity. Upon $\mathrm{CN}^{-}$attack the AuNPs became smaller and the rodamine B molecules would gradually be desorbed from the 
surface leading to a recovery in of the emission. With the use of this sensing material a remarkable detection limit of $\mathrm{CN}^{-}$as low as $8.0 \times 10^{-8} \mathrm{~mol} \mathrm{dm}^{-3}$ was achieved.
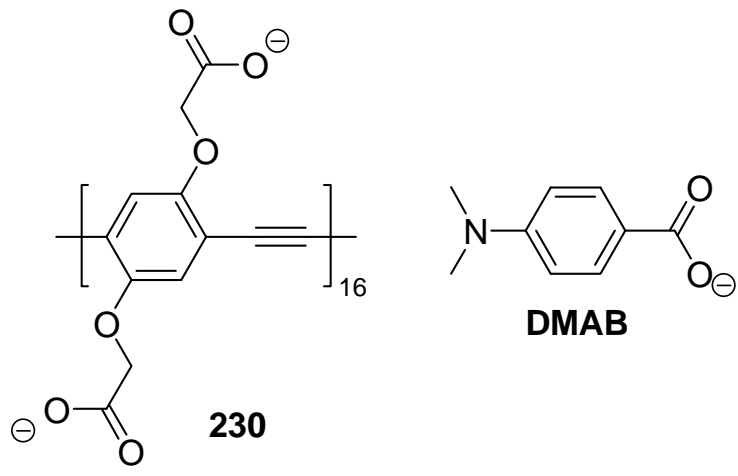

DMAB

Fig. 102 Structure of polymer 230 and DMAB.

Cube-shaped magnetic cobalt spinel ferrite $\left(\mathrm{CoFe}_{2} \mathrm{O}_{4}\right)$ coated with DMAB (NPDMAB) were used as starting materials together with poly-(p-phenyleneethynylene), 230, for the fluorescence sensing of $\mathrm{P}_{2} \mathrm{O}_{7}{ }^{4-}$ and ATP (Figure 102). ${ }^{261}$ When NP-DMAB were mixed with 230, a displacement of the DMAB from the nanoparticle surface occurs yielding 230-NP that was poorly fluorescent due to an FRET process between the nanoparticles and the excited state of 230. Addition of $\mathrm{P}_{2} \mathrm{O}_{7}{ }^{4-}$ and ATP to aqueous solutions (PIPES, $\mathrm{pH}$ 7.2) of the 230-NP ensemble induced a remarkable emission enhancement whereas addition of triphosphate, ADP, AMP and $\mathrm{PO}_{4}{ }^{3-}$ induced moderate enhancements. The emission revival observed with $\mathrm{P}_{2} \mathrm{O}_{7}{ }^{4-}$ and ATP was ascribed to a disruption of the 230-NP ensemble and subsequent release of 230 to the solution. Addition of only $2 \mu \mathrm{mol}$ of $\mathrm{P}_{2} \mathrm{O}_{7}{ }^{4-}$ was able to induce the turn-on of the fluorescence whereas a very weak fluorescence was observed for concentrations up to $200 \mu \mathrm{mol}$ of $\mathrm{PO}_{4}{ }^{3-}$. A possible use in bio-diagnosis applications was suggested. 


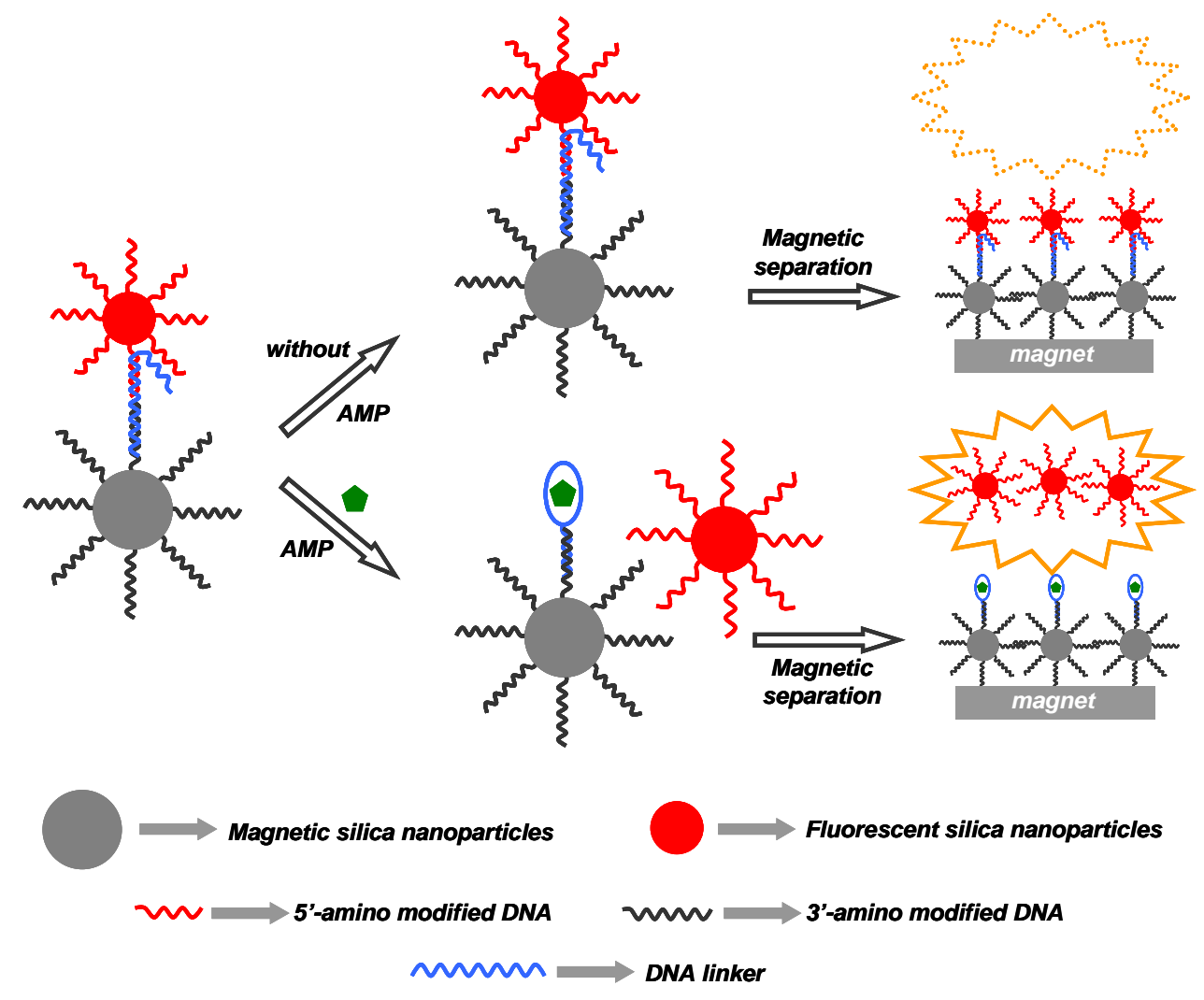

Fig. 103 Schematic representation of a probe for AMP detection by the use of magnetic and fluorescent silica nanoparticles.

Magnetic and fluorescent silica nanoparticles were employed in the development of a new AMP probe based on the aptamer-induced disassembly of a complex formed between both types of nanoparticles (Figure 103). ${ }^{262}$ The sensory system was composed by three elements namely (i) magnetic silica microspheres functionalized with 3'-amino modified DNA, (ii) fluorescent silica nanoparticles functionalized with 5'-amino modified DNA, and (iii) a DNA linker that acts as detection probe. This DNA linker contains three well defined segments, segment a, that can hybridize with the magnetic silica microspheres, segment $b$, that can hybridize with the last five bases of the fluorescent silica nanoparticles, and finally segment $\mathrm{c}$, that is the AMP aptamer sequence that can hybridize with the first seven bases of the fluorescente silica nanoparticles. In the presence of AMP, the aptamer bind this nucleotide and does not hybridize with the seven bases of the fluorescent silica nanoparticles. Upon magnetic removal of the magnetic silica nanoparticles the fluorescence was measured in the solution. Addition of increasing quantities of AMP to suspension containing the sensory system induced an increase in the emission intensity at $586 \mathrm{~nm}$ in the solution after 
magnetic separation. The response was highly selective because the aptamer binding specificity and UMP, CMP and GMP were unable to induce an increase of the fluorescence in the solution.<smiles>CC(C)NC(OCO)OCCNC(=O)/C=C/C(=O)NC(CCC(=O)OC1CCCCC1)C(=O)OC1CCCCC1</smiles>

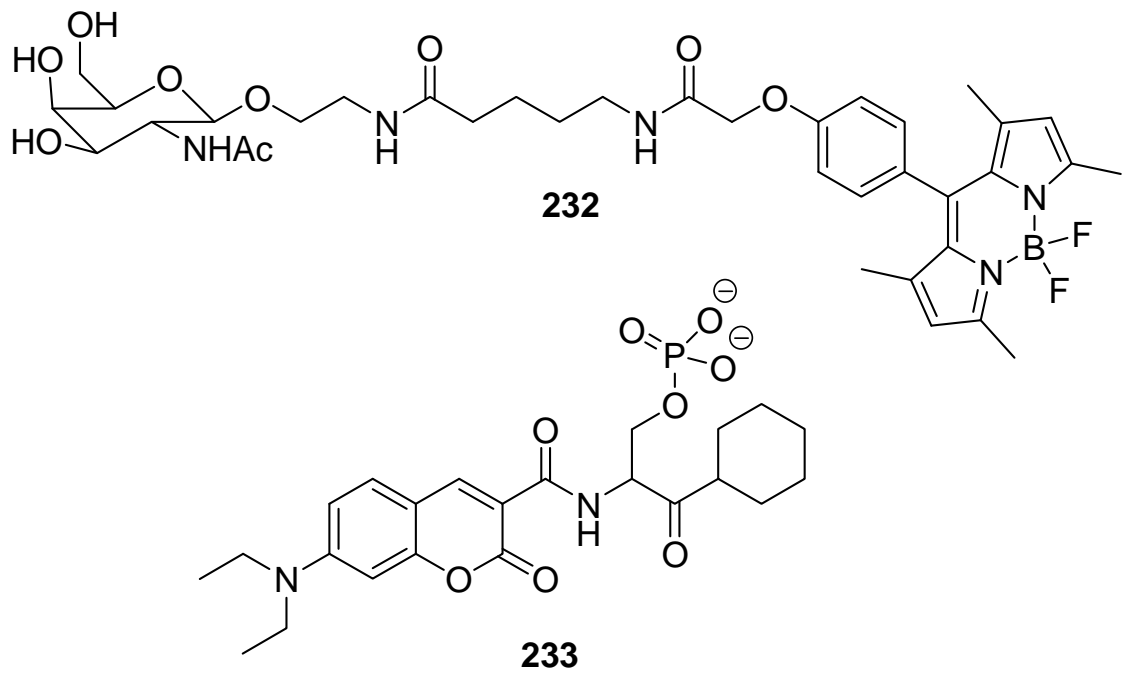

Fig. 104 Structure of receptors 231, 232 and 233.

A displacement-like assay based on the use of a hybrid material composed by a supramolecular hydrogel, enzymes and aminoethyl-modified MCM-41 type mesoporous silica particles encapsulating a fluorescente dye was developed for the sensing of polyanions of biological importance. ${ }^{263}$ An amino functionalized MCM-41 material was loaded with phosphorylated coumarin 233 at $\mathrm{pH} 5.0$; an electrostatic interaction between the protonated amines and the $\mathrm{PO}_{4}{ }^{3-}$ fragment of 233 is established (Figure 104). Then this loaded mesoporous material was incorporated into a supramolecular hydrogel matrix formed by 231 and 232 (with an aqueous hydrophilic gel phase and a fibrous hydrophobic structure) that also contains the enzymes acid phosphatase (ACP) and alkaline phosphatase (AP). Addition of heparin, chondroitin sulfate, sucrose octasulfate (Suc-8S) and inositol hexaphosphate $\left(\mathrm{IP}_{6}\right)$ to water suspensions of the supramolecular hydrogel at $\mathrm{pH} 5.0$ induced the release of 233 into the aqueous gel phase due coordination of the polyanions with the protonated amino 
moieties in the MCM-41 solid. In this aqueous phase fluorophore 233 was hydrolyzed by the enzyme (AP or APC) and the coumarin without the $\mathrm{PO}_{4}{ }^{3-}$ was accumulated into the supramolecular fiber of the hydrogel that is hydrophobic. Due to the fact that BODIPY derivative 232 was located in the hydrophobic domain of the supramolecular gel a FRET process from the coumarin to the BODIPY was produced that enables fluorescent detection of the added polyanions.

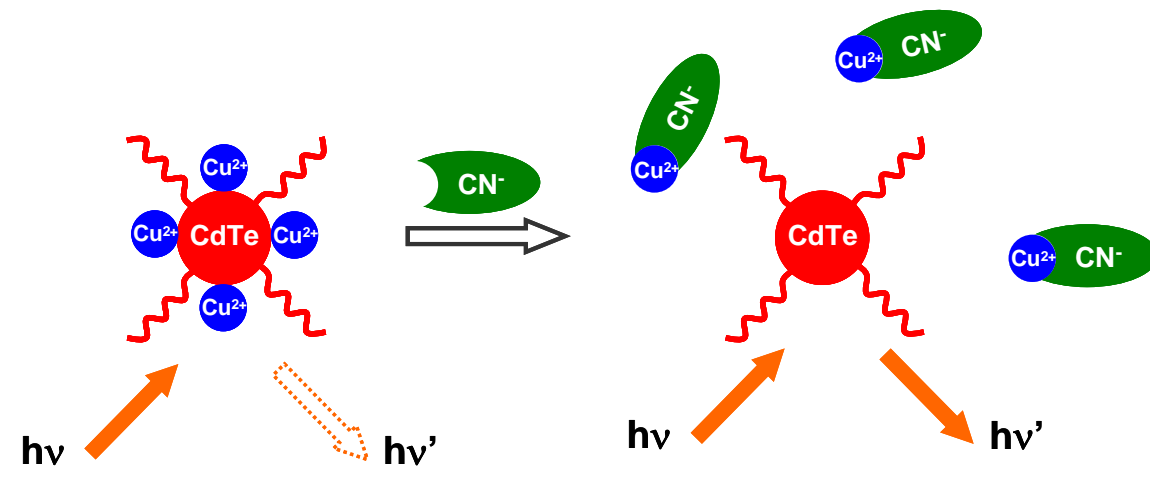

Fig. $105 \mathrm{CdTe}$ quantum dots for the fluorescent sensing of $\mathrm{CN}^{-}$anion.

CdTe quantum dots capped with mercaptosuccinic acid have been successfully applied for photoluminescent $\mathrm{CN}^{-}$sensing in water (Figure 105). ${ }^{264}$ At this respect, water (TRIS buffer, $\mathrm{pH}$ 7.0) suspensions of CdTe quantum dots show an emission maxiumn at $610 \mathrm{~nm}$ upon excitation at $500 \mathrm{~nm}$. The emission band at $610 \mathrm{~nm}$ was gradually quenched upon addition of $\mathrm{Cu}^{2+}$ cation due to the adsorption of this metal cation into the surface of CdTe quantum dots. Addition of $\mathrm{CN}^{-}$anions induced the recovery of the CdTe quantum dots emission because a displacement of the $\mathrm{Cu}^{2+}$ ion from the surface was produced due to the formation of $\left[\mathrm{Cu}(\mathrm{CN})_{n}\right]^{(\mathrm{n}-1)-}$ complexes. The fluorescent response observed was highly selective and other anions tested $\left(\mathrm{AcO}^{-}, \mathrm{Br}^{-}\right.$, $\mathrm{BrO}_{3}{ }^{-}, \mathrm{Cl}^{-}, \mathrm{ClO}_{4}{ }^{-}, \mathrm{CO}_{3}{ }^{2-}, \mathrm{C}_{2} \mathrm{O}_{4}{ }^{2-}, \mathrm{F}^{-}, \mathrm{IO}_{3}{ }^{-}, \mathrm{I}^{-}, \mathrm{NO}_{2}{ }^{-}, \mathrm{PO}_{4}{ }^{3-}, \mathrm{SO}_{3}{ }^{2-}, \mathrm{SO}_{4}{ }^{2-}, \mathrm{S}_{2}{ }^{-}$and $\mathrm{SCN}^{-}$) induced no changes in the emission profile of the $\mathrm{Cu}^{2+}$-covered $\mathrm{CdTe}$ quantum dots.

\section{4.- Concluding remarks.}

In this review an account of the examples reported in the year 2009 dealing with the design of chromogenic and fluorogenic chemosensors or reagents for anions has been given. The examples above show how the combination of suitable binding sites and signaling events can be coupled in order to obtain, in certain cases, highly selective 
responses for target anions. The first part embraces chromogenic systems, whereas the second section contains examples of fluorogenic signaling. In both cases a classification was made in relation to the signaling paradigm used. Thus most of the examples reported belong to one of the following protocols; (i) the binding site - signaling unit protocols, (ii) the displacement approach and (iii) the design of chemodosimeters. Additionally, we have included a section that shows the use of hybrid materials, in this later case the anion signalling concepts arise in most cases from the suitable combination of molecular/supramolecular functions and nanoscopic scaffoldings.

As stated above we published a comprehensive review on chromo-fluorogenic anion chemosensor and reagents in 2003 that contained all the examples reported in the chemical literature in this field. This review in 2003 included a total of 190 reports of chromo-fluorogenic probes for anions. The review we have completed now encloses more than 130 papers reported alone in 2009 in this area. This gives a clear indication of the increasing interest that the design of anion signalling systems is reaching within the scientific community. When one compares the two reviews it is evident that still today, the most common approximation to the development of chromo-fluorogenic anion probes is the binding site-signalling subunit approach. This protocol follow concepts of anion coordination chemistry coupled with suitable signal mechanisms generation. This approach still is highly interest and will continue being a landmark paradigm in the future research of selective molecular chemosensors for target anions. From a closer look to both reviews it is also clear that the number of examples dealing with the use of specific anion-induced reactions (the chemodosimeter approach) is the protocol that more has increased in relation to the relative number of examples reported. Thus whereas about only 15 reports were found in the literature until 2003, in the year 2009 alone more than 35 examples have been described using this paradigm. We have also found a significant number of new concepts for anion signalling that in most cases involve the use of nanoparticles or nanostructured scaffoldings.

In the examples reported, there are still a large number of systems that show optical signalling of anions in non aqueous environments. This is especially so, for protocols which are based in the reactivity of basic anions with acidic dyes, the signalling protocols dealing with hydrogen bonding interactions or deprotonation processes. Whereas this is still a widely used approach, in most cases these systems do not display sensing features in the presence of water. Additionally, there are an increasing number of highly selective systems showing favourable signalling features in 
aqueous environments and in highly competitive media. However, in spite of the potential use of many of these probes for the detection of anions in real samples, there is still a lack of complete analytical studies and future efforts may be necessary in this line.

In summary, the chemistry of chromo-fluorogenic anion chemosensor is today a well established area within the field of anion supramolecular chemistry and a number of new advances are envisioned. We believe that upcoming studies will probably involve the search of different signalling paradigms (for instance based in nanotechnology) the use of novel fluorescent subunits (for instance NIR dyes), analytical applications (especially bio-applications in complex systems), the signalling of more demanding anions, etc. All these advances will surely come from new original concepts that will result in the near future in highly selective and specific sensing receptors for targeting new anions of environmental and biological importance. 


\section{5.- References.}

${ }^{1}$ F. P. Schmidtchen, A, Gleich, A. Schummer, Pure Appl. Chem., 1989, 61, 1535-1546.

2 B. Dietrich, Pure Appl. Chem., 1993, 65, 1457-1464.

${ }^{3}$ J. L. Atwood, K. T. Holman, J. W. Steed, Chem. Commun., 1996, 1401-1407.

${ }^{4}$ F. P. Schmidtchen, M. Berger, Chem. Rev., 1997, 97, 1609-1646.

${ }^{5}$ M. M. G. Antonisse, D. N. Reinhoudt, Chem. Commun., 1998, 443-448.

${ }^{6}$ P. A. Gale, Coord. Chem. Rev., 2000, 199, 181-233.

${ }^{7}$ P. A. Gale, Coord. Chem. Rev., 2001, 213, 79-128.

${ }^{8}$ P. A. Gale, Coord. Chem. Rev., 2003, 240, 191-221.

${ }^{9}$ P. A. Gale, R. Quesada, Coord. Chem. Rev., 2006, 250, 3219-3244.

${ }^{10}$ P. A. Gale, S. E. García-Garrido, J. Garric, Chem. Soc. Rev., 2008, 37, 151-190.

${ }^{11}$ C. Caltagirone, P. A. Gale, Chem. Soc. Rev., 2009, 38, 520-563.

${ }^{12}$ S. Kubik, Chem. Soc. Rev., 2009, 38, 585-605.

${ }^{13}$ F. P. Schimdtchen, Top. Curr. Chem., 2005, 255, 1-29.

${ }^{14}$ F. P. Schmidtchen, Coord. Chem. Rev., 2006, 250, 2918-2928.

${ }^{15}$ P. A. Gale, Acc. Chem. Res., 2006, 39, 465-475.

${ }^{16}$ J. L. Sessler, S. Camiolo, P. A. Gale, Coord. Chem. Rev., 2003, 240, 17-55.

${ }^{17}$ C. R. Bondy, S. J. Loeb, Coord. Chem. Rev., 2003, 240, 77-99.

${ }^{18}$ K. Choi, A. D. Hamilton, Coord. Chem. Rev., 2003, 240, 101-110.

${ }^{19}$ A. P. Davis, Coord. Chem. Rev., 2006, 250, 2939-2951.

${ }^{20}$ M. D. Best, S. L. Tobey, E. V. Anslyn, Coord. Chem. Rev., 2003, 240, 3-15.

${ }^{21}$ J. M: Llinares, D. Powell, K. Bowman-James, Coord, Chem. Rev., 2003, 240, 57-75.

${ }^{22}$ K. A. Schug, W. Lindner, Chem. Rev., 2005, 105, 67-113.

${ }^{23}$ J. Yoon, S. K. Kim, N. J. Singh, K. S. Kim, Chem. Soc. Rev., 2006, 35, 355-360.

${ }^{24}$ P. Blondeau, M. Segura, R. Pérez-Fernández, J. de Mendoza, Chem. Soc. Rev., 2007, $36,198-210$.

${ }^{25}$ Z. Xu, S. K. Kim, J. Yoon, Chem. Soc. Rev., 2010, 39, 1457-1466.

${ }^{26}$ E. García-España, P. Díaz, J. M. Llinares, A. Bianchi, Coord. Chem. Rev., 2006, 250, 2952-2986.

${ }^{27}$ C. Schmuck, Coord. Chem. Rev., 2006, 250, 3053-3067.

${ }^{28}$ V. Amendola, L. Fabbrizzi, C. Mangano, P. Pallavicini, A. Poggi, A. Taglietti, Coord. Chem. Rev., 2001, 219-221, 821-837.

${ }^{29}$ P. D. Beer, E. J. Hayes, Coord. Chem. Rev., 2003, 240, 167-189. 
${ }^{30}$ J. W. Steed, Chem. Soc. Rev., 2009, 38, 506-519.

${ }^{31}$ E. J. O’Neil, B. D. Smith, Coord. Chem. Rev., 2006, 250, 3068-3080.

${ }^{32}$ C. R. Rice, Coord. Chem. Rev., 2006, 250, 3190-3199.

${ }^{33}$ V. Amendola, L. Fabbrizzi, Chem. Commun., 2009, 513-531.

${ }^{34}$ R. Martínez-Máñez, F. Sancenón, Chem. Rev., 2003, 103, 4419-4476.

${ }^{35}$ E. A. Katayev, Y. A. Ustynyuk, J. L. Sessler, Coord. Chem. Rev., 2006, 250, 30043037.

${ }^{36}$ C. Suksai, T. Tuntulani, Chem. Soc. Rev., 2003, 32, 192-202.

${ }^{37}$ S. K. Kim, D. H. Lee, J. -I. Hong, J. Yoon, Acc. Chem. Res., 2009, 42, 23-31.

${ }^{38}$ P. D. Beer, Coord. Chem. Rev., 2000, 205, 131-155.

${ }^{39}$ P. D. Beer, Chem. Commun., 1996, 689-696.

${ }^{40}$ A. P. de Silva, H. Q. N: Gunaratne, T. Gunnlaugsson, A. J. M. Huxley, C. P. McCoy, J. T. Rademacher, T. E. Rice, Chem. Rev., 1997, 97, 1515-1566.

${ }^{41}$ T. Gunnlaugsson, M. Glynn, G. M. Tocci, P. E. Kruger, F. M: Pfeffer, Coord. Chem. Rev., 2006, 250, 3094-3117.

${ }^{42}$ V. Amendola, D. Esteban-Gómez, L. Fabbrizzi, M. Lichelli, Acc. Chem. Res., 2006, 39, 343-353.

${ }^{43}$ T. Gunnlaugsson, H. D. P. Ali, M. Glynn, P. E. Kruger, G. M: Hussey, F. M. Pfeffer, C. M. G. Dos Santos, J. Tierney, J. Fluoresc., 2005, 15, 287-299.

${ }^{44}$ S. L. Wiskur, H. Ait-Haddou, J. J. Lavigne, E. V. Anslyn, Acc. Chem. Res., 2001, 34, 963-972.

${ }^{45}$ B. T. Nguyen, E. V. Anslyn, Coord. Chem. Rev., 2006, 250, 3118-3127.

${ }^{46}$ Z. Xu, X. Chen, H. N.Kim, J. Yoon, Chem. Soc. Rev., 2010, 39, 127-137.

${ }^{47}$ R. Martínez-Máñez, F. Sancenón, J. Fluoresc., 2005, 15, 267-285.

${ }^{48}$ Y. M. Hijji, B. Barare, A. P. Kennedy, R. Butcher, Sens. Actuators B, 2009, 136, 297 302.

49 Y. -M. Zhang, Q. Lin, T. -B. Wei, D. -D. Wang, H. Yao, Y. -L. Wang, Sens. Actuators B, 2009, 137, 447-455.

${ }^{50}$ P. Anzenbacher Jr., R. Nishiyabu, M. A. Palacios, Coord. Chem. Rev., 2006, 250, 2929-2938.

${ }^{51}$ P. Anzenbacher Jr., A. C. Try, H. Miyaji, K. Jursíková, V. M. Lynch, M. Marquez, J. L. Sessler, J. Am. Chem. Soc., 2000, 122, 10268-10272.

${ }^{52}$ C. B. Black, B. Andrioletti, A. C. Try, C. Ruiperez, J. L. Sessler, J. Am. Chem. Soc., 1999, 121, 10438-10439. 
${ }^{53}$ T. Mizuno, W. -H. Wei, L. R. Eller, J. L: Sessler, J. Am. Chem. Soc., 2002, 124, 1134-1135.

${ }^{54}$ H. Maeda, Y. Kusunose, Chem. Eur. J., 2005, 11, 5661-5666.

${ }^{55}$ T. Ghosh, B. G. Maiya, A. Samanta, Dalton Trans., 2006, 795-801.

${ }^{56}$ D. Aldakov, P. Anzenbacher Jr., J. Am. Chem. Soc., 2004, 126, 4752-4753.

${ }^{57}$ J. L. Sessler, D. -G. Cho, V. Lynch, J. Am. Chem. Soc., 2006, 128, 16518-16519.

${ }^{58}$ S. M. S. Chauhan, T. Bisht, B. Garg, Sens. Actuators B, 2009, 141, 116-123.

${ }^{59}$ X. -W. Liu, R. Yang, A. -F. Li, Z. Li, Y. -F. Gao, X. -X. Luo, Y. -B. Ruan, Y. -B. Jiang, Org. Biomol. Chem., 2009, 7, 4021-4028.

${ }^{60}$ J. N. Babu, V. Bhalla, M. Kumar, R. K. Puri, R. K. Mahajan, New J. Chem., 2009, 33, 675-681.

${ }^{61}$ M. Boiocchi, L. Fabbrizzi, M. Garolfi, M. Licchelli, L. Mosca, C. Zanini, Chem. Eur. J., 2009, 15, 11288-11297.

${ }^{62}$ Y. -S. Lin, G. -M. Tu, C. -Y. Lin, Y. -T. Chang, Y. -P. Yen, New. J. Chem., 2009, 33, 860-867.

${ }^{63}$ G. -Y. Qing, T. -L. Sun, F. Wang, Y. -B. He, X. Yang, Eur. J. Org. Chem., 2009, 841-849.

${ }^{64}$ Q. -S. Lu, L. Dong, J. Zhang, J. Li, L. Jiang, Y. Huang, S. Qin, C. -W. Hu, X. -Q. Yu, Org. Lett., 2009, 11, 669-672.

${ }^{65}$ X. Bao, J. Yu, Y. Zhou, Sens. Actuators B, 2009, 140, 467-472.

${ }^{66}$ V. K. Bhardwaj, M. S. Hundal, G. Hundal, Tetrahedron, 2009, 65, 8556-8562.

${ }^{67}$ C. Caltagirone, A. Mulas, F. Isaia, V. Lippolis, P. A. Gale, M. E. Light, Chem. Commun., 2009, 6279-6279.

${ }^{68}$ Y. Shiraishi, H. Maehara, T. Sugii, D. Wang, T. Hirai, Tetrahedron Lett., 2009, 50, 4293-4296.

${ }^{69}$ Y. Shiraisi, H. Maehara, T. Hirai, Org. Biomol. Chem., 2009, 7, 2072-2076.

${ }^{70}$ S. V. Bhosale, S. V. Bhosale, M. B. Kalyankar, S. J. Langford, Org. Lett., 2009, 11, 5418-5421.

${ }^{71}$ Z. Lin, H. C. Chen, S. -S. Sun, C. -P. Hsu, T. J. Chow, Tetrahedron, 2009, 65, 52165221.

${ }^{72}$ J. Yoo, M. -S. Kim, S. -J. Hong, J. L. Sessler, C. -H. Lee, J. Org. Chem., 2009, 74, 1065-1069.

${ }^{73}$ X. F. Shang, J. Li, H. Lin, P. Jiang, Z. S. Cai, H. K. Lin, Dalton Trans., 2009, 20962102. 
${ }^{74}$ P. Dydio, T. Zieliński, J. Jurczak, J. Org. Chem., 2009, 74, 1525-1530.

${ }^{75}$ L. M. Zimmermann-Dimer, D. C. Reis, C. Machado, V. G. Machado, Tetrahedron, 2009, 65, 4239-4248.

${ }^{76}$ S. Goswami, A. Hazra, R. Chakrabarty, H. -K. Fun, Org. Lett., 2009, 11, 4350-4353.

77 A. Barnard, S. J. Dickson, M. J. Paterson, A. M. Todd, J. W. Steed, Org. Biomol. Chem., 2009, 7, 1554-1561.

${ }^{78}$ C. Y. Hung, A. S. Singh, C. W. Chen, Y. S. Wen, S. S. Sun, Chem. Commun., 2009, 1511-1513.

${ }^{79}$ A. Metzger, E. V. Anslyn, Angew. Chem. Int. Ed., 1998, 37, 649-652.

${ }^{80}$ K. Niikura, A. Metzger, E. V. Anslyn, J. Am. Chem. Soc., 1998, 120, 8533-8534.

${ }^{81}$ H. Ait-Haddou, S. L. Wiskur, V. M. Lynch, E. V. Anslyn, J. Am. Chem. Soc., 2001, 123, 11296-11297.

${ }^{82}$ S. L. Wiskur, E. V. Anslyn, J. Am. Chem. Soc., 2001, 123, 10109-10110.

${ }^{83}$ Z. Zong, E. V. Anslyn, J. Am. Chem. Soc., 2002, 124, 9014-9015.

${ }^{84}$ J. J. Lavigne, E. V. Anslyn, Angew. Chem. Int. Ed., 1999, 38, 3666-3669.

${ }^{85}$ S. L. Wiskur, P. N. Floriano, E. V. Anslyn, J. T. McDevitt, Angew. Chem. Int. Ed., 2003, 42, 2070-2072.

${ }^{86}$ L. Fabbrizzi, N. Marcotte, F. Stomeo, A. Taglietti, Angew. Chem. Int. Ed., 2002, 41, 3811-3814.

${ }^{87}$ M. A. Hortalá, L. Fabbrizzi, N. Marcotte, F. Stomeo, A. Taglietti, J. Am. Chem. Soc., 2003, 125, 20-21.

${ }^{88}$ L. Fabbrizzi, A. Leone, A. Taglietti, Angew. Chem. Int. Ed., 2001, 40, 3066-3069.

${ }^{89}$ S. Y. Kim, J. I. Hong, Tetrahedron Lett., 2009, 50, 1951-1953.

${ }^{90}$ S. Khatua, K. Kim, J. Kang, J. O. Huh, C. S. Hong, D. G. Churchill, Eur. J. Inorg. Chem., 2009, 3266.

${ }^{91}$ A. T. Wright, E. V. Anslyn, Chem. Soc. Rev., 2006, 35, 14-28.

${ }^{92}$ M. Kitamura, S. H. Shabbir, E. V. Anslyn, J. Org. Chem., 2009, 74, 4479-4489.

${ }^{93}$ T. Zhang, N. Y. Edwards, M. Bonizzoni, E. V. Anslyn, J. Am. Chem. Soc., 2009, 131, 11976-11984.

${ }^{94}$ D. Zhang, Inorg. Chem. Commun., 2009, 12, 1255-1258.

${ }^{95}$ S. Li, Y. Zhou, C. Yu, F. Chen, J. Xu, New J. Chem., 2009, 33, 1462-1465.

${ }^{96}$ C. Männel-Croisé, F. Zelder, Inorg. Chem., 2009, 48, 1272-1274.

${ }^{97}$ K. M. Mullen, J. J. Davis, P. D. Beer, New J. Chem., 2009, 33, 769-776. 
${ }^{98}$ F. Sancenón, R. Martínez-Máñez, M. A. Miranda, M. -J. Seguí, J. Soto, Angew. Chem. Int. Ed., 2003, 42, 647-650.

${ }^{99}$ D. Jiménez, R. Martínez-Máñez, F. Sancenón, J. V. Ros-Lis, A. Benito, J. Soto, J. Am. Chem. Soc., 2003, 125, 9000-9001.

${ }^{100}$ S. Solé, F. P. Gabbaï, Chem. Commun., 2004, 1284-1285.

${ }^{101}$ W. Wang, J. O. Escobedo, C. M. Lawrence, R. M. Strongin, J. Am. Chem. Soc., 2004, 126, 3400-3401.

${ }^{102}$ M. Zhang, M. Yu, F. Li, M. Zhu, M. Li, Y. Gao, L. Li, Z. Liu, J. Zhang, D. Zhang, T. Yi, C, Huang, J. Am. Chem. Soc., 2007, 129, 10322-10323.

${ }^{103}$ D. -G. Cho, J. H. Kim, J. L. Sessler, J. Am. Chem. Soc., 2008, 130, 12163-12167.

104 T. Ábalos, S. Royo, R. Martínez-Máñez, F. Sancenón, J. Soto, A. M. Costero, S. Gil, M. Parra, New J. Chem., 2009, 33, 1641-1645.

105 S. -P. Wang, W. -J. Deng, D. Sun, M. Yan, H. Zheng, J. -G. Xu, Org. Biomol. Chem., 2009, 7, 4017-4020.

${ }^{106}$ F. J. Huo, Y. Q. Sun, J. Su, J. B. Chao, H.J. Zhi, C. X. Yin, Org. Lett., 2009, 11, 21, 4918-4921.

${ }^{107}$ G. -J. Kim, H. -J. Kim, Tetrahedron Lett., 2010, 51, 185-187.

${ }^{108}$ Y. -K. Yang, J. Tae, Org. Lett., 2006, 8, 5721-5723.

${ }^{109}$ Z. Ekmeki, M. D. Yilmaz, E. U. Akkaya, Org. Lett., 2008, 10, 461-464.

${ }^{110}$ M. Tomasulo, F. M. Raymo, Org. Lett., 2005, 7, 4633-4636.

111 T. W. Hudnall, F. P. Gabbaï, J. Am. Chem. Soc., 2007, 129, 11978-11986.

${ }^{112}$ N. Gimeno, X. Li, J. R. Durrant, R. Vilar, Chem. Eur. J., 2008, 14, 3006-3012.

113 J. V. Ros-Lis, R. Martínez-Máñez, J. Soto, Chem. Commun., 2005, 5260-5262.

${ }^{114}$ X. Lou, L. Zhang, J. Qin, Z. Li, Chem. Commun., 2008, 5848-5850.

${ }^{115}$ Y. Shiraishi, K. Adachi, M. Itoh, T. Hirai, Org. Lett., 2009, 11, 3482-3485.

${ }^{116}$ Y. Sun, G. Wang, W. Guo, Tetrahedron, 2009, 65, 3480-3485.

${ }^{117}$ S. Kumar, S. Kumar, Tetrahedron Lett., 2009, 50, 4463-4466.

${ }^{118}$ T. Ábalos, S. Royo, R. Martínez-Máñez, F. Sancenón, J. Soto, A. M. Costero, S. Gil, M. Parra, New J. Chem., 2009, 33, 1641-1645.

${ }^{119}$ S. J. Hong, J. Yoo, S. H. Kim, J. S. Kim, J. Yoon, C. H. Lee, Chem. Commun., 2009, 189-191.

${ }^{120}$ P. Kaur, D. Sareen, S. Kaur, K. Singh, Inorg. Chem. Commun., 2009, 12, 272-275.

${ }^{121}$ H. T. Niu, X. Jiang, J. He, J. P. Cheng, Tetrahedron Letters, 2009, 50, 6668-6671.

${ }^{122}$ G. Qian, X. Li, Z. Y. Wang, J. Mater. Chem., 2009, 19, 522-530. 
${ }^{123}$ T. W. Hudnall, C. -W. Chiu, F. P. Gabbaï, Acc. Chem. Res., 2009, 42, 388-397.

${ }^{124}$ C. R. Wade, F. P. Gabbai, Dalton Trans., 2009, 9169-9175.

${ }^{125}$ Y. Kim, F. P. Gabbaï, J. Am. Chem. Soc., 2009, 131, 9, 3363-3369.

${ }^{126}$ S. T. Lam, N. Zhu, V. W. W. Yam, Inorganic Chemistry, 2009, 48, 20, 9664-9670.

${ }^{127}$ J. Wang, H. B. Liu, W. Wang, I. Kim, C. S. Ha, Dalton Trans., 2009, 10422-10425.

${ }^{128}$ D. S. Kim, Y. M. Chung, M. Jun, K. H. Ahn, J. Org. Chem., 2009, 74, 4849-4854.

${ }^{129}$ A. B. Descalzo, R. Martínez-Máñez, F. Sancenón, K. Hoffmann, K. Rurack, Angew. Chem. Int. Ed., 2006, 45, 5924-5948.

${ }^{130}$ The Supramolecular Chemistry of Organic-Inorganic Hybrid Materials (K. Rurack and R. Martínez-Máñez Ed.), Wiley, 2010.

${ }^{131}$ R. Martínez-Máñez, F. Sancenón, Coord. Chem. Rev., 2006, 250, 3081-3093.

132 M. Comes, G. Rodríguez-López, M. D. Marcos, R. Martínez-Máñez, F. Sancenón, J. Soto, L. A. Villaescusa, P. Amorós, D. Beltrán, Angew. Chem. Int. Ed., 2005, 44, 2918 2922.

${ }^{133}$ R. Casaús, E. Aznar, M. D. Marcos, R. Martínez-Máñez, F. Sancenón, J. Soto, P. Amorós, Angew. Chem. Int. Ed., 2006, 45, 6661-6664.

${ }^{134}$ C. Coll, R. Martínez-Máñez, M. D. Marcos, F. Sancenón, J. Soto, Angew. Chem. Int. Ed., 2007, 46, 1675-1678.

${ }^{135}$ C. Coll, R. Casasús, E. Aznar, M. D. Marcos, R. Martínez-Máñez, F. Sancenón, J. Soto, P. Amorós, Chem. Commun., 2007, 1957-1959.

${ }^{136}$ P.Calero, E. Aznar, M. Lloris, M. D. Marcos, R. Martínez-Máñez, J. V. Ros-Lis, J. Soto, F. Sancenón, Chem. Commun., 2008, 1668-1670.

137 M. Comes, M. D. Marcos, R. Martínez-Máñez, F. Sancenón, J. Soto, L. A. Villaescusa, P. Amorós, Chem. Commun., 2008, 3639-3641.

138 E. Climent, R. Casasús, M. D. Marcos, R. Martínez-Máñez, F. Sancenón, J. Soto, Chem. Commun., 2008, 6531-6533.

139 M. -C. Daniel, J. Ruiz, S. Nlate, J. Palumbo, J. -C. Blais, D. Astruc, Chem. Commun., 2001, 2000-2001.

${ }^{140}$ P. D. Beer, D. P. Cormode, J. J. Davis, Chem. Commun., 2004, 414-415.

${ }^{141}$ A. Labande, D. Astruc, Chem. Commun., 2001, 1007-1008.

${ }^{142}$ M. -C. Daniel, J. Ruiz, S. Nlate, J. -C. Blais, D. Astruc, J. Am. Chem. Soc., 2003, 125, 2617-2628. 
M. Comes, E. Aznar, M. Moragues, M. D. Marcos, R. Martínez-Máñez, F. Sancenón, J. Soto, L. A. Villaescusa, L. Gil, P. Amorós, Chem. Eur. J., 2009, 15, 90249033.

${ }^{144}$ Z. Yao, X. Feng, C. Li, G. Shi, Chem. Commun., 2009, 5886-5888.

145 M.C. Daniel, D. Astruc, Chem. Rev., 2004, 104, 293-346.

${ }^{146}$ U. Kreibig, M. Vollmer, Optical Properties of Metal Clusters, Springer, Berlin, 1998.

${ }^{147}$ N. L. Rosi, C. A. Mirkin, Chem. Rev., 2005, 105, 1547-1562.

${ }^{148}$ E. Katz, I. Willner, Angew. Chem. Int. Ed., 2004, 43, 6042-6108.

${ }^{149}$ G. Patel, S. Menon, Chem. Commun., 2009, 3563-3565.

150 W. L. Daniel, M. S. Han, J. -S. Lee, C. A. Mirkin, J. Am. Chem. Soc., 2009, 131 (18), 6362-6363.

151 E. Climent, P. Calero, M.D. Marcos, R. Martínez-Máñez, F. Sancenón, J. Soto, Chem. Eur. J., 2009, 15, 1816-1820.

152 J.V. Ros-Lis, B. García, D. Jiménez, R. Martínez-Máñez, F. Sancenón, J. Soto, F. Golzalvo, M.C. Valldecabres, J. Am. Chem. Soc., 2004, 126, 4064-4065.

${ }^{153}$ E. Climent, R. Casasús, M. D. Marcos, R. Martínez-Máñez, F. Sancenón, J. Soto, Dalton Trans., 2009, 4806-4814.

${ }^{154}$ E. Aznar, R. Martínez-Mañez, F. Sancenón, Expert Opin. Drug Deliv., 2009, 6, 643655.

${ }^{155}$ R. Casasús, E. Aznar, M. D. Marcos, R. Martínez-Máñez, F. Sancenón, J. Soto, P. Amorós, Angew. Chem. Int. Ed., 2006, 45, 6661-6664.

${ }^{156}$ C. Coll, R. Casasús, E. Aznar, M. D. Marcos, R. Martínez-Máñez, F. Sancenón, J. Soto, P. Amorós, Chem. Commun., 2007, 1957-1959.

157 E. Climent, A. Bernardos, R. Martínez-Máñez, A. Maquieira, M. D. Marcos, N. Pastor-Navarro, R. Puchades, F. Sancenón, J. Soto, P. Amorós, J. Am. Chem. Soc., 2009, 131, 14075-14080.

${ }^{158}$ E. Climent, M. D. Marcos, R. Martínez-Máñez, F. Sancenón, J. Soto, K. Rurack, P. Amorós, Angew. Chem. Int. Ed., 2009, 48, 8519-8522.

159 E. Aznar, C. Coll, M. D. Marcos, R. Martínez-Máñez, F. Sancenón, J. Soto, P. Amorós, J. Cano, E. Ruiz, Chem. Eur. J., 2009, 15, 6877-6888.

${ }^{160}$ A. Jose, S. Stadlbauer, B. König, Chem. Eur. J., 2009, 15, 7404-7412.

${ }^{161}$ K. Ghosh, A. R. Sarkar, A. Patra, Tetrahedron Lett., 2009, 50, 6557-6561.

${ }^{162}$ Z. -Q. Hu, C. -L. Liu, H. -Y. Lu, X. -D. Yang, Sensors Act. B Chem., 2009, 141, 200-204. 
${ }^{163}$ K. Ghosh, A. R. Sarkar, Tetrahedron Lett., 2009, 50, 85-88.

${ }^{164}$ K. Fujimoto, S. Yamada, M. Inouye, Chem. Commun., 2009, 7164-7166.

${ }^{165}$ Z. Xu, N. J. Singh, J. Lim, J. Pan, H. N. Kim, S. Park, K. S. Kim, J. Yoon, J. Am. Chem. Soc., 2009, 131, 15528-15533.

${ }^{166}$ L. Zeng, P. Wang, H. Zhang, X. Zhuang, Q. Dai, W. Liu, Org. Lett., 2009, 11, 42944297.

${ }^{167}$ M. Kumar, R. Kumar, V. Bhalla, Tetrahedron, 2009, 65, 4340-4344.

${ }^{168}$ A. K: Nair, P. P. Neelakandan, D. Ramaiah, Chem. Commun., 2009, 6352-6354.

${ }^{169}$ X. -H. Huang, Y. -B. He, C. -G. Hu, Z. -H. Chen, Eur. J. Org. Chem., 2009, 15491553.

${ }^{170}$ N. Singh, H. J. Jung, D. O. Jang, Tetrahedron Lett., 2009, 50, 71-74.

${ }^{171}$ Z. Zeng, L. Spiccia, Chem. Eur. J., 2009, 15, 12941-12944.

${ }^{172}$ H. Singh, N. Kaur, J. Dunn, R. Behan, R. C. Mulrooney, J. F. Callan, Eur. Pol. J., 2009, 45, 272-277.

173 E. B. Veale, G. M. Tocci, F. M. Pfeffer, P. E. Kruger, T. Gunnlaugsson, Org. Biomol. Chem., 2009, 7, 3447-3454.

${ }^{174}$ F. M. Muñiz, V. Alcázar, L. Simón, C. Raposo, E. Calle, J. R. Morán, Eur. J. Org. Chem., 2009, 1009-1015.

${ }^{175}$ M. Toganoh, H. Miyachi, H. Akimaru, F. Ito, T. Nagamura, H. Furuta, Org. Biomol. Chem., 2009, 7, 3027-3030.

${ }^{176}$ A. Shundo, J. P. Hill, K. Ariga, Chem. Eur. J., 2009, 15, 2486-2490.

177 L. Panzella, A. Pezzella, M. Arzillo, P. Manini, A. Napolitano, M. d'Ischia, Tetrahedron, 2009, 65, 2032-2036.

${ }^{178}$ R. Pérez-Ruiz, Y. Díaz, B. Goldfuss, D. Hertel, K. Meerholz, A. G. Griesbeck, Org. Biomol. Chem., 2009, 7, 3499-3504.

179 J. R. Hiscock, C. Caltagirone, M. E. Light, M. B. Hursthouse, P. A. Gale, Org. Biomol. Chem., 2009, 7, 1781-1783.

${ }^{180}$ A. M: Costero, J. V. Colomer, S. Gil, M. Parra, Eur. J. Org. Chem., 2009, 36733677.

${ }^{181}$ K. Ghosh, G. Masanta, A. P. Chattopadhyay, Eur. J. Org. Chem., 2009, 4515-4524.

${ }^{182}$ H. J. Kim, S. Bhuniya, R. K. Mahajan, R. Puri, H. Liu, K. C. Ko, J. Y. Lee, J. S. Kim, Chem. Commun., 2009, 7128-7130.

${ }^{183}$ G. W. Lee, N. Singh, H. J. Jung, D. O. Jang, Tetrahedron Lett., 2009, 50, 807-810.

${ }^{184}$ A. Pramanik, G. Das, Tetrahedron, 2009, 65, 2196-2200. 
${ }^{185}$ D. Curiel, A. Espinosa, M. Más-Montoya, G. Sánchez, A. Tarraga, Chem. Commun., 2009, 7539-7541.

186 (a) C. Bazzicalupi, A. Bencini, S. Biagini, E. Faggi, S. Meini, C. Giorgi, A. Spepi, B. Valtancoli, J. Org. Chem., 2009, 74, 7349-7363. (b) C. Bazzicalupi, S. Biagini, A. Bencini, E. Faggi, C. Giorgi, I. Matera, B. Valtancoli, Chem. Commun., 2006, 40874089 .

${ }^{187}$ K. -Y. Pu, B. Liu, Adv. Funct. Mater., 2009, 19, 277-284.

${ }^{188}$ R. B. Jagt, R. E. Gómez-Biagi, M. Nitz, Angew. Chem. Int. Ed., 2009, 48, $1995-$ 1997.

189 J. Qian, X. Qian, Y. Xu, Chem. Eur. J., 2009, 15, 319-323.

${ }^{190}$ M. J. Kim, K. M. K. Swamy, K. M. Lee, A. R. Jagdale, Y. Kim, S. -J. Kim, K. H. Yoo, J. Yoon, Chem. Commun., 2009, 7215-7217.

${ }^{191}$ S. Goswami, R. Chakrabarty, Tetrahedron Lett., 2009, 50, 5994-5997.

${ }^{192}$ H. -L. Kwon, W. -L. Wong, C. -S. Lee, C. -T. Yeung, P. -F. Teng, Inorg. Chem. Commun., 2009, 12, 815-818.

${ }^{193}$ X. Chen, M. J. Jou, J. Yoon, Org. Lett., 2009, 11, 2181-2184.

${ }^{194}$ C. -C. Chou, H. -J. Liu, L. H. -C. Chao, Chem. Commun., 2009, 6382-6384.

195 A. Ojida, T. Sakamoto, M. Inoue, S. Fujishima, G. Lippens, I. Hamachi, J. Am. Chem. Soc., 2009, 131, 6543-6548.

${ }^{196}$ H. -W. Rhee, S. J. Choi, S. H. Yoo, Y. O. Jang, H. H. Park, R. M. Pinto, J. C. Cameselle, F. J. Sandoval, S. Roje, K. Han, D. S. Chung, J. Suh, J. -I. Hong, J. Am. Chem. Soc., 2009, 131, 10107-10112.

${ }^{197}$ M. M. G. Dos Santos, A. J. Harte, S. J. Quinn, T. Gunnlaugsson, Coord, Chem. Rev., 2008, 252, 2512-2527.

198 J. P. Leonard, T. Gunnlaugsson, J. Fluoresc., 2005, 15, 585-595.

199 H. -B. Xu, X. -M. Chen, Q. -S. Zhang, L. -Y. Zhang, Z. -N. Chen, Chem. Commun., 2009, 7318-7320.

${ }^{200}$ C. M. G. dos Santos, T. Gunnlaugsson, Dalton Trans., 2009, 4712-4721.

${ }^{201}$ Z. Pálinkás, A. Roca-Sabio, M. Mato-Iglesias, D. Esteban-Gómez, C. Platas-Iglesias, A. de Blas, T. Rodríguez-Blas, E. Tóth, Inorg. Chem., 2009, 48, 8878-8889.

${ }^{202}$ R. Pal, D. Parker, L. C. Costello, Org. Biomol. Chem., 2009, 7, 1525-1528.

203 M. E. Masaki, D. Paul, R. Nakamura, Y. Kataoka, S. Shinoda, H. Tsukube, Tetrahedron, 2009, 65, 2525-2530. 
${ }^{204}$ N. C. A. Baker, N. McGaughey, N. C. Fletcher, A. V. Chernikov, P. N. Horton, M. B. Hursthouse, Dalton Trans., 2009, 965-972.

${ }^{205}$ E. Berni, I. Gosse, D. Bardocco, P. Pastore, N. Sojic, S. Pinet, Chem. Eur. J., 2009, $15,5145-5152$.

${ }^{206}$ H. S. Jung, H. J. Kim, J. Vicens, J. S. Kim, Tetrahedrn Letters, 2009, 50, 983-987.

${ }^{207}$ M. Boiocchi, M. Bonizzoni, L. Fabbrizzi, G. Piovani, A. Taglietti, Angew. Chem. Int. Ed., 2004, 43, 3847-3852.

${ }^{208}$ Y. Kubo, A. Kobayashi, T. Ishida, Y. Misawa, T. D. James, Chem. Commun., 2005, 2846-2848.

${ }^{209}$ Q. Zeng, P. Cai, Z. Li, J. Qin, B. Z. Tang, Chem. Commun., 2008, 1094-1096.

${ }^{210}$ J. Massue, S. J. Quinn, T. Gunnlaugsson, J. Am. Chem. Soc., 2008, 130, 6900-6901.

${ }^{211}$ H. H. Jang, S. Yi, M. H. Kim, S. Kim, N. H. Lee, M. S. Han, Tetrahedron Letters, 2009, 50, 6241-6243.

${ }^{212}$ S. Horie, Y. Kubo, Chem. Lett., 2009, 38, 616-617.

${ }^{213}$ L. Tang, Y. Li, H. Zhang, Z. Guo, J. Qian, Tetrahedron Letters, 2009, 50, 68446847.

${ }^{214}$ J. V. Carolan, S. J. Butler, K. A. Jolliffle, J. Org. Chem., 2009, 74, 8, 2992-2996.

${ }^{215}$ M. J. McDonaugh, A. J. Reynolds, W. Y. G. Lee, K. A. Jolliffe, Chem. Commun., 2006, 2971-2973.

${ }^{216}$ S. Khatua, S. H. Choi, J. Lee, K. Kim, Y. Do, D. G. Churchill, Inorg. Chem., 2009, 48, 7, 2993-2999.

${ }^{217}$ G. Ambrosi, M. Formica, V. Fusi, L. Giorgi, A. Guerri, E. Macedi, M. Micheloni, P. Paoli, R. Pontellini, P. Rossi, Inorg. Chem., 2009, 48, 5901-5912.

${ }^{218}$ S. -Y. Chung, S. -W. Nam, J. Lim, S. Park, J. Yoon, Chem. Commun., 2009, 28662868 .

${ }^{219}$ R. Guliyev, O. Buyukcakir, F. Sozmen, O. A. Bozdemir, Tetrahedron Letters, 2009, $50,5139-5141$.

${ }^{220}$ W. Lin, L. Yuan, X. Cao, B. Chen, Y. Feng, Sensors and Actuators B, 2009, 138, 637-641.

${ }^{221}$ A. B. Descalzo, K. Rurack, Chem. Eur. J., 2009, 15, 3173-3185.

${ }^{222}$ R. Joseph, B. Ramanujam, A. Acharya, C. P. Rao, J. Org. Chem., 2009, 74, 81818190 .

${ }^{223}$ K. -H. Chen, J. -H. Liao, H. -Y. Chan, J. -M. Fang, J. Org. Chem., 2009, 74, 895898. 
${ }^{224}$ C. Zhong, T. Mu, L. Wang, E. Fu, J. Qin, Chem. Commun., 2009, 4091-4093.

${ }^{225}$ X. Y. Liu, D. R. Bai, S. Wang, Angew. Chem. Int. Ed., 2006, 45, 5475-5478.

${ }^{226}$ S. Sreejith, K. P. Divya, A. Ajayaghosh, Angew. Chem. Int. Ed., 2008, 47, 78837887.

${ }^{227}$ M. H. Lee, T. Agou, J. Kobayashi, T. Kawashima, F. P. Gabbaï, Chem. Commun., 2007, 1133-1135.

${ }^{228}$ K. -S. Lee, T. -K. Kim, J. H. Lee, H. -J. Kim, J. -I. Hong, Chem. Commun., 2008, 6173-6175.

${ }^{229}$ X. Chen, S. -K. Ko, M. J. Kim, I. Shin, J. Yoon, Chem. Commun., 2010, 46, 27512753.

${ }^{230}$ H. -Y. Shiu, H. -C. Chong, Y. -C. Leung, M. -K. Wong, C. -M. Che, Chem. Eur. J., 2010, 16, 3308-3313.

${ }^{231}$ C. -L. Chen, Y. -H. Chen, C. -Y. Chen, S. -S. Sun, Org. Lett., 2006, 8, 5053-5056.

${ }^{232}$ K. -S. Lee, H. -J. Kim, G. -H. Kim, I. Shin, J. -I. Hong, Org. Lett., 2008, 10, 49-51.

${ }^{233}$ G. -J. Kim, H. -J. Kim, Tetrahedron Lett., 2010, 51, 2914-2916.

${ }^{234}$ R. Bagudu, J. R. Lakowicz, C. D. Geddes, J. Am. Chem. Soc., 2005, 127, 3635-3641.

${ }^{235}$ L. Yi, H. Li, L. Sun, L. Liu, C. Zhang, Z. Xi, Angew. Chem. Int. Ed., 2009, 48, 40344037.

${ }^{236}$ W. Lin, L. Yuan, Z. Cao, Y. Feng, L. Long, Chem. Eur. J., 2009, 15, 5096-5103.

${ }^{237}$ S. Ji, J. Yang, Q. Yang, S. Liu, M. Chen, J. Zhao, J. Org. Chem., 2009, 74, 48554865 .

${ }^{238}$ K. Huang, H. Yang, Z. Zhou, H. Chen, F. Li, T. Yi, C. Huang, Inorganica Chimica Acta, 2009, 362, 2577-2580.

${ }^{239}$ V. Hong, A. A. Kislukhin, M. G. Finn, J. Am. Chem. Soc., 2009, 131, 9986-9994.

${ }^{240}$ H. Li, J. Fan, J. Wang, M. Tian, J. Du, S. Sun, P. Sun, X. Peng, Chem. Commun., 2009, 5904-5906.

${ }^{241}$ H. Li, J. Xu, H. Yan, Sensors and Actuators B, 2009, 139, 483-487.

${ }^{242}$ K. Kikuchi, S. Hashimoto, S. Mizukami, T. Nagano, Org. Lett., 2009, 11, 13, $2732-$ 2735.

${ }^{243}$ T. Agou, M. Sekine, J. Kobayashi, T. Kawashima, Chem. Commun., 2009, 18941896.

${ }^{244}$ Z. Xu, S. K. Kim, S. J. Han, C. Lee, G. Kociok-Kohn, T. D. James, J. Yoon, Eur. J. Org. Chem., 2009, 3058-3065. 
${ }^{245}$ C. -H. Zhao, E. Sakuda, A. Wakamiya, S. Yamaguchi, Chem. Eur. J., 2009, 15, 10603-10612.

${ }^{246}$ G. Meng, S. Velayudham, A. Smith, R. Luck, H. Liu, Macromolecules, 2009, 42 , 1995-2001.

${ }^{247}$ T. Agou, M. Sekine, J. Kobayashi, T. Kawashima, Chem. Eur. J., 2009, 15, 50565062 .

${ }^{248}$ Y. Kim, H. Zhao, F. P. Gabbaï, Angew. Chem. Int. Ed., 2009, 48, 4957-4960.

249 M. Jamkratoke, V. Ruangpornvisuti, G. Tumcharen, T. Tuntulani, B. Tomapatanaget, J. Org. Chem., 2009, 74, 3919-3922.

${ }^{250}$ J. Yoshino, N. Kano, T. Kawashima, J. Org. Chem., 2009, 74, 7496-7503.

${ }^{251}$ J. Jo, D. Lee, J. Am. Chem. Soc., 2009, 131, 16283-16291.

${ }^{252}$ L. Peng, M. Wang, G. Zhang, D. Zhang, D. Zhu, Org. Lett., 2009, 11, 9, 1943-1946.

${ }^{253}$ W. Lin, L. Long, B. Chen, W. Tan, Chem. Eur. J., 2009, 15, 2305-2309.

${ }^{254}$ Y. K. Yang, H. J. Cho, J. Lee, I. Shin, J. Tae, Org. Lett., 2009, 11, 859-861.

${ }^{255}$ Z. N. Sun, H. L. Wang, F. Q. Liu, Y. Chen, P. Kwong, H. Tam, D. Yang, Org. Lett., 2009, 11, 1887-1890.

${ }^{256}$ Y. Sun, C. Zhong, R. Gong, H. Mu, E. Fu, J. Org. Chem., 2009, 74, 7943-7946.

${ }^{257}$ R. C. Mulrooney, N. Singh, N. Kaur, J. F. Callan, Chem. Commun., 2009, 686-688.

${ }^{258}$ L. Zhao, K. M. Mullen, M. J. Chmielewski, A. Brown, N. Bampos, P. D. Beer, J. J. Davis, New J. Chem., 2009, 33, 760-768.

${ }^{259}$ Y. Qiu, H. Deng, J. Mou, S. Yang, M. Zeller, S. R. Batten, H. Wu, J. Li, Chem. Commun., 2009, 5415-5417.

${ }^{260}$ L. Shang, L. Jin, S. Dong, Chem. Commun., 2009, 3077-3079.

${ }^{261}$ I. -B. Kim, M. H. Han, R. L. Phillips, B. Samanta, V. M. Rotello, Z. J. Zhang, U. H.

F. Bunz, Chem. Eur. J., 2009, 15, 449-456.

${ }^{262}$ Y. Song, C. Zhao, J. Ren, X. Qu, Chem. Commun., 2009, 1975-1977.

263 A. Wada, S. Tamaru, M. Ikeda, I. Hamachi, J. Am. Chem. Soc., 2009, 131, 53215330 .

${ }^{264}$ L. Shang, L. Zhang, S. Dong, Analyst, 2009, 134, 107-113. 